Application $\$ 9103$ - Three Sisters Golf Resorts Inc.

\title{
Application to Construct a Recreational and Tourism Project in the Town of Canmore, Alberta
}

November 1992

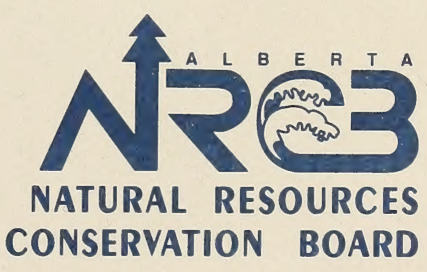




\section{- National Library Bibliotheque nationale




\section{DECISION REPORT}

Application \#9103 - Three Sisters Golf Resorts Inc.

\section{Application to Construct a Recreational and Tourism Project in the Town of Canmore, Alberta}




\begin{abstract}
APPLICATION TO CONSTRUCT A RECREATIONAL AND TOURISM PROJECT IN THE TOWN OF

CANMORE, ALBERTA

NRCB Application 9103
\end{abstract}

November 1992

Published by:

Natural Resources Conservation Board

10th Floor, 640 Fifth Avenue S.W.

Calgary, Alberta

T2P 3G4

Telephone: (403) 297-8303

Facsimile: (403) 297-5270 


\section{TABLE OF CONTENTS}

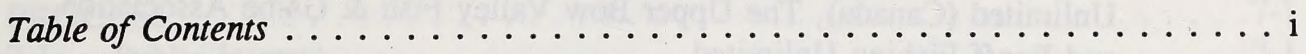

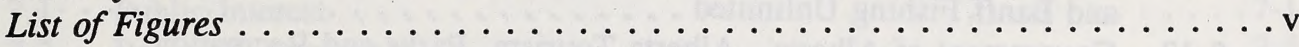

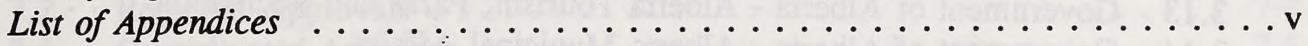

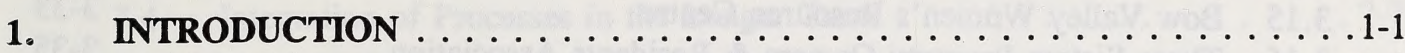

1.1 Background . . . . . . . . . . . . . . . . . . . 1-1

1.2 Natural Resources Conservation Board (NRCB) Jurisdiction . . . . . . . 1-4

$1.3 \quad$ NRCB Review Process . . . . . . . . . . . . . . . . . . 1-4

1.4 The Role of Alberta Environment and Other Alberta Government

Departments . . . . . . . . . . . . . . . . 1-6

1.5 The Role of Federal Government Departments . . . . . . . . . . . 1-7

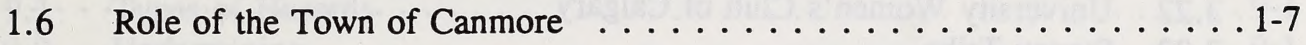

2. THE APPLICATION AND SUPPORTING INFORMATION . . . . . . 2-1

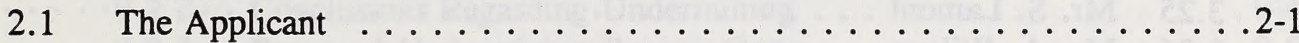

2.2 The Proposed Project . . . . . . . . . . . . . . . . . 2-1

2.2.1 Physical Location and Suitability for Development . . . . . . 2-1

2.2.2 The Proposed Development . . . . . . . . . . . . 2-2

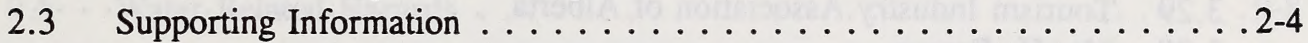

2.3.1 Vegetation .................... . . .

2.3 .2 Wildlife ...................... . . 6

2.3.3 Water Resources ................... . . . . .

2.3.4 Other Resource Effects ... . . . . . . . . . . . . 2-8

2.3.5 Geology, Geotechnical and Mining . . . . . . . . . . 2-9

2.3.6 Socio-Economic Effects . . . . . . . . . . . . . 2-11

3. THE POSITIONS OF PARTICIPANTS AND SUPPORTING

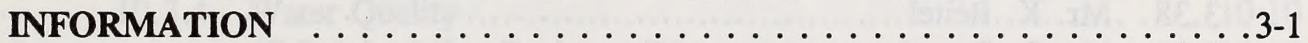

3.1 Canadian Parks and Wilderness Society, The Alpine Club of Canada and The Sierra Club of Western Canada ... . . . . . . . . . . . . 3-1

3.2 Government of Canada - Environment Canada - Canadian Parks Service . . 3-5

3.3 Bow Valley Naturalists . . . . . . . . . . . . . . . . . . . 3-8

3.4 Alberta Wilderness Association, Speak Up for Wildlife Foundation, and Adventure Group Ltd . . . . . . . . . . . . . . . . . . 3-12

3.5 Town of Canmore/Mount Rundle School Division . . . . . . . . . . . 3-17

3.6 Mr. R. Haimila . . . . . . . . . . . . . . . . . . . . . 3-22

3.7 Calgary Regional Planning Commission . . . . . . . . . . . . . 3-23

3.8 Federation of Alberta Naturalists . . . . . . . . . . . . . . . 3-24

3.9 Northern Light Society . . . . . . . . . . . . . . . . . . . . 3-26

3.10 Ms. B. Belyea . . . . . . . . . . . . . . . . . . . . 3-26

3.11 National Trail Association . . . . . . . . . . . . . . . 3-26 
3.12 Trout Unlimited (Canada), The Upper Bow Valley Chapter of Trout Unlimited (Canada), The Upper Bow Valley Fish \& Game Association and Banff Fishing Unlimited

3.13 Government of Alberta - Alberta Tourism, Parks and Recreation . . . . 3-31

3.14 Government of Alberta - Alberta Municipal Affairs . . . . . . . . . 3-32

3.15 Bow Valley Women's Resource Centre . . . . . . . . . . . . . . 3-33

3.16 Three Sisters Property Owners \& Residents Association . . . . . . . . . . 3-35

3.17 Bow Corridor Organization For Responsible Development . . . . . . 3-36

3.18 Municipal District of Bighorn No. $8 \ldots \ldots \ldots \ldots \ldots . . \ldots$. . . . . . . . . . . . . . . . . .

3.19 Pacific Western . . . . . . . . . . . . . . . . . . . 3-40

3.20 Ms. S. Webb . . . . . . . . . . . . . . . . . . 3-40

3.21 Bow Corridor Adult Literacy Project . . . . . . . . . . . . . . 3-41

3.22 University Women's Club of Calgary . . . . . . . . . . . 3-41

3.23 Stoney Tribe . . . . . . . . . . . . . . . . . . . 3-42

3.24 Ms. L. Klatzel-Mudry . . . . . . . . . . . . . . . . . . . . 3-43

3.25 Mr. S. Lamont . . . . . . . . . . . . . . . . . . . . . . . . 3-44

3.26 Ms. A. Wilson . . . . . . . . . . . . . . . . . . . 3-44

3.27 Alberta Construction Association . . . . . . . . . . . . . . . 3-44

3.28 Canmore, Bow Valley and Kananaskis Chamber of Commerce . . . . . 3-45

3.29 Tourism Industry Association of Alberta . . . . . . . . . . . . . . 3-46

3.30 Ms. H. Bracco . . . . . . . . . . . . . . . . . . . . . . 3-46

3.31 Green Central Station . . . . . . . . . . . . . . . . . . 3-46

3.32 Canadian Ski Association - Alberta Division . . . . . . . . . . . . 3-47

3.33 Mr. J. Streda . . . . . . . . . . . . . . . . . . . . 3-47

3.34 Ms. C. Campbell . . . . . . . . . . . . . . . . . . . . 3-47

3.35 Mr. L. Upton . . . . . . . . . . . . . . . . . 3-47

3.36 Ms. M. Nicks . . . . . . . . . . . . . . . . . . . 3-48

3.37 Earth First! . . . . . . . . . . . . . . . . . . . 3-48

3.38 Mr. K. Beitel . . . . . . . . . . . . . . . . . . . . . . . 3-48

3.39 Mr. S. Greenberg . . . . . . . . . . . . . . . . . . . 3-48

3.40 Mr. B. Davis . . . . . . . . . . . . . . . . . . . . . . . . . . 3-49

3.41 Mr. J. Kievit . . . . . . . . . . . . . . . . . . . . . 3-49

3.42 Other Written Submissions . . . . . . . . . . . . . . . . . . . . 3-49

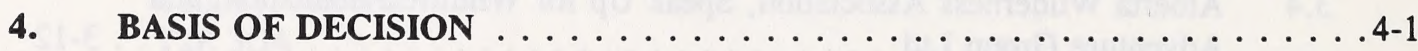

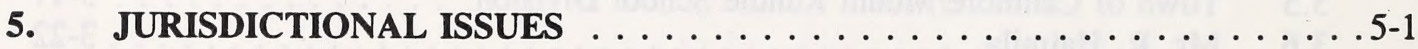

5.1 The "Public Interest" Test . . . . . . . . . . . . . . 5-1

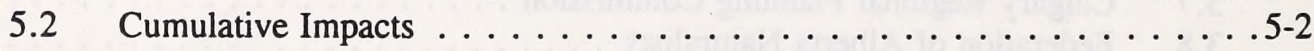

6. THE CONCEPTUAL NATURE OF THE PROPOSED PROJECT AND THE ADEQUACY OF THE APPLICATION AND OF OTHER 
iii

7. CO-ORDINATION OF THE NRCB PROCESS WITH THE PLANNING

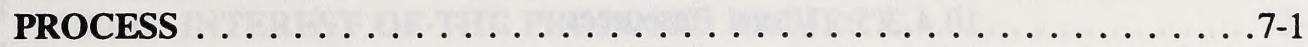

$7.1 \quad$ Public Interest $\ldots \ldots \ldots \ldots \ldots \ldots \ldots \ldots \ldots \ldots \ldots \ldots \ldots \ldots \ldots$

7.2 Required Approvals .................... . . . .

7.3 Co-ordinated Approach . . . . . . . . . . . . . . 7-5

7.4 Integration of Processes in the Longer Term . . . . . . . . . 7-7

8. THE BASE SITUATION FROM WHICH TO ASSESS THE

CUMULATIVE EFFECTS OF THE THREE SISTERS APPLICATION . . . 8-1

9. GEOTECHNICAL HAZARDS TO DEVELOPMENT OF THE PROPOSED PROJECT $\ldots \ldots \ldots \ldots \ldots \ldots \ldots \ldots \ldots \ldots \ldots \ldots \ldots . \ldots \ldots$

9.1 Types of Hazards $\ldots \ldots \ldots \ldots \ldots \ldots \ldots \ldots \ldots \ldots . \ldots \ldots$

9.2 Undermining . . . . . . . . . . . . . . . . . 9.1

9.2.1 General Constraints . . . . . . . . . . . . . . .9-1

9.2.2 Conclusions Regarding Undermining . . . . . . . . . . . 9-4

9.2.3 Proposed Undermining Review Group . . . . . . . . . . . 9-5

9.3 Underground Fires . . . . . . . . . . . . . . . . . 9-6

9.4 Potential Methane Problems . . . . . . . . . . . . . . . . . 9-7

9.5 Water Related Hazards . . . . . . . . . . . . . . . . . . 9-8

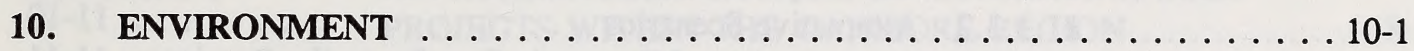

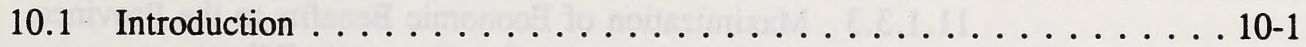

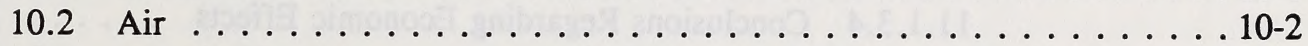

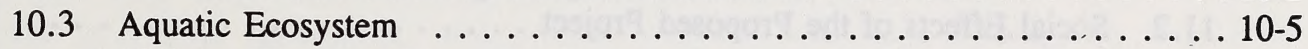

10.3.1 The Bow River Ecosystem . . . . . . . . . . . 10-5

10.3.2 Water Supply . . . . . . . . . . . . . . . . 10-7

10.3 .3 Water Flows . . . . . . . . . . . . . . . . . 10-9

10.3.4 Water Quality . . . . . . . . . . . . . . . . . 10-10

10.3.4.1 Mine Drainage Water ............ 10-10

10.3.4.2 Potential Effects of Chemical Use on Golf Courses

and Residential Lots . . . . . . . . . . . 10-12

10.3.4.3 Construction Effects . . . . . . . . . . . 10-14

10.3.4.4 Wastewater Treatment ............. 10-15

10.3.4.5 Monitoring . . . . . . . . . . . . 10-16

10.3.4.6 Ecotoxicological Assessment . . . . . . . . . 10-17

10.3.5 Aquatic Biota . . . . . . . . . . . . . . . 10-17

10.4 Terrestrial Ecosystems . . . . . . . . . . . . . . . . . 10-20

10.4.1 Background . . . . . . . . . . . . . . 10-20

10.4.2 Affected Ecosystems . . . . . . . . . . . . . . . 10-21

10.4.3 Affected Landscape Types . . . . . . . . . . . . . 10-23

10.4.3.1 Alluvial Fans . . . . . . . . . . . . . . . . 10-23

10.4.3.2 Riparian Vegetation . . . . . . . . . . . . . . 10-24

10.4.3.3 Wetlands ................ 10-25 
10.4.3.4 Forest and Grassland . . . . . . . . . . 10-26

10.4.3.5 Visual Resources . . . . . . . . . . 10-27

10.4.4 Affected Ecosystem Components . . . . . . . . . . . 10-28

10.4.4.1 Soils and Surficial Materials . . . . . . . . 10 10 28

10.4.4.2 Vegetation ................ 10-30

10.4.4.3 Wildlife ................... 10-33

10.4.5 Conclusion with Respect to Terrestrial Ecosystems . . . . . . 10-48

10.5 Ecosystem Management ... . . . . . . . . . . . . 10-52

10.5.1 Regional Outlook . . . . . . . . . . . . . . . 10-52

10.5.2 Tasks and Goals for Regional Ecosystem Advisory Group . . . 10-53

11. ECONOMIC AND SOCIAL EFFECTS OF THE PROPOSED PROJECT ‥ 11-1

11.1 Economic Effects of the Proposed Project . . . . . . . . . . . 11-1

11.1.1 Introduction . . . . . . . . . . . . . . . . 11-1

11.1.2 Potential Markets For the Proposed Facilities and Services . . 11-2

11.1.2.1 Hotels and Related Convention, Commercial and Recreational Facilities . . . . . . . . . 11-3

11.1.2.2 Residential . . . . . . . . . . . . . 11-5

11.1.3 Economic Effects of The Proposed Project and Alternative

Scenarios . . . . . . . . . . . . . . 11-7

11.1.3.1 The Proposed Project . . . . . . . . . . . 11-8

11.1.3.2 Alternative Scenarios . . . . . . . . . . . . 11-10

11.1.3.3 Maximization of Economic Benefits to the Province 11-11

11.1.3.4 Conclusions Regarding Economic Effects ... . . 11-12

11.2 Social Effects of the Proposed Project . . . . . . . . . . . . . 11-12

11.2.1 Introduction . . . . . . . . . . . . . . 11-12

11.2.2 Growth of the Town and the Effects on the Lifestyle of Its

Citizens .......................... 11-13

11.2.3 Effects on Services to Canmore Residents . . . . . . . . . 11-15

11.2.3.1 Utility Services ... . . . . . . . . . . 11-15

11.2.3.2 Other Community Services . . . . . . . . . 11-17

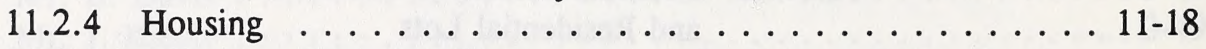

11.2.5 Effects on Historical Resources and On Current Recreational

Use of the Area . . . . . . . . . . . . 11-22

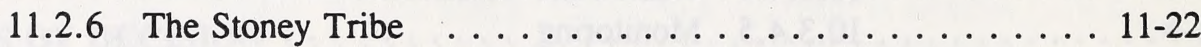

11.3 Financial Effects on the Town of Canmore ............. 11-23

12. THE NEED FOR ONGOING PLANNING AND CONTROLS $\ldots \ldots \ldots \ldots 12-1$

12.1 Introduction . . . . . . . . . . . . . . . . 12-1

12.2 Views of the Board . . . . . . . . . . . . . . . 12-2

12.3 Guidelines and General Principles . . . . . . . . . . . . 12-3 
13. OVERALL CONCLUSIONS AND DECISION RESPECTING THE PUBLIC INTEREST OF THE PROPOSED PROJECT . . . . . . . . . . 13-1

13.1 Overall Conclusions . . . . . . . . . . . . . . . . . 13-1

13.2 Decision ........................... 13-10

\section{LIST OF FIGURES}

FIGURE 1-1

FIGURE 1-2

FIGURE 1-3

FIGURE 8-1

APPENDIX A

APPENDIX B

APPENDIX C

APPENDIX D
PROPOSED THREE SISTERS GOLF RESORTS INC. DEVELOPMENT LOCATION $\ldots \ldots \ldots \ldots \ldots \ldots \ldots \ldots$. . . . . .

EXPANDED VIEW OF PROPOSED THREE SISTERS GOLF RESORTS INC. DEVELOPMENT $\ldots \ldots \ldots \ldots \ldots$ 1-3

PROPOSED DEVELOPMENT PODS AND ASSOCIATED MINING CONSTRAINT AREAS . . . . . . . . . 1-5

APPROXIMATE LOCATIONS OF OTHER PROPOSED PROJECTS WITHIN THE CANMORE REGION . . . . . . . 8-3

\section{LIST OF APPENDICES}

THREE SISTERS GOLF RESORTS HEARING - LIST OF PARTICIPANTS . . . . . . . . . . . . A A-1

THREE SISTERS' SUMMARY OF IMPACTS AND MITIGATIONS . . . . . . . . . . . . . B-1 FORM OF APPROVAL $\ldots \ldots \ldots \ldots \ldots \ldots$ C-1 SUMMARY OF BOARD RECOMMENDATIONS $\ldots \ldots \ldots$ D-1 
Digitized by the Internet Archive in 2015

https://archive.org/details/applicationtocon00albe 
Application 9103 was received from Three Sisters Golf Resorts Inc. (Three Sisters) on October 9, 1991, for approval to develop a recreational and tourism project within the boundaries of the Town of Canmore (the Town). The project would include a resort and convention complex, associated with a variety of housing, golf courses and a range of commercial services on 1,036 hectares $(\mathrm{ha})^{1}$. The regional location of the proposed project is shown in Figure 1-1 and the outline of the Three Sisters lands are shown, in relation to the Town of Canmore and the Municipal District of Bighorn (MD of Bighorn), in Figure 1-2. A more detailed representation of the proposed project area is provided in Figure 1-3.

The area covered by Application 9103 includes the lands that were made the subject of an Environmental Impact Assessment (EIA). This area is not the whole of the Applicant's contiguous lands. The area known as Golf Course C is entirely within the property, but is excluded from the Application because it was the subject of a separate EIA which received approval from the Department of the Environment (Alberta Environment) prior to the proclamation of the Natural Resources Conservation Board Act (the NRCB Act). At the extreme western end of the Applicant's property, a parcel known as "Canmore 75", is also excluded from the Application because it is purely residential and no EIA was required by Alberta Environment. Both of these areas were occasionally referenced throughout the hearing.

Most of the Three Sisters lands, along with some adjacent territory, were annexed to the Town of Canmore from the MD of Bighorn in 1991. The annexed area amounted to some 5,390 ha. The Three Sisters development proposal was first submitted to the MD of Bighorn in 1989 and, after annexation, was submitted to the new local jurisdiction, the Town of Canmore. Negotiations leading to the development of the lands have been ongoing since that time.

Throughout this Decision Report there will be frequent references to the Canmore/Bow Corridor or the Bow Corridor. These terms, as used by the Board, are intended to refer generally to the Bow River Valley from the Banff Park Gates downstream to the Stoney Reserve. The Three Sisters lands lie primarily in the Bow Corridor, but the south-east portion extends into the Wind Valley. For purposes of this Decision Report, the Board considers the boundary between the Bow Valley and the Wind Valley to be a generally west to east line, extending from the heights of Wind Ridge across the mouth of the valley towards Pigeon Mountain as shown on Figure 1-3.

1 One hectare is approximately equal to 2.47 acres. 
1-2

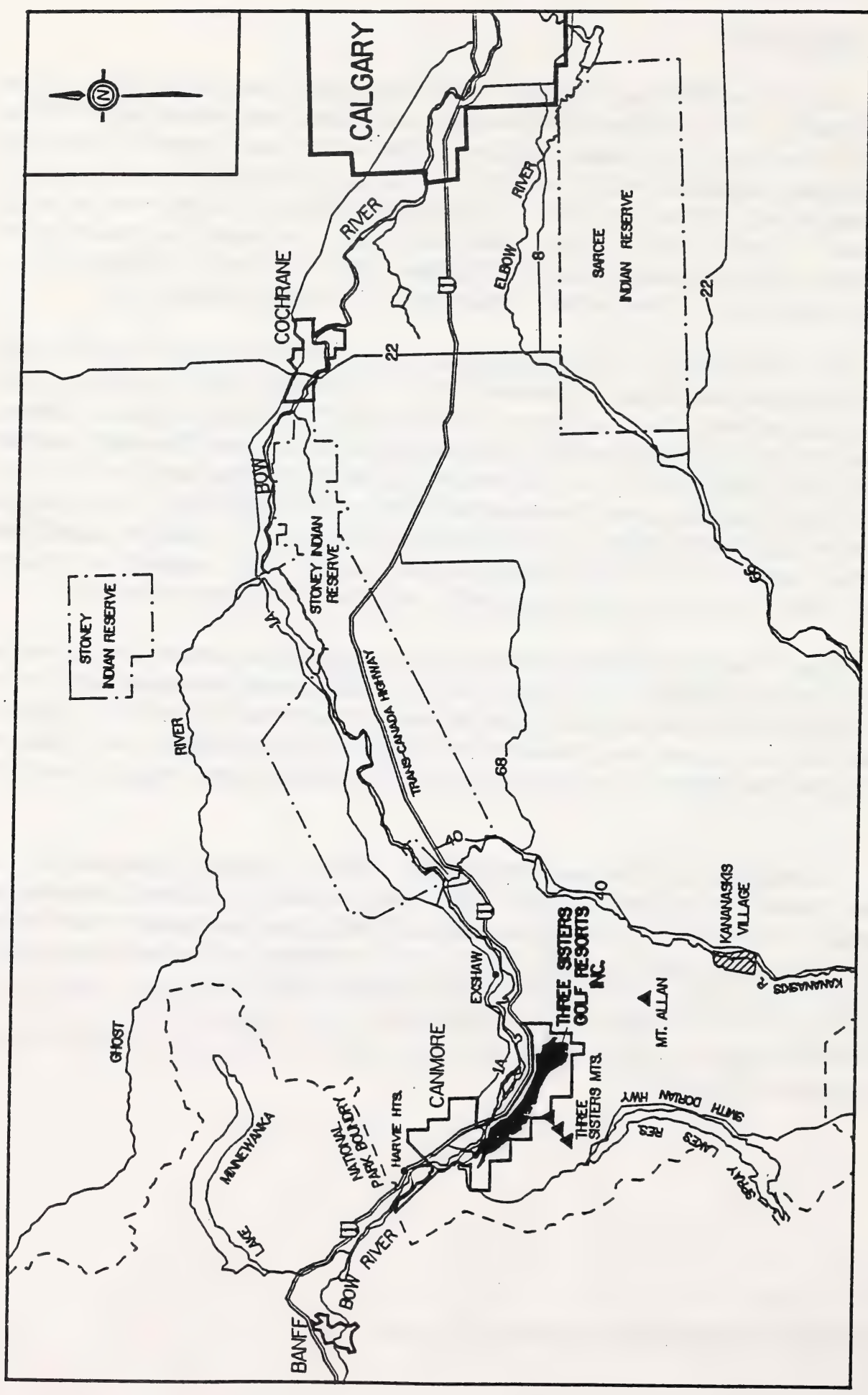

을 


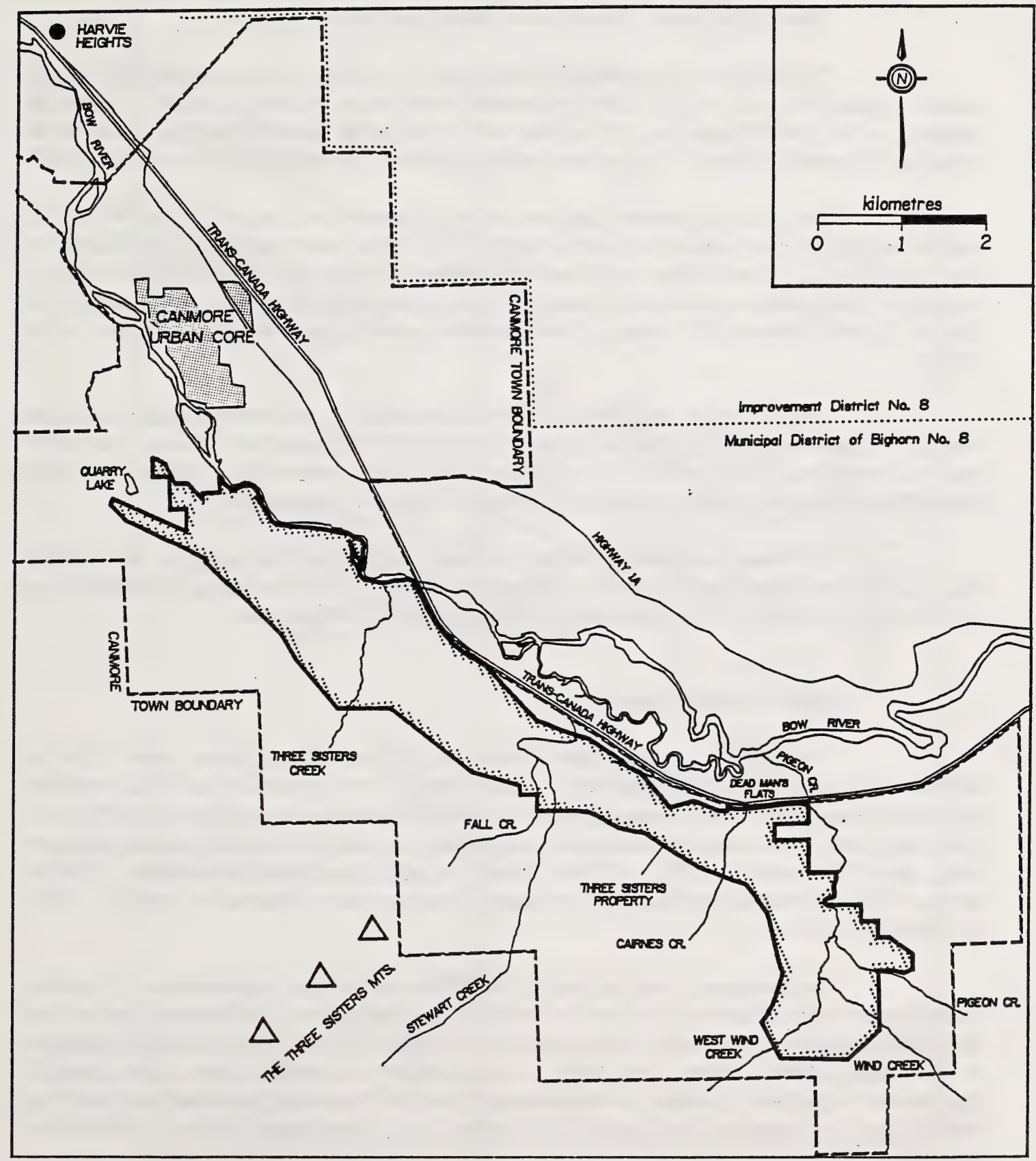

FIGURE 1-2 EXPANDED VIEW OF PROPOSED THREE SISTERS GOLF RESORTS INC. DEVELOPMENT 
1.2 Natural Resources Conservation Board (NRCB) Jurisdiction

The NRCB ACt established a Board to "....provide for an impartial process to review projects that will or may affect the natural resources of Alberta in order to determine whether, in the Board's opinion, the projects are in the public interest, having regard to the social and economic effects of the projects and the effect of the projects on the environment".

The types of projects that are subject to review, as set out in the NRCB Act, include recreational or tourism projects for which an EIA has been ordered by the Minister of the Environment. Three Sisters was directed to prepare an EIA by Alberta Environment on August 30,1990, and therefore the proposed project, exclusive of the previously approved Golf Course C and "Canmore 75" parcel, is a reviewable project subject to the jurisdiction of the NRCB.

The NRCB ACt prohibits the commencement of a reviewable project unless the NRCB, on application, has granted an approval, with the authorization of Cabinet. The NRCB approval required for this project is in addition to all other approvals, licences or permits required under any other act, regulation or by-law in force in the province.

The Board has jurisdiction only to determine whether the proposed development that is the subject of the Application is in the public interest. It does not have jurisdiction to act as an ongoing regulator of the operations of the project, if it is approved.

\subsection{NRCB Review Process}

The Application from Three Sisters included the EIA prepared under Terms of Reference issued by Alberta Environment. After review of the Application, and after receiving comments from Alberta Environment and other Alberta Government departments, the Town of Canmore, Federal Government Departments and others, the staff of the NRCB sent a deficiency letter, dated December 31, 1991, to Three Sisters requesting additional information. Prior to receipt of this additional information, a prehearing meeting was scheduled for March 9, 1992, in Canmore, Alberta.

The prehearing meeting was for the purpose of hearing representations respecting certain aspects of the hearing to be held to consider the Application. The matters dealt with at the meeting were the Application review process, the role of Alberta Environment with respect to the Three Sisters project, the status and availability of baseline data, other possible applications in the Bow Corridor, the location and timing of the hearing and deadlines for filing submissions, and requests from potential interveners to be considered eligible for intervener funding. 


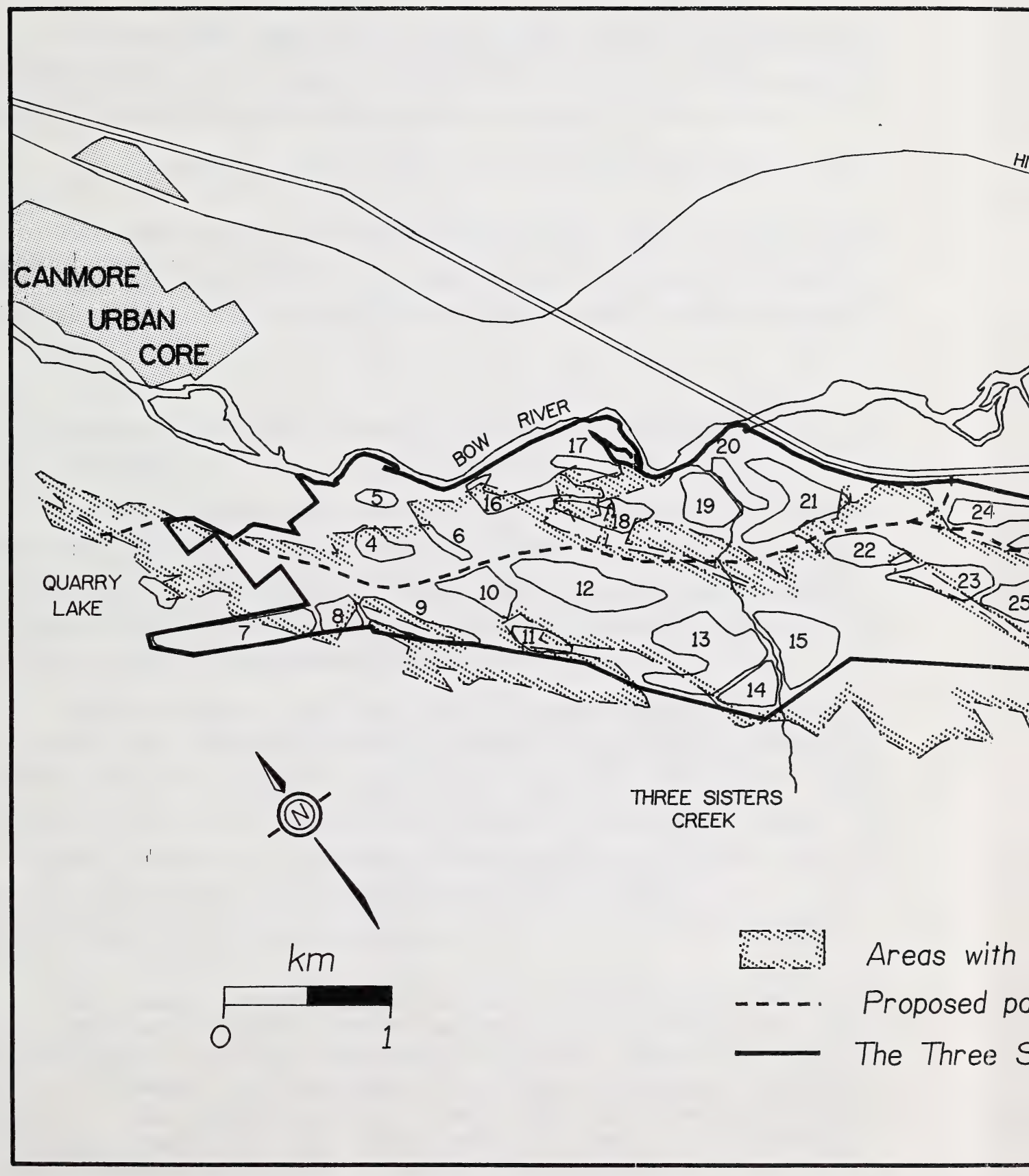




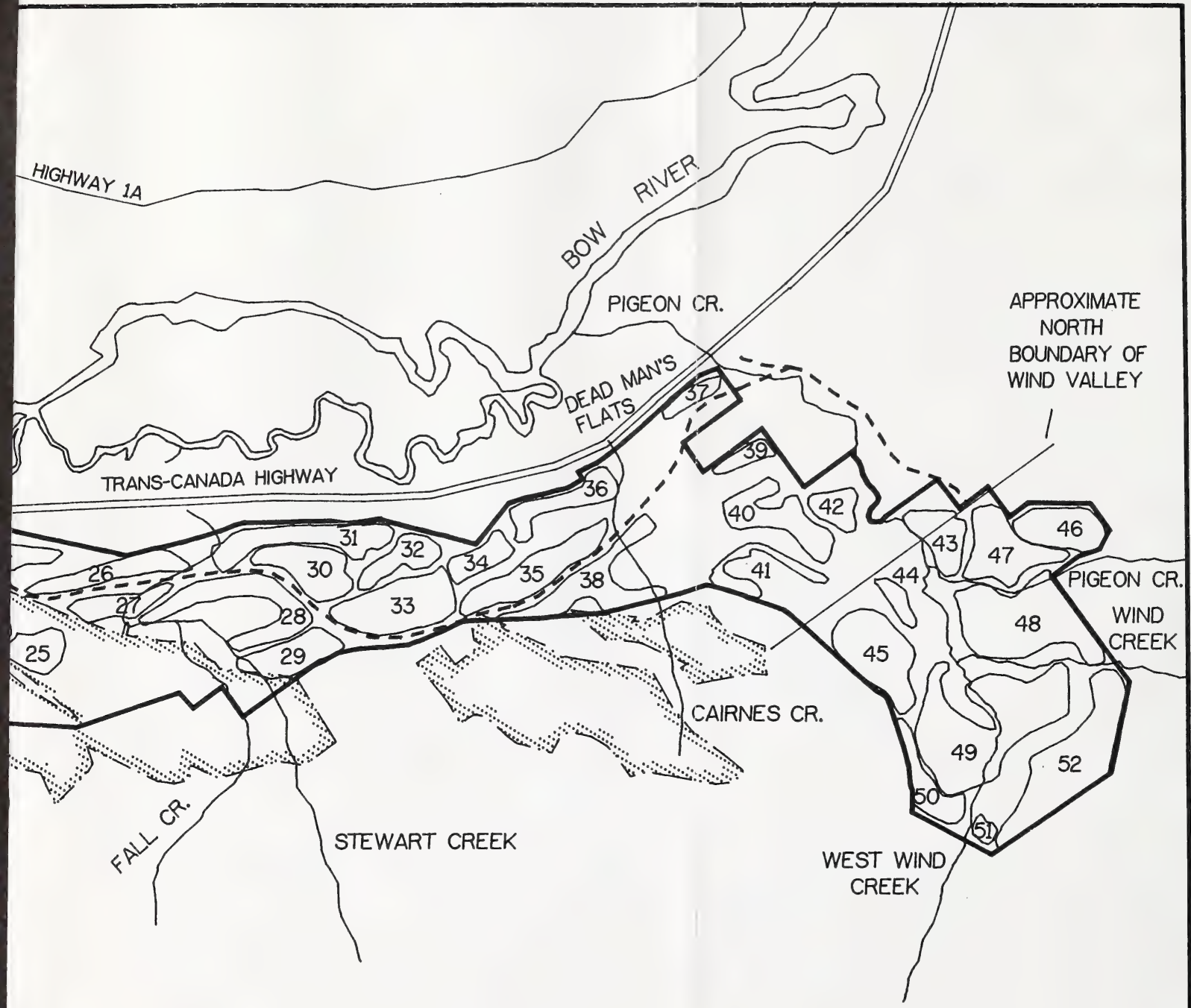

th medium and high mining constraints.

parkway.

Sisters Property. 
The Board heard representations from a number of individuals, groups and organizations, as well as from the Town of Canmore and the Mt. Rundle School Division (School Division) and scheduled a hearing for June 15, 1992, in Canmore. The Board also decided that a number of groups were eligible for advance funding from Three Sisters.

The written decision of this prehearing meeting is available from the NRCB on request.

The hearing opened in the Canmore Recreation Centre on June 15, 1992, with G.J. DeSorcy, P.Eng.; G.A. Yarranton, Ph.D.; C.H. Weir, P.Eng.; and C. Dahl Rees, M.A., LL.B., sitting. The hearing concluded on July 23, 1992, having convened from June 15 to July 23, 1992, with weekends and holidays excepted. The hearing participants are listed in Appendix A.

1.4

The Role of Alberta Environment and Other Alberta Government Departments

Alberta Environment made a statement at the commencement of the hearing regarding the role of Alberta Government departments. Alberta Environment is responsible for the administration of the Alberta Environmental Assessment Process, including screening of projects to determine the need for EIA reports, ensuring public consultation throughout the EIA process, issuing Terms of Reference, and coordinating interdepartmental reviews of EIA documents to ensure that they are consistent with the Terms of Reference.

Alberta Environment stated that on August 30, 1990, it requested Three Sisters to prepare an EIA report. Terms of Reference were issued to the Applicant on December 20, 1990, reflecting advice from the public, local municipalities, and the Provincial and Federal Governments. When Three Sisters filed the EIA with Alberta Environment on October 9, 1991, Alberta Environment initiated an interdepartmental review of the documents and advised the NRCB of a number of deficiencies. Supplemental Information was requested from the Applicant on December 31, 1991, and was filed by the Applicant on March 16, 1992. It was referred to Alberta Environment for review, and the Department advised the NRCB that, for its purposes, the EIA was suitable for discussion at a public hearing.

The function of Alberta Environment staff at the hearing was described as assisting the NRCB with its review of the EIA and supplemental information and asking questions of the Applicant to facilitate understanding. In this role, Alberta Environment was assisted by staff of several other departments of the Alberta Government. In addition, consultants for two other departments, Alberta Tourism, Parks and Recreation and Alberta Municipal Affairs, entered a total of three studies undertaken by the respective departments. (These studies are discussed in Section 3.)

Alberta Environment will have a regulatory role for the withdrawal of surface and groundwaters, the alteration of watercourses and, under the Clean Water Act, for sewer and 
water infrastructure. Alberta Environment stated that it would not be in a position to consider regulatory approvals until the Board had made its decision respecting Application 9103.

Two Federal departments participated in the hearing and an opening statement was made regarding their role in the process. It was stated that the Canadian Parks Service of Environment Canada (Canada Parks Service) would be presenting evidence and the Department of Fisheries and Oceans (DFO) would be confining its participation to asking questions.

Canada Parks Service explained that it had ongoing concerns and interests which were outlined in its submission. These were described as relating to the maintenance of the integrity of Banff National Park. Many wildlife species and components of ecosystems are trans-boundary and the Federal departments believe that it is important to cooperate with Provincial and local jurisdictions in managing these ecosystems.

It was pointed out that the Conservation and Protection Service of Environment Canada has a wide mandate, including wildlife, migratory birds and endangered species.

DFO participated with the intent of questioning the Applicant on perceived information deficiencies and the potential effects of the development on fish and fish habitat. The Department stated that it plays a leadership role in the stewardship of Canadian marine and freshwater fisheries as a result of the Constitution Act of 1982. The Province of Alberta administers provisions on the deposit of deleterious substances on behalf of DFO although the Federal Minister remains responsible.

\subsection{Role of the Town of Canmore}

At the outset of the hearing, the Town of Canmore stated its role in the consideration of the Three Sisters Application. The Town said it hoped that the hearing process would prove to be a valuable decision making tool for the Town of Canmore, the balance of the Bow Corridor communities, the Province of Alberta and ultimately, the environment. The Town requested that the Board consider, not just the specific information related to the Application before the Board, but also the impact of generally similar land uses, developments and subdivisions, so that the Town could benefit from the process and better undertake its responsibilities under the Alberta Planning Act.

On behalf of the Town, Mayor Andrews explained the special circumstances surrounding the position of the Town in relation to the Application and the current status of its statutory responsibilities and documents under the Alberta Planning Act. It was noted that Canmore has been an active and thoughtful participant in the planning process since its incorporation and the existing planning documents have been in place for some time. In 1991, 
the Town of Canmore annexed a total of some 5,390 ha of land from the MD of Bighom and to a lesser extent from Improvement Districts (I.D.'s) 5 and 8. The annexation took place with the concurrence of the MD of Bighorn and included about 1,036 ha of the Applicant's land that is the subject of the Application before the Board.

It was stated that, partly as a result of the annexation, the Town embarked on a complete revision of the General Municipal Plan (GMP) which was first adopted in 1984. A new draft GMP was generated and informally introduced to the public shortly before the hearing. The Mayor stated that the draft in existence at the time the hearing opened may very well be amended as a result of the public review process, including the formal public hearing that is required by Part 6 of the Alberta Planning Act. Upon third reading, the document will become the formal planning statement by the community of Canmore and a collective vision of its economic, social and land use future. Once the plan is adopted, the other planning documents, such as the land use by-law, will be revised to conform to the GMP. It was stated that the GMP must be consistent with the Calgary Regional Plan. In turn, the GMP will indicate areas suitable for Area Structure Plans (ASP) that must be in conformity and Council will then be in a position to approve land use districts, subdivision plans and developments that conform over all.

The Town said that it had been unable to determine whether it approved or disapproved of the Application before the Board, because the task of GMP preparation was incomplete at the time of the hearing. As a consequence, the Town stated that it would assist the Board only by bringing forward the best quality and most accurate information and statistics and by placing the development proposal in the Town context.

The Town also stated that if the Application before the Board is approved in whole or in part, there will be a need to integrate the one time review and determination of the NRCB process with the statutorily parallel processes of the Planning Act. The Town said it recognizes that change and evolution are a part of the ongoing planning process and that it will have responsibilities for good planning with respect to the development for many years to come, if an approval is given by the NRCB. 
This Section of the Decision Report summarizes the proposed project and the information submitted by Three Sisters in support of its Application. As a result of the extensive amount of information contained in the public record regarding this Application, the Board emphasizes the summary nature of this Section. The summary is included in order to provide those who are unfamiliar with the Application with a greater understanding of the Board's decision whereas the Board has based its decision on the whole of the public record. Those readers who would like to gain a more detailed familiarity with the contents of the Application record are advised that they may do so by appointment at the Calgary office of the NRCB during normal office hours.

\section{1}

The Applicant

In its Application, Three Sisters stated that it is an Alberta company having incorporated on July 5, 1989, with its head office located in Calgary. The ownership and management of the company was said to be controlled by Albertans with shareholders and officers of the company having had related experience in the Canmore/Bow Corridor area.

The philosophy of the Applicant, as stated in the EIA, is intended to respect the lifestyle and sense of community which exists in the Town of Canmore and to recognize that community growth is best managed by a long term plan and controlled growth strategy consistent with the Town of Canmore policies. The Applicant stated that it is dedicated to the rehabilitation of former mine sites, recognizes the importance of the environmental trust inherent in a land exchange with the Province that took place in 1989, and sees the Town, the Province and Three Sisters working together as partners to benefit the Town of Canmore and residents of the Bow Corridor.

\subsection{The Proposed Project}

2.2.1 Physical Location and Suitability for Development

Three Sisters is proposing a plan for the development of 1,036 ha within the boundaries of the Town of Canmore. The lands affected are located south and west of the Bow River, extending from the existing development within the Town of Canmore some ten kilometers $(\mathrm{km})$ to the vicinity of Dead Man's Flats and into the Wind Valley, as shown on Figures 1-1 and 1-2.

It was stated that the original land holdings were acquired by the Applicant in 1989, and after acquiring the property, Three Sisters negotiated a "land exchange" with the Government of Alberta. Three Sisters gave up 538 ha in return for 359 ha The Applicant said the exchange removed from private ownership sensitive wildlife lands located mostly in the Wind Valley and the Wind Ridge area. These lands were placed in the public domain and in return, 
Three Sisters was said to have received abutting lands in the Bow Valley to permit more efficient and contiguous development from one end of its property to the other.

The lands are considered by the Applicant to have two distinct physical parts. The first part was described as consisting of a series of benchlands south of the Trans-Canada Highway and the Bow River. The second, making up the remaining quarter of the property, was said to be located at the south eastern end in what is termed Wind Valley. This location was described as being geographically isolated from the remainder of the property with Three Sisters' land holdings making up about five percent of the total Wind Valley watershed.

The Applicant's lands were described as being undeveloped at the present time. Three Sisters said that there are a number of significant physical constraints to the development of the property, including the presence of wildlife and wildlife habitat, past mining operations that have left part of the area undermined, historical and archeological resources, water courses, steep slopes, adverse soil conditions and avalanche areas. The Applicant categorized the suitability of the lands for development into three classes: lands with no physical constraints, lands with constraints capable of being mitigated and lands with severe constraints. The results of this classification were stated as being one of the major determinants of the development plan forming the basis of the Application.

\subsubsection{The Proposed Development}

Three Sisters expects to provide a broad range of land uses with a mixed development of resort, convention, commercial, and residential facilities, but the long term focus of the whole development is described as being two fold, residential and resort, with a complete product mix being required for each. The plan calls for more intensive development in two centres, but some development will extend throughout the whole area of the property.

One centre, referred to as the Tower Mountain site, is planned for the Wind Valley and the Bow Valley at the easterly end of the property. The rest of the development is intended to be focused at the westerly end of the property, from Stewart Creek west to the urban area of Canmore. Forested open space will be located throughout the property and, according to the Applicant, 74 percent of the entire Three Sisters property will remain green as either natural forest, golf course, or planted grass in residential areas.

At build out, some 15,000 persons are expected to be added to the total population of the Town of Canmore, along with an additional 2,425 hotel rooms, and 6,085 housing units, including 700 staff housing units. The Applicant proposes to develop the lands over a time frame of twenty years or more, following a sequence that will partly be a response to market forces. The plan calls for four phases of approximately five years each; only Phase 1 has been set out by annual intervals to date. The Applicant expressed its intention of starting the development in the Wind Valley-Tower Mountain area as a priority. 
The proposed project includes 52 parcels, known as pods, which constitute separate nodes of development within which the general uses and densities are described. The Applicant also provided a broad indication of the phasing of the various pods. The pods are separated by land left in a natural state, wildlife corridors, and golf courses. The overall plan is described as being conceptual in nature. The Applicant's objective is to build a framework for a step by step planning process that is anticipated to proceed for many years, moving towards a greater and greater level of detail and precision.

The Tower Mountain resort centered around pods 41, 49 and 52 in Figure 1-3 is intended to offer a full amenity package. The scale, setting, and scenic drama of the location are expected to be the focus of an international resort complex, beginning with 400 rooms and reaching over 2,000 rooms at build out. The attraction of the complex was described by Mr. Brook Melchin, as being founded on five themes: setting, health and recreation, convention and education, cottage industry, retail and entertainment. The Applicant indicated an interest on the part of the Marriott Hotel chain to participate in the development of hotel space on the property and expects to offer a product in the mid-price range for the international market. Total space for hotel, restaurant, convention, retail and other attractions at build out is estimated at 111,500 square metres $\left(\mathrm{m}^{2}\right)$. Two golf courses would be associated with this part of the plan, one of which would be located partly in Wind Valley, and a wide range of housing would also be provided.

The other major focus would be the Stewart Creek community centre which is planned to accommodate community and neighbourhood retail outlets and services. This location is expected to provide a more traditional village centre and is shown as pod 30 in Figure 1-3. Three Sisters stated that hotel accommodation is not planned for this site, but alternative tourism accommodations would be considered. The centre was described as being the focus of modest and lower cost residential housing with school and other facilities located in close proximity. Total commercial space to build out is estimated at $21,800 \mathrm{~m}^{2}$. Two golf courses would also be associated with this general location.

Various types and styles of housing are planned to be grouped in various locations throughout the property. Typical residential units would include single family homes and large estate homes, townhouses, apartments, modular homes, and staff housing and dormitory accommodation. Lot sizes are expected to vary to provide a range of market choice. It is expected that about 6,085 housing units would be built at an average of 320 units per year. According to the Applicant, affordable housing is included in the proposal in order to ease existing and long term housing problems anticipated in the Canmore area. It was stated that low and modest cost housing would make up over 60 percent of all proposed residential units. Three Sisters would require hotel operators to provide accommodation for 50 percent of their staff close to the facility. Additional rental and permanent housing for staff would be distributed throughout the development.

The master plan of development shows that servicing for both water supply and sanitary sewage treatment would be provided from two directions. The Tower Mountain area 
would be serviced from Dead Man's Flats, where treatment facilities would be located and from which trunk services would be extended to the Wind Valley and west to the Stewart Creek area. The westerly part of the development would be serviced by an extension of the present Town of Canmore systems, which would require expansion and upgrading. Three Sisters proposes that all sewage treatment would be constructed to tertiary standards and would be built in stages, with the first stage being an extension from Dead Man's Flats to Wind Valley. Water supply would follow a similar pattern of origin and timing.

The Applicant indicated that depending on base flows and run off volumes, the requirements for golf course irrigation would be met in whole or in part from Stewart, Three Sisters, Pigeon and Wind Creeks, from groundwater, or from the treated water system. A comprehensive storm water handling system is planned which would utilize soil percolation and possibly retention ponds.

Solid waste disposal is expected to be provided through a regional program that is under discussion at present and Three Sisters proposes to participate in its formulation. Electricity, natural gas, telephone and cable are all available from existing utility companies. A low speed arterial road is planned within the property linking the entire area. Access from Canmore is expected to be from the Spray Lakes road. Planned access from Dead Man's Flats would require a significant upgrade of the Trans-Canada Highway interchange at that location. The Applicant stated that interior roads would service all parts of the development from the parkway arterial.

Three Sisters said that the details of fire protection remain to be determined in consultation with the Town of Canmore. The Applicant intends to provide school reserve land in the Stewart Creek community centre, but during the initial development stages, existing Canmore schools might be used. The provision of police protection, health care, social services, library and recreation services would be formulated with the appropriate authorities.

The Applicant noted that there has been a considerable history to the evolution of the present master plan and that a number of possible options were considered. They included: a private resort with 60 or 70 owners; a "residential only" proposal, with a single golf course; a Three Sisters site resort option located near pods 16, 17 and 18 which are shown on Figure 1-3; a coal development and mining option; a methane recovery option; and development to quarry building stone. According to Three Sisters, the present proposal was not finalized by the Applicant until late 1991 as a result of financial considerations and mining constraint analysis.

\subsection{Supporting Information}

The Applicant prepared an EIA that examined environmental and socio-economic conditions prior to the project, the likely changes that would be generated as a consequence of the development and operation of the project, and a number of mitigation measures to deal with 
potential negative impacts. The major areas of review were: current land and resource use and the status of present resources, impact assessment and mitigation analysis, public consultation and alternative development scenarios.

The Applicant's method of examining the potential impact of the project was to collect and assess baseline data, and then estimate the potential effects on the present situation. Impacts were then classified into three categories: positive, negative and cumulative. Measures to deal with the potentially adverse impacts were then proposed if the Applicant believed mitigation was possible. In addition, a number of impacts were identified that, in the Applicant's opinion, could not be mitigated or avoided. A "Summary of Impacts and Mitigation" was prepared by the Applicant describing a broad range of potential social, economic and environmental impacts and possible mitigative strategies for these impacts where applicable. A copy of this summary is attached as Appendix B to supplement the following descriptive account of the Applicant's views on these matters.

\subsubsection{Vegetation}

The EIA submitted by the Applicant showed that baseline information on vegetation was collected through a mapping exercise and a survey of potential occurrences of rare and endangered species. A vegetation scheme was adopted from a provincial wildlife habitat classification scheme.

According to the Applicant, the vegetation on the property is presently comprised of forest cover types and open grassland meadows. Many of the open grassland areas are attributable to previous mining activity and a considerable percentage of the natural landscape has been disturbed by previous human activity. The most extensive areas of disturbance occur in the western end of the property where coal mining took place in various locations from the late 19th century to 1979. Many of these areas have been reclaimed and revegetated. The forest cover types include closed and open canopies of white spruce and lodgepole pine, and closed canopies of trembling aspen, mixedwood and Douglas fir. Most of the pine communities are in a transition phase according to the Applicant and will eventually succeed to white spruce.

The mixed wood forest communities are comprised of trembling aspen and combinations of lodgepole pine and white spruce. At higher elevations, Englemann spruce and Douglas fir may be present in the understory. Wetland areas, bogs, and shrub meadows are found along the creeks and depressional areas. Douglas fir stands are found in isolated pockets in the Wind Valley. This tree species was particularly noted since it is not common in Alberta. However, no plant species of rare, endangered or overall uncommon nature were found.

Three Sisters stated that all important impacts to vegetation could be mitigated or avoided. It acknowledged that the removal of Douglas fir during clearing would be an important impact, but suggested that it could be held to negligible levels by selectively preventing the cutting of the species. It also acknowledged that the long term loss of some 624 ha of natural 
forest and meadow cover was an important impact, but suggested that this was minor in a regional context.

Three Sisters also referred to other impacts on vegetation that it considered not to be significant. These included the use of non-native plants on golf courses and elsewhere, trampling and erosion due to increased recreational use, increased salination in creeks, and changes in drainage patterns, all of which could be mitigated to some extent.

With respect to cumulative impacts on vegetation as a result of all developments in the Bow Corridor, the Applicant acknowledged a loss of vegetation that would be locally important. It suggested that mitigation plans, similar to those proposed by Three Sisters, should be required of other developers.

\subsubsection{Wildlife}

A number of studies were undertaken by the Applicant to establish the current status of wildlife and wildlife habitat and the potential impacts of the development proposal on both.

In respect of assembling an information base on wildlife, the Applicant took the position that it had a limited responsibility to undertake regional or cumulative impact analysis. A biophysical study area was therefore defined by the Applicant in order to determine the limits of this responsibility. Quantitative habitat evaluation procedures were utilized to determine baseline habitat availability in the biophysical study area for nine key species of wildlife. These species were stated to have been purposely selected to represent a broad range of habitat requirements, with each of the key species representing a specific group of wildlife. The same procedures were described as being used to quantify potential habitat losses associated with the development.

The Applicant carried out habitat evaluations for large mammals, small mammals, upland game birds, songbirds, reptiles and amphibians. The EIA documentation described the assessment procedure, the selection of key species for habitat modelling, the habitat evaluation models, Habitat Suitability Indices (HSI), and the use of habitat units as a basis for analysis. The documentation also identified groups of specific field surveys that were conducted at various times to provide regional and site-specific baseline information on wildlife. Important regional factors affecting wildlife were recognized: existing residential and industrial development, grazing leases, the Trans-Canada Highway, hunting, trapping and non-consumptive residential use.

A number of concerns were acknowledged in the EIA, including the presence of six rare and endangered species. It was stated that the development would also have a negative impact on some other species. In the large mammal group, specific concerns were raised with respect to the grizzly and black bear, wolverine, bighorn sheep and elk. The information also 
showed that many concerns about impacts were focused on the Wind Valley, although not exclusively so. Bighorn sheep are found on the slopes of Pigeon Mountain and Wind Ridge, while the elk seem to use both the upper slopes of Wind Valley and the bottom lands. Grizzly bear use the valley as an early summer feeding area since the fen in the valley bottom is a source of horsetails, which make up an important part of their diet at that time.

Outside the Wind Valley, the Stewart Creek mineral lick was described as an attraction for bighorn sheep and continued access to the site after development was a concern. Also described were important movement corridors for elk through Wind Valley and along the Bow Valley part of the development.

The Applicant stated that no mitigation could prevent the loss of wolverine from the Wind Valley or potential losses of grizzly and black bear. Long term loss of the habitat of other large carnivores through fragmentation was also considered to be a problem. The Applicant proposed a number of design measures to deal with a whole range of mitigable impacts. The most important of these measures was believed to be the provision of wildlife corridors to preserve movement patterns, although it was acknowledged that the possible success of these measures is unknown. The development of habitat enhancement areas was also planned as a means of improving habitat for some wildlife species after development. Other mitigations proposed were the restriction of road speeds and timing construction so as to minimize effects on wildlife. Restrictions on public access to the Wind Ridge and Stewart Creek trails were also an important part of the proposed mitigation.

The Applicant said that it expected that corridors for the larger wildlife would benefit the smaller species also.

\subsubsection{Water Resources}

Information was presented on surface and groundwater hydrology, water quality and fisheries and aquatic organisms. Existing data were reviewed, additional data were collected and habitat evaluation studies undertaken to determine possible impacts of development on the sport fishery.

The three largest stream channels that cross the Three Sisters property from headwaters in the mountains to the south draining to the Bow River are Three Sisters Creek, Stewart Creek and Pigeon Creek with its tributaries Wind, West and South Wind Creeks. Portions of the Three Sisters and Stewart Creeks are ephemeral or intermittent, and only reach the Bow River on the surface after heavy rainfall and runoff. The Bow River parallels the length of the property and forms the northern boundary from a point east of Three Sisters Drive within the Town of Canmore to the Trans-Canada Highway crossing.

Available baseline data for sportfish showed that mountain whitefish make up 80 percent of the species, brown trout make up 15 percent and the remainder are eastern brook, 
rainbow, cutthroat and bull trout. Brook and brown trout spawn in the side channels of the Bow River near the mouth of Stewart Creek and outside the Three Sisters property limits in Policeman and Canmore Creeks. Bow River seepage channels also contain spawning beds, notably F Creek, which is the closest to the Three Sisters project area. Fisheries information for Pigeon Creek was described as limited. The Applicant stated that there are no fish in Wind, South Wind, West Wind Creek, or Pigeon Creek above the waterfall. The fishery below the waterfall on Pigeon Creek will require mitigation measures according to the Applicant.

Technical information submitted by the Applicant showed that for both surface and groundwater, the concentrations of most quality parameters were below the guidelines set by Canadian Council of Resource and Environment Ministers, or were below levels of concern. Impacts on the aquatic environment could be caused by construction activity, general surface run off and storm water drainage, golf course run-off, stream crossings, alteration of stream beds, and water withdrawal for various uses. Potential negative impacts described by the Applicant were increases in erosion, stream siltation, addition of deleterious chemicals and significant surface water losses.

The Applicant described a number of measures for mitigation. An ongoing monitoring program to deal with the application of chemicals to golf courses was proposed as part of an Integrated Pest Management (IPM) program. Other impacts were expected to be dealt with through engineered solutions. The Applicant proposed tertiary treatment of sewage and completion of water supply and storm water management facilities, possibly including storm retention ponds, to at least provincial standards. Water withdrawals were estimated at less than one percent of the average annual flow of the Bow River and are not expected to affect the flow.

\subsubsection{Other Resource Effects}

With respect to air quality, the Applicant submitted climatic and meteorological data, but stated that no baseline data were available on air quality in the Bow Corridor. A cumulative impact assessment of contaminant emissions was therefore conducted by the Applicant. Possible contaminant emissions from natural gas consumption, residential wood consumption, and highway and local traffic were estimated. The Applicant stated that the results showed that highway traffic is now, and will be in future, a major contributor to pollution; residential wood combustion is also expected to be a significant contributor of polyaromatic hydrocarbon $(\mathrm{PAH})$ levels. The predicted values presented by the Applicant were said to indicate that mitigation measures to limit residential wood consumption through by-law and building standard controls would be useful, but highway traffic emissions were said to be almost totally beyond the Applicant's control.

A preliminary visual impact analysis was submitted by Three Sisters, but due to the present level of detail in the design, the Applicant stated that specific implications are not known at this time. The Applicant therefore proposed a more detailed analysis as plans are developed. The impacts are expected to be dealt with through design guidelines and controls 
registered against subdivisions and through agreements with property owners. The Applicant stated that the recommendations of the Bow-Canmore Visual Impact Assessment report of Alberta Tourism, Parks and Recreation will be followed.

An historical and archaeological resource evaluation was conducted and ten prehistoric sites were identified, two of which were individual artifacts and eight of which were composites. Several historic features were considered worthy of preservation, mostly associated with coal mining: in all, 122 historic mining features were found. It was recommended that 14 historic features be preserved and that the development plan incorporate a coal mining theme. A letter from Alberta Culture and MultiCulturalism was entered as an exhibit indicating steps to be taken by the Applicant prior to any work beginning on the Three Sisters lands in the event of an approval of the project. Three Sisters undertook to meet the requirements requested by the Department.

\subsubsection{Geology, Geotechnical and Mining}

According to information provided in the Applicant's EIA, the Bow River follows a pre-glacial valley established during the quaternary period. The subject lands are located within this valley in the Front Ranges of the Rocky Mountains. Drainage courses from the mountains have transported extensive quantities of materials that have been deposited in the form of alluvial fans and cones over bedrock. The soils consist of glacial till, flood plain deposits, alluvial fans and cones, and weathered bedrock.

The property is located in an area where coal mining was carried out for about 90 years until 1979. Stratigraphically, the area lies within the Kootenay formation of the Cascade coal basin. The sedimentary rock beds, including the coal, have been extensively folded and faulted and are comprised of a succession of shales, sandstones, conglomerates and coal, with vertical to west-dipping axial planes. There are bedding planes, joints, and a variety of faults throughout and, because of the faulting, the coal beds have been severely disturbed.

According to the information presented, the Three Sisters lands were extensively affected by underground mining and to a lesser extent by surface mining. About ten mined seams have been identified. The system used in the Canmore mines for extraction of coal is known as room and pillar and this system has had much to do with the particular impacts found at the surface. Coal recovery was said to be in two stages. The first stage was described as roadway development and the second, pillar extraction. Following the completion of both stages, coal recovery was said to range from 40 percent to 90 percent of the coal in place with pillar extraction being conducted on slightly more than 50 percent of the mined area. The roadways and pillar sizes varied, so that the stability of mined areas also varied considerably. Most mines were accessed by slope drivages and shafts were rarely used, except for air supply. Rock tunnels were also occasionally used and were driven horizontally across the strata to intersect the coal seams. 
Three Sisters acknowledged concerns regarding possible subsidence at the surface due to the underground collapse of mine workings and the potential for methane emissions. The information provided showed that a number of conditions give rise to concern about surface stability over the old workings. These are: extreme friability and low strength of seam, gradients of mined seam, faults and folds, high strength of intervening rock bed, amount and thickness of coal removed, and the number of seams mined.

These conditions, according to the analysis by the Applicant's experts, create a number of constraints to the development of the Three Sisters property. Stability of the surface, openings to old workings, flows of possibly polluted mine water, gas emissions and possible spontaneous combustion were assessed. A number of components of a mitigative strategy were discussed. The key elements are expected to be the development of a mining constraints classification system and the development of safe foundation systems for all structures. Much of the presentation centred on the proposal for a classification procedure by the Applicant's mining experts. The Application of the procedure has not been completed beyond the preliminary level, but is further advanced with respect to Golf Course C, which is not a part of Application 9103.

Four levels of data collection with increasing levels of detail were proposed, from desk top studies through ground truthing, with progression to each new level depending on the findings of the previous stage. The Applicant stated that the cost of extensive examination in the early stages of site planning could not be justified. Constraint zones were proposed that are capable of being subdivided for greater detail with reference to site specific planning at a more advanced stage. The high constraint zones include all areas where a high potential for unstable ground exists. Within this zone, large buildings could not be constructed without the complete removal, or very expensive treatment, of the unstable ground. Three Sisters stated that most of these areas will be reserved for golf courses and service corridors. The other constraint zones will be reserved from development until varying degrees of ground truthing have taken place.

These mitigation measures would, according to the Applicant, be supplemented by special engineering measures which are expected to include special foundation designs, special techniques for locating services across high constraint zones, and sealing of old openings for public safety. The quality of mine drainage water would be monitored, in part to determine its suitability for irrigation. Methane was not considered by the Applicant to be a serious hazard requiring mitigation, because methane is much lighter than air and, in the case of the mine tunnels, may have vented to the surface. With respect to unmined coal deposits, the Applicant believes that water pressure would keep the methane adsorbed on the coal within the coal bed. Spontaneous combustion was also not considered to be a major concern, because of the difficulty of igniting the Canmore coals. A number of measures were proposed to minimize the possibilities of surface activity causing fire in mined and unmined coal seams. 


\subsubsection{Socio-Economic Effects}

The Applicant presented socio-economic information in order to show the potential effects of the project over a time frame of 20 years. The Applicant took the position that the impacts of the proposed Three Sisters project could be assessed by means of a comparison of forecasts for the Town of Canmore and surrounding area with and without the project. However, the Applicant believed an estimate of cumulative impacts was too difficult to consider in the absence of firm estimates for other possible developments in the valley.

The socio-economic information presented in the EIA and at the hearing included socio-economic impacts and their mitigation, the benefits of tourism to the Town of Canmore, the Bow Corridor and the economy of Alberta, and the proposals of Three Sisters to monitor and manage impacts over time.

Basic information was presented about the local economy to show that Canmore has undergone changes in the past decade. According to Three Sisters, the Bow Valley has become dependent on the tourist industry for the majority of its economic activity, although a number of employment sectors are represented. Canmore's population is estimated at about 5,300 persons with an unemployment rate, at the time of the EIA submission, of 2.8 percent. Growth rates in recent years were said to have approached 10 percent, and in some respects the local economy was said to have been showing signs of strain, particularly in the housing sector. The Applicant provided information to suggest that the cost of housing has been increasing rapidly. Consequently, it was stated that there is a definite shortage of low cost housing and no financial incentive to construct rental accommodation at this time. It was also suggested that there is a significant lack of retail commercial space. According to the Applicant, current upward pressure on the housing market is in part due to speculative activity.

Three Sisters expects its proposal, if approved, to result in continued growth for the Town of Canmore over the next twenty years. The Applicant contended that the magnitude of growth is difficult to forecast and a number of figures were used to show that population growth rates in the Town of Canmore will likely approach 10 percent for at least the initial years of the development. The Applicant discussed its public participation program and, using results from information gained at public meetings and from questionnaires, concluded that respondents were not opposed to the kind of growth that might be generated by the proposed project. It was stated, however, that mitigation measures to deal with growth pressure would be desirable in the early years of project construction.

The Applicant described the details of the various elements of the proposed development, showing how 50 percent of the housing units are likely to be available at relatively low cost, either with less than 50 foot lots, or as multi-family, condominium and apartment units. An additional 30 percent are expected to be in the mid-price range and 20 percent in the higher price range. The Applicant proposes to provide staff housing units for at least 50 percent of the direct resort employees close to the resort location. A description of the possible housing 
and commercial mix in the 52 development pods proposed for the project was provided to show that there is a mixed product of residential accommodation planned across a wide price range.

The Applicant stated that the Wind Valley resort development is important to the economic success of the proposed project as designed and, since it is scheduled to proceed in the early years of the development, the timing of this construction will also benefit the Town financially. The resort, described as an international destination resort, is said to be dependent on the attractiveness of the Wind Valley location. The Marriott Hotel chain is expected to offer accommodation in the mid-price range with room rates averaging about $\$ 140$ per night. It was stated that, if the location were not to be approved, a hotel could possibly be included in a redesigned project outside the Wind Valley, but that the market appeal of such a development would be greatly reduced.

The direct and indirect benefits of the project were estimated in terms of employment and expenditures by residents and non-residents. A substantial amount of new employment is expected to occur during the construction period with 80 percent or more of the employment being supplied from outside the local area. It was estimated that operating the resort would create about 5,200 direct jobs and 1,800 indirect jobs. Major increases in gross domestic product and gross output are forecast to occur. Benefits of increased tourism to the provincial economy were described and the importance of the resort as a catalyst for regional attraction was emphasized. A symbiotic relationship of this development with the Town of Banff and Lake Louise attractions was predicted by the Applicant.

The Applicant concluded as a result of its technical analysis, that the development could be expected to create a major benefit to the provincial economy. Construction was estimated to generate almost $\$ 40$ million in total provincial corporate and personal income taxes. Income taxes from operation of the facilities were also estimated to add significantly to provincial revenues.

Benefits to the Town of Canmore were also estimated. Increases in tax assessment at the completion of the proposed project were estimated at some $\$ 580$ million, with $\$ 385$ million of the total estimate being from residential sources. It was acknowledged that the Town would face some large capital outlays for renewal and expansion of infrastructure during the early years of Three Sisters development, some of which are expected to be caused by other developments. It was concluded by the Applicant that early development of the commercial portion of the project would financially mitigate these effects and in the long run, the Town would experience significant net financial benefits.

The Applicant entered a number of proposals to mitigate negative impacts. Specifically, a monitoring program was proposed to deal with uncertainties. The program would address community characteristics and project impacts in consultation with local stakeholders. The plans developed to deal with observed impacts are expected to be modified in response to analysis of their effectiveness on a semi-annual basis. Negotiations between stakeholders and 
Three Sisters were proposed by the company as a way to deal with negative impacts as and when they arise.

A number of specific commitments were also made by the President of Three Sisters, Mr. Richard Melchin. He noted that the Town has sought infrastructure funding from the Government of Alberta and undertook on behalf of the company to bear any capital costs of the Town's infrastructure that are attributable to the project and not covered by provincial assistance. Since the costs of start up at the Wind Valley end of the project might expose the Town to risk, Three Sisters also offered to work out an agreement with the Town to participate in managing these financial risks until tax revenues come on stream. The Applicant also proposed to reserve a portion of revenues in a sinking fund to be used for cultural activity, the arts, and recreation in the community. Finally, Three Sisters undertook to ensure a balanced supply of affordable housing to assist Canmore with this recognized need. 


\section{THE POSITIONS OF PARTICIPANTS AND SUPPORTING INFORMATION}

As indicated in the previous Section, as a result of the extensive amount of information contained in the public record, the Board emphasizes the summary nature of this Section. Like the previous Section, this summary is included in order to provide those unfamiliar with the Application with a greater understanding of the Board's decision whereas the Board has based its decision on the whole of the public record. As noted previously, those readers who would like to gain a more detailed familiarity with the contents of submissions by participants in the hearing are advised that they may view the record by appointment at the Calgary office of the NRCB during normal office hours.

Canadian Parks and Wilderness Society, The Alpine Club of Canada and The Sierra Club of Western Canada (CPAWS Group)

The CPAWS Group was opposed to the Application on the grounds that the Three Sisters project as presented was not in the public interest and would have direct negative effects on members of the CPAWS Group, especially those 448 members or supporters who reside in the Bow Valley. The CPAWS Group requested that the Board refuse to grant approval to the Wind Valley portion of the Application and also asked the Board to defer a decision on the rest of the Application until a cumulative effects assessment was completed.

The CPAWS Group maintained that it would not be in the economic, social or environmental interest of Alberta for the area east of Golf Course C or the Wind Valley to be developed because of the serious consequences to the environmental integrity of this critical area. It contended that there would be a major degradation of the quality of life that Canmore and area residents currently enjoy if the development were to proceed. The CPAWS Group believes that a healthy economy and healthy social fabric depend on a healthy environment. It also contended that a large development in a relatively wild area would negatively impact the business of the Alpine Club of Canada.

Information from experts was presented to show that Wind Valley is a high quality environment for a variety of ungulates and carnivores. The area was considered to be unique in its ecological richness and because of its proximity to a major population center. The experts indicated that vegetation, terrain, hydrology and climate provide a favorable combination that gives rise to a very productive and diverse ecosystem. The Wind Valley was described as an ecological hot spot.

A memorandum was introduced to show that, in 1979, the then Assistant Deputy Minister of the Fish and Wildlife Division of Alberta Forestry, Lands and Wildlife, Mr. G. Kerr, had recommended the purchase of all lands then known as the Dillingham property, now the Three Sisters property, to provide environmental protection and improve recreation opportunities. The Wind Valley-Wind Ridge area was especially referred to at that time as being absolutely critical to the long term well being of wildlife in the Pigeon Mountain-Wind RidgeRibbon Creek complex, which was described as a year round wildlife area of major importance. 
valley. Intensive use of these areas as well as the increased potential for contact with domestic animals was thought to increase the likelihood of disease, especially lungworm infection. The experts suggested that increased contact with humans, through use of the golf courses, lawns and roads, and the habit of sheep to visit the salt lick at Stewart Creek would result in the habituation of bighorn sheep which could ultimately be hazardous for them. The potential for a reduction in population due primarily to increased levels of disease was thought to be significant because experience has shown that bighorn sheep populations of 100 or less are generally expected to become extinct.

The CPAWS Group contended that there would be a high likelihood for major cumulative effects in the foreseeable future and that the full impact of the Three Sisters development on wide ranging animals such as the large carnivores could not be assessed without considering the cumulative effects of present and proposed activities at the Three Sisters lands and elsewhere in the Bow Valley, northern Kananaskis Country and Banff National Park. It emphasized the need for a cumulative assessment of development in the montane region which is already heavily impacted, very precious and rare. The Three Sisters EIA was characterized as a traditional assessment that has examined the consequences of a single source of disturbance and therefore has a number of shortcomings. It was described as ignoring the synergistic effects on the ecosystem of repeated developments and animal behavioral changes in response to increasing levels of disturbance. It was criticized for not providing for the development of comprehensive environmental goals. The panel described several approaches to cumulative assessment and concluded that without information on cumulative effects, the impacts to regional populations of wildlife could not be predicted. It was, however, noted that the EIA seriously underestimated the long term and regional implications of development on large carnivores.

In its closing arguments, the CPAWS Group stated that it is opposed to any development in Wind Valley and is neither opposed nor in support of the remainder of the development for want of information on which to form an opinion. It recommended that the Wind Valley area be given a strictly protected status because of its biological and scenic values and access into Wind Valley be controlled by allowing only pedestrian traffic, hardening trails and putting up signs. Technical experts also indicated that a massive residential and recreational development was inappropriate and would deprive the public of an ecological site near to Calgary that maintains the quality of life. They expressed the belief that development should be higher density and nearer to the Town so as to have less impact.

The CPAWS Group requested the Board to defer a decision on the rest of the project pending a cumulative impact assessment. The major reason for recommending a cumulative impact assessment was that cumulative assessment identification was an essential aid to effective decision making. In the case of the proposed Three Sisters project, the CPAWS Group contended that there were serious deficiencies in the environmental information which limited the ability to assess and make good decisions on the cumulative effects of the balance of development in the Bow Valley. 
The view was also expressed that there needs to be a process (referred to as a regional initiative) in place that accommodates all the parties that are affected by such decisions in an open manner and at a very early stage in planning. The CPAWS Group indicated that when such a process is instituted, the need for new information becomes acute and, in the case of the Bow Valley, new vegetation and other biological information would be required, along with basic information on the ranges of top predators, for example. Over a period of time, a learn-as-you-go approach could be adopted through structured management and monitoring on a regional basis. It was recommended that the local people should play an integral role in such a process.

Government of Canada - Environment Canada - Canadian Parks Service (Canada Parks Service)

The Canada Parks Service's written submission and presentation were made by representatives of the Canada Parks Service's and the Conservation and Protection Branches. They indicated that their responsibility for the protection of Banff National Park justified their intervention because the integrity of the Park was influenced by events, including developments in the Bow Corridor, that took place beyond its boundaries. Canada Parks Service cited legislation and policies to further justify their participation. These included the Migratory Birds Convention Act and Regulations; Canada Wildlife Act; Canada Water Act; Fisheries Act; National Parks Act; A Wildlife Policy for Canada; Sustainable Development: A Special Role for National, Provincial, and Territorial Parks; World Conservation Strategy; and Prospectus for an Alberta Conservation Strategy (1987).

Their intervention was based largely on an ecosystem and cumulative effects analysis. Canada Parks Service stated that they were neutral with respect to the Three Sisters proposal but were in favor of sustainable development.

Their submission listed three main objectives: (1) to ensure that development did not impede low elevation wildlife movements between Banff National Park and the montane region of the eastern slopes, (2) to ensure that the Bow Corridor does not become a population sink, which would increase mortality and habitat alienation for wildlife, and (3) to ensure that development does not result in adverse cumulative effects in the Central Rocky Mountain Ecosystem, especially for species listed by COSEWIC as valuable or endangered.

A major concern of Canada Parks Service was the cumulative effect of the Three Sisters development, taken together with other existing and proposed developments in the Bow Valley.

Canada Parks Service expressed concern that proposed developments in the Bow Corridor would result in the loss and alienation of habitat for various wildlife groups, including COSEWIC species. It also stated that the area considered by the EIA was insufficient to determine the real effects of the development and that the whole Central Rocky Mountain 
ecosystem should have been considered. It suggested that development could reduce the amount of range available to wildlife, lower genetic integrity, and cause populations of several wildlife species to decline. It also urged that the Board not accept the loss of COSEWIC species to development because such losses would contravene "A Wildlife Policy for Canada", to which Alberta is signatory, and could reduce the viability of regional populations. Canada Parks Service considered the loss of winter range for ungulates an important issue because the Three Sisters property contains a greater proportion of important ungulate winter range than Banff National Park. It concluded that the loss of high and very high quality wintering habitat as a result of the proposed Three Sisters project could have a significant impact on wildlife populations, especially elk. Wind Valley was singled out as being particularly important because of its unique attractiveness to wildlife, the abundance of wildlife present, and because it is at the hub of several wildlife movement corridors.

A further concern of Canada Parks Service was that the project would block wildlife travel corridors, some of which are also regarded as critical wildlife habitat. Canada Parks Service indicated that most corridors run parallel to the Bow Valley from Banff National Park to the Dead Man's Flats area near the eastern edge of the proposed development. However, north-south corridors cross the valley at Dead Man's Flats and west of Canmore. Wind Valley was also designated as an important corridor. Canada Parks Service indicated that development in the Bow Corridor would result in lost or fragmented habitat, and the interruption of travel corridors. It noted that travel along corridors within the valley has already been restricted by residential development.

Canada Parks Service's submission also contained a number of concerns about specific groups of wildlife. The submission indicated that 76 percent of the 181 species of birds listed by the Applicant were protected under the Migratory Birds Convention Act and that 59 species are neotropical migrants, which appear to be declining in the Western Hemisphere. It was suggested that the plan be evaluated on a larger scale because of the presence of these migratory species. Canada Parks Service was also concerned that only nesting requirements were considered by the Applicant and presented evidence to indicate that the Habitat Evaluation Procedures (HEP) used may not have been appropriate in a local context.

Canada Parks Service contended that, in contrast to the Applicant's reports, the area from Banff National Park to beyond the limit of the Three Sisters development was contiguous ungulate range that is used by elk, mule deer, white-tailed deer, moose, and bighorn sheep. It indicated that because many of these animals undertake seasonal migrations, the potential impact of the project extended over a much larger area than that defined by the Applicant.

Several concerns were expressed about the potential impacts of the project on carnivores. Canada Parks Service noted that only the largest parks and reserves have sufficient area to support populations of large carnivores, which have extensive ranges. It was contended that the lack of comprehensive information about the status and ecological requirements of carnivores in the region precluded sound decisions being made on their behalf. However, 
Canada Parks Service noted that grizzly bears, black bears, cougars and wolverines or signs of their presence were observed in the area of the proposed project. It was further suggested that the area had the potential to support wolves, which are increasing in the region. However, Canada Parks Service believes that the proposed development would eliminate most large and small carnivores from the project area and urged that the loss of endangered carnivores not be accepted by the NRCB.

Various factors contributing to animal mortality were discussed in the context of population sinks for wildlife. Roadside fencing programs, which appear to be an effective means of preventing road kills in Banff National Park, were described in detail. However, the Canada Parks Service panel believed that aversive conditioning had little potential to reduce indirect mortality in habituated elk.

Canada Parks Service contended that the EIA was inadequate in several areas and suggested that the HEP models used and the supporting data were questionable. Stated inadequacies include a lack of historical ecological information for use in assessing and predicting the impacts of future disturbance, the small area encompassed by the biophysical study, a lack of regional baseline data, the lack of consideration given to the ecological importance of montane habitat, the experimental nature of the proposed mitigation strategies and their potential counter-productivity in respect of some species, the potential loss of forestdwelling species that are declining at the expense of common species that occupy open habitats, and failure to identify patterns and connections operating within and between trophic levels. Other stated concerns included a failure to address the effect of the project on long term system dynamics, and a lack of specific information about the development and monitoring of waste water facilities and the effects of water withdrawals on the hydrological regime.

A number of recommendations were included in Canada Parks Service's submission. The principal recommendation was the need to establish a multi jurisdictional, multidisciplinary commission to coordinate development and mitigation on an ecosystem wide basis. It was felt that such a commission was necessary because political boundaries were meaningless when considering ecological issues and because the responsibility for conducting regional and cumulative studies may not be wholly or even largely the responsibility of the Applicant. An action program was recommended for dealing with regional assessment that would cover three things: ecosystem management links, research ecosystem links, and research management links. Canada Parks Service suggested that the Bow Valley was in danger of being overdeveloped because of its high tourism potential and agreed with the Applicant that there was need to form a commission to address the issue of the cumulative effects of proposed developments within the region. Canada Parks Service stated that it was committed to participating in such a committee. Several models for such a committee were mentioned. One of these was to initially establish a coordinating and advisory group, which would later be responsible for land use issues. It was suggested that a committee be tailored specifically for the Bow Corridor and include a variety of interested parties as well as technical expertise. 
Canada Parks Service also contended that, in reviewing development proposals on the basis of cumulative effects, viable as opposed to minimum viable wildlife populations and habitat diversity should be the benchmark for cumulative effects analysis. It also recommended that critical habitat and corridors be identified and protected before development begins. It was suggested that the loss or displacement of wildlife such as vulnerable large carnivores, should not be acceptable to the NRCB unless prior arrangements for regional compensation were made; however, it pointed out that, in a strict sense, compensation may not occur because providing habitat to certain species usually involves losses to others with different requirements. Mechanisms for compensation could include the manipulation of hunting regulations and guarantees of land protection for habitat use, especially for species listed by COSEWIC. It pointed out that the guiding principle of "A Wildlife Policy for Canada", which has been signed by the Province of Alberta, is "The maintenance of viable natural populations of wildlife always takes precedence over use by people". It was also recommended that the pace of development be controlled to allow mitigation techniques, especially those that are experimental, to be assessed over time. Another recommendation was that fragmentation of development be avoided because it could result in the fragmentation of wildlife habitat.

Canada Parks Service indicated that it regarded the development proposal as an opportunity to take a medium to long term view of the future in a regional perspective. It expressed the hope that this would continue into the future in consultation with neighboring jurisdictions.

\subsection{Bow Valley Naturalists (BV Naturalists)}

The BV Naturalists took the position that the proposed Three Sisters development should not be allowed to proceed because it would erode the ecological integrity of the Bow Valley. It suggested that a long term ecological view be taken with respect to development in the area. The BV Naturalists believe that the social will in the 1990's is to prevent damage to ecosystems and repair the damage that presently exists; it cited various references in support of this position. Thus, it believes that the protection and maintenance of ecosystems is preferable to the mitigation of impacts resulting from development. It suggested that the Bow Valley has already been significantly disturbed and that additional disturbance from the proposed Three Sisters development would be unacceptable and perhaps not mitigable.

The BV Naturalists' submission consisted of a number of documents which focussed on a number of general concerns about development in the Bow Valley and concerns specific to the proposed Three Sisters development and the content of the EIA. The BV Naturalists' submission was structured to show that; firstly, the ecology of the area would be severely impacted; secondly, insufficient and inadequate assessment techniques were applied in the EIA of the Applicant; and thirdly, these potential impacts were not assessed in a manner that would allow the conclusion that the project would be in the public interest. 
The BV Naturalists expressed concern about the impacts of the proposed Three Sisters development on the montane ecosystem, which it considers provincially important as well as sensitive to development. It noted that montane is the second most disturbed forested ecosystem in Alberta, after aspen parkland. The BV Naturalists stated that 70 percent of the Bow River Valley subregion is currently subjected to surface disturbance and that this percentage would be increased by the proposed Three Sisters development.

The lack of a cumulative impacts assessment was also a concern. It suggested that nibbling, the accumulation of individually insignificant impacts in time and space, was especially difficult to deal with from a management standpoint. It further suggested than an inordinate amount of effort was being expended on development of the Bow Valley compared to the amount expended to understand ecosystems and the impact of development. It was suggested that marketing studies, which indicate that tourism potential is high in the Bow Valley but do not consider environmental constraints, are at least partly responsible for the focus on development.

The BV Naturalists believe that increased tourism will lead to the loss of wilderness values in the Bow Corridor. It argued that this loss would result from the demand for increased camping and hiking opportunities in conjunction with the private ownership of land in the area. It believes that these factors could force users into alpine areas where the vegetation has little capacity to withstand human disturbance. Soil compaction from hikers and off-road vehicles was said to be a major factor in the degradation of alpine vegetation. It indicated that compaction alters the chemistry of soils and results in reduced aeration, which in turn decreases the nutrients available to plants. The BV Naturalists suggested that possible consequences to alpine areas include increased soil erosion, invasion by weedy plant species, and degradation of wildlife habitat. Increased tourism, it believes, would also lead to the degradation of adjacent areas if development and the closure of hiking trails displaced wilderness users into these areas.

Concern was also expressed that the effects of development on Banff National Park were not assessed. The BV Naturalists stated that the Three Sisters and The Canmore Alpine Development Company Ltd. (CADCO) developments would generate a 50 percent increase in visitors to Banff National Park, a world heritage site that is already ecologically stressed by high use. It was also stated that the Banff National Park budget is not expected to meet future demands for park expenditures effectively at these forecast levels of visitation.

The effects of the proposed development on the hydrological regime of the Bow Valley was also a concern. The BV Naturalists was concerned that Three Sisters would use the cheapest and most effective chemicals available rather than those with the least environmental impact and noted that contamination of ground water by agricultural chemicals has become a major concern in both Ontario and the United States. It also suggested that water used by the development might be channelled into runoff rather than into aquifers and lead to a groundwater deficiency, a potential increase in flood frequency, and further pesticide contamination of the Bow River. 
The impact of development on wildlife was a major concern of the BV Naturalists. A principal concern was the loss of montane habitat to wildlife. The BV Naturalists' submission indicated that because of its highly variable nature and mild winter weather conditions, the montane supports a greater abundance and diversity of wildlife than other mountain habitats. It was suggested that montane is especially important to species with low populations, such as the grizzly bear. The BV Naturalists believe that human activities in the Bow Corridor have already caused substantial impact on the montane ecosystem, including the loss, fragmentation, and alienation of wildlife habitat. It argued that further losses will cause an additional decline in wildlife populations in this area. Alluvial fans were singled out as an area of concern because these areas, which are important wildlife habitat, are considered attractive from a recreational standpoint, and their active processes are frequently curtailed to facilitate development.

The cougar received special attention from the BV Naturalists because it believed that additional development would result in habitat loss and restricted movements for the species. There was also concern that human-cougar interaction could lead to cougar control programs and the creation of a population sink for the species.

The BV Naturalists also mentioned that development could lead to reduced air quality, which, when combined with low temperatures, could be detrimental to wildlife populations in the vicinity of development.

The BV Naturalists expressed a number of concerns about the nature and content of the Applicant's EIA. It asserted that many of the assessment techniques used were inadequate or inappropriate, and that the impacts of the proposed Three Sisters development on the Bow Valley would be greater than those identified by the Applicant. It also stated that the significance of the montane ecosystem was not adequately addressed in the EIA.

The BV Naturalists stated that the assessment of climate and air quality was deficient because of inadequate data that was subject to large errors. It suggested that the impact of air pollution may have been underestimated as a result of these inaccuracies and because the synergistic effects of pollutants were not considered. The BV Naturalists also contended that using dispersion to deal with air pollution was irresponsible. It indicated that, as a minimum, a more detailed one year study should have been conducted. The BV Naturalists also stated that there was inadequate information about potential effects of land use changes on the hydrological regime in the vicinity of the proposed Three Sisters development.

The BV Naturalists contended that the vegetation assessment was of limited value because it was mapped at an inappropriate scale and used overly broad, heterogenous cover types. It also indicated that an ecological land classification, which was described as an "integrated, ecosystematic" approach, was preferable to the "single theme" approach adopted by the Applicant. Moreover, the lack of soils information was seen as a major deficiency. The BV Naturalists further suggested that the approach used by the Applicant was not suitable for assessing the impact of increased recreation on soils and vegetation, and considered the lack of 
such an assessment an additional deficiency. According to the BV Naturalists, the status of uncommon or rare plant species in the area is in doubt because the timing and methodology used in vegetation sampling was inappropriate. Other stated concerns included failure to adopt a consistent policy for old growth forest, failure to deal with fragmentation and its effects on forest interior species, and failure to consider the potential invasion of non-native plants.

A number of concerns were expressed about the avifauna portion of the EIA. These included inadequate and late sampling, failure to examine seasonal habitat requirements, failure to provide information about certain groups of birds, such as nocturnal species, water based species and species of special concern. The BV Naturalists were also concerned that the proposed project had not been altered to accommodate impacts on avifauna and large carnivores and felt that mitigation plans were not flexible enough to protect habitat for special species, such as the great grey owl, if they were found during the interval between project approval and construction.

There was also concern that forage enhancement projects did not constitute a suitable replacement for montane ecosystem components and that enhancement sites might be located in areas that were ecologically inappropriate because of high elevations or adverse soil characteristics. It also suggested that the concept of replacing habitat should be extended to include losses due to fragmented and alienated habitat, which cannot be used by wildlife.

The limitations of HEP used in the EIA were also a source of concern. The BV Naturalists indicated that the HEP models were inadequate because of the broad habitat classifications and generalized forage types used, the low level of sampling effort, and the use of HEP models that have not been validated. It felt that other biophysical characteristics, such as slope, soils, elevation, and aspect, should have been included as habitat characteristics in the models. The BV Naturalists also suggested that HEP, which does not consider the fragmentation or alienation of habitat, has significant limitations in defining habitat supply and predicting habitat related impact. It was also argued that HEP models were imprecise and tended to gloss over subtle but important ecosystem processes.

The BV Naturalists argued that several ecosystem processes had not been adequately addressed. These processes include aquifer response to water withdrawal, variability in climate, vegetation succession resulting from natural and human disturbance, dispersion of species and their genetic material, and migratory patterns of avifauna. It also indicated that the stabilization of alluvial fans and wildfire suppression were unmitigated interruptions of natural processes. The BV Naturalists also stated that the Applicant's focus on mitigating effects on profile species, such as bighorn sheep and elk was inappropriate and that mitigation should be achieved instead through ecosystem management. It also contended that it was the responsibility of the Applicant to develop plans to restore natural systems if altered tourism values resulted in the failure of the development in the future.

A number of recommendations, most of which were concerned with cumulative effects, were contained in the documents submitted by the BV Naturalists. The BV Naturalists 
believe that because of the complex jurisdictional situation in the area, an ecosystem approach to managing cumulative impacts is necessary. It suggested that this approach involve the identification of threatened resources, data collection, mapping, and modelling to determine independent and cumulative effects of development in relation to acceptable levels of disturbance. A monitoring program to compare the impact of current developments in relation to established thresholds was also suggested. The BV Naturalists indicated that such a plan might limit human activity in order to protect the ecological integrity of the Bow Corridor. As well, it contended that developments outside of protected areas must not be allowed to proceed at the expense of protected areas and believes that the applicants for any such developments should contribute financially to assessing and managing their impacts on protected areas.

Other recommendations of the BV Naturalists were that a risk management system for agricultural chemicals and a comprehensive, reviewable monitoring program be established by the Applicant. The BV Naturalists also suggested that government staff should be available to share information at NRCB hearings.

The BV Naturalists also commented on the possibility of a partial approval of the Application by the Board. It was the opinion of the BV Naturalists that there is only one development proposal before the Board and the same deficiencies that relate to the whole Application would not be removed by a partial approval. The final position of BV Naturalists was therefore described as one of no development and that no compromises or partial approvals would be appropriate.

Alberta Wilderness Association, Speak Up for Wildlife Foundation, and Adventure Group Ltd. (AWA Group)

The AWA Group presented information on vegetation and wildlife issues, geotechnical and mining issues, and economic issues in support of its position that the Application should not be approved. A representative explained that the AWA Group has had a long association with the planning of the Bow Corridor and has ongoing concerns about the piecemeal approach taken over the past twenty years or so. The issues of primary concern to the AWA Group, and the basis for its objection, were described as relating to the need for a full and thorough consideration before further developments are approved in the Bow Corridor. The AWA Group also had concerns about the quality of the Applicant's EIA.

The AWA Group expressed the opinion that development within the entire Bow Corridor should only proceed after the area has been subjected to a full, thorough and scientifically valid, planning team assessment and after those recommendations have been approved by the public. Without this type of planning, the AWA Group fears that the diverse wildlife base of the area and its natural appeal will be lost.

A particular concern was expressed for the protection of the Wind Valley-Pigeon Mountain-Ribbon Creek complex, where the AWA Group stated that it would not be able to 
condone any development. The Group argued that the Board should not grant approval for the project because the Three Sisters project area includes critical wildlife habitat and important migration or movement corridors which connect Kananaskis and Banff. Furthermore, impacts on water quality could affect extremely important trout spawning beds which are located in the Bow River adjacent to the Three Sisters site.

The AWA Group submitted that the Applicant had not considered and governed itself in accordance with plans and policies developed for the area such as the Kananaskis Country Integrated Resource Plan, The Eastern Slopes Policy, The Coal Policy of the Province of Alberta and The Calgary Regional Planning Commission Environmentally Sensitive Areas Study, most of which identify Wind Valley as important wildlife habitat. The Group requested the Board to consider these policies in its decision. It also requested that the Board take into consideration its contention that the Applicant's permits to construct Golf Courses A and B have lapsed.

The AWA Group believes that the Three Sisters development would create extensive and major threats to the conservation of remaining native habitats and biological diversity in the Bow Valley Corridor. It also believes that the mitigation proposals of the Applicant would result in disturbed natural areas, impaired wildlife habitats and habituated wildlife. Information was submitted to support these concerns in the areas of wildlife, wildlife habitat and water quality. The effects on bears and elk were described as well as the impact of various activities on a variety of wildlife resulting from golf course maintenance. The effects dealt with included habituation, urine burns, nitrate poisoning, physical turf destruction, ground squirrel control, adjacent land use impositions and killing and trapping of animals.

The AWA Group contended that golf courses are not good for wildlife because they cause habituation which results in expensive management, often by harassment of the animal through aversive conditioning, and often results in the destruction of the animal. Additionally, human-animal interactions on golf courses result in direct mortality of wildlife and mortality can occur from loss of habitat or from pesticide ingestion after animals have grazed on the golf course. It also contended that the elk forage enhancement sites and proposed thermal and hiding covers would be placed near or inside the development area and as a result encourage habituation by drawing animals onto the golf courses.

The AWA Group also expressed an opinion that habitat for non-habituated free ranging animals must be effective in providing security. It presented evidence to support its conclusion that habitat effectiveness is reduced by human activity and that roads and associated activities have the most significant negative influence on habitat effectiveness. It was concerned that the proposed Three Sisters project, including at least a two road system, would cause the site to become a dead spot or barrier to movement because of a near zero habitat effectiveness, especially for grizzly bears.

The AWA Group's experts were concerned that tertiary treatment might not be adequate to treat domestic sewage and that irrigation of the golf course with mine water, along 
with the use of pesticides and fertilizers, might decrease groundwater or surface water quality. It also saw a need to define and monitor indicator species in watercourses such as benthic invertebrates that would provide an early warning system of harmful effects on water quality.

The AWA Group indicated that the evidence put forth by the Applicant was inaccurate, inadequate and based on bad science and bad methodology. It pointed out that not all critical wildlife habitat on land originally owned by Three Sisters was exchanged with the government for other lands. Some critical habitat, as defined by Mr. Gordon Kerr when he was Assistant Deputy Minister of Alberta Forestry, Lands and Wildlife, remains on the property and includes the valley floor where Three Sisters plans to develop its resort, not just Wind Ridge and the steep, rocky slopes at the back of the valley.

Other deficiencies in the EIA and associated documents identified by the AWA Group include a lack of baseline data with respect to large and small animals, vegetation (especially rare and endangered plants), songbirds and fisheries. Lack of baseline information on hydrology was also identified especially with respect to low flows in the Bow River which would be most relevant for defining exposure to pesticide contamination and nutrient enrichment. The need for groundwater information was emphasized because groundwater is one of the main potential pathways for contaminant movement as pesticides and herbicides from the golf courses could eventually work their way into the Bow River.

The AWA Group believes that the EIA should have included a clear delineation of geographical and temporal scope with respect to the assessment of toxicology. It also thought it should have included a clear listing of assumptions and constraints associated with baseline data, movement and fate of contaminants data and toxicity data for pesticides. It indicated that there was no ranking of hazards associated with toxicity and no mitigation planning for buffers around tees, greens and fairways.

On a broader scale, the AWA Group believes that the EIA should have been addressed at an ecosystem level and should have looked at parameters such as diversity, relative abundance, productivity and habitat user food chain transfer. Additionally, it indicated that the EIA should have addressed incremental effects, especially to wildlife habitat, and cumulative impacts on an already stressed ecological area as the Applicant was required to do by the Board.

The AWA Group was concerned that there appeared to be a lack of commitment to environmental protection on the part of the Applicant.

The AWA Group contended that the Three Sisters area must be considered as a whole, and that Wind Valley could not exist unaffected if the development occurred elsewhere on the Three Sisters property. Although the AWA Group asked the Board not to grant approval to the project, it requested a number of recommendations in the event that approval was granted. 
The AWA Group identified the need for an overall comprehensive planning program and expressed a belief that development within the entire Bow Corridor should proceed only after the area had been subjected to a full, thorough and scientifically valid planning team assessment and after the team's recommendations had been approved by the public. If the Board decided to approve the proposed project, the AWA Group requested that it defer decision until a regional planning group was established to properly address the issues. The AWA Group indicated that it had long maintained that the existing hamlets and the Town of Canmore along with the urban fringe, are the most appropriate locations for intensive uses and related facility developments. The AWA Group recommends that developments such as the Three Sisters proposal be directed to existing communities outside of the national parks.

If approval was granted, the AWA Group requested that it be on the condition that serious deficiencies in the EIA be addressed prior to approval and the Board impose on Three Sisters a commitment by them to stop the development if ungulate populations are adversely affected by the pods, and that the determination of whether the populations are adversely affected be made by Alberta Forestry, Lands and Wildlife.

A submission and presentation were made to raise a number of concerns about geotechnical and mining matters. These concerns related to hydrodynamics in the undermined area and groundwater flow, groundwater chemistry, and subsidence. Information was presented to show that possible changes to the groundwater flow pattern and chemistry were not addressed in the Three Sisters EIA and important basic data are missing and have not yet been collected. It was therefore contended that a realistic assessment of the environmental feasibility and economic viability is not possible on the basis of the EIA.

The transport pattern of groundwater from the development area to discharge locations along the Bow River was demonstrated in a theoretical sense, using information available in the EIA. An argument was made that if development were to take place, downward movement of groundwater would be reinforced by recharge from irrigation. This pattern could result in greater discharge of groundwater to the Bow River and could have an effect on the spawning areas of fish. The analysis was limited to the groundwater system and there was no information on whether there would be an effect on the river water quality, or whether there would be a problem created for fish spawning.

The information presented by the AWA Group showed an expected contribution of heavy metals and sulphide from the mine drainage waters towards the river. A change in the chemistry of groundwaters was postulated as a result of the increased transfer of oxygen from the surface irrigation water which could be expected to move downward in the groundwater system. This was forecast to result potentially in decreasing $\mathrm{pH}$ values and an increase in the content of dissolved heavy metals; thus acid mine drainage could be a concern. It was submitted that there would be oxidation of pyritic material taking place, but it was also acknowledged that there would be buffering occurring as a result of an appreciable amount of carbonate also being transported. 
The potential for production of hydrogen sulphide by bacterial action and its accumulation in areas of low ground was also indicated as a concern. The effect was not expected to exceed nuisance levels and the chances of occurrence were estimated as very remote. As a result of all these concerns, it was argued that more investigation should take place of the basic characteristics of groundwater flow and chemistry before Three Sisters is permitted to proceed.

Concern was also expressed about the stability of undermined areas, particularly where increased amounts of groundwater flow and changed water chemistry could occur. It was contended that there is insufficient data for a clear understanding to be reached of the kind of subsidence going on. Slow subsidence was identified as a particular concern and frequent and regular monitoring of surface changes before development takes place over undermined lands was strongly recommended.

In areas that have been mined, potential development of servicing systems could also give rise to increased concern about breakage of supply lines. Other issues identified as receiving insufficient attention from the Applicant were the possibility of methane venting and of the potential accumulation of pesticides in groundwater. A strong recommendation was made that rigorous, in depth studies be conducted before approval of the Application is considered.

A submission and presentation were made by the AWA Group relating to the socio-economic aspects of the proposed development. The submission dealt with the treatment by the Applicant of the project benefits as presented in the EIA. An analysis of the estimated tourism benefits and of the basic assumptions of tourism demand was undertaken to refute the claims contained in the EIA. The Application was characterized as a housing development with a tourism appendage and primarily as a land development scheme. The analysis was used to support the conclusion that almost no useful information was provided in the EIA about the true economic implications of the proposal.

It was contended that, at the present time, "tourism is approached in a motherhood fashion rather than in a realistic context of demand analysis". The market demand analysis in the Applicant's submission was criticized as being inaccurate and lacking in supporting documentation. The trend forecasts of the Applicant's submission were criticized as lacking an economic basis for the assumption of continued straight line growth in tourism activity.

The AWA Group reached the conclusion that Canmore is unlikely to become a resort destination in the short run and, as a result, the Three Sisters proposal is unlikely to become economically viable as a tourism project in the near term. It was concluded from the numbers used in the EIA that the proposal is more likely to be fantasy than reality and could well have large costs associated with it, if permitted to proceed. It was acknowledged, however, that the offer of the Applicant to assume the servicing costs not covered by provincial grants would alter the economic cost picture from the Town's viewpoint. 
A number of concerns related to the possible preferences of the residents of Canmore were identified by the AWA Group. Analysis was offered to show that the future population growth of the Town might be very different from the estimates provided in the EIA. In particular, a shortage of workers in some key areas, such as construction, could occur, because Canmore already exhibits very high employment levels. Several alternative visions to the one presented by Three Sisters were suggested. These included a regional centre servicing both the Banff National Park and Kananaskis Country, a consultants' community, a bedroom community for Banff and perhaps an eco-tourism and adventure tourism centre for the southern Rockies. The conclusion was reached that the Three Sisters proposal should be reviewed in terms of Canmore's needs and not the other way round.

An opening statement and submissions dealing with all parts of the Application were made on behalf of the Town of Canmore. The Town also provided expert testimony on geotechnical and mining issues, and social and economic matters. The Town took the position that it cannot approve or disapprove of the Application during the period of the hearing.

The Town stated that its purpose at the hearing was to improve the quality of the information before the Board as a basis for decision making. For this purpose, the Town presented a review and comments on certain aspects of the Application and offered information on the past, present and possible future growth of the Town, as well as the current status of any applicable statutory planning documents and those in preparation. Information about the local planning process was reviewed and suggestions offered on how the possible approval of the Board could best be tailored to fit with the ongoing approval process under the Planning Act at the local level.

The Town expressed the view that land use and human settlement of any land is achieved in a continuum and that the local planning authority is obligated to stay involved through the planning, construction and operation stages of a development, whereas the Board approval process is an administrative one associated with a one time approval before the start of development. It was submitted that the Board should be aware that there are impacts of the development that cannot feasibly be delineated at this time and that will need to be dealt with through the ongoing planning process, for example, the incorporation of sound environmental principles into each stage of project design. It was explained that an environmental assessment is only a part of an ongoing, local, planning process wherein issues are addressed along with social, economic, financial and other matters prior to decisions being made. It was noted that the Planning Act requires the municipality to deal with community values and balance issues in the public interest without infringing on individual rights, except to the extent necessary.

It was pointed out that the traditional municipal approach to planning would, if followed, probably lead to incremental development of the Applicant's land and that the planning process might never address the broader question as to whether the development as a whole 
would be in the public interest. It was noted that s. 9 of the NRCB Act provides that the approval of the Board does not eliminate other necessary approvals and that these approvals would probably proceed sequentially according to some statutory framework such as an Area Structure Plan (ASP). At each identified stage, the Town would have to deal with each of the issues and segments to determine the municipal public interest at that time. Thus, the Town has framed its new General Municipal Plan (GMP) to be relatively neutral to any developments that may be proposed or imminent, in order that each can be assessed on its merits against the background of the plan.

The specific framing of any possible approval to be issued by the Board was described as a matter of some concern to the Town. It was noted that the Applicant had requested that the Board provide for "certainty of use" as well as maintaining flexibility. The Town provided a record of a resolution listing a number of questions that must be answered in the matter of public interest before the development can receive the Town's approval. In the Town's opinion, it would not be in a position to issue approvals, even if the Board should do so, because many of the questions have not been addressed or answered. On the other hand, it was stated that the request of the Applicant to receive a Board approval at a level of detail approaching an ASP might also pose problems if implemented through a Board order. An ASP is not cast in stone in the Town's view and it could be modified to fit circumstances over time, but a Board approval would not be open to change so that it could not take on the same flexibility as an ASP.

The concept of "certainty of use" as requested by the Applicant was described as being of more appeal to the Town, provided that "certainty of use" would not be interpreted to mean "permitted use" pursuant to the Planning Act. According to the Town, certainty of use could mean confirmation of land uses in the area, but subject to certain restrictions that relate to matters such as scale, density and location. The Town's position would not contemplate a "non-decision" by the Board, but if the Board chose to prohibit development on some part of the Applicant's property, then the Town would be obliged to work with that decision. The Town stated that it could work effectively with a decision which identifies the sorts of uses to be located in major parts of the area. It was noted, however, that if all land uses were determined in the Board's decision, and if all of the timing were to be decided, the public review process accompanying the future GMP and the various local approval processes would be meaningless.

The Town also expressed interest in receiving and considering Board recommendations to the extent that they are incorporated in a decision. Specifically, the Town would welcome guidance on such matters as monitoring of social programs, the creation of a recreational foundation by the developer, distribution of economic benefits, empowerment of the municipality to deal with employee housing service charges and land leases, negotiation of a private housing corporation with the developer, geotechnical and undermining constraints, water quality issues, air quality, and, if in a general form, visual impact. The Town considered the 
Applicant's request for a fixed location of a transportation corridor to be premature and that the request might be dealt with in a non-binding way by the Board.

The planning documents in force in the Town of Canmore and the then current draft of the Town's new GMP were reviewed and their status explained in relation to the history of the Three Sisters Application. The history of plans and planning approvals has apparently been complicated by the annexation to the Town of the Applicant's and other lands in 1991. The opinion was expressed that, while annexation to an urban municipality carries with it an implication of future development, constraints exist and any development would have to be reviewed thoroughly in the light of the statutory planning provisions in effect before approvals are issued.

The status, goals and content of the existing GMP and other applicable documents were reviewed. The Regional Plan was recognized as a superior guiding document. It was explained that several plans and by-laws of the MD of Bighorn still apply to the Applicant's lands and have effect as a result of the annexation until replaced. On the other hand, the Town's existing GMP was said to not apply to the area of the Application, except insofar as it demonstrates the present general intent of the Town with respect to development. The South Corridor Area Structure Plan, formerly of the MD of Bighorn, was noted as relating directly to the Applicant's lands. It was stated that the Tower Mountain Area Structure Plan, first presented by the Applicant to the MD of Bighorn, and a general master plan were received by the Town in 1990, but consideration of these documents was deferred until a number of background studies specified by the Town have been completed.

The new Canmore GMP was presented in a draft stage and was available for public discussion purposes. It was expected that public hearings would be held and the plan adopted some time in the early fall of 1992 . The new plan was described as providing a framework for planning and identifying parts of the Town suitable for the completion of an ASP, including the Three Sisters property.

The future application of the GMP to the Applicant's property was described as uncertain, depending on public input and possible revisions to the Plan. It would appear that at least portions of the Wind Valley part of the property are identified as being subject to considerable development constraints due to environmental considerations. Other portions of the municipality, within the Bow Corridor, were described as being suitable for an ASP.

Current applications and approvals were also reviewed to indicate the cumulative nature and extent of the growth currently taking place in the Town. The following were stated as having received approval or were under consideration: 531 single family housing units, 913 multi family housing units, and 722 hotel units, with an added 528 hotel units along with 1,533 dwelling units of various kinds expected at some time in the future. Other less certain developments in the Town and the MD of Bighorn were also mentioned by representatives of the Town. A Development Permit for Golf Course $C$ was said to have been issued, but a stop work order was said to be in effect and approvals on Courses A and B have lapsed. 
The Town stated that the work contained in the Applicant's EIA was comprehensive with some exceptions.

With respect to the wildlife component of the EIA, the material was judged to be thorough. However, there were some concerns on the part of the Towns expert's because the EIA did not place emphasis on the geographic areas within the development that showed heavy use by a variety of species. It was noted on behalf of the Town that the wildlife and vegetation impacts are not areas that the municipal planning authorities have traditionally dealt with and the Town would not feel comfortable trying to deal with these, or the broader ecosystem implications of either.

One other area of concern was the lack of an integrated biophysical description and assessment of the significance of environmentally sensitive areas such as Wind Valley. The Town was concerned that treatment of rare plants and microhabitats was superficial and vegetation monitoring and mitigation plans were incomplete. The information provided on fisheries and aquatic resources was believed to be insufficient to assess the potential for impacts on the aquatic environment. It was also stated that instream flow needs for the Bow River and affected tributaries were not well assessed; therefore, the mitigation measures described were judged to be inadequate.

A presentation was made to review the work conducted in the EIA and the Applicant's approach to classify lands subject to undermining and their suitability for development. The information led to the conclusion that the Town's experts had no problem in principle with the methods that have been proposed and that were being implemented for the construction of Golf Course C. The Town considered the Applicant's submission of a map showing the extent of mining in each seam including the location of charted mine portals, shafts, waste refuse areas, surface mined areas and reclaimed areas to be an important contribution toward risk assessment. According to the Town, detailed mapping at 1:5,000 should be completed as soon as possible. It was also suggested that the scale be increased to $1: 1,000$ for analytical purposes.

Various observations were made on a four stage proofing process proposed by the Applicant's experts and the need for as thorough a desk top study as possible in Stage One was emphasized. There was also a perceived need to implement a surface deformation measurement program to be implemented in areas of medium and high constraint at a frequency of at least twice a year. The most important inadequacy in the current data base was noted as the lack of information on the extraction height in coal workings. Ground truthing would be critical in determining sensitivity to this factor by means of a drilling program. It was stated that it would not be practical or cost effective to undertake such a program until the sensitive areas have been selected in the Stage One analysis. Concern was expressed that the ground truthing done on Golf Course $\mathrm{C}$ has not been adequate.

Some other actions were highlighted as being helpful in assessing the potential risks of locating development on undermined lands. These were measurement of mine water 
levels, use of down hole cameras, and durability tests. It was stated that all mine openings, both on and off the property, should be located and closed off as a public safety measure. The most important parameter on which insufficient information was said to exist is the width:depth ratio of openings and any ground truthing efforts that close this information gap would be of assistance.

It was believed that the Task Force formed by the Alberta Environment to formulate site specific guidelines for the undermined areas would be likely to produce an approach similar in philosophy to the four stage approach proposed by the Applicant's experts. The end products of the two approaches were expected to be compatible. It was noted that the Task Force is expected to have its work completed by the fall of 1992. It is also expected that the Town will be in a position to adopt the standards and constraints recommended by the Task Force, possibly as an alternative to the present constraints that only permit development where no risk is evident.

The Town made presentations and a submission on a range of social and economic matters related to the Three Sisters development and the wider implications of this and other developments for the future of the Town. It was pointed out that the Three Sisters development is characterized by uncertainty due to its scale, comprehensiveness and unknown demand, but the Town believes that, although the greater risk rests with the developer and the investors, the local authorities also face considerable risk, particularly in the early years and if the development does not materialize as anticipated.

Expert opinion was presented to the effect that the population, employment and municipal finance estimates provided by the Applicant should be considered as being optimistic. This analysis incorporated a number of assumptions that were considered to result in an overstatement of the potential benefits associated with the project. The Town recommended that the Applicant be required to front end the capital costs of providing services and operate them until they reach a predetermined threshold before the Town would assume responsibility. It was noted that the Town has no opportunity under the Planning Act to levy for such matters as recreation facilities and the monitoring of impacts, if such were agreed upon. It was also recommended that residential development in the Wind Valley should only proceed after a resort is built in order to reduce operating risk for the Town.

Information was provided that the Town's total population could be expected to increase by about 15,000 people over the next twenty years and analysis showed that the existing supply of vacant land is inadequate to meet the longer term growth needs. The importance of monitoring the changes as they occur in order to deal with the inherent uncertainties of the situation was emphasized. However, it was stated that monitoring would have budgetary implications and there may be some serious legal implications in the area of potential liability in the event that negative impacts occur. It also stated that the importance of monitoring potential problems should not be discounted, but that monitoring may not offer solutions when needed. As a result, it was suggested that negative impacts may not be dealt with until the effects are well under way. 
An overview of the present status and future needs of other hard services supplied by the Town was provided. Major upgrades to the systems for the provision of sewer and water were said to be needed whether or not the Three Sisters proposal proceeds.

The Applicant undertook to bear the costs of on-site and off-site hard services solely allocable to the Three Sisters development and not covered by provincial funding. This undertaking was welcomed by the Town, as was the Applicant's offer to bear some of the risks of operating the Dead Man's Flats facilities during the early years.

A number of features were pointed to as desirable tools for the Town to manage potential impacts resulting from the Application in the event of an approval. These included a mechanism for monitoring the direct and regional implications of impacts, greater authority to assess levies and charges to cover costs of providing hard and soft services clearly caused by the development, and a mechanism for determining fairness in terms of the costs assessed. With respect to the creation of a regional planning mechanism the Town's position was described as being one of support in principle. Within such a body, a split between the environmental and socio-economic groupings was recommended to minimize the cumbersome effects of size.

Mr. Haimila presented a submission for information purposes in the geotechnical and mining part of the hearing and took issue with some of the conclusions reached and mitigations recommended in the Applicant's EIA. The presentation identified the complexity of the undermining issue and the difficulty of assessing the safety of the undermined areas for future development. He described his position as having public safety foremost if development were to be contemplated and stated that the public should be well informed about the hazards.

In his presentation, Mr. Haimila recommended that the Town of Canmore should have a complete set of mine plans made available for public review. He provided a review of the various mining operations and produced maps to illustrate the extent and the nature of coal operations that have taken place on the Applicant's property. He noted that the problems of undermining extend beyond the Three Sisters property boundary near Canmore and, in the past, coal mining extraction took place in the more distant parts of the Applicant's property, for example in Wind Valley. Mr. Haimila agreed with the Applicant's and the Town's experts that the only way to address the problems is to undertake a comprehensive geotechnical study in critical areas, but it was his opinion that the work should be completed before any approvals might be given.

Mr. Haimila also expressed concern on the matter of methane gas seepage, questioning whether the issue had been properly addressed in the EIA. He also stated that he did not believe that adequate testing had been done to show that there has been no mine water contamination. In the light of all the above concerns, he asked the Board to impose a condition 
in its decision on Three Sisters requiring the execution of a financial instrument to cover predicted long term liabilities.

\section{7}

\section{Calgary Regional Planning Commission (CRPC)}

The CRPC presented a submission to the hearing and discussed a number of general planning matters related to the application of Alberta planning legislation to the Three Sisters proposal. The CRPC also noted a number of concerns about the conformity of the Application to the Regional Plan and made a number of recommendations for the Board to consider. It was the CRPC's position that the preparation of the Town of Canmore GMP should have been more advanced before the hearing took place in order to assist with the evaluation of the proposal. In addition, the CRPC expressed the view that the Board's conclusions should focus on general principles and direction, leaving the long term implementation to the land use planning process.

The relationship of the Regional Plan to local planning provisions was described by the CRPC, noting that the Calgary Regional Plan is the overall framework document in the planning hierarchy. The nature of the Plan was described as being that of a policy document, with some provisions that are mandatory, provisions which if violated would be the basis for a referral on the question of conformity, and some that are advisory in nature. The CRPC's submission contained recommendations, one of the purposes of which was to identify potential areas of conflict between the Application and the Regional Plan.

A number of provisions of the Regional Plan that would have application to the Three Sisters proposal were referenced including servicing, conservation and environment and public safety as well as several general planning issues. Regional servicing and transportation corridors were major servicing concerns. It was noted that the parkway road proposed by the Applicant would have significant impacts on the Trans-Canada Highway.

The CRPC's primary environmental concern was the conservation of regionally significant areas and wildlife. The CRPC's 1983 study of environmentally significant areas identified Wind Ridge as winter range for bighorn sheep and elk. The CRPC noted, however, that the critical ranges are in public ownership, thereby focusing some concern on the issue of limiting public access to critical wildlife habitat.

The issue of undermining was identified by the CRPC as a public safety concern. Constraint mapping was recommended as an important element in meeting the Regional Plan requirement that development be discouraged on hazardous lands, along with a rigorous in-field testing program. Other matters of concern were the potential for coal bed methane seepage and a perceived lack of adequate attention in the EIA to fire protection and prevention measures.

General planning concerns were raised relative to the provision of soft services such as recreation facilities and the need for the Applicant to negotiate with the Town, Alberta 
Environment and Alberta Transportation \& Utilities on the specific nature and design of future hard service improvements that might be needed. It was stated that the Calgary Regional Plan says little about socio-economic matters in any way that would provide significant constraints on the development. A provision in the Calgary Regional Plan was noted as encouraging urban municipalities to attract economic growth to balance their assessment and employment base and to develop economically balanced communities.

The CRPC made 12 specific recommendations and indicated that if these were required and implemented in the form of conditions, conformity of the project with the Calgary Regional Plan would be accomplished.

The recommendations dealt with the design of the parkway road, protection of wildlife movement corridors, control of public access to critical habitat lands, construction and site design, identification of geotechnical hazards, flood proofing, affordable housing, mitigation for highway disruption, emergency services, social needs, maintenance of water quality in the Bow River, and the need for a body to participate in the planning and development process in the Bow Corridor on behalf of the Calgary Regional Planning Commission members. In this regard, it was noted that the CRPC was bringing a perspective to the hearing that was broader than the Bow Corridor.

The CRPC supported a number of proposals made during the hearing for some form of ongoing regional advisory body. One model that was cited as a possible starting point for a multi-jurisdictional structure was the Elbow River Water Quality Task Force and Steering Committee, but the opinion was expressed that local interest groups should be included in any Bow Corridor structure. The Board was asked to consider providing a mandate and guidance on regional management as part of its decision. The need for a special growth management mechanism was not supported, because it was felt that existing planning mechanisms could be used effectively.

A number of suggestions were raised about the nature of an appropriate Board approval. Firstly, the Board was urged to focus on general principles and direction so as to make the decision as timeless as possible, thereby precluding the need for future amendments. Secondly, to the greatest extent possible, implementation should be delegated to planning bodies best positioned to undertake the planning tasks as they arise. Thirdly, the CRPC suggested the need for a mechanism for review of the Application if approved, because of the length of time to project build out. In this regard, the CPRC thought it would be helpful for the Board to establish clear thresholds and standards which, if not met, would trigger a further review of the project, or require a re-application to the Board.

\subsection{Federation of Alberta Naturalists (Alberta Naturalists)}

The Federation of Alberta Naturalists was described as an organization of member clubs, many of which are local. It expressed general concern about the proposed Three Sisters 
development, but the part of the project that encroached on Wind Valley was the principal concern of the Alberta Naturalists. The organization believes that Wind Valley represents a rare and complete ecosystem, which will be negatively affected by the proposed project.

Alberta Naturalists indicated that Wind Valley provides critical wildlife habitat and contains some of the most productive habitat in Alberta for bighorn sheep. A specific concern appeared to be the potential cumulative impact of the proposed Three Sisters development combined with other proposed developments, and the impact of hunting in Wind Valley. The Alberta Naturalists expressed concern that these cumulative impacts would increase levels of stress in bighorn sheep, which could result in decreased levels of reproduction. Other wildlife concerns expressed by the Alberta Naturalists included the potential alienation of large predators from portions of their range and the potential for conflicts with humans. Alberta Naturalists also felt that the Applicant had not adequately addressed potential impacts on the wolverine and cougar.

Alberta Naturalists was also concerned that corridor blockage would interfere with movements between Kananaskis Country and the Bow Valley by both wildlife and hikers; however, it believed that the current level of foot traffic was already producing undesirable effects.

The potential use of water sources for irrigation was a further concern of Alberta Naturalists. It suggested that irrigation demands for the proposed Three Sisters development could lead to the construction of dams to regulate seasonally fluctuating water flows. It indicated that this would adversely affect upstream semi-aquatic animals and could affect fish inhabiting reaches downstream of the project.

Alberta Naturalists initially indicated that it would not oppose the project if irrigation concerns were overcome and the Wind Valley portion was eliminated from the development. It suggested that the area near Canmore be developed first because this would allow more time to obtain information about the potential impacts of development on Wind Valley. In its closing statement, the Alberta Naturalists said it was no longer able to recommend approval of any part of the proposed project.

Alberta Naturalists indicated that biophysical information about the area covered by the EIA contained enormous gaps and is so far inadequate for planning and mitigation purposes. The Alberta Naturalists recognized that the collection of such information should not be the sole responsibility of the Applicant but suggested that the Applicant bear a proportionate share of the responsibility and cost of obtaining adequate data. Alberta Naturalists believe that there is a need to identify areas requiring special consideration, such as those supporting rare or endangered species, or important breeding habitats. It also suggested that a number of technical committees, each responsible for a specific group of plants or animals, be established for this purpose. 
Alberta Naturalists was also concerned that mitigation efforts might decline if the management of Three Sisters changed hands. Suggested solutions included conservation easements, reclamation bonds, and mechanisms for considering the constraints to be applied at each stage of development. Alberta Naturalists recommended that the project be developed so as to avoid expensive reclamation and restoration in the future. The Alberta Naturalists also supported the concept of a regional advisory committee and offered some insights as to the role and composition of such a committee.

Northern Light Society (Northern Light)

Mr. C. Saunders stated that Northern Light became involved because the area is special to most Albertans and Canadians and because remaining wild land is becoming scarce. Effects on the quantity and quality of water available to downstream users was also of concern to him. He stated that developing a significant amount of land as proposed by Three Sisters would destroy the natural features that people have been coming to Canmore to enjoy. It was his contention that the situation should be looked at more holistically and from the point of view of need as opposed to desirability. In particular the cumulative effects should be taken into account.

Concern was also expressed about the potential effects of chemicals transported through groundwater. A number of illustrations and examples were used to demonstrate the effects in various locations. The opinion was expressed that the chemicals proposed for use by Three Sisters are deadly. It was argued that the development should not be approved and that if parts were to receive approval, the Wind Valley and Stewart Creek area should be protected.

Ms. Belyea was opposed to the development. She cited the critical state of the Bow Valley and the potential for it to become an ecological washout, if Three Sisters is permitted to proceed. She argued for the preservation of the natural inheritance and the fundamental values inherent in the views of the unspoiled valley. She believes that Canmore residents should have the final say in saving what they have inherited.

The objective of the Trail Association was described as being the creation of a foot trail or hiking trail route across Canada which would function as an environmentally protected corridor. A representative of the Association described the close cooperation shown by the Applicant and the willingness on its part to designate trail routes. 
Trout Unlimited (Canada), The Upper Bow Valley Chapter of Trout Unlimited (Canada), The Upper Bow Valley Fish \& Game Association and Banff Fishing Unlimited (Trout Unlimited Group)

Trout Unlimited (Canada) is a national organization with over 3,000 contributors whose stated priority is to work in partnership with industry, business, government, landowners, anglers and other stakeholders that want to participate in a proactive effort to enhance and protect cold water fisheries. The Trout Unlimited Group believes that part of its role is to ensure that development is undertaken on a more sustained basis and it considers the maintenance of biodiversity and ecosystem integrity appropriate goals for land use planners. Thus, it believes that management should be conducted on an ecosystem basis and that processes, such as energy and water flow, nutrient cycles, and natural disturbances including fire, flood, and drought, should be recognized and considered in management decisions. It also believes that research and monitoring programs are essential elements of good management. The Trout Unlimited Group contended that management systems in the past have tended to look at developments in isolation and that fish habitat has been degraded or destroyed as a result. However, it also stated that the differences between ecosystem and planning unit boundaries make it difficult to manage cumulative impacts. It also contended that the developers do not have the capacity to consider the big picture and that this is the responsibility of the Board. Although it stated that fisheries concerns were probably not sufficient to reject the Application, the Trout Unlimited Group urged that the NRCB err on the side of caution when considering the Applicant's proposal.

The Trout Unlimited Group was concerned about the cumulative loss of fish habitat and contended that further small losses were unacceptable because, when they accumulated over time, fish habitat and especially trout habitat was degraded. It considered trout habitat, which it said occurred in only about a millionth of the earth's flowing, cold, fresh water, to be a fragile resource and noted that trout populations in mountain habitats have suffered serious declines as a result of golf course developments.

The Trout Unlimited Group indicated that because of inadequate information supplied in the EIA, it was unable to support the project as outlined. However, it thought it was entirely possible for the Three Sisters development to maintain or even enhance fish habitat. It believes that stakeholders should be involved in the design of the golf courses and suggested that a stakeholders advisory group, which would consider development in the area, be created.

The Trout Unlimited Group's submission consisted primarily of an extensive literature review covering two principal issues, potential risks to the aquatic environment from golf courses and deficiencies in the Applicant's EIA.

The Trout Unlimited Group reported that it was able to reach three significant conclusions about golf courses and fisheries from its literature review. The first of these was that it was possible to construct and maintain golf courses that have minimal effects on the aquatic environment as long as environmentally friendly options were chosen. The second was 
that at least 16 potential detrimental impacts of golf courses on fresh water environments had been identified. The third conclusion was that only limited information was available on these potential impacts. Its submission also contained recommendations, which were obtained through the literature review, to deal with the 16 impacts.

The 16 potential impacts listed by the Trout Unlimited Group fall into five general categories: (1) the contamination of water, (2) elevated water temperatures, (3) the alteration of flow regimes, (4) the removal of buffer strips along water courses, and (5) the effects of soil compaction on streams fed by groundwater.

Although the Trout Unlimited Group indicated that Three Sisters had done a good job of ensuring that the design and operation of the golf course would minimize contamination of aquatic systems by chemicals, it took the position that contamination from chemicals was the most controversial issue. It was suggested that, compared to other land uses, the impact caused by golf courses was similar to that of residential development. Further, because Alberta Environment does not have the authority to prevent the use of any chemicals registered for use in Canada, the Group argued that it would be possible for Three Sisters to control moulds by using mercury based chemicals, which are a health concern in even small amounts. The Trout Unlimited Group was also concerned about the contamination of aquatic systems from pesticide runoff and leaching into groundwater. A further concern is that some of the proposed chemicals could affect the reproductive capability of fish by reducing the amount of aquatic vegetation and populations of invertebrates.

The Trout Unlimited Group was also concerned that the golf course could result in increased erosion and sedimentation, and the channelization of streams. It stated that these impacts could reduce the value of water courses for spawning. It was further concerned that an increased human population and tourism could lead to increased fishing pressure and declining fish stocks unless proper fisheries management procedures were implemented.

The Trout Unlimited Group contended that the major deficiency in the Applicant's EIA was a lack of detail about the fisheries resource and a lack of site specific information with respect to development, and suggested that these deficiencies could compromise the value of the NRCB hearings. A lack of information about the design of Golf Courses A, B, and D and inaccurate information contained in the EIA about existing land uses in the area represented additional deficiencies in the opinion of the Group.

The Trout Unlimited Group also believes that the aquatic resources of the area are susceptible to contamination from chemicals applied to golf courses and stated that a discussion about safeguards to prevent the contamination of dry ephemeral stream beds was lacking. The Trout Unlimited Group also stated that the 25 meter (m) streamside buffers proposed by the Applicant were insufficient and that the Applicant should be required to explain the rationale for not including streamside buffers along tees, fairways and greens. 
Several deficiencies in the Applicant's fisheries inventory were mentioned. These included the failure of the EIA to deal with several fish species, including the bull trout and mountain sucker which are classified as vulnerable, and a failure to discuss streams in which brook trout spawning has been documented. The Trout Unlimited Group also stated that the Applicant had prematurely concluded that the reach of Pigeon Creek above the falls was barren of fish. It contended that fisheries mitigation procedures other than changes in fishing regulations should be considered and suggested that habitat enhancement and stocking were other potential mitigation methods.

The Trout Unlimited Group stated that the Applicant's EIA should have directed greater attention to the cumulative impact of development on fisheries. It suggested that increased pressure and restrictive angling regulations in the vicinity of the Three Sisters development could displace anglers to Banff National Park and Kananaskis Country, resulting in greater fishing pressure in those areas. The Trout Unlimited Group also indicated that increased fishing pressure as a result of the Three Sisters development could cause a further decline in the brook trout population. It believes that, in contrast to the Applicant's view, Bill Griffith Creek and the surrounding Canmore Flats Natural Area would experience increased tourism as a result of development and the project may therefore pose a significant risk to brown and brook trout that spawn and incubate there.

A further concern of the Trout Unlimited Group was a lack of sufficient information about the instream flow needs of Pigeon Creek and the Bow River. It indicated that there could be a significant impact on the Bow River fishery downstream of the proposed project by reducing flow rates in the Bow River by about six percent. It also stated that the Applicant did not adequately address the impact of its irrigation demands on the Pigeon Creek drainage. Failure to address the effect of urbanization on streams was considered an additional deficiency and it was indicated that the diversity of invertebrates in urban streams is only about one-half of that in rural streams. The Trout Unlimited Group also considered the failure of the Applicant to consider benthic invertebrates and fish in its monitoring plan a deficiency. The Trout Unlimited Group also contended that the construction timing constraints for brook trout contained in the EIA were in error. It noted that the EIA recommended that construction not proceed between September 15th to December 30th but stated that a period of August 24th to December 30th was more realistic. The unauthorized installation of culverts by the Applicant was also a concern of the Trout Unlimited Group, which contended that it raised doubts about Three Sisters' willingness to abide by regulatory conditions.

The Trout Unlimited Group suggested that the following issues needed to be addressed before firm recommendations could be made: (1) the source of irrigation water, (2) the impact of water withdrawal and urbanization on streams with fishery capability, (3) the capability of holding ponds to control storm water runoff, (4) the impact of the project on ground and surface water hydrology, and (5) the provision of the final draft of the Integrated Pest Management plan. 
The Trout Unlimited Group indicated that Three Sisters appeared to be prepared to follow most of the recommendations to reduce nutrient loading that were found in the literature; however, because there are no firm plans in place, the Group believes that some of these recommendations would not be considered by the Applicant.

The retention of streamside buffers at least $30 \mathrm{~m}$ wide was the principal recommendation of the Trout Unlimited Group, which stated that the $25 \mathrm{~m}$ buffers proposed by the Applicant were inadequate. It also stated that the Applicant should be required to maintain buffers along tees, greens, and fairways because without them, there was potential for pesticides to be applied in potentially vulnerable areas. The Trout Unlimited Group indicated that the most effective buffers were 20 to $50 \mathrm{~m}$ wide and believes that a $30 \mathrm{~m}$ buffer as recommended by the Alberta Fish and Wildlife should be used by the Applicant. It suggested that a $30 \mathrm{~m}$ buffer would help reduce the contamination of streams by filtering pollutants, reduce erosion and sedimentation, and help to maintain proper water temperature by reducing heating by direct sunlight. It also reported that fallen woody debris from buffer strips created many of the pools required by overwintering fish. A discussion about buffer strips indicated that it might be feasible to determine the width of effective buffer strips on a site-by-site basis. Other recommendations for the protection of aquatic habitat included the provisions that only two fairways be allowed to cross the stream within $300 \mathrm{~m}$ of each other, that fairways cross streams perpendicularly, that fairway construction not involve filling or grading of buffers, and that other facilities not be located within buffers.

The Trout Unlimited Group stated that, in order to prevent elevated water temperatures, there should be no construction of on-channel ponds, water withdrawals should be restricted, and runoff from impervious surfaces should be controlled. It also recommended that the Applicant be required to maintain pre-development flows and stream channel morphology to prevent erosion and protect spawning habitat.

Several recommendations were made about Pigeon Creek. One of these was that fish habitat in the upper Pigeon Creek drainage be protected to allow the reintroduction of cutthroat trout. It noted that populations of cutthroat trout are declining throughout most of their range and that Pigeon Creek was proposed as a reintroduction site by Alberta Fish and Wildlife in the past. The Trout Unlimited Group also stated that annual electrofishing surveys of Pigeon Creek proposed by the Applicant should be increased to twice yearly (spring and fall) because of the migratory nature of some fish species. It was also contended that the instream flow needs of Pigeon Creek need to be assessed before licences for water withdrawals are granted.

The Trout Unlimited Group believe that the impact of contaminants on aquatic resources would be small if its recommendations were followed but stated that the mitigation strategy proposed by Three Sisters would not be as effective. As a result, the Trout Unlimited Group indicated that some replanning was needed to minimize the impacts of golf course development on the aquatic environment. It therefore recommended that Three Sisters address the concerns of the Trout Unlimited Group before approval for the proposed project is granted. 
3.13 Government of Alberta - Alberta Tourism, Parks and Recreation (Tourism, Parks and Recreation)

Consultants who prepared two reports for Alberta Tourism, Parks and Recreation presented their reports at the hearing. Alberta Tourism, Parks and Recreation took no position on the Application but was described as being in support of tourism development generally throughout the province. The reports presented were: the "Bow/Canmore Area Market Demand Study" and " The Case for Tourism Employment: How Beneficial?".

Within the reports, it was stated that the Bow/Canmore area has long been identified as a region of significant tourism potential and therefore a study was commissioned to determine what types of tourism products would be best suited to the market demands and projections. It was believed that the area is in a unique position of having little development in place and thus being able to learn from, and avoid, the mistakes of others.

In the Bow/Canmore Area Market Demand Study, market trends were examined and a number of facts determined in relation to various other parts of the world. Several world wide trends are expected to take hold in the Bow Corridor. The time and value conscious consumer is expected to demand quality facilities; future consumers are expected to desire a central booking agency; markets in the shoulder seasons are expected to fill out; increased marketing expenditures will likely be required; and suppliers are expected to concentrate on niche markets. The basis for competitive positioning was examined across a variety of tourist activities and several specific recommendations made about actions to be taken in future.

It was concluded by the consultants that Canmore is presently an overflow area and a service centre for Banff and carries a much less attractive image than Banff. A synergy between the two communities was noted. The Bow/Canmore area is expected to become a resort destination and will ultimately encompass several different types of resorts serving several market niches. One of the greatest strengths of the area was considered to be its land base and resources, but the available facilities were seen as needing some improvements. The market was stated as offering good, long term potential for the development of the Bow/Canmore area as a major, international resort, destination area, which the proposed Three Sisters development would strengthen, if an approval were to be given.

The second report dealing with the economic case for tourism development used an economic model to estimate the potential benefits of the Three Sisters proposal. One of the key objectives of the study was to demonstrate the importance of direct, indirect, and induced employment resulting from the construction and operation of major tourism projects. A number of economic indicators were used to estimate the benefits of the tourism sector to the provincial economy and the potential regional and local impacts of the proposed Three Sisters development.

The Tourism Economic Impact Model (TEIM) was described as being based upon input-output analysis. It was stated that the model was not employed to estimate the net benefits 
of the Three Sisters Application as compared to alternative developments because no well-defined set of alternatives was available for this purpose.

The Three Sisters analysis was prepared as a case study and as a basic focus for the work as a whole. The case study concluded that the impacts of the proposed Three Sisters development in terms of capital and infrastructure expenditures would be similar and that the ratio of provincial to local impacts would be large. This result was not considered to be surprising because the economy of Canmore was described as being too small and too limited to sustain the level of capital expenditures required by this project.

The three levels of government were described as gaining substantial tax revenues irrespective of the type of expenditure. However, because the same tax revenues are not typically spent in the region where they are collected, they represent potential leakages from the provincial economy. The report concluded that tourism has emerged as a major generator of employment opportunities, income, government revenues, induced investment, export earnings and foreign exchange, as well as a viable instrument of regional development.

\subsection{Government of Alberta - Alberta Municipal Affairs (Municipal Affairs)}

A report was submitted by consultants working on behalf of Municipal Affairs and a presentation was made on behalf of the Department and Tourism, Parks and Recreation, both of which sponsored the preparation of the report. It was explained that the report, "Bow Corridor Employee Housing Study", was entered for information purposes, since its subject matter was related to the present and future management of the housing problems in the Bow Corridor. Municipal Affairs did not take a position on the Three Sisters Application.

It was explained that the impetus for the report was the recognition that a problem related to the provision of affordable and accessible employee housing did exist in the Bow Corridor and that there exists the potential for it to escalate. One of the key aspects of the report was the examination of the problem of providing employee housing beyond the needs of the young, seasonal employee. Data collection and issue identification work was undertaken with the assistance of the Corridor municipalities, workshops and open houses. The situational analysis prepared as a part of the report identified a number of issues, including: high land and servicing costs, increasing spillover effect from Banff, shortage of low to middle income affordable housing and rental accommodation, and increasing demand for second and retirement homes.

The following employee housing mechanisms were identified as preferred options: an employee housing service charge, a joint public private venture, the use of development agreements to obtain suitable housing, regulatory controls, non-profit housing cooperatives and ground leases. A program of implementation was also described, calling for immediate, near term and long term strategies to be put in place to solve any observed problems. The report noted a concern with down valley effects exhibited by resort communities elsewhere; this effect 
is said to occur where few of the people who work in a resort community can afford to live there and must live in less expensive communities nearby. The authors of the report hope that their information will assist the Bow Corridor municipalities to deal with emerging problems before a potential shortage of affordable housing can become a problem for the urban fabric of the Bow Corridor.

Municipal Affairs' consultants stated that the most important recommendation in the housing report for the Board to consider would be the possibility of acquiring land in some way for the municipality, or a housing agency, in order to implement the proposed mechanisms. The consultants expressed a preference for the creation of a municipal housing corporation to allocate and distribute affordable employee housing units. They also urged the Town to actively pursue some type of employee housing service charge with various forms of commercial development. It was also suggested that Three Sisters be asked to assist in the monitoring and assessment of the current housing supply and demand to determine the types and numbers of units required.

Bow Valley Women's Resource Centre (Women's Resource Centre)

The Women's Resource Centre made a written submission and appeared at the hearing as a result of its concern for possible social and economic impacts of the Application, particularly as these potential impacts might affect women and children. The Women's Resource Centre was concerned that the proposed development would have a significant impact on its members and programs, as well as on the Town of Canmore. Representatives explained that the Centre was not opposed to the project, or against employment creation in the community, but stated that some changes in the proposed project should be required. The Women's Resource Centre noted four areas of concern for their membership: housing, employment and income, daycare, and the destabilizing effects of rapid development and growth on a community. The Women's Resource Centre presented information on the potential community impact of the development in terms of these issues.

The Women's Resource Centre was founded in 1982 with the objective of serving women of all ages and to provide support in the areas of culture, health, community and youth services. It stated that it provides community referral services wherever possible for personal and family problems, as well as involving women in a variety of community volunteer work. It was explained in this context that most of the concerns about the Application came from these areas of community involvement. Specifically, the Women's Resource Centre prepared a housing assessment and a community impact study in order to assess the work included in the Application on these matters.

The housing assessment by the Women's Resource Centre gave rise to a number of their concerns in terms of inconsistencies, flawed calculations and unanswered questions, particularly regarding population and housing demand projections, affordable and suitable staff housing, day care, transportation and project phasing. It was recommended by the Women's 
Resource Centre that Three Sisters be required to provide suitable and affordable housing for its employees, that an on-site day care facility for the children of its employees also be required, and that Three Sisters provide a transportation system connecting staff housing areas, work sites and the Town of Canmore.

The issue of affordable housing was dealt with at some length. It was stated that the rental market in Canmore for single persons or single parents is very difficult at present and that the Three Sisters project can be expected to make it worse; in some cases a single parent might expect to pay up to about 60 percent of income for housing accommodation. The Applicant's planned percentages of housing types were not expected to provide adequately for people expected to be in the low to modest income categories.

It was stated that the Three Sisters housing policy assumes that the vast majority of its staff will be either single or willing to share with another staff member, but that no staff accommodations were planned for married and single income families with children. The proposed housing mix was said to force these groups to seek accommodation within the Canmore market, thus making the current housing shortages worse in future. The Women's Resource Centre therefore recommended that the Applicant be required to alter the housing mix designated in the pods to provide more low to medium income accommodation and avoid problems indicative of ghettos and stratification of income levels.

The Women's Resource Centre stated that Canmore already has some boom town characteristics. Strains were suggested to be evident in the fabric of the social structure, community systems and culture. According to the study, these strains are particularly experienced by women, who have a stabilizing and integrating effect on the social life of the community. The Women's Resource Centre expects that the Three Sisters project will greatly increase these strains. It was argued that the project will have a disproportionate effect on women because tourism employs a large number of women at low income levels and the needs of women were not addressed adequately by the Applicant.

A number of mitigations were suggested by the Women's Resource Centre. A vehicle to involve resident participation in the planning and control of development was desired. Investigation of additional and alternative avenues of economic and tourism development were also desired, including consultation with other resort communities with experience to share. The Applicant, it was stated, should be required to provide for on-site day care and to create staff housing that meets the needs of those employed directly by the project. It was believed that the developer should be asked to support Canmore services to the greatest extent possible and to try to influence the ultimate operators of the facilities to follow progressive social and employment policies.

It was noted that two major characteristics of small town living are the availability of community support and the involvement of residents in their community. Canmore was described as being unique in its current liveability and there is a real fear that Canmore will grow to be like Banff. It was contended that one of the basic elements that suffers in a boom 
town environment is liveability, wherein the economic benefits of growth bring a decline in a variety of measures relative to the quality of life. Conflict was said to increase with social breakdown and, at the same time, newcomers were identified as having different values, and hence, a potential desire to change the community. It was proposed that women in Canmore want controlled growth and want continued control, hence their recommendation that a vehicle be created for resident participation in the ongoing planning process.

One of the basic problems for women in boom towns, according to the Women's Resource Centre, is a lack of reasonable job opportunities. Low wages and job insecurity were seen to leave women unable to pay high rents and living costs. Work in the tourist industry was described as being hard on women in particular, requiring both shift work and split shifts, hence the Women's Resource Centre recommended a requirement to provide child care facilities and special transportation to the job site. In this regard the Women's Resource Centre acknowledged that the Board could not be expected to resolve the gender equality question. However, it was recommended that the Board require the Applicant to put in place some of the employment, employee participation and management policies referenced in the Three Sisters submission, along with an educational and advancement policy for locally hired women. In addition, the Women's Resource Centre requested the Board to require the Applicant to provide suitable staff housing for women and, in particular, single mothers.

The Women's Resource Centre supported the Applicant's proposals for a social monitoring program, but saw the responsibility as not being entirely that of Three Sisters. It was asserted that other developments will cause equivalent problems and therefore it was recommended that the Town take responsibility for the monitoring program. The Town was perceived to have the vehicle to undertake the task through its Family and Community Support Services and its new Social Planning Goals. It was further stated that it would be of assistance if a reserve fund were to be set aside in trust to respond to anticipated social stresses.

\subsection{Three Sisters Property Owners \& Residents Association (Property Owners/Residents Association)}

The President of the Property Owners/Residents Association, Ms. Freels, explained that the Property Owners/Residents Association was incorporated in 1992 to act as a representative for the people of the Hamlet of Dead Man's Flats. The group was described as consisting of small business operators and residents who are mostly employed in local businesses. Many residents are said to be approaching retirement and concern was expressed because two businesses have closed recently. The Property Owners/Residents Association supported the Three Sisters Application.

The Property Owners/Residents Association said that it reviewed the environmental impacts of the development, including the loss of grizzly bear and other habitat, the Applicant's proposed mitigation measures, and the development pressures on the Bow Corridor. The Association referred to environmental damage that has already occurred including 
tree cutting, poaching and damage from four wheel drive vehicles. On balance, it was expected that the development would bring back pleasant conditions. The Association also suggested that environmental protection, including the possible banning of weed killers and fungicides, should be instituted through development and operating permits.

It was concluded by the Property Owners/Residents Association that the economic benefits of the project cannot be overstated in these difficult times. However, it was suggested that additional mitigation opportunities be considered, such as a hospitality training school, and requested that the Applicant increase the component of small scale, family operated business opportunities in the plan. The Applicant's willingness to welcome community input was considered to be positive.

The Association also referred to efforts that had been made to deal with the need for low cost housing by building condominiums intended to be marketed at $\$ 55,000$ per unit. However, the general shortage of this sort of housing and demand from Calgary was said to have forced prices up to about $\$ 75,000$ per unit. The Three Sisters project was viewed as assisting with this problem.

\subsection{Bow Corridor Organization For Responsible Development (BowCORD)}

BowCORD is an association of Bow Corridor residents who advocate a responsible approach to development of the region. The association has about 250 members in the Canmore, Bow Corridor and Calgary areas who recognize a common bond of interest in the future of the Bow Valley. The association presented information in the hearing relating to community planning and the socio-economic impact of the Three Sisters proposal. BowCORD urged that the Board should not approve any part of the Applicant's proposal under any circumstances because it was fundamentally not in the public interest due to the likely adverse social and economic effects upon the local community. BowCORD also submitted that there would be no benefit to the Province of Alberta that would justify any form of approval.

The submission focussed on local values and concerns of a social and economic nature, but recognized that these had to be placed in a regional context. A refusal to approve the project at this time was advocated as a means of preserving options for the future of Canmore as well as the other communities of the Bow Corridor. In BowCORD's view, denial of the Application would permit the Town to develop a vision for the future through its new GMP and other means and would be consistent with the wishes of the people to the extent that such wishes have been expressed through various surveys.

In this regard BowCORD referenced Three Sisters' own survey and the Praxis survey conducted on behalf of the Town, stating that this latter survey concluded that there was a consensus in the community that priority should be placed on Canmore's quality of life and the need for environmental protection. There was a stated desire to see quality development and stringent development controls. A number of other documents were referenced to demonstrate 
that the vision of the Applicant as described in the Application would, if approved, come into significant conflict with the community's vision of its own future.

BowCORD's submission was divided into two parts. The first part evaluated the Application from a community and tourism development planning perspective. The thrust of this evaluation was to examine whether there are ways that the process for community planning generally, and the Three Sisters project in particular, could be improved from local and provincial viewpoints. It was noted that growth rates in the Town have exceeded five percent in recent years and annual rates of 10 percent are generally considered dangerous to the fabric of any community. BowCORD said that the Three Sisters proposal will push growth rates to this level and will absorb almost all of the remaining developable lands within the Town. This, it was asserted, will void the community and regional planning processes in favor of the developer's view of the future.

It was observed that the large scale of the development proposal compared to the present size of the Town makes the potential future of the community, as envisaged by the Applicant, radically different from its present or recent past. According to BowCORD, expectation of rapid change has sparked discussion and debate about the Town's future. The project, it was stated, also has the potential to change the area well beyond Canmore's boundaries. BowCORD concluded that Town residents have not yet had an opportunity to consider fully any realistic alternatives for the future, or the benefits and costs associated with each of the possible alternatives. It maintained that the scale and density of development proposed by Three Sisters, and in particular the Wind Valley resort, is not consistent with the South Corridor Area Structure Plan.

BowCORD suggested that the preferred method of exploring options for the future is for the community to arrive at a vision, or preferred future, through an open process of discussion and consideration. In the case of Canmore, BowCORD stated that the community is still divided as to its preferred future. Hence, the process should not be reduced to a choice of approving or rejecting a development that represents only one of several options available for the use of the subject property. The group offered a rationale for this position, on the basis of which it was concluded that the real issue is the way in which the future growth of Canmore can be effectively managed. Within this perspective BowCORD acknowledged a need for development of additional land for urban uses, but stated that the real issue is the form and pace of development that will yield the best net overall results for Canmore. According to BowCORD, the existing proposal may or may not be the best use of the lands from local, regional or provincial viewpoints, because the impacts have not been adequately assessed.

From the provincial viewpoint, existing policy documents in the form of the Bow Corridor Local Integrated Resource Plan and the Tourism Development Framework were reviewed. BowCORD concluded that the documents leave a wide range of opportunities for developers and communities to work out the kind and scale of development that should actually occur. BowCORD stated that the absence of a provincial strategy carries with it the risk of decisions being made on a project by project basis. No process was said to exist for the 
systematic evaluation of a full range of tourism and recreation opportunities; hence, it was concluded that the best combination of benefits for the communities of Alberta is unknown.

The second part of the BowCORD submission consisted of an evaluation of the socio-economic impacts of the proposed project. BowCORD forecast a substantial negative impact on Canmore and the Bow Corridor as a result of the Three Sisters project. The effects were identified as a large influx of people that would increase the population four to six fold, employment increases that would benefit outsiders, a decline in the average real income of households, a significant increase in the cost of housing and living and a large increase in the number of non-permanent residents.

According to BowCORD, the benefits and costs of the proposal should be evaluated with respect to the preferences of existing Bow Corridor residents. The Organization contended that surveys have shown that the residents of Canmore prefer to maintain their small town lifestyle and that the increases in population, employment, business and property values proposed to be generated by the Three Sisters project should be viewed as costs rather than benefits because they threaten this lifestyle. In addition, the association submitted that the project also threatens the environmental quality of the community.

According to BowCORD, the Three Sisters project will not contribute to economic diversification of the province. The Three Sisters EIA has exaggerated the benefits to the provincial economy by assuming that all the economic activity generated by the resort would be new. It was contended that if displacement effects were taken into account, the net positive impact would be much smaller. It was further argued that the socio-economic analysis manipulated the assumptions and data in arbitrary and inconsistent ways in order to maximize apparent benefits and minimize the costs. In support of this conclusion the BowCORD submission re-examined employment benefits, and the impact of the project on housing prices and on local taxes.

The Association was also critical of the information provided by the Alberta Tourism, Parks and Recreation using input-output analysis on the impact of tourism. It was submitted that such analysis is not an appropriate way of measuring the value of tourism to the economy because the method double counts many of the expenditures rather than measuring the net of alternative expenditures that would otherwise be made elsewhere within the province.

BowCORD indicated that it supports responsible development, but in its opinion, the Three Sisters proposal is too large for the existing planning and community framework to handle effectively. It was asserted that mega projects generally are perceived to have a negative impact on the quality of life: BowCORD therefore subscribed to a go slow approach to community growth.

Finally, the submission suggested some alternative uses of the property that would help deal with the lack of affordable housing, and that would conform with slow growth rates rather than stimulate existing rates. The Association offered the prospect of small tourism 
developments in the form of the Swiss Model as one way of encouraging slow community growth. It emphasized that a negative decision by the Board would not necessarily mean that the lands would be sterilized nor that tourism would be excluded from the economic future of Canmore. In fact, it was thought that adventure recreation, ecotourism and cultural tourism in the Banff area may benefit from the absence of a development at the scale of Three Sisters.

The MD of Bighorn presented a brief to the hearing in support of the Three Sisters Application. The MD of Bighorn was described as being incorporated in 1988 with a current population of 1,440 residents, of which about 975 are said to live in the Bow Corridor. In the Bow Corridor portion of the MD of Bighorn, it was stated there are four hamlets and two settlements. The Hamlet of Dead Man's Flats would be closest to the Three Sisters development.

The Deputy Reeve of the MD of Bighorn, Ms. Fraser, explained that the proposed development had been a part of the MD until the lands were annexed in 1991. It was further stated that the MD understood that the Town would approve the development after the lands were annexed to the Town. Prior to the annexation, the MD was said to be working with the proponent to ensure that a development plan would be prepared to deal with all of the issues effectively. At the time, Council for the MD favoured the development of private land over public land and considered that Three Sisters was a good corporate citizen throughout the negotiations. The Deputy Reeve noted a number of development steps and approvals that had been worked out with Three Sisters at the time, including the South Corridor Area Structure Plan, the Tower Mountain Area Structure Plan and various steps towards the approval of Golf Course C. In addition, the status of other development proposals within the jurisdiction of the MD were also reviewed.

The MD of Bighom expressed the opinion that a number of matters are important in the assessment of the Application: the current use of the lands for recreation, the mitigation of the mining hazards and the return of undermined lands to use, the land exchange with the Province intended to protect critical wildlife areas, and the public consultation program conducted by the Applicant.

The issues that could impact the MD were identified as: the protection of water quality in the Bow River which is a source of water for communities in the MD of Bighorn, the generation of new jobs as a direct and indirect result of the project, the economic spinoffs from construction and the purchase of goods and services, and the wildlife mitigation measures recommended by the Applicant. The MD of Bighorn noted that the communities of Dead Man's Flats and Lac des Arcs could be expected to receive special benefit from any upgrading of the sewer and water systems. Also it was stated that with the development, a regional solid waste facility would become more attractive. It was noted that there is a shortage of affordable 
housing in the Bow Corridor and the Applicant's proposal was seen as potentially helping to satisfy that need.

The MD of Bighorn strongly supported the proposal for a regional monitoring committee to address future development issues of all kinds. In this regard it was suggested that if the Board issues an approval it should be framed in such a way that latitude would be left to the municipality with long term planning jurisdiction and definitive lines should be drawn as to major land use planning constraints.

\subsection{Pacific Western (Pacific Western)}

Pacific Western presented information and made a submission expressing support for the Application and the belief that the proposal would be in the public interest of the people living in the Canmore/Bow Corridor as well as Albertans generally. Pacific Western's business was described as being the transportation of tourists by bus or motorcoach, in the Bow Corridor area, from Calgary to Vancouver, and within the National Parks to the Columbia Icefields and Jasper. Pacific Western believes that the company would be well placed to provide a first class transportation service to the new development should it proceed.

According to Pacific Western, the following factors were considered in reaching its conclusion that the proposed project would have a positive benefit: the residential component of the proposed Three Sisters project should ease the housing shortage in Banff and Canmore; employment opportunities could result in 5,200 jobs being created with 100 of them at Pacific Western; the business climate could benefit from the synergistic effect of the new attractions and a significant increase in tourism expenditures could therefore be forecast; and the province and local authorities could also be expected to benefit greatly from increased tax returns.

The submission noted the importance of preserving the natural beauty and wildlife of the Bow Corridor and suggested that the proposed Three Sisters development plan would accomplish that. It was stated that the viability of the tourism industry depends on the popularity of the destination and this in turn depends on the natural beauty of the area, man made attractions, and the availability of accommodation. In Pacific Western's opinion, the Three Sisters proposal will greatly strengthen these factors in the Bow Corridor and, because of the development restrictions of the National Parks, the Canmore area would be a logical extension of the National Parks' tourism facilities.

Ms. Webb said that she has lived in Banff and the Bow Valley for 34 years and opposes the Application. She noted opinions of future trend analysts who were said to forecast the notion that mega development is not the way of the future, and hence, she supported the concept of small scale tourism such as a cottage industry. She also stated that it is important 
to consider the sense of place that she believes Canmore now retains, one that she felt would be lost if the proposed Three Sisters project proceeds. She expressed concern about the environmental consequences of the proposed project, especially on the Wind Valley. In addition, Ms. Webb was concerned that the Board should take an unbiased look at the broader implications of the Application.

The Adult Literacy Project made a presentation on behalf of adult learners and their tutors. The stated purpose of the organization is to upgrade reading and writing skills of people who were unable to develop these skills in their youth.

Two concerns were referenced that, in the opinion of the organization, should be addressed before the proposed project is approved. Firstly, the majority of adult learners are likely to have low paying jobs and often work shiftwork that is scheduled on short notice, thereby preventing them from planning their learning time effectively. It was therefore recommended that the tourism industry promote opportunities for literacy upgrading. Secondly, a lack of staff housing for single families and a lack of affordable housing in the Bow Corridor was perceived to be a problem; hence, it was recommended that these matters be addressed before the Application is approved.

The University Women's Club was stated as representing the Alberta Provincial Council of University Women and the Alberta Council of the Canadian Federation of Women. In its submission, the University Women's Club expressed concern about the lack of a master plan for the proposed project and requested a delay in the project until this concern has been addressed.

The University Women's Club also expressed the view that the approval of one development tends to attract more development in an increasingly unstoppable cycle. It was stated that the opportunity still exists to put a long term plan in place before irreparable harm is done to the Bow Valley and its environment. The possible environmental impacts of the Three Sisters proposal, taken in conjunction with the approved Hyatt Regency resort, were cited as threatening to the biodiversity of the valley, a biodiversity that Canada has agreed to protect as a signatory to the Biodiversity Convention. The encroachment on the natural beauty of the Wind Valley and the cumulative impacts of development on the Bow River were also stated as concerns.

The need for the project was questioned, since another "megaproject has already been approved" and the "over-exploitation of the province's tourism potential" could be possible. The University Women's Club stated that both tourists and residents alike benefit from the peace 
and beauty that the remaining natural areas of the Bow Valley afford. Alberta should, in the opinion of the University Women's Club, offer the wilderness and wildlife as a constant attraction for people living in a world where environmental degradation was said to have become the norm. The University Women's Club therefore recommended the Board take steps necessary to protect Wind Valley.

\section{Stoney Tribe}

The Stoney Tribe made a written submission and presentation during the hearing on social and economic matters taking the position that it is a special population group by virtue of its traditional use of the area for hunting and as its "homeland". It made a number of recommendations for consideration, which it asked the Board to impose on the Applicant as conditions of approval that would be binding on successors and assigns. The Stoney Reserves consist of about 56,000 ha with the main reserve located in the Bow Valley between Calgary and Banff. The Stoney Tribe stated that there are numerous trails, traplines, camping and cultural sites situated throughout the Bow Corridor that have been subject to their traditional and current use.

One major concern of the Stoney Tribe was described as the desire to share in the many employment opportunities as well as the indirect business benefits likely to be created by the proposed Three Sisters project. In addition, it was requested that the Stoney Tribe be recognized as a special population group which will be directly affected in a negative way by the project. An affirmative action program for employment and training was requested. In particular, specific percentages of employment were requested according to the nature of employment created.

It was also recommended that the Applicant be required to contract with the Stoney Tribe for certain goods and services available on the reserve and explore the potential for cross marketing opportunities with Stoney businesses. Concern was also expressed for the young people who are faced with high unemployment on their reserves. Several ways of benefiting the Stoney Tribe were suggested, by involving them in work at the resort as experienced in some places in the United States. With respect to human resources, the Stoney Tribe requested that Three Sisters be required to utilize the facilities of the Tribal Administration for all matters related to employment and selection.

The Stoney Tribe stated Three Sisters should also be asked to establish a Stoney cultural information centre on the site of the proposed development, and Stoney place names should be used wherever possible. It was explained that the Stoney Tribe is working to preserve the best of its culture and heritage. It was requested that Three Sisters be required to enter into an agreement with the Stoney Tribal Council to commission the Nakoda Institute to document and report on the historical and cultural significance of the development site in the period prior to white contact. 
The Stoney Tribe requested that the Applicant be required to provide compensation for a number of losses anticipated to result from the development including the degradation of hunting, trapping, wildlife and other resources. In particular, the opinion was expressed that the Wind Valley should be protected and held sacred to the Stoney people, as it is now.

In reference to the possibility of a regional management or decision making body for the Bow Corridor, it was stated that the Stoney Tribe should be a participant through the Stoney Tribal Council. However, it was emphasized that the Applicant or any other party could utilize many ways of incorporating the views of the Stoney Tribe in the planning process.

Ms. Klatzel-Mudry made a presentation on behalf of her family and herself to identify concerns and discuss alternatives to the proposed Three Sisters development. Ms. Klatzel-Mudry stated that her family highly values the natural environment and considers the development as an inappropriate land use and as potentially putting a hole in the heart of the Bow Valley in disregard for its unique ecosystem. The preservation of Wind Valley was stated as being a particular concern since it is regarded as an ecological jewel.

The draft Convention on Biodiversity was referenced as being morally binding on Canada in terms of the obligations that it contains. A number of the terms of the Convention were noted to demonstrate that Canada has a responsibility to take actions consistent with the agreement. In particular, the fundamental requirement of the Convention was stated as being the in-situ conservation of ecosystems and natural habitats and recovery of viable populations in their natural surroundings. Ms. Klatzel-Mudry stated her belief that the proposed Three Sisters development contravenes the spirit of the Convention, even with the Applicant's proposed mitigative measures, and even if it were to be scaled down.

A second major concern expressed by Ms. Klatzel-Mudry was the potential danger of methane gas in the coal measures. It was her opinion that the Board and the community should know more about coal bed methane before any decisions are made regarding land use. It was noted that various drill and surface tests have been conducted over the years on the property to determine the commercial potential and volumes, since it is known that Canmore coals have some of the highest content of adsorbed methane ever recorded. It was stated that resource evaluations and safety hazards must be determined before project planning is initiated. The selection of Wind Valley for development by Three Sisters was questioned as a result of evidence presented by Ms. Klatzel-Mudry suggesting that methane seepage may constitute an unknown but significant hazard. 
Mr. Lamont stated that he is "absolutely and fundamentally opposed to the project in its entirety". He noted that he viewed the decision as one of moral and ethical choice and criticized the Applicant's position on the ground that it is premised upon the view that part of the natural environment must be sacrificed for growth and progress. He was also critical of what he described as the western social belief that people are somehow separate from, and can control, nature. He stated his belief that there is no demonstrated need for the project and that, as an alternative, the lands should be set aside as parks, or otherwise put into the hands of the public. He suggested outdoor tourism, ecotourism, and mountain experience activities as alternative uses of the lands. He also advocated what he described as true, community based planning and the encouragement of non-equity, housing cooperatives. He stated that he considered that the physical separation of the residences of permanent and non-permanent workers in the proposed Three Sisters development would cause community problems.

Ms. Wilson was "totally irrevocably opposed to the development" because of its potential effects on lifestyle. She was also opposed to the possibility of any partial approvals. She stated that local problems derived from unwillingness to make decisions and not on the need for more debate. Ms. Wilson preferred that a decision be deferred until after the forthcoming municipal election.

The Construction Association made a written submission and presented information at the hearing in support of the Application. The Association stated that it believes that Three Sisters can improve the welfare of Alberta and its citizens because the size of the proposed project could generate a significant construction work force and would provide considerable revenue to all levels of government. The Construction Association was said to represent 1,400 member businesses and nine regional associations throughout the province, employing some 87,000 workers. It was also stated that it has an affiliate in Calgary with 405 firms employing several thousand workers.

The Construction Association said that the proposed Three Sisters project could be expected to have large spin-offs throughout the entire Calgary-Canmore-Banff corridor in terms of both direct and indirect employment across a wide range of trades and professions. It was noted that the construction industry now operates year round using procedures that were developed in Alberta and that this has changed the character of the industry. Employees with these skills were expected to serve the proposed Three Sisters project well, in the form of cost effective construction. The Construction Association also noted that its members are aware of 
environmental concerns and that their Association promotes this awareness through seminars and the encouragement of tender specifications which include mitigation of impacts.

With respect to the specifics of the proposed project, the Construction Association presented figures to demonstrate potential employment and tax benefits resulting from the project. Its expectation is that the effects of construction expenditures could significantly contribute to the economic recovery of the region; in this regard, the high unemployment rate among construction trades in Calgary was referenced. The Association expected that it would be feasible for workers to commute from Calgary on a daily basis.

The Construction Association raised a concern of the possibility that several other significant projects hinge on the Board's decision on the proposed Three Sisters project. It was suggested that a negative decision would send a message around the world that Alberta no longer welcomes investors and that Alberta does not wish to compete in the global market place. The Construction Association concluded its presentation with an offer to provide input at any future stage, recognizing that many other approvals would still be needed subsequent to any possible favourable decision by the Board.

Canmore, Bow Valley and Kananaskis Chamber of Commerce (Local Chamber of Commerce)

The Local Chamber of Commerce supported the Application for a number of reasons. First, it suggested that the negative social impacts that would most likely be associated with the proposed development would be greater if the project does not proceed. Secondly, the Chamber expressed the view that job creation is necessary to ensure the region's long term economic well being and a project approval would secure this well being. It suggested that preservation of a small town atmosphere desired by many Canmore residents, did not require the preservation of Canmore as a small town. Thirdly, the Chamber submitted that current increases in land prices were the greatest single threat to Canmore's quality of life and that allowing the development would alleviate this.

According to the Chamber, there are currently no tourism operations in Canmore targeted toward the high end of the market. The proposed development would act as an anchor and Canmore operators would have the opportunity to supply tourist related products for the whole range of the market thereby capturing substantial spin off. Finally, the Chamber suggested that the proposal would contribute favorably to long term planning, future levels of residential taxation, and to public access. 
3.29 Tourism Industry Association of Alberta (TIAALTA)

TIAALTA presented a submission in favour of the Application, provided that the Applicant meets the needs of government and all applicable regulations. TIAALTA stated it has a membership composed of tourist related regions, hotel, motel and restaurant associations, and ski area and campground associations of Alberta, with a total membership of 10,000 businesses.

It was stated that TIAALTA looks on all of Alberta as a potential tourism resource and therefore regards tourism development proposals, such as Three Sisters, as beneficial, provided that environmental and other issues are addressed through the approval processes. TIAALTA stated many benefits derive from tourism and accrue to the provincial economy. TIAALTA referred to the Tourism Education Council that has established standards and educational processes for employees in the industry, a code of ethics adopted by the Canadian and Alberta associations, and a University of Calgary educational program, all of which were thought to be beneficial for employee upgrading. TIAALTA recommended that the Applicant become familiar with these matters and endeavour to utilize them in operating the resort.

Ms. H. Bracco

Ms. Bracco stated that she was a teacher and a tourism industry guide with a neutral position in regard to the Application. She expressed concerns arising from her perception that the pace of growth in Canmore would be forced if the development were to proceed. She expressed the view that a steady pace of growth more in line with the long term historical rate in the community would be safer. She noted that Canmore residents have a strong sense of community history and would wish to see that sense maintained and not lost to rapid growth. Ms. Bracco stated that she felt that an approval would be premature if given prior to the approval of the Town's new GMP because there is currently no agreed upon vision and no established goals for the Town. Whatever the decision of the Board, she felt that it is likely to strongly influence the Town's future.

\subsection{1}

Green Central Station

On behalf of the group, Mr. Carson stated an objection to both the scale and style of the project. He recommended that the project be rejected and that some of the provincial funds that might be earmarked for the project infrastructure be used to acquire the Three Sisters lands for future public use. Mr. Carson made it clear that his opposition was based on the belief that the focus of planning should be on natural systems and not natural resources and that land should not be treated as a commodity of exchange. He stated his belief that the planet cannot go on supporting unending growth.

He also expressed the opinion that municipal and community opposition will not be easily overcome and that "green visionaries" and an aroused community will effect change. 
He characterized the conflict of opinions about the merits of the Three Sisters Application as a local expression of a global problem. He also suggested that there might be a way to pursue development in the Three Sisters area at a reduced scale with the primary purpose of providing affordable housing.

\subsection{Canadian Ski Association - Alberta Division (Ski Association)}

Appearing on behalf of the Canadian Ski Association; Mr. Fischer stated that the Association has about 16,000 members in Alberta with activities adding about a million dollars annually to the local economy. The Ski Association expressed concern about the lack of affordable housing and the handicap that this imposes on the area as a potential ski training centre at the international level. In this regard, it was noted that the nordic centre in Canmore sets a standard for facilities of its type throughout the world. It was stated that the proposed Three Sisters development would likely alleviate some of the housing problems in the Town, thereby encouraging a greater use of the facility for longer term ski training.

In addition, new employment would also be welcomed to provide opportunities for athletes to support themselves in training. Therefore, the Association supported the development as being beneficial by mitigating against the housing problem and by contributing employment opportunities for athletes.

\subsection{3}

\section{Mr. J. Streda}

Mr. Streda appeared before the Board to present the view that the Town should be required to hold a plebiscite on the Three Sisters Application because it was not empowered to make decisions that would totally change the character of the community. He stated his view that the majority of the older people in Canmore were opposed to the project, fearing a decline in the quality of life and a destruction of the environment.

Ms. Campbell said that she has been a resident of Canmore for 24 years and was opposed to the development because it is not consistent with people's image of the Bow Valley. She cautioned that, in her opinion, change should come from within the community and the Application should be approached with great caution.

Mr. Upton stated that he had resided in Canmore for five years and was opposed to the Application. He expressed the view that the scope, values, and insight of the proposal 
are all wrong. According to Mr. Upton, the proposal, particularly in the Tower Mountain area, is environmentally and economically unsound. He recommended that the Wind Valley should be held as environmental reserve and development should be kept contiguous to the Town. He believes that Golf Course C and some limited housing development would be acceptable.

\section{$3.36 \quad$ Ms. M. Nicks}

Ms. Nicks stated that she owns and operates a local business in Canmore and wished to express a viewpoint that differed from that of the Local Chamber of Commerce. She expressed concern with the scale, type and location of the development. She also anticipates a significant deterioration in the environment if the development is permitted to proceed. She anticipates that the resort, as proposed, would be in competition with Banff and that a smaller scale and different type of experience than that found in Banff should be offered.

Ms. Nicks also noted that the Praxis survey had shown a split in the community over tourism development; it was her opinion that the community was at the crossroads in development and should have a bias towards cultural preservation and the future quality of life.

Earth First!

Earth First! made a presentation to the hearing including a video showing the natural values of the Wind Valley and some other parts of the Three Sisters property. Earth First! is opposed to the development. It was asserted that it would not be possible to save Wind Valley if all the area around it were to be developed. The ecosystem, it was stated, cannot be reduced to that sort of scale. It was also suggested that a wise decision would deal with the whole area. Earth First! was therefore opposed to every part of the development.

Mr. Beitel was opposed to the Application. He described himself as an expert on backcountry ethics, with an interest in minimizing the impact of development on backcountry environments. He presented information to establish that the Wind Valley is a backcountry environment and hence, the principles of backcountry ethics should apply to decisions related to Wind Valley.

Mr. Greenberg, a resident of Canmore, stated that he is not opposed to all development, but felt that the Application as it stands should be rejected. He noted that developments in the Bow Valley are a deep concern for the residents, in terms of the 
preservation of the existing lifestyle and the protection of the natural setting. He proposed that a valley wide plan to maximize environmental protection and encourage conservative growth should be put in place.

Mr. Davis stated that he is a past president of the Alberta Restaurant and Food Services Association and that he was in support of the Application as planned. He noted that there are many economic advantages to be gained from tourism and change has to be accepted. He described the opportunities for students from the Southern Alberta Institute of Technology arising from tourism and stated that they were very enthusiastic about the potential employment opportunities. He also noted that, in his opinion, the Applicant is both environmentally informed and knowledgeable.

\subsection{1}

\section{Mr. J. Kievit}

Mr. Kievit stated that he had been a resident of Canmore since the early 1970's and is opposed to the development. He described the community as he believed it was when he arrived and the overwhelming influx of newcomers he senses are living in the Town now. He fears the decline in the quality of life, the loss of small town atmosphere, social degradation and environmental breakdown that he believes the development will bring.

A number of parties filed written submissions regarding the Application but did not appear at the hearing. These written submissions were either supportive of or opposed to the Application for reasons generally consistent with the reasons put forward by other participants in the public hearing. 
The Board is directed by the NRCB ACt to review the Three Sisters Application to determine whether, in the Board's opinion, the proposed recreational and tourism project in the Town of Canmore, is in the public interest, having regard to the social and economic effects of the project and its effect on the environment. The proposed project is substantial in size and the Application and supporting information are voluminous and detailed. The hearing was lengthy and involved more than 40 groups or individual participants who also raised concerns, some of which were complex, and submitted much information, some of which was detailed. The Bow Corridor, in which the project would be located, is environmentally sensitive and there are a number of other developments proposed for the area. All of these matters combined result in a number of issues which relate to the public interest which the Board believes it should assess prior to dealing in detail with the environmental, social, and economic effects of the proposal.

Participants in the hearing raised a number of jurisdictional matters including the interpretation of s. 2 of the $N R C B A C t$, which defines the terms of reference for determining the public interest. Others questioned the jurisdiction of the Board to consider cumulative effects. The Board believes it should first deal with these:

- jurisdictional issues.

A number of participants suggested that the Three Sisters Application was not definitive enough to allow an assessment of the public interest or that there was insufficient data available to do so. Others questioned the lack of data for the entire Bow Corridor. Consequently the Board believes it should next address:

- the conceptual nature of the proposed project and the adequacy of the Application and of other information.

The Board would proceed further with its assessment only if it is satisfied that sufficient data are available to do so.

The proposed project is in the Town of Canmore and would be subject to the local planning process of the Town as defined by the Alberta Planning Act. Essentially all hearing participants who expressed an opinion agreed that coordination of the two processes is important. As a result, the Board believes it should, prior to assessing the specific Three Sisters proposal, deal with:

- the coordination of the NRCB process with the local planning process.

There was much discussion at the hearing about the need for the Board to have regard for other existing and planned developments in the Bow Corridor when assessing the public interest of the Three Sisters Application. The Board agrees that such need exists and that it would be useful for it to next consider: 
- the base situation respecting developments in the Bow Corridor from which the Board should assess the effects of the Three Sisters proposal in a cumulative manner.

The Board believes it should then go on to assess in detail, having regard for the input received from participants in the hearing, the effects that would likely result if the proposed project proceeds, and the mitigative measures that may be taken to reduce any adverse effects. This would be done in the context of the cumulative effects of developments in the Bow Corridor, and would deal specifically with the following matters:

- geotechnical hazards to the proposed project primarily resulting from earlier coal mining operations in the area.

- an assessment of environmental effects, and a discussion of mitigation and monitoring, including consideration of the following specific issues:

- airsheds;

- aquatic ecosystem;

- terrestrial ecosystems; and

- ecosystem management.

- an assessment of social and economic effects, and a discussion of mitigation and monitoring, including a consideration of the following specific issues:

- potential markets for the various proposed facilities and services;

- economic effects on the province and region;

- growth of the Town and effects on the lifestyle of its citizens;

- effects on services;

- effects on housing;

- effects on historical resources and on current recreational use of the area;

- effects on the Stoney Tribe; and

- financial effects on the Town of Canmore.

Many parties raised concerns at the hearing about the handling of future applications for development in the Bow Corridor and the need for coordinated controls with respect to the many projects that may proceed in the area. The Board therefore believes it would be appropriate to deal with the following matter, having regard for its conclusions regarding the environmental, social and economic effects of the proposed project:

- the need for ongoing efficient planning and controls regarding developments in the Bow Corridor. 
Certain participants in the hearing raised issues which can be considered as jurisdictional matters. The Board will deal with two of these issues, the public interest test and the appropriateness of reviewing cumulative impacts, as preliminary matters.

\section{$5.1 \quad$ The "Public Interest" Test}

\section{S. 2 of the $N R C B$ Act reads as follows:}

"The purpose of this Act is to provide for an impartial process to review projects that will or may affect the natural resources of Alberta in order to determine whether, in the Board's opinion, the projects are in the public interest, having regard to the social and economic effects of the projects and the effect of the projects on the environment."

The Board considers that its duty to be discharged pursuant to $\mathrm{s.2}$ of the $N R C B$ $A c t$ is, broadly speaking, to weigh its conclusions respecting the various effects, some positive and some negative, that may result from a proposal, and to balance these effects in forming an overall opinion as to the public interest. The Board expounded this view in its Decision Report regarding Chem Security (Alberta) Ltd.

The public interest test was primarily addressed by the Applicant and by the CPAWS Group in the hearing. The Board has considered each of their positions.

Three Sisters took the position that the NRCB Act requires a two step balancing test to be carried out by the Board in order to determine whether a project is in the public interest. According to Three Sisters, the first step is an assessment of the net impacts of each of the social, economic and environmental components having regard to the local, regional and provincial perspectives, and considering always that the balancing is done with respect to a specific project. The second step requires that the Board simultaneously balance the net social effects, the net economic effects and the net environmental effects and from this reach a determination as to whether the project is in the public interest.

The CPAWS Group argued that the use of the word "and" in s. 2 of the $N R C B$ Act directs the Board to make a separate determination as to the public interest with respect to each component. According to the CPAWS Group the Board must be satisfied that each component is in the public interest before a project should be allowed to proceed.

With respect to the position advocated by the Applicant, the Board agrees in general that a simultaneous or joint balancing of the social effects, the economic effects and the environmental effects is required in making a determination as to whether a reviewable project is in the public interest. However the Board believes that there is little utility in surmising the number of steps which may be required to ultimately reach a decision. Further, the Board 


\section{$5-2$}

believes that while there is a "netting-out" procedure which takes place in forming an opinion as to the overall effect, positive or negative, of any given project, because of the weight or magnitude of certain effects as compared to others the procedure cannot be reduced to a formula for tallying or summing up somewhat mathematically the net impacts of each of the three categories with the result dictating the public interest. For example, the Board does not believe that a "netting" procedure which found two of the three components producing "net positive" impacts would necessarily mean that the overall impact of a reviewable project could be considered to be in the public interest, if a negative impact in the third category were of sufficient concern or weight on its own to tip the scales against the project or a portion thereof.

The Board also agrees with Three Sisters that local, regional and provincial perspectives must all be taken into account when assessing the overall public interest. The Board considers that reviewable projects before it will differ in the territorial scope of their effects, some having impacts which are more localized than others. The Board also considers that each reviewable project may differ in the scope of the territorial effects in each of the categories of social, economic and environmental effects. In other words, it would be possible for a project to create a local economic effect but a regional environmental effect and a social effect of interest at a provincial level.

With respect to the argument advanced by the CPAWS Group, the Board believes that the plain language of $\mathrm{s} .2$ of the $N R C B$ Act requires a determination of the Board as to whether in its opinion a reviewable project is in the public interest, and that in making such determination the Board must have regard to each of the social effects, economic effects and the environmental effects of the proposed project. The Board does not agree with the CPAWS Group that the language of s. 2 directs the Board that it must find that each of these effects of a reviewable project is in the public interest for the project to be considered overall to be in the public interest. The Board believes that it is directed to consider each of these effects in forming its opinion regarding the overall public interest, and the Board will do so.

\section{Cumulative Impacts}

Three participants in particular discussed the Board's duty to consider cumulative impacts of the proposed project.

Three Sisters stated that there is no legal responsibility to complete an assessment of the cumulative impacts of its project. The Applicant indicated that the NRCB Act does not contain a specific reference to the need for cumulative effects to be considered by the Board when making its decision. The Applicant contrasted this with s.47(d) of the Environmental Protection and Enhancement Act, which received Royal Assent on June 26, 1992. This section would require an environmental impact assessment to include, unless the Director provided otherwise, a description of potential cumulative impacts. The Terms of Reference developed by Alberta Environment for the EIA prepared by the Applicant called for the assessment of cumulative impacts; however, the Applicant took the position that these impacts were properly 
limited to the impacts resulting within the boundaries of the project area as defined in the map attached to the Terms of Reference. Because Appendix 3 to the schedule to the Board's Rules of Practice (Alta. Reg. 345/91) states that an application shall include "when applicable" an assessment of cumulative impacts, the Applicant took the position that the Board did not make the determination as to whether such a review. would be applicable as the Land Surface Conservation and Reclamation Act is the legislation under which the EIA was authorized for Three Sisters. Three Sisters therefore stated that the Land Surface Conservation and Reclamation Act is a paramount statute to the NRCB Act. Further, Three Sisters stated that even if the Board wished to consider cumulative effects, it should only consider those projects that are reasonably foreseeable. The Applicant stated that reasonably foreseeable projects are those projects for which NRCB approval has been formally sought.

Notwithstanding the foregoing arguments, the Applicant submitted that it had completed a cumulative impact assessment to the extent that the Board's Rules of Practice request and that it had adequately identified cumulative effects. The Applicant further submitted that concern with the cumulative impacts must focus on future monitoring rather than on the development as scrutinized in the Three Sisters Application.

The CPAWS Group took the position that the need for a cumulative impact assessment is crucial given that the montane ecosystem is limited and therefore the cumulative impacts on this resource are potentially greater than would be the case if the project were proposed for an ecosystem with a greater geographic territory. Further, the CPAWS Group argued that s. 8 of the Land Surface Conservation and Reclamation Act is somewhat irrelevant in that it does not mandate any particular contents of an EIA; rather what is important are the policies and procedures that have been developed in practice by Alberta Environment. The CPAWS Group also referred to Appendix 3 of the Board's Rules of Practice, indicating that a cumulative effects assessment can be ordered. The CPAWS Group therefore concluded that there is statutory authority in Alberta for cumulative impacts assessment. In respect of the Bow Valley portion of the project, the CPAWS Group requested a cumulative effects assessment and that consideration be deferred for this portion until the cumulative effects assessment has been performed.

The AWA Group concurred with the CPAWS Group that Appendix 3 of the Board's Rules of Practice was a specific indication of a statutory authority in Alberta to consider cumulative effects of a development. The AWA Group submitted that the NRCB Regulations constitute specific legislation which applies to the proceeding and that the general s. 8 of the Land Surface Conservation and Reclamation Act did not take precedence over the NRCB legislation, or was not paramount in any way, and therefore did not govern the proceeding.

It is the view of the Board that the public interest must be served by a meaningful assessment of the likely social, economic and environmental effects of a reviewable project. The Board feels that there is a kind of "maximum carrying capacity" for change in societies and ecosystems. In other words, certain results or effects of any given new development may be absorbed without great damage to the social fabric or to the viability of ecosystems or 
components thereof. However the combined effect of a number of new developments, each of which may be acceptable in and of themselves, together with the "background" effect that existing populations and economies have on the social fabric or systems and on the health of ecosystems, may be more than such systems can bear without damage or breakdown. Therefore the Board does not believe that the public interest can be served without consideration of a reviewable project in the context of the cumulative effects of the base case plus developments the Board has reason to believe will proceed.

The Board intends to discharge its duties under the $N R C B$ Act by including in its deliberations a reasonable consideration of cumulative effects of the Three Sisters project. A number of the requests for supplemental information in the Board's deficiency letter to Three Sisters of December 31, 1991, were based upon this intention and clearly required information of a cumulative or regional nature, particularly with regard to certain environmental impacts or issues. The Board, as noted at page 4 of the Report of the prehearing meeting of March 9 , 1992, determined that it would assess the Three Sisters Application having appropriate regard for the likely effects of other projects in the area that are in existence or expected to proceed. The Board does not accept the proposition that cumulative impacts should be viewed only within the confines of a specific project area or that cumulative impacts should be reviewed only in terms of future monitoring, as this would preclude meaningful assessment prior to development.

With respect to the specific arguments placed before the Board regarding cumulative effects assessments, the Board believes that s.7(c) of Appendix 3 of its Rules of Practice reflects its intention to require cumulative effects assessments on resources and resource uses of a project for the region within which resources may be significantly affected by the project. The Board believes that a cumulative effects assessment is "applicable" in respect of the Three Sisters Application, as was reflected in its deficiency letter of December 31, 1991, in the prehearing meeting and in the Report of the Pre-hearing Meeting for the Three Sisters Application. Whether or not the Land Surface Conservation and Reclamation Act has an impact on the Board's procedures is not really germane in the opinion of the Board, particularly in the case of the Three Sisters Application, since the Applicant stated that it had within feasible limits considered the cumulative impacts of its project. The Board notes that the Applicant considered potential major recreation developments and the natural growth of the Town of Canmore. The base situation from which the Board will assess the cumulative effects of the proposed Three Sisters project is described in Section 8 of this Decision Report. 
A number of participants in the hearing suggested that the Application was too conceptual in nature to allow a proper assessment as to whether or not it was in the public interest. They pointed to the need for baseline and other relevant information dealing with the entire region rather than only the Applicant's lands. Some suggested that to proceed with the project in the face of such uncertainty could not be justified.

Recognizing that the Application is somewhat more conceptual in nature than would normally be expected in applications to the NRCB, and that the question of the adequacy of baseline information was raised as early as, and prior to, the prehearing meeting on March 9 , 1992, the Board believes it should clarify its position in this regard.

The Application by Three Sisters is for a project to construct a number of different types of facilities (residential housing of various kinds, golf courses, hotels and other commercial space), on a substantial area of land $(1,036 \mathrm{ha})$ over a lengthy time period (20 years or more). The Board would expect that such a proposal would be less definitive than would be the case for a particular single facility to be constructed within a couple of years of receipt of an approval. A less definitive proposal would allow sufficient flexibility for such a project, as it unfolds with time, to be adjusted to reflect changed conditions and circumstances, for example with respect to the environment or the economy. It is also relevant that the proposed Three Sisters project would be subject, on an ongoing basis over the 20 or more years of development, to the local planning process of the Town of Canmore. This ongoing process reduces the need for the initial proposal to include all details respecting the development, particularly in the longterm. (The co-ordination of the NRCB process and the local planning process is discussed in Section 7.)

On the basis of the information filed by Three Sisters and statements made at the hearing, the Board considers the Application to be a request for approval of the recreational and tourism project as described in specifically identified maps and in other parts of the Application. The approval requested by Three Sisters would provide certainty of land use for the various areas of the project, guidelines setting out the minimum development density for each area, approved transportation routes and utility corridors, approved general locations for the proposed golf courses, and general direction on timing that would allow initial development to proceed simultaneously on the eastern and western parts of the project lands and for the total project to be completed in 20 or so years. The approval requested by Three Sisters would provide a framework for subsequent subdivision and development, but would allow flexibility for changes to details in consultation with the Town.

Having regard for the proposed phasing of the project over a lengthy time period and for the ongoing role of the Town, the Board is satisfied that the project proposed by Three Sisters is sufficiently detailed that the Board can appropriately assess whether or not it is in the public interest. 
In terms of the adequacy of the information contained in the Application, the Board notes that the EIA, which is a major portion of the Application, was prepared in accordance with the Terms of Reference issued by Alberta Environment prior to the existence of the NRCB Act. Considerable supplementary information was requested by Board staff, having regard for comments respecting deficiencies received from Alberta Environment, Federal Government departments and the Town of Canmore. Following receipt of the supplementary information, both the Board and Alberta Environment considered the Application sufficiently complete to proceed to hearing. Additionally, considerably more information was filed at the hearing by the Applicant in response to questions, and by other participants in presenting their positions on the Application.

The Board recognizes that much of the information it received is specific to the Three Sisters lands as opposed to elsewhere in the Bow Corridor. That is to be expected given that the Three Sisters proposal is the only application before the Board and that the Terms of Reference for the EIA focused on the Three Sisters lands. The Board also recognizes that one can always use more and better information when making decisions such as it now faces, particularly where a large sensitive area is involved and where there are a number of projects which may proceed in the same area with somewhat similar and possibly cumulative effects.

Notwithstanding, the Board is satisfied that the information in the Application and otherwise filed at the hearing is sufficient to allow it to proceed with an evaluation of the Three Sisters project. If in its assessment of any particular aspect of the proposal, the Board determines that it lacks specific information, it will address the lack of such information having regard for the particular information and its importance in the overall review of the Application. 


\section{CO-ORDINATION OF THE NRCB PROCESS WITH THE PLANNING PROCESS}

It is evident to the Board that there is some degree of overlap between the function of the Board under the NRCB ACt and certain functions of a municipal planning authority under the Planning Act.

In considering the issue of coordinating the Board's functions with those of planning agencies in Alberta, the Board has had regard to s.9(3) of the NRCB Act, which provides:

"An approval granted under this Act does not dispense with the requirement to obtain any other licence, permit, approval or other authorization in respect of the reviewable project."

Notwithstanding the fact that the NRCB Act clearly contemplates a "layered" approach for an applicant for obtaining approvals in the Province of Alberta, the Board is concerned that such an approach may create an unreasonable burden for proponents of reviewable projects. The Board recognizes that Three Sisters, if it receives NRCB approval, would face the necessity of obtaining a number of approvals in accordance with the planning process, as well as from various government departments. The Board also recognizes that the Applicant's proposal would receive close scrutiny through the municipal planning process over the build out period of the project.

In order to achieve a measure of equity for the proponent, the Board believes that any approval it might issue should give the Applicant a reasonable degree of certainty of use but at the same time not usurp the powers of the municipal planning authorities. The Board has no desire to see the interest of local residents and stakeholders thwarted by sterilizing the effectiveness of the public process in local planning matters. In short, the Board believes that both levels of jurisdiction, the Board and the local planning authorities, can discharge their respective duties in the public interest.

In the Board's view, this approach to discharging public interest duties is consistent with both the NRCB Act and the Planning Act. The purposes of both Acts, as set forth in s.2 of each Act, are as follows:

\section{S. 2, NRCB Act:}

"The purpose of this Act is to provide for an impartial process to review projects that will or may affect the natural resources of Alberta in order to determine whether, in the Board's opinion, the projects are in the public interest, having regard to the social and economic effects of the projects and the effect of the projects on the environment." 


\section{S.2, Planning Act:}

"The purpose of this Act and the regulations is to provide means whereby plans and related measures may be prepared and adopted to

(a) achieve the orderly, economical and beneficial development and use of land and patterns of human settlement, and

(b) maintain and improve the quality of the physical environment within which patterns of human settlement are situated in Alberta,

without infringing on the rights of individuals except to the extent that is necessary for the greater public interest."

Some of the matters to be considered under these statutes will be common to both jurisdictions. The consideration of natural resources is an example of where some commonality can be expected to arise. The purpose of the $N R C B A C t$ is to "provide for an impartial process to review projects that will or may affect the natural resources of Alberta" (s.2, NRCB Act), which "natural resources" include the "subsurface, land surface, water, fauna and flora resources of Alberta" (s.1(g), NRCB Act). Since the land surface is one of the natural resources which must be considered in determining the public interest under the $N R C B A C t$, there is potential for some overlap with the planning process.

However, it is also clear that the considerations and duties under each statute are not identical. For example, in terms of environmental considerations, the Board must have regard to the effect of reviewable projects on the "environment", which is defined in s.1(c) of the NRCB ACt as "the components of the earth", including "(i) air, land and water, (ii) all layers of the atmosphere, (iii) all organic and inorganic matter and living organisms, and (iv) the interacting natural systems that include components referred to in subclauses (i) to (iii)", whereas the environmental considerations of any planning commissions or approving authorities under the Planning Act would relate specifically to the context of the relationship of the physical environment to patterns of human settlement. The Board therefore considers that its review of the environment must of necessity be broader than the review of the environment for the purposes of the Planning Act as stated in s.2 thereof, and that patterns of human settlement would be only one of a number of relevant considerations for the Board in respect of the environmental impacts of development. The Board believes that its broader mandate is also underscored by s.5(2) of the NRCB ACt which provides, in part, that "the Board may...order that no... authorization may be issued or granted...by any agency of the Government or a municipality to any person with respect to a reviewable project until such time as an approval in respect of the project has been granted under this Act." In other words, the Board may preempt any other approval process until the broad requirements of the NRCB ACt have been met. 
The broader mandate of the Board is further reflected in that the Board has the ability to bind the Crown through its mandatory orders and conditions, whereas the Planning Act does not bind the Crown.

The Board considers that the legislation is directing a broad review of the public interest for reviewable projects under the $N R C B$ Act in addition to more site specific reviews of such projects pursuant to the Planning Act. The Board believes that the public interest can best be served by co-ordination of these processes to the greatest degree possible. In considering the potential for co-ordination of the processes the Board has had regard for s.2.1 of the Planning $A c t$, which provides as follows:

"2.1(1) A condition of a licence, permit, approval or other authorization granted by the Lieutenant Governor in Council, a Minister of the Crown or a government agency pursuant to an enactment prevails over any condition of a development permit that conflicts with it.

(2) In this section, "government agency" means a corporation that is an agent of the Crown in right of Alberta, a government official or any corporation, commission, board or other body empowered to exercise quasi-judicial or governmental functions and whose members are appointed by one or more of the following:

(a) an Act of the Legislature;

(b) the Lieutenant Governor in Council;

(c) a Minister of the Crown."

The Board is a "government agency" for purposes of this section. Based on this section the Board considers that a development permit, which is the final site specific approval required under the Planning Act prior to development, must be consistent with a mandatory order of the Board or a condition of any Board approval in order to be effective. Any inconsistent aspects of the permit would not stand. Since the Board's approval is paramount to this level of site specific approval, the Board believes it may be appropriate to integrate its approval process with the more general level of statutory plans as prescribed in the Planning Act for the Alberta planning process. However, based on evidence presented at the hearing regarding the uncertainty in application of Regional Plans to actual land use by-laws and development permits issued thereunder, the Board believes that its mandatory approvals are distinct from planning documents in that the Board's approvals must be reflected in the ultimate site specific approvals.

The Board has had regard for all of the planning documents placed in evidence before it at the hearing, including the Eastern Slopes Policy, the Bow Corridor Local Integrated Resource Plan, the MD of Bighorn General Municipal Plan, the South Corridor Area Structure Plan and the Town of Canmore Draft General Municipal Plan. The Board recognizes the 
varying degrees of detail in different levels of plans and recognizes the efforts made by various agencies to plan both in respect of public lands, through the integrated resource plans made pursuant to the Public Lands Act and in respect of private lands, through the hierarchy of plans made pursuant to the Planning Act. The Board also recognizes that its own approval, particularly in this case, could bridge the two processes and combine elements of public land management and private land use control. For example, a condition requiring the Applicant to provide a design approved by the Fish and Wildlife Division of Alberta Forestry, Lands and Wildlife in respect of the size and location of wildlife mitigation corridors on the Three Sisters lands would effectively give a public agency a measure of planning jurisdiction over private lands. This would be an expansion of the ordinary purview of Forestry, Lands and Wildlife. The Board believes that such integration of expertise and approaches can be a valuable result of the hearing process pursuant to the $N R C B A C t$, and that such integration would be in the public interest.

As is clear from s.9(3) of the NRCB Act, there is a need for both NRCB approval and local planning approvals for the Three Sisters project. The Board adopts the interpretation of the two statutes expounded by Mr. Robinson of the CRPC, that both approvals are necessary but not sufficient in and of themselves. Although both the Board approvals and the approvals of the municipal council of the Town of Canmore are required before development in the project area may proceed, the Board believes that it is clear that any condition of an approval granted by the Board in respect of the project will be binding upon the municipal council of the Town of Canmore, and upon the Alberta Planning Board if any municipal planning decision is appealed, and in case of conflict would prevail over any condition of a development permit issued by the Town. This conclusion is consistent with s.2.1(1) of the Planning Act and is a conclusion which was espoused by both the CRPC and counsel to the Town of Canmore.

Because both the approval of the NRCB and the approval of the Town of Canmore as a municipal planning authority, or the Alberta Planning Board on appeal from the Town, are required by legislation and because neither approval is sufficient alone to enable the Applicant to construct facilities on the project lands, it follows that an order of the Board in respect of the project is not finally determinative of the issue as to whether the project may proceed. The Board recognizes that it could approve all or part of the project but that the Applicant may not be successful in developing the parts of the project approved by the Board owing to failure by the Applicant to receive approval from the Town (or the appeal board) for more detailed plans for development in such areas. It also follows that if the Board fails to approve all or part of the project, the refused project or part could not proceed, whether or not the Town as a local planning authority (or the appeal board) approved the development.

The Board was urged by several participants, particularly BowCORD and individuals from the local area, to refrain from approving any part of the Application, as Board approval would arguably hamper the citizenry in their local initiatives to be effective in 
restricting or controlling development in the area. Since the local citizens are entitled to participate in the processes of planning approvals to be granted by the Town following this decision of the Board, and since such processes could result in a complete rejection of all or any part of the project approved by the Board, the Board has difficulty understanding how much more effective a process the local citizenry could wish. Some participants in the hearing suggested that certain procedural conventions in the Town planning process may operate to reduce community participation. The Board assumes that the Town will consider this matter. The Board also notes the importance of environmental assessments and the growing concern of the public over their effectiveness, and expects that the Town would make available for public review any relevant environmental assessments or studies at an appropriate stage in the approval process.

\section{Co-ordinated Approach}

In general, the Board accepts the views espoused by both the CRPC and the Town of Canmore that for purposes of the Three Sisters Application the Board can be considered as if it were part of the planning process, although technically not a planning authority for purposes of the Planning Act. In this regard, various requests were made of the Board to consider issuing an approval which would fit into the hierarchy of plans in Alberta as described by both the CRPC and the Town of Canmore, or which would serve as a proxy for one of these types of plans.

For example, the Board was urged by the Applicant to issue an approval which would give the Applicant the same level of detail as an Area Structure Plan. Such an approval in the Board's understanding could effectively operate as a planning document of a more specific nature than a General Municipal Plan. On the other hand, the Town of Canmore urged the Board to make its approval similar to a Regional Plan, which, from the description provided by the CRPC, the Board takes to be a planning document setting out strategic land use policy and capable of being implemented through General Municipal Plans and Area Structure Plans.

In referring to the draft General Municipal Plan of the Town of Canmore, presented in evidence in the hearing, the contents of an area structure plan to be prepared for the Town were stated to include the following:

- sequence or phasing of proposed development;

- specific land uses;

- general location of public open space systems;

- population density;

- general location of major transportation routes and public utilities;

- provision and location of community services including recreation and school facilities;

- design guidelines and architectural controls;

an undermining assessment as per Alberta Environment site specific 
specifications;

- an environmental impact analysis;

- a socio economic impact analysis;

- a visual impact assessment;

- location of wildlife corridors; and

- location of buffer zones

While it is evident that the Board does not have a mandate to operate as a planning commission or an approving authority for purposes of the Planning Act, the Board does believe that any approvals granted by it under the NRCB ACt and the conditions contained therein will have an impact on the planning process. Therefore while the Board does not believe that it has been directed by legislation to deliver, in effect, a Regional Plan or an Area Structure Plan, the Board is mindful of the monumentality of the process which has been undertaken by the Applicant in this proceeding and prior to this proceeding in the planning process, and does not wish any applicant to be forced through unnecessarily duplicative proceedings.

The Board believes it appropriate to address in any approval of the Three Sisters project the overall structure of the development, including sequencing or phasing of the project, land uses, general location of open spaces, minimum densities, general location of major transportation routes and public utilities, constraints due to undermining or coal seam methane, constraints due to environmental or social effects, location of wildlife corridors and location of buffer zones. However, the Board would not expect to include certain other items contemplated by the Town of Canmore for inclusion in its Area Structure Plans, such as design guidelines and architectural controls, because the Board considers them too detailed to be considered as part of its process.

The Board is satisfied that such an approval would not denude the Town of its authority under The Planning Act, nor would it preclude the effectiveness of public participation processes in the Town, owing to the need for both the approval of the Board and the approval of the Town before the project may ultimately proceed.

In reaching the conclusions just stated, the Board accepts the characterization of the Town as a competent and sophisticated planning authority, as described by its counsel during the hearing. It is important to note, however, that certain of the Board's areas of jurisdiction are not dealt with by the Town, particularly with respect to certain details of socio economic impacts of development and the monitoring thereof and with respect to impacts of developments on ecosystems and the monitoring thereof. For example, with reference to socio economic effects of development, the Town acknowledged the difficulty that it had in assuring the supply of affordable housing to meet the need therefor and indicated that this was a social problem which was not completely capable of being addressed within its jurisdiction. With respect to ecosystem planning, the Town acknowledged an in-house incapability of assessing wildlife impacts of development. Further, in respect of the issue of monitoring of both environmental and socio economic impacts, the Town indicated that it should take the lead in socio economic monitoring but expressed reservations regarding manpower, cost to the Town and liability. 
The Board believes that the co-ordination of any approval it issues or recommendations it makes with the planning approvals yet to be granted by the Town is the most reasonable approach in the public interest, in that a broad, long term overview such as that undertaken in the hearing will be more beneficial to the public in Alberta than a fragmented approach. The Board considers that it has been fortunate for the public interest that the Applicant has presented the project as a whole, thereby allowing an in depth review of all of the impacts of the project before more specific approvals were sought. Most likely such a review would not have been possible if the proponent had proceeded piecemeal.

\subsection{Integration of Processes in the Longer Term}

The Board has described a coordinated approach which it believes will be effective and efficient given the existing legislation and the current circumstances. It believes there may be potential for a greater degree of coordination in the long term. The Board considers that the general issue of sustainable development, as reflected in the Environmental Protection and Enhancement Act, should be reviewed in the context of planning pursuant to the Planning Act, the Public Lands Act and other relevant legislation, to ensure that the planning process is environmentally sound and responsive to public concerns, while at the same time reasonably efficient.

Following release of this Decision Report, the Board plans to initiate discussions with the Town of Canmore, the Applicant, major Canmore based interveners, the CRPC, Municipal Affairs and other interested parties, to review the approval process for reviewable projects and to consider ways in which it could be streamlined. With regard to the larger issue of planning and the environment, the Board would recommend that Alberta Environment, through the Sustainable Development Co-ordinating Council, take the lead role in a study of the matter. 
In Section 5.2 of the Decision Report the Board concludes that it should assess the Three Sisters Application having regard for the cumulative effects that are likely to result, not only from the Three Sisters project, but generally from existing facilities and users of the area and including the future projects which can be expected to proceed with some certainty. To set the stage for subsequent sections of the Decision Report, this Section describes the base situation from which the Board believes it would be appropriate to assess the effects of the Three Sisters project.

Clearly, the existing developments in the Town of Canmore and the Bow Corridor are part of the base from which the effects of the proposal should be measured. This includes all existing residential, tourism, other commercial and industrial facilities and the people who currently reside in the area or who visit or use it.

In terms of future facilities, the Board believes it should only have regard for those developments where there is a reasonable expectation that they will proceed. It is difficult to speculate what these may be, given the present state of the economy and other numerous uncertainties regarding the future. For this reason, the Board has decided to attach considerable significance to the question of whether or not future projects have already been given approvals. It will include in the base from which it assesses the Three Sisters Application, all projects where the project required approvals have been given, unless it has information to strongly suggest that the projects will not proceed. The Board recognizes that this will likely include projects which will be substantially delayed or not proceed at all, but these would compensate for other new projects not now identified which would likely go ahead in future.

There are a number of proposed projects, some of which are substantial in size, which are being discussed but where major approvals have not been issued. Some of these are projects where an EIA is required and which would come before the NRCB. The Board would plan to assess these projects, if and when it receives applications, on a cumulative basis including a consideration of the decision on the Three Sisters Application. It therefore does not see the need to consider such projects as part of the base for its assessment of this Application.

There will likely be other future projects not yet approved where NRCB approval will not be required. The Board believes that the Town, the MD of Bighorn, or whatever the approval body is, should give consideration to such proposals on a cumulative basis having regard for facilities then in existence or approved. For this reason, the Board will not attempt to include recognition of such future projects in its assessment of the subject Application.

In summary, the Board will include in the base from which it assesses the cumulative effects of the Three Sisters Application:

- the existing Town and all existing developments and current users of the Bow Corridor in the vicinity of the proposed Three Sisters project; 
- the following approved projects, shown by the corresponding numbers on Figure 8-1, which can be reasonably expected to proceed along with the related growth in the Town and in the users of the area;

1. Golf Course C, an 18 hole golf course on the Three Sisters lands not subject to NRCB review;

2. a residential development on the Canmore 75 lands owned by Three Sisters but not subject to NRCB review, including about 62 single detached lots and 50 multi family lots;

3. the Canmore Alpine Development Company (CADCO) project, including 733 residential units, 800 staff housing units, an 18 hole golf course and a 503 room hotel (the remainder of the 500 hotel rooms are not yet approved);

4. the Alpine Resort Haven time-share resort with 38 chalets;

5. an 18 hole golf course at Kananaskis Guest Ranch;

6. a 119 unit hotel, a 60 unit hotel and a 40 unit apartment hotel, all on Highway $1 \mathrm{~A}$;

7. a 25 unit townhouse development on the benchlands;

8. a 12 unit condominium development in downtown Canmore;

9. a 130 unit townhouse development in the Cougar Creek subdivision;

10. a number of subdivisions for single detached and multi-family residences and for mobile home lots, with a total of over 800 units; and

11. a 30 thousand tonne per year sodium silicate glass plant near existing industrial operations in the Corridor.

As indicated previously, the Board will have regard for the above listed developments and related population and user impacts when assessing the Three Sisters Application. However, it must again recognize that the detailed information submitted by Three Sisters relates primarily to its proposed development on its own lands. Therefore, the Board acknowledges that the information available to it regarding the above listed projects is such that it can only include in a general way the effects of these future projects, along with the effects of existing developments in the area, in the base from which it will assess the Three Sisters Application. 


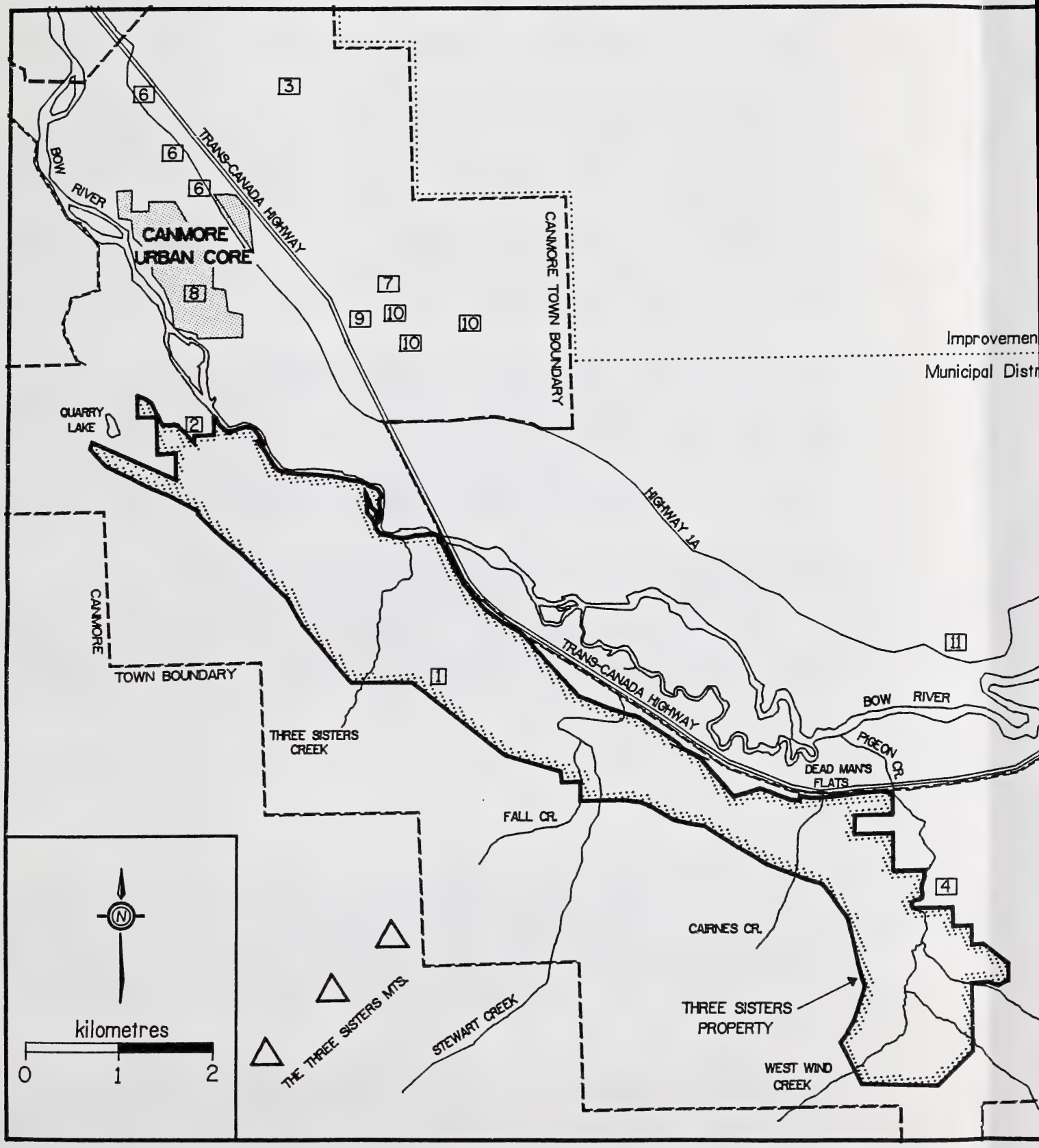


vement District No. 8

1) District of Bighorn No. 8

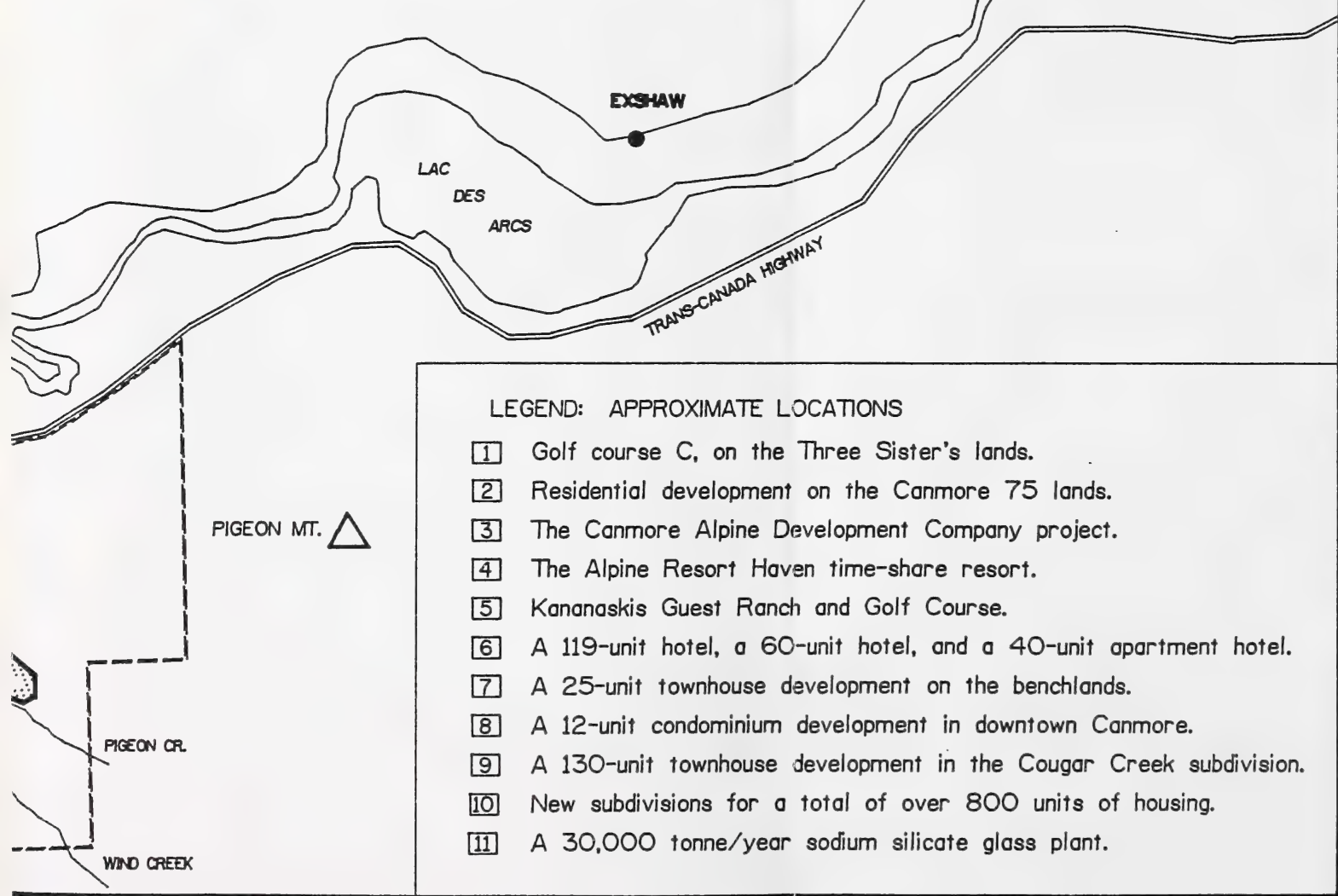




\section{GEOTECHNICAL HAZARDS TO DEVELOPMENT OF THE PROPOSED PROJECT}

\subsection{Types of Hazards}

There are four general types of foreseeable geotechnical hazards in respect of the Three Sisters project lands which must be addressed prior to development: undermining, the potential for underground fires, potential methane hazards and water related hazards. The hazards due to undermining are particularly significant, as nearly one-half of the project lands have been undermined. Underground fires, if ever ignited, could present an extreme hazard. Since the Canmore coal measures are quite gaseous, the potential for methane migration must also be viewed as significant. Water related hazards such as flooding, groundwater levels and icings are also geotechnical matters which warrant special consideration prior to development.

Evidence at the hearing indicated that to date no portion of the undermined Three Sisters lands had been studied enough from a geotechnical perspective to allow construction of buildings to proceed with confidence. The Applicant's experts have developed a four stage proofing program, and Stage Four was yet to be carried out on any part of the lands. Golf Course $\mathrm{C}$ has been studied more comprehensively than the remainder of the project lands, but as of the date of the hearing, final surface reconnaissance work had not been done on that site.

The Board notes that a Geotechnical Task Group, consisting of representatives from the Town of Canmore, Alberta Environment and the Energy Resources Conservation Board's (ERCB's) Coal Department, was created in June, 1992 to review background information on mining in the Canmore area and to identify certain types of hazards for the Town and Alberta Environment. This Group is expected to prepare a final report in the fall of 1992.

\section{$9.2 \quad$ Undermining}

\subsubsection{General Constraints}

The project lands were extensively undermined from 1886 to 1979 . Three Sisters indicated that there were roughly 10 coal seams which were mined although they had 16 different names. The main risk to development to be encountered on undermined areas on the Three Sisters property is the potential for settlement or subsidence over old underground mine workings. Another risk arises from openings at the surface such as adits, shafts or collapse areas.

The Applicant described three main zones for its property with respect to undermining risks. These zones consist of areas where there is no constraint to development, areas of medium constraint to development and areas of high constraint to development. In the medium constraint zone, the Applicant proposed that building would generally be allowed depending upon the economic viability of remedial geotechnical work. Medium constraint zones generally consist of all undermined lands which are not classified as high constraint zones. In areas of high constraint, i.e., where the potential for unstable ground is the highest, buildings 


\subsection{Types of Hazards}

There are four general types of foreseeable geotechnical hazards in respect of the Three Sisters project lands which must be addressed prior to development: undermining, the potential for underground fires, potential methane hazards and water related hazards. The hazards due to undermining are particularly significant, as nearly one-half of the project lands have been undermined. Underground fires, if ever ignited, could present an extreme hazard. Since the Canmore coal measures are quite gaseous, the potential for methane migration must also be viewed as significant. Water related hazards such as flooding, groundwater levels and icings are also geotechnical matters which warrant special consideration prior to development.

Evidence at the hearing indicated that to date no portion of the undermined Three Sisters lands had been studied enough from a geotechnical perspective to allow construction of buildings to proceed with confidence. The Applicant's experts have developed a four stage proofing program, and Stage Four was yet to be carried out on any part of the lands. Golf Course $C$ has been studied more comprehensively than the remainder of the project lands, but as of the date of the hearing, final surface reconnaissance work had not been done on that site.

The Board notes that a Geotechnical Task Group, consisting of representatives from the Town of Canmore, Alberta Environment and the Energy Resources Conservation Board's (ERCB's) Coal Department, was created in June, 1992 to review background information on mining in the Canmore area and to identify certain types of hazards for the Town and Alberta Environment. This Group is expected to prepare a final report in the fall of 1992.

\section{$9.2 \quad$ Undermining}

\subsubsection{General Constraints}

The project lands were extensively undermined from 1886 to 1979 . Three Sisters indicated that there were roughly 10 coal seams which were mined although they had 16 different names. The main risk to development to be encountered on undermined areas on the Three Sisters property is the potential for settlement or subsidence over old underground mine workings. Another risk arises from openings at the surface such as adits, shafts or collapse areas.

The Applicant described three main zones for its property with respect to undermining risks. These zones consist of areas where there is no constraint to development, areas of medium constraint to development and areas of high constraint to development. In the medium constraint zone, the Applicant proposed that building would generally be allowed depending upon the economic viability of remedial geotechnical work. Medium constraint zones generally consist of all undermined lands which are not classified as high constraint zones. In areas of high constraint, i.e., where the potential for unstable ground is the highest, buildings 
would generally be prohibited depending upon the economics of remedial geotechnical work. The proponent considered that for high constraint zones, golf course development was generally appropriate and that roads and utility services could be developed if satisfactory engineering reports were received beforehand.

In determining which zones were developable, the Applicant's experts took several criteria into account in preparing the constraint maps, including the type of mining operations utilized, the geological and mining conditions for the Canmore coal field and data on behaviour of strata and surface subsidence which has largely been developed in Europe and the United States.

In the four stage proofing program the Applicant's mining experts begin with information from mine maps and records on the location and depth of seams mined, the gradient of mined seams and the amount of coal extracted at various locations. They use a figure of $4 \mathrm{~m}$ for the average thickness of coal extracted, based on knowledge of usual mined thicknesses of coal measures in the area. From this information the experts assume certain heights of potential roof collapses above extracted seams and build in a safety factor of two. By multiplying the average seam thickness $(4 \mathrm{~m})$ by the determined collapse multiplier, then multiplying the result by the safety factor of two, a depth in $\mathrm{m}$ is obtained, which depth is taken to be the minimum depth from surface to mined seam necessary to establish acceptably safe building conditions at the surface. Put another way, if any mined seam were located closer to the surface than this depth figure, the area would be classified as a high constraint zone. As an example, for depillared areas the collapse multiplier used was seven; multiplying the seam thickness $(4 \mathrm{~m})$ by seven and then by two (the safety factor) produces a depth of $56 \mathrm{~m}$. Wherever the mine maps showed that a seam was depillared at a depth of $56 \mathrm{~m}$ or less, the surface would initially be classified as a high constraint zone, to be further examined and tested.

The constraint mapping methodology used by the Applicant received a great deal of attention at the hearing. Some participants suggested that relevant considerations such as width of tunnels, width:depth ratios, actual mined thicknesses and location of unmined coal seams had been ignored. Other criticisms related to the rationale for the use of the average seam thickness of $4 \mathrm{~m}$ and the size of the safety multipliers. Mr. Haimila in particular introduced evidence as to subsidence depths in other locales and parts of the world. The Board notes that the Town of Canmore was not comfortable with the parameter of a maximum extraction height of $4 \mathrm{~m}$ and felt that the high constraint zone could not be adequately defined today, based on drill tests suggesting that collapse zones could actually be higher than predicted by the Applicant's experts.

The Board accepts the fact that the geological characteristics of different mined areas will create differing subsidence patterns or propensities. Disagreements regarding the safety multipliers appear to the Board to centre on what the geology of the particular area implies in terms of competence of bearing strata above coal seams. The Board considers that the constraint mapping is in the early stages, that certain considerations such as unmined coal seam locations, width of tunnels, multiple seam mining, actual mined thicknesses and 
width:depth ratios should be taken into account, and that more work will be required to establish confidence that the local geological characteristics and subsidence patterns have been properly defined.

One of the main issues relating to the reliability of the constraint mapping approach is obviously the availability and completeness of mine maps. The ERCB has quite an extensive set of mine maps for the Canmore area, although other organizations such as the Town of Canmore and the Glenbow Museum were also mentioned as having data relevant to the mining history at Canmore. Evidence was brought forward that perhaps up to one-third of the maps for cross sections was missing, and the view was expressed by certain participants that the incompleteness of such base data as mine maps should cause a fundamental uneasiness with the entire constraint mapping process. However the Applicant's mining experts expressed the view that there exist maps of all the mining operations, some maps being more detailed than others depending upon the scale and upon the point in time they were prepared, and that the missing cross section maps could be reconstructed from the mine maps so that complete mapping was feasible. Where complete mine maps are available, the Board regards the Applicant's constraint mapping method as philosophically sound, and notes that with reference to the Canmore 75 area, the ground reconnaissance work had confirmed close correlation between the mine maps and surface subsidence features.

The influence of "complex geology" in the area was also discussed. "Complex geology" means that the rock strata are fractured or contorted to a significant degree. The relevance of complex geology is that where there is considerable folding and faulting of strata it is harder to establish hazard locations than where the seams are relatively flat and lying in unbroken planes. The Applicant's experts and certain other interveners appeared to disagree as to whether the geology was really all that complex in the area. The Applicant stated that if the mine maps are available, the geology is generally known and any uncertainty which may be associated with complex geology would be removed. However if an area did contain a considerable degree of folding or faulting it was acknowledged by the Applicant's experts that more ground truthing would be required for that location.

The Applicant's experts proposed a four stage proofing process to be undertaken prior to development. In summary, these stages are: Stage One, a desk top study based on mine records which results in tentative plans indicating high and medium constraint zones; Stage Two, involving ground truthing (drilling, trenching and site investigations); Stage Three, reporting on the results of the Stage Two ground truthing and modifying the preliminary constraint zones; and finally, Stage Four, additional ground truthing prior to construction based upon the results achieved up to that point. No area of the project lands had been proofed beyond Stage Three. The Applicant's experts stated that in 90 percent of the project lands under review only Stage One had been completed.

The Board accepts that constraint mapping is a prudent and necessary step and recommends to the Town that where the mine maps are incomplete, extra ground truthing be requested by way of drill testing, radar evaluation and other surface reconnaissance work. 
With regard to openings at the surface and the risk to public safety, the Applicant's experts believe that because of the competence of the strata surrounding the coal seams, because mining has not taken place for 13 years and since there were no calamities identified with building of the Spray Lakes road over an undermined area, most subsidence has already occurred and the land is generally stable. Certain participants, most notably Mr. Haimila and Mr. Steele, said that there was still a substantial risk of further subsidence on the undermined lands far into the future. The Applicant generally took the position that the risk of further subsidence in the future would be confined to areas above shallow steep workings, steep workings mined close to the bedrock surface, shallow flat depillared areas and shallow mine roadways, all of which would be included in its high constraint zones.

The Board recognizes that there is disagreement as to the boundaries of the high constraint areas and believes more work is necessary to clarify what areas can be expected to exhibit surface instability in the future and what areas are likely to be stable now or to stabilize in the near term. The Board notes the view of the Applicant that surface monitoring would likely take five years for the majority of the area using such techniques as survey monuments and routine measurement of subsidence, and assumes that five years would be a minimum, based on the differences in opinion expressed at the hearing on potential length of time for subsidence in the area.

Several mitigative measures were proposed by the Applicant for the high constraint zones. In respect of construction of golf courses, the Applicant's mining experts recommended drilling and blasting to fill cavities, injection of a gravel slurry or other material to stabilize the workings, or use of geotextile membranes on which to build the golf course. Other suggested mitigations involve sealing of openings with various degrees of work to be undertaken, from backfilling to rigid plugs, and fencing off of areas which could be a danger to the public such as shafts or cave-ins. The Board considers that the final ground truthing stage would establish which of these mitigative procedures would be appropriate for each area. The Board also believes that the four stage proofing program will provide the necessary planning advice as to the proper location of structures and facilities so that costs of mitigation may be minimized.

\subsubsection{Conclusions Regarding Undermining}

Three Sisters has taken an engineered approach to the mining hazards, i.e., that with proper expert study and design, development can occur above undermined areas. In contrast, some participants suggested that a no risk approach would be more appropriate. A no risk approach would likely allow no development on undermined land and would perhaps call for the creation of safety zones or setbacks from mined areas. Three Sisters felt that a no risk approach would be unreasonable, given the experience in Europe and elsewhere in the world of building structures over undermined areas, and would also have an undesirable effect on infrastructure costs due to the fact that over 400 ha would be undevelopable, causing significant "leapfrogging" of development from the Town's eastern boundary eastward to the closest 
unmined area. Three Sisters felt that for medium constraint zones and for limited development in high constraint zones (such as golf courses and utilities) the proposed four stage proofing program would result in sound engineering, which would allow for safe development. The Board concurs.

The Board's acceptance of the engineered approach is premised upon completion of a proofing program similar to that described by Three Sisters prior to commencing developments. The Board is of the opinion that this approach could benefit through the implementation by the Town of Canmore of recommendations of an Undermining Review Group regarding particular engineering solutions for the various undermined areas of the project lands. (Recommendations regarding an Undermining Review Group will follow in Section 9.2.3.)

The Board would condition any approval issued to prohibit development on any undermined lands until Stage Four of the ground truthing process has been completed and the Town is satisfied that acceptable engineering and design work has been done with regard to a site or a general area.

The Board notes with approval the commitment of Three Sisters to seek insurance for undermining risks at reasonable rates. The Board also notes the undertaking by Three Sisters to place caveats on the titles to undermined lands in order to alert subsequent landowners and their insurers to a potential geotechnical risk from undermining. The Board would recommend that the Town take steps to ensure that purchasers of lands are alerted to this risk.

It is unclear from the record whether the Applicant accepts full responsibility for the costs of preventative mitigation on undermined lands, i.e., the costs of bringing all the undermined lands to a safe state for general public access, or whether there are proposals being considered by Alberta Environment, the Town of Canmore and the Applicant for sharing of such costs.

The Board is primarily concerned with public safety on the undermined lands and notes that the issues of cost sharing and the public interest which may be associated therewith were not advanced fully enough before it to enable the Board to take a position. The Board considers that, as in many situations in which environmental remediation is needed, both private and public funds may be required to be expended.

\subsubsection{Proposed Undermining Review Group}

As indicated in the previous Section, the Board would prohibit development on the undermined project lands until a comprehensive assessment satisfactory to the Town of Canmore has been undertaken.

The Board recommends that the Town take the initiative in the creation of an Undermining Review Group to oversee such a program and advise the Town. The Group would 
consist of the mining experts retained by the Applicant, the mining experts retained by the Town, a representative from the Town, a representative from the ERCB and a representative from the public. The Board has confidence in the calibre of expertise presented at the hearing and would expect the continued participation by this level of experts. The Board also considers that it was fortunate to have received evidence from individuals who have personal knowledge of the Canmore mines, such as Messrs. Stephenson and Haimila, and assumes the Undermining Review Group would make use of such expertise. The purpose of the Undermining Review Group would be to oversee the four stage proofing program as proposed by Three Sisters, with such modifications as the Group may consider appropriate. For example, the Board would expect the Undermining Review Group to refine the constraint mapping parameters, including collapse multipliers, and to recommend the testing programs which should be undertaken as part of the ground truthing process.

The constraint maps and the reports of the Undermining Review Group should be made available to the Town of Canmore, the ERCB, Alberta Environment and the public prior to the final decisions by the Town respecting development of undermined areas. The Board would expect the Applicant and the Town to fund the participation of their respective experts, and that the costs of public participation in this group would be jointly funded by the developer, the Town and the ERCB. The Board believes the Undermining Review Group should be part of the regional planning and monitoring initiative which is described in Section 12 of this Decision Report.

The Board would recommend that Alberta Environment have regard for advice from the Undermining Review Group as to measures which could or should be undertaken to ensure safe development and public safety on any undermined provincial lands adjacent to the Town.

The Board is confident that the report of the Geotechnical Task Group will be of great assistance to the work of the Undermining Review Group. Also of assistance to the Group will be the procedures developed by the Town in approving the development of Golf Course C.

9.3

Underground Fires

With regard to the risk of underground fires, the danger of spontaneous combustion was felt to be very low because of the characteristics of the coal and the fact that there have been no recorded events of spontaneous combustion in nearly 100 years of mining at Canmore. This evidence was not seriously challenged. There have apparently been instances of ignition of methane underground from lightning striking steel rails and from sparks from machinery. The potential for methane ignition by sparks caused from falling rocks was felt by the Applicant's experts to be low, and the Board finds this position credible. A greater hazard was seen to be inadvertent ignition of underground coal seams by the public through burning of garbage or location of recreational fires near coal seam outcroppings. 
The danger of an underground mine fire is extreme once it is started because it is very difficult to extinguish. The Board believes that there are extensive coal seam outcroppings on the project lands, of varying sizes and degrees of accessibility. Some outcroppings will be covered by overburden or topsoil during development. Others will remain exposed. The Board recommends that the Town of Canmore address safeguards in respect of underground fires during the ongoing approval process. Possible measures which could be required by the Town would include prohibiting the location of garbage dumps near coal seam outcroppings, placing signs near outcroppings which would prohibit open fires and distributing pamphlets or information to property owners and visitors to the area educating them regarding the risk of underground fires.

9.4

Potential Methane Problems

The Board heard evidence that the Canmore coal measures contain a large amount of methane gas. Methane can be highly explosive when mixed with the proper amount of air. The evidence indicates that methane migrates easily from dry coal seams with the characteristics of the Canmore coals, up through man made openings or natural cracks and fissures and eventually dissipates into the atmosphere. The Board was informed that such migration can lead to methane collecting in rock strata overlying the coal seams or, more importantly, in the basements of buildings which are constructed over coal seams, whether such seams are mined or unmined. If a certain amount of methane accumulates in basements an electrical spark or a furnace pilot light may cause an explosion.

Evidence at the hearing suggested that where coal seams have been mined the methane generally escapes more rapidly to the surface through tunnels and openings than where the seams exist in their natural state. It was also stated that coal seams exist under a significant proportion of the entire Three Sisters property in mined, partially mined and unmined states. Where coal seams are exposed to the surface, methane would have been migrating to the surface for a great many years. Above mined seams methane would have been migrating into the atmosphere for many years and may at this point have largely dissipated from dry coal seams in mined areas, provided that the methane has had the opportunity to escape to the surface through openings or fissures. However, if the permeability of overlying strata is low and fissures leading to the surface have not formed, methane may have accumulated and remain at present in underground voids.

If coal seams are flooded, either in underground mine workings which have filled with water or in seams existing below the water table, the methane remains largely trapped and has difficulty migrating out of the coal seam. The AWA Group challenged the notion that water pressure keeps methane from escaping. The Board has carefully considered the evidence before it on this issue and believes that water pressure does keep methane largely trapped in coal seams, although some small amount of gas may escape through water and migrate to the surface. The Board considers that dewatering of coal seams by natural fluctuations in the level of the water table will allow methane to escape under ordinary conditions, and that in an unseasonably dry 
year the water table may drop more dramatically than usual and allow larger quantities of methane to escape to the surface. To minimize the possibility of methane release from coal seams, the Board would not allow the withdrawal of minewater for use in the proposed project, except for monitoring purposes or emergencies such as fires.

The Board believes that the risk of methane seepage into buildings is sufficient that proper engineering and design work will have to be done prior to construction on any lands which are underlain by coal measures, whether mined or unmined, to ensure that methane seepage into buildings does not present a hazard. The Board recommends that the Town of Canmore review the advice it receives from the Geotechnical Task Group and/or the recommended Undermining Review Group regarding necessary engineering methods in various areas to safeguard against methane seepage into buildings, and that the Town require appropriate safeguards to be utilized, for example through development agreements, conditions to development permits or by-laws. The Board further recommends that the Town ensure that steps be taken to inform any prospective purchasers of buildings or lots in these areas that there is some degree of risk regarding the possible accumulation of methane from the coal seams.

\section{Water Related Hazards}

The major water related hazards to development are seen by the Board to be flooding, shallow groundwater in alluvial materials and icings.

In respect of flooding, Three Sisters developed 1:100 year floodplain maps for all of the creeks within the project lands and for the Bow River where it is adjacent to the lands. Based on the evaluation by the Applicant's engineering consultants, it appears that there is only limited potential for flooding on the Three Sisters property in a 1:100 year flood event. This is partly due to relatively steep channels which appear capable of containing excess water, particularly in the Pigeon Creek watershed in the Wind Valley. Around Three Sisters Creek where it enters the project lands there appears to be some risk of flooding in a 1:100 year event, but a greater risk for blockage by debris in this location, which blockage could cause the creek to change course and significantly damage adjacent property.

The alternatives available to mitigate against flooding and potential erosion accompanying flooding are dykings and rip-rap or other armouring of banks in areas where trees and brush would be removed along reaches of water courses. The Applicant proposed that in housing development areas close to creeks, dyking would be installed to an elevation of at least one $\mathrm{m}$ above natural ground level and that the stream side shoulder of the dykes would be lined with armouring to protect against erosion. The dykes were proposed to be offset at least $30 \mathrm{~m}$ from the creek centre line. If possible the dykes would serve as access roads to the development.

During development, vegetation would be removed along some creek banks both in residential and golf course developments. The Applicant proposed to use natural stones to 


\section{9-9}

stabilize such regions to prevent scouring and debris jams downstream. The Applicant also stated that the channels would be made to look as natural as possible and that geotechnical membranes would be used to stabilize the banks and allow revegetation as rapidly as possible. The Applicant stated that risk due to debris flow could be reduced by clearing deadfall from all creeks on an annual basis.

The CRPC indicated that it knew three areas on the project lands where flooding would be of concern: the Bow River, Stewart Creek and Pigeon Creek areas. The CRPC indicated that the Bow River will be reviewed in 1992 as part of the Canada-Alberta Flood Damage Reduction Program, which will determine areas of flood risk. Such determinations will assist the Town in its development approval process. However this exercise will not include Stewart Creek and the Pigeon Creek watershed. The CRPC is of the opinion that monitoring in order to keep watersheds free of debris would be very important because log jams onsite or offsite of the project lands could create flooding problems in developed areas.

The Board believes that the proposed dyking, armouring of banks, elevation of golf course greens and tees and continual monitoring and removal of debris are all measures which should be used on the property to prevent flood damage. The Board assumes that the Town, as part of the planning process, would develop adequate flood prevention measures such as zoning to prohibit development in the 1:100 year flood plain, requirements for dyking where needed along the Bow River, Stewart Creek and Three Sisters Creek areas, armouring of stream banks and debris removal.

Much of the soil on the Three Sisters site is alluvial material originating from erosion of the mountains. There is a potential for soil instability in some areas, particularly where the water table is high. The Board considers that testing will be necessary to determine the ordinary water table levels in alluvial material and that specific construction measures may be required for certain areas where the water table is high. The Board would expect areas of shallow groundwater to be located near the Bow River. The Board recommends to the Town that the ongoing approval process include provision for ground water testing to establish whether foundations can be safely laid in areas where the water table is high.

Icings, being groundwater seepages that freeze in the winter, occur on the Three Sisters property. Icings can create a hazard to structures near them such as roadways or buildings. Evidence before the Board indicated that icings were few on the property and were not likely to become a risk to human activity or property. The Board accepts this evidence.

The Board considers that none of the water related hazards discussed herein is serious enough to preclude development if proper engineering work is undertaken. 
Introduction

The Board heard evidence about the possible effects of the proposed project and the possible cumulative effects of existing and approved development in the region on southern Rocky Mountain ecosystems and their components. The terrestrial ecosystems that may be affected were referred to as the alpine, subalpine and montane ecosystems, distinguished largely by elevation; the aquatic ecosystem likely to be most affected consists of the Bow River and its tributaries and the airsheds of concern are those of the Bow Valley and Wind Valley.

Although the Board heard evidence about potential effects at the ecosystem scale, it also heard in much greater detail about possible effects on ecosystem components. Many of these effects would be site specific. Because of the interdependence of ecosystem components and the scale of the areas occupied by ecosystems, the Board believes that the potential impact of a project cannot be understood by attending only to local effects on individual components. The Board also believes that because of the likelihood of additive or synergistic effects of developments it is important to examine the effects of any one project in a cumulative and a regional context.

The Board believes that it is also important to recognize that ecosystems are dynamic rather than static. An understanding of the processes and rates of change that they exhibit under natural conditions would be useful in assessing impacts of development, but a knowledge of how they are changing under the impact of existing developments would be particularly instructive. The essentially permanent nature of the proposed development means that it would be present throughout the entire duration of the cyclic variation common to temperate, boreal and arctic/alpine ecosystems. Long term non-cyclic changes are also possible.

Three Sisters and several interveners presented evidence to the Board that the Wind Valley and Bow Valley portions of the area to be occupied by the proposed project are different. Wind Valley is, and has been, less disturbed than the Bow Valley portion of Three Sisters' lands, in that it differs in its physical environment and supports a greater number of species. Some of the species living in Wind Valley but not in the Bow Valley are endangered, threatened or otherwise thought to be of particular value by biologists, naturalists, residents and tourists. Because of the distinction made by many participants in the hearing between the two parts of the area proposed for development, the Board examined the potential effects of development in each part of the area as well as in the whole. The approximate boundary between the Wind Valley and Bow Valley parts of the project area is discussed in Section 1 and shown on Figure 1-3.

With these considerations in mind, the Board intends to review environmental matters by first identifying what resources may be at risk if the project goes ahead. This will include a consideration of the Wind Valley and Bow Valley parts of the project and of the distinction between them at the ecosystem scale. The Board will then review the possible effects of the proposed project, first at a broad ecosystem level and then more specifically for individual 
ecosystem components. Differences between possible effects of the Wind Valley and Bow Valley parts of the project will be identified. In reaching conclusions about the magnitude of each potential effect, the Board will take into account possible measures to avoid, mitigate or compensate for it. The Board will proceed from such conclusions to develop, where appropriate, conditions necessary to ensure that, if approved, any potentially undesirable effects of the project would not be unacceptable. Finally the Board will assess the probable total net effect of the Wind Valley and Bow Valley parts of the project, and of the complete project as proposed, assuming that measures to avoid, mitigate or compensate for impacts which are required by the Board or were undertaken by the Applicant would be applied and the Board's conditions adhered to. This overall conclusion will be used, together with conclusions about social and economic effects, in assessing whether or not the project, or any part of it, is in the public interest.

10.2 Air

The reason for examining potential effects of the proposed project on air is that emissions of atmospheric pollutants in the Bow and Wind Valleys would increase if the project were built. Hotels, residences, commercial buildings and motor vehicles would all contribute to the increased emissions. During stagnant atmospheric conditions, when there is little air movement, concentrations of pollutants in air might reach unacceptable levels. Unacceptable levels are defined by regulators such as Alberta Environment as those above which there may be risks to human health, or, in the case of some pollutants, to the environment. Such risks may be immediate or short term, for example when people are subjected to high exposures of gaseous pollutants, especially if they suffer from respiratory ailments, or long term, for example when people are repeatedly exposed to pollutants at lower concentrations. A specific example might be long term exposure to PAH present in soot particles produced by incomplete combustion.

The Applicant's approach to assessing effects on air quality was that commonly practised in environmental assessment. Three Sisters prepared an inventory of sources of emissions in the area, estimated what future emissions would be if the project were to go ahead, and used a model to predict ambient concentrations at ground level under various weather conditions. Interveners offered a number of criticisms of the comprehensiveness of the source inventory and the choice of model used. They suggested that the predicted future concentrations of atmospheric pollutants may be somewhat low. Whether or not this is the case, the Applicant did predict that under some circumstances the ambient concentrations of some pollutants could exceed Alberta standards. In the Board's opinion, what is important is that steps should be taken to avoid such exceedances and to curtail them if they do occur. These steps would have to involve control of emissions at their sources.

Four types of emission sources were discussed in the evidence before the Board: industrial, construction, motor vehicle and residential. The proposed project does not involve any industrial development. It would include commercial development in the form of buildings for retail and personal service businesses. Emissions from commercial facilities would be from 
combustion of natural gas in furnaces and can be included with similar residential emissions for the purposes of assessment. The quantity of domestic emissions would be the greater of the two if the project were to be approved.

The Applicant undertook to control the raising of dust during construction by watering dry ground surfaces. Other emissions to the atmosphere during construction would be in the form of exhaust from equipment and motor vehicles. Local motor vehicle traffic and traffic on nearby sections of the Trans-Canada Highway would be increased if the project were to go ahead and exhaust emissions would increase as a result. Some of the exceedances predicted by the Applicant were of oxides of nitrogen $\left(\mathrm{NO}_{x}\right)$ when expressed as nitrogen dioxide $\left(\mathrm{NO}_{2}\right)$ at certain locations along the Trans-Canada Highway. In fact the Applicant's modelling suggested that, under some weather conditions, exceedances may already be occurring at some of those locations. However, the Applicant also pointed out that ambient air quality standards specifically refer to $\mathrm{NO}_{2}$ and that $\mathrm{NO}_{2}$ would normally be expected to constitute about one-half of the total $\mathrm{NO}_{\mathrm{x}}$. On this basis, predicted $\mathrm{NO}_{2}$ concentrations would not exceed ambient standards. The Applicant predicted no exceedances within the proposed development area arising from the operation of construction equipment or from other proposed sources within the project area. These predictions were not challenged.

Three Sisters suggested that little can be done to reduce $\mathrm{NO}_{\mathrm{x}}$ emissions from motor vehicles except by improvement of emission control equipment, engine design and fuel formulations and through detailed road design. Vehicle improvements are beyond the scope of the Application and the power of the Applicant. Roads would be designed by Three Sisters in accordance with the Town's guidelines. The Board agrees that Three Sisters is not in a position to influence motor vehicle design but recommends that it take into account the desirability of reducing $\mathrm{NO}_{\mathrm{x}}$ emissions when designing roads in the project.

Three Sisters also predicted that construction and operation of the proposed project could lead to exceedances of Alberta standards for concentrations of suspended particulates with associated PAH in air at ground level during stagnant air conditions. The principal source of these pollutants would be domestic wood burning stoves, although there could be contributions from other sources where combustion is not complete such as faulty gas furnaces, poorly tuned motor vehicles and, as one intervener suggested, camp fires. The Board believes that the contribution of these secondary sources to air pollution would be insignificant, but measures to reduce and control emissions from wood burning stoves would be desirable to limit the frequency and duration of exceedances of Alberta standards and to reduce health risks.

The Applicant suggested that the use of direct air intake fireplaces for burning wood would reduce emissions below those that would be expected from other types of fireplaces or wood stoves by increasing the efficiency of combustion. Burning only natural gas and not wood would be even more effective. Given the climate of Canmore, residences would have to have gas or oil fired heating if wood burning were not allowed at certain times. The Board understands that provision of natural gas service to building lots is a common requirement in subdivision development agreements in Alberta. The Board also heard evidence about measures 
taken to control emissions in Whitehorse, Cranbrook, Vail, Colorado, the Puget Sound area of Washington State and Juneau, Alaska. Several participants recommended curtailment of wood burning during weather conditions conducive to the increase of pollutant concentrations in local airsheds.

If the project, or part of it, were to be approved, the Board would recommend that the Town impose an architectural control or by-law to ensure that direct air intake fireplaces be the only wood burning equipment allowed in residences built within the project area. In addition, the Board would recommend that the Town consider introducing a by-law that would allow it to curtail wood burning during periods when air in the Bow or Wind Valleys is likely to be stagnant.

The question of whether or not the Wind Valley and Bow Valley constitute distinct airsheds was a subject of contention at the hearing. In the Board's view the evidence on this matter was inconclusive. Of more practical significance were the questions of whether air in Wind Valley might remain stagnant when air in the Bow Valley is flushing through and whether upslope air movement into Wind Valley might carry pollutants which could become trapped there. Again no conclusive evidence was available on either question but Three Sisters' evidence suggested that the Trans-Canada Highway, which is the principal source of $\mathrm{NO}_{\mathrm{x}}$ emissions, is too far from the entrance to Wind Valley to support the view that $\mathrm{NO}_{2}$ exceedances might occur there. On the other hand, if either of the phenomena do occur, they could result in higher concentrations of suspended particulates and PAH in Wind Valley than would otherwise be the case. In either case, the Board believes that the measures it has recommended above would still be sufficient to ameliorate air pollution episodes to an acceptable level.

In distinguishing between the effects on air quality of different components of the proposed development, it is self evident that there would be relationships between both type and quantity of development and expected quantity of emissions. Of the pollutants that could rise, on occasion, to concentrations above Alberta standards, $\mathrm{NO}_{2}$ concentrations would be directly related to traffic volumes and hence more or less directly to the number of residents. As discussed earlier, $\mathrm{NO}_{\mathrm{x}}$ emissions are not likely to be a problem within the project area assuming appropriate road design. Suspended particulate and PAH concentrations would be affected more by private residences than by hotels or commercial establishments. If the air in Wind Valley were to remain stagnant for a long period, and if it were to contain some 1,500 residences as proposed by the Applicant, there could be a potential for higher concentrations of these pollutants there than elsewhere because of the relatively small volume of air in Wind Valley. Nevertheless, the Board believes that this eventuality could be avoided by prudent application of its recommendations with respect to the type of wood burning equipment installed in houses on the property and control of its use. 
10.3 Aquatic Ecosystem

There are a number of ways in which the proposed project could affect water. Water would be used primarily for domestic purposes and for golf course irrigation. Water withdrawal for the project could affect other water users if supply is short and it could affect organisms dependent on water if streamflows are significantly reduced. The project could also result in increased flow of wastewater from the Town and increased input of chemicals and suspended sediment to waterbodies. If input quantities were sufficiently large, downstream water users and aquatic biota could be affected. This Section of the Decision Report deals with these possible effects.

\subsubsection{The Bow River Ecosystem}

All surface and shallow groundwater draining from the Three Sisters property reaches the Bow River, including groundwater moving through the abandoned coal mine workings. The water on the site and the organisms which live in it form a part of the Bow River ecosystem. The Bow River rises west of the site and flows eastward through the Towns of Banff and Canmore before passing along the north boundary of the project area. Both Towns discharge wastewater into the river. The flow of wastewater entering the Bow River from the Town of Banff amounts to $3,650,000 \mathrm{~m}^{3} /$ year and the flow from the Town of Canmore amounts to $1,840,000 \mathrm{~m}^{3} /$ year, both discharging on a continuous basis. In Banff National Park, there may be discharges from Lake Louise, Mount Norquay and Tunnel Mountain. Entering the Bow River east of Canmore is the Kananaskis tributary which receives effluent from the Evan Thomas treatment plant and a lagoon at Barrier Lake. The Banff wastewater treatment plant incorporates tertiary treatment followed by ultraviolet disinfection. The Canmore plant consists of a rotary biological contactor followed by primary and secondary settling with no disinfection prior to discharge. A new plant is currently in the planning stage that would include nutrient removal and disinfection. Three Sisters said that it favoured such a tertiary treatment plant.

The City of Calgary is some $125 \mathrm{~km}$ downstream of the property. In that $125 \mathrm{~km}$ reach of the river there are four hydroelectric dams and a number of sources of chemical input to the river. Immediately to the north of the eastern end of the Three Sisters' property, effluent to the Bow River from the hamlet of Dead Man's Flats amounts to $64,600 \mathrm{~m}^{3} /$ year discharged on a continuous basis. This effluent arises from an aerated two cell lagoon system with a one month retention time. The Applicant proposed that this facility would be replaced in conjunction with construction of its project by a tertiary treatment system incorporating ozonation of the effluent. Further municipal discharges downstream enter the river from Exshaw $(66,800$ $\mathrm{m}^{3} /$ year), Seebe $\left(9,100 \mathrm{~m}^{3} /\right.$ year $)$ and Cochrane $\left(701,000 \mathrm{~m}^{3} /\right.$ year $)$. The Exshaw system consists of a two cell aerated lagoon with about a one month retention and continuous discharge, the Seebe system consists of a two cell lined lagoon with a less than annual discharge frequency and the Cochrane plant consists of a three cell aerated lagoon followed by disinfection, with consideration of piping sewage to Calgary at a later date. In addition to this, at the Stoney Indian Reserve at Morley there is an aerated lagoon. Agricultural discharges are of primary 
concern in the Jumping Pound area where there is considerable discharge from two intensive livestock operations.

In Banff National Park, the potable water supply originates from groundwater. The Town of Canmore obtains water from two sources, a surface supply from Spray lakes treated by direct filtration and groundwater obtained via a well at Policeman's Creek. Both Dead Man's Flats and Exshaw receive their water from wells. Seebe, which is a private system, receives its water from an infiltration gallery with disinfection as treatment. Cochrane utilizes an infiltration gallery with subsequent coagulation/filtration/disinfection. The Stoney Indian Reserve also uses water from the Bow River system. Calgary draws about $225,000 \mathrm{~m}^{3} /$ day from the Bow River via the Bearspaw plant and an average of $199,000 \mathrm{~m}^{3} /$ day from the Elbow River via the Glenmore plant. The Bearspaw treatment plant consists of flocculation, sedimentation, filtration with a polyelectrolyte filter aid, fluoridation, and disinfection. Total licensed water withdrawals from the Bow River between Canmore and Calgary are 295,000 acre-feet per year of which over 98 percent is for municipal use.

The Bow Valley part of the proposed project area crosses the drainage basins of five steeply sloping creeks which are, from west to east, an unnamed creek, Three Sisters Creek, Fall Creek, Stewart Creek, and Cairnes Creek. The combined drainage area for these streams is approximately $24 \mathrm{~km}^{2}$. Water flowing in Three Sisters Creek and Stewart Creek enters the alluvium in their lower reaches except during spring freshet when surface flow reaches the Bow River. The Bow Valley portion of the project touches the west bank of Pigeon Creek in one short reach below the waterfall and extends across the Pigeon Creek drainage in the upper reaches immediately north of the mouth of Wind Valley. The smaller creeks in the Bow Valley part of the project area are ephemeral throughout their lengths. Wind Valley is drained by the relatively shallow sloped Pigeon Creek and its tributaries Wind and West Wind Creeks. Their combined drainage basin comprises an area of $57 \mathrm{~km}^{2}$. Surface flows in these creeks are year round.

There are two drainages from mine adits on the property. A small wetland has formed around a drainage at the Wilson No. 3 mine site. Water flowing from the other drainage at the mine tipple site flows into a small pond and then into the Bow River. It is believed that some of this water comes from Stewart Creek via groundwater recharge. Other surface waters near the property include the man made Quarry Lake immediately to the west of the Three Sisters property and two small ponds to the north, between the property boundary and the TransCanada Highway.

Surface waters from the property drain either directly through shallow groundwater or through abandoned mine workings into the Bow River. Shallow groundwater is recharged by drainage of surface flows or precipitation into the alluvial fans which cover a large portion of the project area. Some drainage water reaches the abandoned mine workings most of which are submerged. There is some groundwater discharge at higher elevations, for example in Wind Valley where a relatively large fen is groundwater fed. Groundwater discharges at many points near and in the braided channels of the Bow River. It is the relatively 
warm groundwater that maintains open water conditions in some of these channels during winter. Information is lacking about the flow of deep groundwater. Three Sisters suggested that while shallow groundwater in coarse alluvium can flow towards the Bow River, the angle of repose of the underlying rock strata is such that deep groundwater could flow away from the river. It also noted that rates of flow in deep groundwater are likely to be much less than those in shallow groundwater which is therefore of greater interest in assessing or monitoring potential impacts. The Board accepts this reasoning.

The ponds, fens and creeks on the property and the Bow River provide a variety of aquatic and semi-aquatic habitats for algae, aquatic plants, invertebrates and vertebrates including fish and amphibians. An electroshocking survey of the major creeks conducted by Three Sisters did not find any fish in Three Sisters and Stewart Creeks, and they are absent from the intermittent Cairnes and unnamed creeks. Brook and brown trout and mountain whitefish were found in the lower reaches of Pigeon Creek, below a $10 \mathrm{~m}$ waterfall. The relatively warm water upwelling in sidechannels of the Bow River provides a significant area for trout. The long-toed salamander is known to occur in Quarry Lake which is not on the property but may receive water draining from it.

In the Board's view, the Bow River, its tributaries, and surface and groundwater that flow in to them are appropriately considered as a single ecosystem. The Alberta Government recognized this when it established the Bow River Water Quality Task Force to examine water quality within it. The report of the Task Force was introduced into evidence by the Applicant and by interveners at the hearing. With respect to differences between the Bow and Wind Valley parts of the proposed project area, the Board believes that broad scale impacts of the proposed project on water quality in the Bow River would probably not differ significantly with the distribution of development within the Applicant's property but they would vary with the amount of development. Similar arguments apply to water supply because water used by the project would ultimately be returned to the river. Potential for effects on aquatic biota in lower Pigeon Creek would depend on whether or not there is development in Wind Valley. This matter is dealt with in Section 10.3.5.

\subsubsection{Water Supply}

Three Sisters provided estimates of the volumes of water that would be required for domestic use and golf course irrigation at full build-out and noted that irrigation would normally occur during the months of May through September only. The estimates were not challenged by other participants and appear reasonable to the Board.

The Applicant said that water for domestic purposes would be taken from the Canmore municipal supply and from groundwater wells at Dead Man's Flats. It had also considered a number of sources of water for irrigation: the Town municipal water supply from Spray Lakes; groundwater wells at Dead Man's Flats currently supplying water to that 
community; creeks on the property including Stewart, Three Sisters, Wind and West Wind; groundwater in or draining from old mine workings; and treated greywater from existing and future wastewater treatment plants. It appeared that only the first two were considered as sources of drinking water. Three Sisters stated that decisions had not yet been made about what volumes of water would be taken from what sources and that final decisions about water withdrawals would be made by the Town. The Board accepts that it is reasonable to delay detailed decisions about water withdrawals until there is greater certainty about the quantity, type, location and timing of demand. However, interveners raised a number of concerns about water withdrawals and potential water sources that can be addressed now.. By addressing them it may be possible to reduce the acceptable alternatives to a more manageable number.

The Applicant provided evidence that total water withdrawals for the proposed project could result in a maximum reduction in flow of the Bow River of less than one percent at any time and argued that such a reduction would have no significant effect on downstream users or on organisms living in the river downstream of the project. The Board accepts this conclusion and also notes that, in addition to approval by the Town, Three Sisters would have to obtain licences from Alberta Environment to permit it to withdraw water. Alberta Environment would have to be satisfied that existing water users would not be significantly adversely affected before it would issue those licences.

Three Sisters reported that it is already taking water from Stewart Creek under a water licence for use on Golf Course $C$ which is not subject to the Board's review. It suggested that it might also take water for irrigation from Three Sisters and Pigeon Creeks, but conceded that taking water from Pigeon Creek may be unwise because of the fish habitat in the lower reaches. The Board has considered the evidence and concluded that there is insufficient reason to object to the taking of water from either Stewart or Three Sisters Creeks. The Board deals with Pigeon Creek in Section 10.3.3.

Although Three Sisters had initially considered using minewater from wells for irrigation, by the time of the hearing it had come to the conclusion that this would not be advisable. One of the reasons mentioned was doubt about the quality of most of the minewater. In addition, withdrawal of minewater could bring about greater changes in minewater levels than the seasonal changes now occurring. This could, in turn, affect the potential for both terrain subsidence and the release of methane adsorbed on coal. However, the water flowing from mine workings to the surface at the tipple site is of good quality and is running directly into the Bow River. The Board would require that water not be withdrawn from wells accessing minewater except for monitoring purposes or emergencies such as fires but would have no objection to the use of water for irrigation from the discharge to the surface at the tipple site.

Another source of water for golf course irrigation that is under consideration by Three Sisters is greywater from the existing Canmore and proposed Dead Man's Flats wastewater treatment plants. Greywater of the quality safe for use in irrigation is normally from plants applying secondary treatment. At Canmore, the greywater would have to be disinfected with ozone to remove Giardia and other pathogens before it could be used. If the proposed 
upgrading of the Canmore plant were to provide tertiary treatment and the proposed new Dead Man's Flats plant were to do the same, the effluent would not be particularly useful for irrigation. Tertiary treatment is designed to remove nutrients such as nitrates and phosphates so there would be no point in incurring the cost of providing additional piping to carry the tertiary treated water from the plants to the golf courses if water from other sources were more readily available. It would be possible to intercept water at the nutrient rich secondary treatment level, but discharge of tertiary treated waters would be preferable for reasons of public health if tertiary treatment were available. Use of greywater for irrigation is often proposed as a way of reducing the use of fertilizers while avoiding the discharge of nutrient rich water directly to the river. If tertiary treatment of wastewater is available this potential benefit disappears and direct application of fertilizers is at an advantage because time and quantity of application can be precisely controlled and addition of unwanted pollutants such as common inorganic salts can be avoided.

The Board does not have any a priori objection to the use of disinfected greywater for golf course irrigation. However, the Applicant has proposed and the Board has recommended in Section 10.3.4.4 of this Decision Report the use of tertiary treatment at both Canmore and Dead Man's Flats. The Board assumes that its recommendation would be adopted. If this were the case, greywater irrigation would probably not be attempted.

Three Sisters said that all of the demand for water for the proposed project could be met from existing municipal supplies at Canmore and Dead Man's Flats. Some interveners expressed concern that the additional demand would exceed the supply, but the Applicant said that supplies would be adequate if proposed upgrading of facilities at the Spray Lakes reservoir and Dead Man's Flats were implemented. Three Sisters also said that the Town was in favour of constructing a water supply loop connecting both municipal sources. The Board heard no evidence to contradict these statements by the Applicant and believes that water supplies from municipal sources would be adequate for the project.

\subsubsection{Water Flows}

Participants agreed that construction of the proposed project would also alter the hydrological characteristics of the site. The replacement of part of the present ground surface by roofed and paved areas would increase the rapidity of runoff during and after precipitation, raising peak flows and shortening their duration. Diversion of this water to a storm sewer system could reduce groundwater recharge in some areas and, consequentially, reduce groundwater discharge in others. The contouring of golf course fairways to direct drainage away from creeks and fairway edges and into storage ponds could reduce streamflow in some areas. Whether or not it would reduce groundwater recharge would depend on the permeability of the materials below the fairways. Golf course irrigation could increase groundwater recharge, but if Three Sisters uses monitoring of subsurface moisture to control irrigation, the increase might be minimal. Finally, taking water from creeks on the site for irrigation purposes would 


\section{$10-10$}

reduce streamflow but would not increase groundwater flow by the same amount because evaporation and transpiration would increase on irrigated land.

Interveners were concerned that these changes in hydrology could adversely affect aquatic biota including fish in creeks on the site and in the Bow River and vegetation growing in areas where groundwater discharges at or close to the surface. Of particular concern were fish resident in the reach of Pigeon Creek below the waterfall, fish spawning in backchannels of the Bow River fed by groundwater from the project area, and vegetation on seepage areas at the toes of alluvial fans.

Three Sisters stated that it would not take water from Pigeon Creek or its tributaries. In the Board's opinion, this would reduce the risk of adverse effects of reduced streamflows on fish downstream of the waterfall to an acceptable level and the Board would require it as a condition of any approval. As there is no evidence that the other creeks on the property support fish, the Board does not believe that changes in flow in the creeks themselves would have unacceptable consequences.

Some interveners suggested that groundwater flows'could be reduced sufficiently to affect fish habitat in the backchannels of the Bow either by exposing gravel beds or because lack of relatively warm groundwater inflow would allow channels to freeze up in winter. Dr. R. Crowther, on behalf of the Applicant, was of the opinion that groundwater discharge into the Bow River channel known as "D" creek, which is downgradient of Stewart Creek, could be affected by withdrawals of water for irrigation from that creek. Withdrawals for irrigation could occur from May to September. The Applicant provided evidence of redd counts for brown trout in the Bow Corridor and Banff National Park. "D" creek accounted for 3.3 percent of the counted redds in 1988 and 7.96 percent in 1989. Dr. Crowther considered the likelihood that groundwater discharge into other back channels would be significantly affected to be very small.

Although the Board would not object to the taking of water from Stewart or Three Sisters Creeks, there is a risk that groundwater flows could be reduced and that their reduction could affect fish. The Board has defined requirements to manage this risk in Section 10.3.4.5. Should it be evident that fish habitat or fish are threatened, the Board is confident that Alberta Forestry, Lands and Wildlife would require Three Sisters to implement remedial action. These

might include directing some clean storm drainage into groundwater recharge areas and replacing some withdrawal of water from the ephemeral creeks by water taken from municipal supplies.

10.3.4 Water Quality

10.3.4.1 Mine Drainage Water

Concern was expressed at the hearing that existing mine drainage water could acidify when released into surface water with consequent adverse effects on surface water quality and aquatic organisms. It was also suggested that sulphate ions in such acid water could be 
reduced by bacterial action to sulphide which could be given off as hydrogen sulphide gas. It was further suggested that hydrogen sulphide may collect in depressions in the ground and, in still air, reach concentrations that could be hazardous to animals or people.

Some interveners suggested that water withdrawals from Three Sisters, Stewart and Pigeon Creeks could alter the seasonal fluctuation in water levels in the old mine workings in a way that would increase the rate of oxidation of exposed materials. This, in turn, might lower the $\mathrm{pH}$ of the mine water and increase the amount of metal and sulphate ions dissolved in it. Interveners also suggested that intrusion of greywater from sewer pipe breakages or golf course irrigation, or of runoff from golf courses and developed areas, could alter the chemistry of minewater so that the amounts of heavy metals and sulphate in solution would increase. It was argued that this would increase the probability of the events described in the previous paragraph.

The Board has considered the evidence before it and does not believe that there is likely to be acid mine drainage at Canmore. The $\mathrm{pH}$ of all of the mine drainage water analyzed was above seven and in most cases was near eight. The rock strata in which the mine workings were excavated are predominantly sandstones and shales but much of the water in the mines and adjacent porous strata drained through limestones which accounts for its high $\mathrm{pH}$ and very high buffering capacity. Finally the sulphur content of the coal itself is 1.2 percent or less in all reported samples from the area proposed for development. Neither acid mine drainage nor the presence of high concentrations of sulphur in minewater would be expected under these conditions. Available analyses of water leaving the mines and of the "receiving water" in the Bow River do not suggest that there is an unacceptable water quality problem at present. Furthermore, the backchannel creeks of the Bow River thought to receive much of the mine drainage water were identified as important spawning habitat for trout which suggests that the quality of water in them is good.

The chemistry of the existing minewater and the buffering capacity of the contiguous rocks are such that very large quantities of chemicals would have to be introduced into the minewater to significantly alter the rates at which chemical species would be leached from the rocks. Chemicals present in wastewater, surface runoff from the site and excess golf course irrigation water would not necessarily be those most effective in lowering $\mathrm{pH}$ and increasing the solubility of chemicals of concern. In addition, Three Sisters has undertaken to design its project to avoid excess irrigation and to direct surface runoff to a retention pond and storm sewer system. The Board accepts this undertaking. For economic reasons, if for no other, the wastewater and storm sewer systems would be designed to avoid frequent failure. If these measures were taken, the quantity of water significantly different in composition from that now entering the mines should be small. Taking these probabilities together, the Board does not believe that there is cause for concern about acid mine drainage, an increase in heavy metals in minewater, or generation of hydrogen sulphide gas, should the project proceed as proposed by the Applicant and in accordance with the Board's conditions. 


\subsubsection{Potential Effects of Chemical Use on Golf Courses and Residential Lots}

Golf course superintendents and homeowners apply chemicals to vegetation to maintain it to their satisfaction. Interveners were concerned that movement of these chemicals into non target ecosystem components could have undesirable effects. Some interveners were also concerned that runoff from paved and roofed areas would contain contaminants such as oil and grease, heavy metals and road salt and that these would reach the Bow River. Three Sisters proposed a large number of measures to avoid, reduce or mitigate these potential impacts on water quality. Some of these were contained in the Applicant's Integrated-Pest Management (IPM) program which includes a number of undertakings.

The Board accepts Three Sisters' evidence that of the chemicals it proposes to use on the golf courses, quintozene is the only one with significant potential for bioaccumulation. Quintozene is relatively insoluble in water and could accumulate in the thatch and topsoil of tees and greens if applied too liberally or too often. The Board recognizes that Three Sisters proposes to use quintozene to control snow mould because the only alternatives currently available are less desirable in terms of potential environmental effects. Mercurial fungicides, for example, are particularly undesirable. Three Sisters undertook not to use mercurial fungicides. The Board would require that Three Sisters implement its stated policy of regularly reviewing all the chemicals it uses to determine if there are more environmentally acceptable alternatives, and that it do so every three years and report the results to Alberta Environment as part of the periodic review of its IPM program. The Board observes that this could lead to the replacement of quintozene by a more acceptable chemical should one become available.

Chemicals may be directly applied to golf courses by aerial spraying or ground application and indirectly applied through irrigation. Three Sisters would be subject under the Agricultural Chemicals Act to regulation that is intended to ensure that chemicals reach their targets and do not stray beyond them and that they are stored and used in a manner that limits the direct exposure of people to them. The regulations include provisions which restrict spraying within $30 \mathrm{~m}$ of watercourses. The Board is satisfied that the requirements placed on Three Sisters by the Agricultural Chemicals Act would be adequate for the intended purposes.

Some interveners were concerned about the fate of chemicals used on the golf courses. These may be taken up by grasses and removed by mowing, retained in the thatch or topsoil, or lost by leaching to groundwater or by drainage to surface water. Three Sisters said that it intended to grade fairways so that water would drain away from the margins towards the centre and that excess surface drainage would be directed to retention ponds. Drainage would also be directed away from watercourses crossing the golf courses. Irrigation would be planned to reduce downward movement of water through the soil to a minimum, especially in areas such as tees and greens where chemical applications and irrigation would be highest. Impermeable liners and controlled drainage would be provided under tees and greens. Although these proposed designs are conceptual, and detailed site specific designs have not yet been developed, the Board regards them as undertakings by Three Sisters. The Board has also included in 
Section 10.3.4.3 requirements for tees and greens constructed in floodplains of creeks that run directly into the Bow River for at least some part of the year.

Because drainage of water through the soil will be limited by Three Sisters there is a possibility that chemicals including salts could accumulate in the thatch and topsoil because only water would be lost by evaporation and transpiration. Some proportion of accumulated chemicals would be removed by mowing, but some would not. Accumulation would be greater in the case of tees and greens. The Applicant said that it would analyze soil samples from time to time in order to adjust rates of chemical application and irrigation. It also noted that removal of the upper layers of tees and greens and their replacement by fresh material is a standard maintenance practice on golf courses at intervals of several years. The Board is satisfied that these measures would be adequate to deal with potential accumulation of chemicals in thatch and topsoil.

If the development were to proceed, use of chemicals by homeowners or tenants could contribute to possible contamination of surface and ground waters. Although Three Sisters could not control use of chemicals by residents, it could reduce the potential for their use by design measures such as retaining tree cover and reducing opportunities for lawn development on residential lots. Three Sisters undertook to do so. It could also provide purchasers of properties within the project with advisory material explaining how attractive features of the area such as native vegetation might be maintained as recommended in Section 10.4.4.2.

Three Sisters acknowledged that entry of contaminants into the drainage system from paved and other developed areas is a possibility and it undertook to install settlement basins to intercept some of them. Responsibility for periodic cleaning of settlement basins would rest with the Town. The Board recognizes that this is a practical approach in use elsewhere in the province and supports it. The Board also recognizes that settlement basins would not intercept all kinds or all quantities of contaminants. As an additional measure, the Board would recommend that the Town require Three Sisters to include in its property owner documents advice to residents and business operators on the desirability and methods of avoiding the release of contaminants into storm drainage.

Three Sisters suggested and the Board agrees that if all the above measures were to be implemented, they would provide reasonable assurance against unacceptable contamination of surface and groundwater by chemicals used in the project area. In addition, Three Sisters has proposed a program to monitor water quality during and after construction of the proposed project. The monitoring program would detect increases in contaminant concentrations and trigger remedial action where appropriate. The Board has reviewed the evidence on what monitoring would be appropriate and made detailed recommendations in Section 10.3.4.5. 


\subsubsection{Construction Effects}

During construction, ground surfaces are stripped of vegetation, graded, subjected to excavation, trampled and driven on. All these activities generate particles of soil or unconsolidated geological materials which may be carried in the air as dust or in water as suspended sediment. Dust may be deposited in water where it adds to the suspended sediment load. Aquatic organisms may be adversely affected by increases in suspended sediment and by the eventual deposition of sediment in places where they live. Deposition of sediment on gravels bearing fish eggs is the particular adverse effect which receives the most public attention. Increased suspended sediment is also undesirable in water intended to be treated and used as drinking water.

As noted in Section 10.2, the Applicant undertook to use water to control the generation of dust during construction. The Board heard suggestions, including proposals from the Applicant, about other measures to reduce the entry of sediment into watercourses during and after construction. Among these suggestions were many conflicting prescriptions for the size, nature, and location of buffer strips to be left along streams. The purpose of buffer strips is to reduce the entry into watercourses of chemical contaminants and sediment from developed areas and to maintain cover of taller plant species along the banks of watercourses in order to preserve the quality of fish habitat. Three Sisters argued that golf course design requirements would not allow the leaving of a $25 \mathrm{~m}$ wide buffer of undisturbed vegetation along creeks in all locations but that the fairway contouring and detailed designs of tees and greens would reduce the entry of contaminants and sediment to streams where buffer strip could not be left, or where they might be narrower or might be occupied by shorter plants.

The Board agrees that $25 \mathrm{~m}$ buffer strips cannot be left at all locations if golf courses are to be built. However, the Board would require that the detailed design of buffer strips along watercourses be approved by Alberta Forestry, Lands and Wildlife. This would be particularly important in the case of Golf Course D which is proposed to be constructed along Pigeon Creek because of the confusing evidence the Board heard about its design and because fish are present in the creek. The Board would also require that, should the project proceed, Three Sisters utilize construction techniques that would reduce disturbance of the environment to the lowest practical level, and these techniques would include:

- elevating the top of any tees and greens constructed in the Pigeon Creek, Three Sisters Creek and Stewart Creek floodplains to above the one in 100 year flood level, installation of an impermeable barrier under such structures and armouring them adequately to avoid washouts;

- sodding areas of graded soil within five $\mathrm{m}$ of Pigeon, Three Sisters and Stewart Creeks within five days of construction; and

- providing an orientation program for construction workers to ensure they understand the potential seriousness of sedimentation problems. 
Another source of short term but potentially large inputs of sediment to watercourses is instream construction. In the proposed project, this could occur when water crossings are built or when, and if, ephemeral creeks are rerouted. In the case of fish bearing creeks, such as Pigeon Creek, the Board would require that instream construction work be conducted according to the requirements of the Water Resources Act and during time periods approved by Alberta Forestry, Lands and Wildlife to protect fish. In addition, the Board would require that Three Sisters adopt construction practices normally used to reduce the amount of sediment entering streams during instream construction.

\subsubsection{Wastewater Treatment}

Disposal of wastewater poses problems because of organisms therein which may cause human and animal infections and because of the nutritional value of inorganic, and in some cases organic, materials that may encourage algal and bacterial growth in receiving waters. Increasing the nutrient concentrations in an aquatic ecosystem is called eutrophication. It leads to changes in the species present and to increases in the seasonal peaks in their numbers. Excessive growth can lead to the formation of blooms or visible high densities of algae; these high populations may collapse when resources become limiting and the breakdown of their dead cells can cause anoxic conditions that are fatal to fish, especially when streamflows are low or water is stagnant. Eutrophication is considered to be undesirable in water used as a source for human use and in waters supporting sport fish populations because the more highly prized species generally prefer less nutrient rich conditions.

Wastewater treatment is designed to avoid or mitigate health risk and eutrophication. Secondary treatment removes coliform bacteria and some parasitic organisms that may infect man, and it breaks down organic compounds. Additional disinfection, for example, by treatment with ozone, may be necessary to kill some parasites, including Giardia, in effluent from secondary treatment plants. Secondary treatment does not remove simple inorganic nutrients such as nitrates and phosphates. Tertiary treatment is designed to remove these as well.

Section 10.3.1 includes a description of water treatment facilities in the Bow River basin upstream of Calgary. As noted there, Three Sisters said that it proposes tertiary treatment and disinfection capability at the proposed Dead Man's Flats plant and the Board agrees that this would be desirable. The Applicant also recommended that the upgraded Canmore treatment plant incorporate the same features. Should the project proceed, the Board would recommend that the Town ensure that tertiary treatment becomes the standard wastewater treatment method. 


\section{$10-16$}

\subsubsection{Monitoring}

In the earlier parts of Section 10.3, the Board has concluded that should the project go ahead, and the Board's conditions be observed, the probable magnitude of impacts on water flows and on water quality would be acceptable. There is, however, an element of uncertainty about this conclusion because of the limited information now available. The Applicant has proposed, and the Board agrees, that the appropriate way to manage this uncertainty is by means of a monitoring program. Three Sisters provided a good deal of information about what it might monitor and how it might do so and many interveners offered suggestions about monitoring. However, the detailed design of a monitoring program cannot be completed until more baseline information, for example about such matters as groundwater movement and detailed design of the project itself, are available. The Board would require that, should the project be approved, Three Sisters design and implement a program to monitor water quantity and water quality to the satisfaction of Alberta Environment and Alberta Forestry, Lands and Wildlife. The Board would make the following recommendations to Three Sisters about what should be done to assist in designing the program:

- gather information about shallow groundwater movement throughout the Three Sisters property;

- identify contaminants most likely to be entering and moving through ground and surface water and locations where these are most likely to be released; and

- identify seasonal periods when contaminant releases are likely to occur and when stream or groundwater flows are of particular importance.

The Board would recommend to Alberta Environment and Alberta Forestry, Lands and Wildlife that the program include the following features:

Regarding water quantity:

- monitoring of areas of groundwater discharge including the toes of alluvial fans to determine whether or not they remain moist or retain open water conditions throughout the same seasons as at present and as noted in Section 10.3.3;

- monitoring of downward flows on golf courses as proposed by Three Sisters to avoid unnecessary irrigation and reduce chemical leaching;

- and, in each case, sampling throughout the season of active flow. 
Regarding water quality:

- selecting for analysis contaminants of primary concern such as pesticides and nutrients rather than expending resources on analysis of a large suite of general parameters of water quality;

- if greywater irrigation is used, analyzing for microbial organisms;

- sampling surface water, groundwater and sediment as appropriate and throughout the season of active flow;

- sampling on specific occasions after irrigation or after the release of contaminants; and

- locating sample stations in surface and groundwater sites where there is a reasonable expectation that contaminants may be intercepted and which bear relation to resources that may be threatened.

\subsubsection{Ecotoxicological Assessment}

The AWA Group suggested that Three Sisters be required to conduct a detailed ecotoxicological assessment of the potential impacts of contaminants that might originate from the proposed development on the components of the Bow River ecosystem including downstream water users. The Board has reviewed the evidence on the identity and quantities of contaminants that might originate from the proposed development and believes that they do not differ significantly from those that might be expected to originate from other real estate developments of a similar scale. Such developments are not normally considered to be sufficiently hazardous to require the kind of assessment proposed and the Board sees no reason to make an exception in this case. The Board believes that concentrating on an appropriate level of wastewater treatment and requiring that domestic and storm sewer systems are designed to stringent standards will provide adequate safeguards against toxicological hazards. The Board has dealt with the matter of runoff of chemicals used on the proposed golf courses earlier in this Section of the Decision Report. As indicated there, it does not consider that the potential impacts are likely to be severe. Extending this conclusion, the Board does not believe that they would be sufficient to call for an ecotoxicological assessment.

\subsubsection{Aquatic Biota}

Although the question of impacts on lower aquatic lifeforms, and in particular benthic algae and invertebrates, was raised by several interveners, the concerns expressed were related to impacts on water quality, potential degradation of the aquatic ecosystem in general, and impacts on fish feeding on lower organisms. If the project were to go ahead and the 


\section{$10-18$}

Board's conditions to protect water quality were to be implemented, the Board's view is that water quality would not be sufficiently impaired to have a major impact on algae or invertebrates. There could be local short term effects, for example during construction in or near creeks, when accidents or emergencies occur, or during extreme weather conditions. Given the nature of the proposed development, the identity and quantity of contaminants that it might generate, and the measures to protect the environment that would be incorporated into its design, the Board believes that such events would be unlikely to have significant long term consequences. The Board heard no evidence that any particular aquatic species would be at risk if the proposed project were to proceed but the potential for impacts on fish populations was the subject of detailed scrutiny, in part because of their importance to anglers.

The Bow River supports an important trout fishery as well as a large population of mountain whitefish also caught by anglers. In 1988, Alberta Forestry, Lands and Wildlife reported the approximate composition of the Bow River sportsfish population as: more than 80 percent mountain whitefish, 15 percent brown trout, with the remainder including eastern brook, rainbow, bull and cutthroat trout. A 1989 electrofishing survey produced a population estimate of 2218 adult whitefish per $\mathrm{km}$ of river.

On the site itself, only Pigeon Creek below the falls is known to support fish. Alberta Forestry, Lands and Wildlife considers it unlikely that any of the other streams, which are ephemeral, would contain fish. A Three Sisters survey of Stewart, Three Sisters and upper Pigeon Creeks, using electroshocking, found no fish. Seepage channels downgradient of the site represent the largest component of current brown trout spawning sites in the corridor, accounting for between 60 to 80 percent. This is of particular importance due to the concerns expressed at the hearing that these might be negatively affected by water use practices on the Three Sisters site. Participants at the hearing concurred that increased angling and its pressure on fish stocks would be the primary effect of the proposed development on the existing fishery.

The Bow River trout fishery is not only important but it is subject to excessive demand. The Trout Unlimited Group expressed concern that fishing pressure is already adversely affecting the fishery and that the resident human population that the project would introduce would exacerbate the problem. At the same time, the Group asked for a recreational buffer to be left along the south bank of the Bow River where the proposed project abuts on it so that anglers may continue to have access to the fishery. The Board recognizes that there is a limit above which the exploitation of a resource such as a fishery is not sustainable. The Board understands that Alberta Forestry, Lands and Wildlife has the responsibility for managing fisheries and that it can limit the number of fishing licenses issued as well as the season when fishing is allowed. The Board does not believe that people who might choose to live on the Three Sisters property if it is developed should be discriminated against in the issuance of fishing licenses. They should enjoy the same rights and be subject to the same restrictions as other residents of Alberta. With respect to the matter of access for anglers, the Applicant undertook to facilitate access at several points along the south bank of the Bow River should the project proceed. 
Other methods of relieving pressure on a fishery are to attempt to increase the size of the fish population by stocking, habitat enhancement, or establishing the fish in areas they do not already inhabit. Several interveners advocated the establishment of a cutthroat trout population in the Pigeon Creek drainage above the waterfall. Available evidence is that there are no fish there now. Some interveners suggested that, should the project proceed, Three Sisters should be required to undertake the establishment of such a fish population to offset what they argued would be adverse effects of the project on the Bow River fishery. Three Sisters' position was not clear. Mr. J. Stelfox of Alberta Forestry, Lands and Wildlife pointed out that decisions about restrictions on fishing, fish stocking and habitat enhancement are normally made on a regional basis by that Department. For this reason the Board takes no position on the need for Three Sisters to establish a cutthroat trout population in Pigeon Creek.

Another concern expressed about fish habitat was that the project might remove or disturb riparian vegetation along fish bearing streams. The lower reaches of Pigeon Creek are the only ones where fish are found, although leaves and branches falling into the creek from upstream vegetation can affect habitat quality downstream. Three Sisters made it clear that it is aware of this potential impact and said that it is still reviewing designs for development, including golf course development along Pigeon Creek with a view to maintaining the quality of fish habitat. Measures that are being considered include not removing woody debris and leaves from the creek, and designing to avoid disturbance of trees and woody shrubs on streambanks. The Board accepts Three Sisters' intentions in this regard as an undertaking.

Wind Valley is drained by Wind Creek and West Wind Creek, tributaries of Pigeon Creek. Within the Pigeon Creek system, the total length of creekbed within the Wind Valley part of the proposed development area is significantly longer than that in the Bow Valley part. It could be argued that the potential for adverse impact increases with the length of creekbed in the area that might be affected unless there are anticipated site specific impacts that would mask that relationship. Whether or not there is development in Wind Valley could influence Alberta Forestry, Lands and Wildlife in its determination of the suitability of the reaches of upper Pigeon Creek for establishment of a cutthroat trout population.

Development in the Bow Valley portion of the project proposed by the Applicant, would be adjacent to only one short stretch of the lower reach of Pigeon Creek where fish reside. There is an active stone quarry just below the waterfall which is about one $\mathrm{km}$ from the Trans-Canada Highway. Additionally, the Applicant indicated that a walking trail would be developed along Pigeon-Wind Creek to give access to this waterfall. Development in Wind Valley would increase the potential for impact on the existing fish population above that which would arise from development in the Bow Valley part of the Three Sisters lands.

Shallow groundwater discharges into the backwater channels of the Bow River could be affected by development in the Bow Valley portion of the project as discussed earlier. Development in Wind Valley would be less likely to affect them, because the creeks in the Pigeon Creek basin are the only ones that are not ephemeral and appear to discharge to the Bow River largely via surface flow. Also, the Applicant stated that its plans no longer include the 
intention to withdraw water from Pigeon Creek, obviating concerns regarding the diversion of water from this basin.

10.4 Terrestrial Ecosystems

10.4.1 Background

An ecosystem consists of a distinguishable set of populations of plant, animal and microbial species and the physical environment in which they live. A terrestrial ecosystem may occupy one or more areas of land. An ecosystem may be broken down into components such as populations of each species, soil types or shallow groundwater. Each component may be acted on by other components and by forces external to the ecosystem. External forces normally directly affect many ecosystem components, but even where an external force affects only one component, the others will be affected through the interaction of components within the ecosystem.

Ecosystems are complex and possess a number of properties that make predicting the influence of disturbance on them difficult. Ecosystems can behave in a simple manner when disturbed. Although the nature of the response of an ecosystem to disturbance is not often linear, ecosystems can respond elastically to disturbance and return to their original states after disturbance ceases. If disturbance is sufficiently severe or prolonged, or a combination of the two, the ecosystem may undergo a sudden change in state comparable to the boiling of water. When this occurs, ecosystems tend to be much less resilient. In other words, they do not readily return to their earlier state after disturbance ceases.

Unfortunately ecosystems do not usually exhibit simple linear responses to disturbance that are readily observable and they do not often undergo changes of state at times and under conditions that can be predicted. In short, ecosystems exhibit resilience to some disturbance, but when disturbed severely enough their condition may be altered in a way that can only be reversed with great difficulty, if at all. The risk of a more or less irreversible changes generally increases with disturbance but not necessarily in a predictable manner. Complex systems generally exhibit linear responses to disturbance under a limited set of conditions only and the nature of their response to disturbance is very sensitive to small differences in the condition of the system. Many important components of ecosystems, such as populations of animals and plant species, exhibit similar unpredictability of response.

Natural ecosystems are subject to repeated disturbance so that much of the time they are in a dynamic state. Ecologists' understanding of the dynamics of temperate, subarctic and arctic/alpine ecosystems is that they exhibit cyclic variation on which are superimposed disturbances at irregular intervals. Significant changes can occur even over the time scale of construction of the Three Sisters development: for example, grassland may be colonized by aspen, spruce or pine, and woodland may be affected by fire, wind, avalanches or pest 
outbreaks. Over the expected life of the project, disturbances of this kind could occur on several occasions.

Most animal populations also exhibit cyclic quasi-periodic variations in numbers of periods shorter than the average recurrence intervals of intermittent disturbances such as fire. Short term cycles are often thought to be related to interaction with the abundance of prey or food species. Information about such cycles is relevant because it can assist in interpreting the degree to which populations may be at risk.

The Board recognizes that there are fundamental obstacles to assessing the effects on ecosystems of the proposed development. However, the Board believes that at least a qualitative assessment of possible effects and the probability of their occurrence can be attempted using evidence about the current state of the ecosystems and information about past disturbances of various kinds and their effects on ecosystems and their components. In general, more information is available about the effects of disturbance on the more conspicuous components of ecosystems than on ecosystems themselves and one way of approaching an assessment is through examining the response of individual components and then attempting to integrate them.

\subsubsection{Affected Ecosystems}

The regional terrestrial ecosystems that might be affected by the proposed project are the alpine, subalpine, and the montane. The Board heard that the montane ecosystem occupies land between about $1,300 \mathrm{~m}$ and 1,550 to $1,600 \mathrm{~m}$ in mountain valleys in the Banff area. The subalpine occupies elevations from 1,600 to $2,300 \mathrm{~m}$ and the alpine, which is above the treeline, lies above $2,300 \mathrm{~m}$. The alpine ecosystem occupies land at higher elevations than the property and may be indirectly affected by the proposed project. The montane ecosystem occupies 70 percent of the Bow Valley portion of Three Sisters' lands and 80 percent of the Wind Valley portion.

The three ecosystems are climatically differentiated. The distinction is roughly correlated with elevation but modified by aspect and the frequency and duration of weather events such as chinooks and inversions. The montane ecosystem is found above the fescue grasslands and aspen parkland of the prairies and lower foothills but below the subalpine. It is characterized by a successional sequence from grassland to Douglas fir, limber pine or to lodgepole pine or aspen followed by white spruce. Black bear and wolf are typical large animals of the montane. The subalpine ecosystem is found immediately above the montane and typically consists of coniferous forests of lodgepole pine or Engelmann spruce and subalpine fir with aspen only on warm sites. Bighorn sheep are characteristic of the subalpine. The alpine ecosystem is found at even higher elevations and occupies land above the treeline. It includes heaths and mountain meadows; marmots are a characteristic animal species.

Impacts on ecosystems are most instructively examined in the context of cumulative effects because most ecosystems occupy large areas and have been, and continue to 
be, subject to many impacts. In the case of terrestrial ecosystems, it is often said that progressive land developments nibble away the land occupied by the ecosystem. At some point, the remaining land occupied by the ecosystem may become too small to ensure its continued existence. Nibbling is compounded by the fragmentation of the land occupied by the ecosystem into small areas which may be too small to provide territories or ranges for individuals or populations, especially of the larger species. Paving or construction has a greater effect than would be expected on the basis of the area of land occupied because animal species in particular may avoid the area near such a development. Habitat fragmentation and habitat alienation, as described above, force organisms to move through less hospitable terrain to get from one remaining area of an ecosystem to another. They may suffer losses in doing so, or they may be discouraged or prevented from moving at all. Habitat alienation and obstruction of movements can be exacerbated by growth of human population, whether permanent or transient, in an area and by increased ease of human access to areas that were not previously subject to frequent disturbance. Finally ecosystems can be affected as development proceeds by the manipulation of natural ecological processes, such as succession, for human management objectives such as fire protection or renewable resource exploitation.

The Board heard a great deal of evidence from many witnesses about the extent, severity and duration of such effects on the ecosystems in the Bow Corridor and the surrounding region and of the possible consequences. Witnesses agreed that the river valley montane ecosystem is under most stress for a number of reasons. It occupies only four relatively small areas in the Alberta Rockies: the Crowsnest Pass, Bow Corridor, North Saskatchewan and Athabasca River Valley montanes and possibly a fifth small area at Smoky River. According to reports quoted by the BV Naturalists, approximately 70 percent of the total area of the montane had been cleared or otherwise directly disturbed by 1984. Furthermore, the areas it occupies consist of narrow strips of land along mountain valleys so that fragmentation caused by development and loss of connection between fragments are more likely than would be the case in an ecosystem occupying a large contiguous area. In addition, human activity in the region is concentrated at the lower elevations where the montane ecosystem is found, so that the montane includes sites preferred for development and is also subject to more intensive disturbance through casual and recreational access.

In the case of the montane and subalpine ecosystems, witnesses agreed that the large animal species and especially the top carnivores are most sensitive to disturbance and can be seen as indicators of the condition of the ecosystems. If one or more of these species are lost, a less than fully functioning ecosystem would remain because the pattern of interaction between components would be changed. In assessing impacts on ecosystems, it is logical to consider these sensitive and important species first and to determine what measures are necessary to ensure their survival. Those measures may be sufficient to protect the other species that live within the ecosystem; if not, further measures may be necessary. 


\subsubsection{Affected Landscape Types}

Interveners expressed concern about the cumulative effects of development on certain landscape types that they suggested are either uncommon regionally or have been subjected to disproportionate impacts. Given the natural tendency to establish human settlements and transportation routes in valleys, it is not surprising that landscape types typically found at lower elevations were most often mentioned in this regard.

\subsubsection{Alluvial Fans}

Alluvial fans are formed by the transport of debris from the upper reaches of mountain streams and its deposition at lower elevations where stream gradients are less. The stream bed wanders across the fan as debris is deposited, often changing position abruptly during peak flows. This channel migration causes a successional cycle in the vegetation on the fan which results in increased biological diversity. In addition, groundwater flow in alluvial fans is typically near the surface, creating moist and relatively nutrient rich conditions for plant growth. Alluvial fans provide good habitat for plant and animal species; active fans provide good habitat for large animal species that prefer heterogeneous vegetation. Not all alluvial fans are active. Upstream conditions may change so that water and/or debris flows are reduced. In this case, growth of a fan may cease and the frequency and extent of channel migration may be reduced, sometimes greatly.

When buildings, roads or railways are constructed on an alluvial fan, the designers normally attempt to stabilize it, by such means as channelizing the stream through the fan and consolidating fan materials beneath structures. If they are successful, their work can stop the successional cycle that is largely responsible for the vegetational heterogeneity on fans and it can interfere with groundwater flows which, in turn, can affect the productivity of the vegetation. Where a fan is more or less inactive, construction measures can be successful; where fans are active the forces at work may be too great to control. The frequency of road and railway washouts on active fans attests to this. Interveners suggested that a significant proportion (27 percent by 1980) of alluvial fans in the Bow Valley within Banff National Park had been impacted in a way that would alienate wildlife and that every fan had been impacted to some extent. They went on to suggest that the cumulative effect of these impacts is important because of the value of the fans as habitat. Some interveners argued that further disturbance of alluvial fans, including those on the Three Sisters property, should not be allowed.

There is a large alluvial fan on the Three Sisters property at Three Sisters Creek and a fairly large one at Stewart Creek. Other fans on the property are small and of less significance. The Stewart Creek fan has already been affected by mine reclamation work and channelization carried out under the direction of Alberta Environment. This has affected the potential for channel migration but, according to the Applicant, groundwater movement in the fan has not been affected. The Board also heard that the Three Sisters Creek fan has been extensively disturbed by the mine railway and haulage road and by other mining activities. 
Alluvial fans on Caimes Creek, Fall Creek, South and West Wind Creeks and Pigeon Creek are smaller and less active and, in the case of Pigeon, Caimes and Fall Creeks are largely off the Applicant's property.

The Board has reviewed the evidence with respect to the disturbance of alluvial fans in the region in general and of the two large fans on the Three Sisters property in particular. The Board considers the fact that the fans on the property have already been disturbed by mining and reclamation over the last 90 or so years to be pertinent. The Applicant is not proposing to disturb pristine alluvial fans. On the other hand, the Board does recognize that the typical location of alluvial fans makes their disturbance by human activity likely and, to a substantial extent, unavoidable. In the Board's view, this means that cumulative effects on alluvial fans are an appropriate matter for the attention of a Regional Ecosystem Advisory Group (Section 10.5.2; the Regional Ecosystem Advisory Group is also discussed in Section 12). With respect to the Three Sisters Creek and Stewart Creek fans, the Applicant would have to take into account shallow groundwater flow in designing its project. Safe design would have to allow groundwater flow to continue in a pattern similar to that now occurring. This should assist in maintaining habitat quality at groundwater discharge sites and help maintain at existing levels the productivity of vegetation that would remain more or less undisturbed. The Board would not require specific action other than as described in Section 10.3.4.5.

\subsubsection{Riparian Vegetation}

The Board heard extensive discussion at the hearing about the relative scarcity of riparian vegetation and its importance to wildlife. The Applicant observed that its property supports very little typical riparian vegetation dominated by willows or by balsam poplar and white spruce and including shrubs common to moist habitats. There is a small area of this kind of vegetation along the lower reach of Pigeon Creek near the Trans-Canada Highway and downstream of it. Most of this area is not on the Applicant's property and is unlikely to be directly affected by construction. A very small part of the area abuts the Applicant's property and could be affected by development. There is also a small peninsula on the Applicant's property which supports this kind of vegetation. It protrudes into the Bow River west of the tipple site. The Applicant said that its proposed development would not encroach on this area.

The Board also heard that the Three Sisters property supports vegetation that is important for fish habitat along streambanks in some areas. Trees and shrubs can shelter streams keeping water temperatures steady and also providing leaf and twig fall that acts as a substrate for invertebrates eaten by fish. This kind of vegetation is present along much of Pigeon Creek and its tributaries, including the Wind and West Wind Creeks in Wind Valley. Removal of this vegetation from the Applicant's property could affect the productivity of the fish habitat below the waterfall in Pigeon Creek. Below the falls the effect might be expected to be roughly proportional to the length of creek bank denuded, but removal of vegetation upstream would also have an effect on productivity because input of detritus would be reduced. Removal 
of riparian vegetation in Wind Valley would also adversely affect the potential for establishment of a trout fishery in Pigeon Creek above the waterfall.

The Board concludes that the potential effects of the proposed project on riparian poplar white spruce willow vegetation would not be significant on a regional scale. However, removal of trees and shrubs along Wind and West Wind Creeks and the upper reach of Pigeon Creek could affect fish habitat as well as reducing habitat available to other plants and animals preferring moist montane conditions. Most of the vegetation in question lies in the Wind Valley portion of the proposed project area. In the Board's view, removal of this-vegetation should be avoided.

\subsubsection{Wetlands}

The wetland of most significance within the proposed project area is the fen in Wind Valley. The Board heard extensive evidence about the fen from several interveners and from the Applicant all of whom agreed in substance. The fen begins within the Three Sisters property at approximately the location of the old horse corral and the new bridge over West Wind Creek and extends for four to five km upstream towards the headwaters of West Wind Creek and beyond the limits of the property. The fen is fed by groundwater discharge as well as surface drainage. The groundwater originates from water draining through limestone formations at higher elevations so that it has a high $\mathrm{pH}$ and is rich in inorganic nutrients. It is over $200 \mathrm{~m}$ wide in places and is more than $100 \mathrm{~m}$ wide for much of its length. Dr. Herrero, on behalf of the CPAWS Group, said that it is the largest fen in the region and is particularly important because up to 80 percent of its field layer vegetation consists of Equisetum (horsetail). This plant forms a large part of the late spring and summer diets of grizzly and black bears. The nutrient rich moist conditions in the fen extend the growing season for Equisetum and increase its value as fodder. A large part of the fen also supports a white spruce population which affords cover for feeding animals. The fen is unusual because of both its size and the composition of its vegetation and it could not be artificially reproduced elsewhere in the region. There was general agreement among participants on the desirability of avoiding impact on the fen.

Three Sisters' proposal for development in Wind Valley includes direct impact on a small part of the fen. Three Sisters said that approximately 20 percent of the fen is on its property and it appears from Three Sisters' development maps that 75 percent of that would be directly affected by development. As currently proposed, the resort centre, a golf course and medium density housing would all affect the fen. Development in Wind Valley would probably lead to greater disturbance of the fen as a result of increased access by people. It could also affect the quantity and quality of surface water flows into the fen which could lead to degradation of the fen peat and changes in its vegetation cover. Finally, the Applicant has identified the fen as a candidate site for peat extraction which would have even more severe effects. The Board would find all of these effects unacceptable. Should the Wind Valley portion of the project proceed, the following requirements of Three Sisters would lessen the effects: 
- avoid encroaching on the fen in the construction of buildings, roads or golf courses;

- attempt to avoid intercepting or blocking groundwater flow in to the fen;

- ensure that surface water flow into the fen is altered as little as possible in quantity, distribution or chemical composition; and

- do not extract peat from the fen.

The Board believes that, if the development were to proceed in Wind Valley as proposed, adverse impacts on the fen could not be entirely avoided and that there would be residual impacts significant enough to cause concern whatever measures were employed.

Wetlands are relatively unusual in the montane, subalpine and alpine ecoregions although there is a major waterfowl staging area at Lac Des Arcs, a few kilometres east of the project area. Within the Three Sisters property there are few wetland sites and of these the fen discussed above is the most important. The Applicant identified two small ponds south of and close to the Trans-Canada Highway that are apparently fed by groundwater from the Stewart Creek drainage. Although these are not on the Applicant's property, they could be affected by changes in surface and groundwater flow brought about by development. The Applicant also identified two small wetlands near Quarry Lake where long-toed salamanders had been seen. In addition to these areas, the BV Naturalists reported some small areas of wetland vegetation on groundwater seeps. The Applicant's development proposals do not include building on any of these sites. Interveners' concerns were that development on the Three Sisters property would alter groundwater flows and that wetlands would be adversely affected.

The Board recognizes this as an appropriate concern and has reviewed the matter of groundwater flows in Section 10.3.3 where it dealt with arrangements for monitoring and remedial action when required. The Board notes that neither Quarry Lake nor the associated wetlands are on the Applicant's property. They are fed by mine drainage water and would probably not be greatly influenced by the proposed development. In addition, Three Sisters has undertaken to monitor water levels in wetlands and the Board believes this would be adequate to detect any problems that might arise and to trigger remedial action. In oral evidence, Mr. Green, on behalf of the Applicant, suggested that existing wetlands should be protected and that wetland habitats could be enhanced. The Board believes that, for wetlands other than the fen in Wind Valley, this could be accomplished through the vegetation management plan (see Section 10.4.4.2).

\subsubsection{Forest and Grassland}

As briefly described in Section 10.4.1, the natural state of the areas of the montane and subalpine ecosystems that can support forest is one of dynamic disequilibrium. Any given site is at some point in a successional cycle that is triggered by recurrent fires and leads from initial colonizers of burnt areas through grassland to aspen or pine and on to spruce or fir. The Board heard that fire return intervals in the montane ecosystem are from about 20 
years for aspen to about 55 years for white spruce Douglas fir pine stands; in the subalpine they are from about 90 years for warm dry sites with pine, spruce and fir to twice that for high elevation sites with fir and spruce.

Natural successional cycles have already been disrupted by human activities which not only start fires but also put them out. The result may be more fires but the area burned may be much less. According to the Applicant, the area in the Bow Corridor that is occupied by grassland now is much less than was the case before European settlement because of fire fighting. Some interveners were concerned that fire fighting and fire prevention measures necessary to protect the proposed development would displace the proportions of successional vegetation types and the visual landscape even further from what might be considered natural. The Applicant noted that wildlife habitat enhancement programs that involve cutting or burning of forest stands are intended to remedy this displacement and to benefit species such as elk that are dependent on grassland.

The Board is in broad agreement with the Applicant's assessment of the fire cycle and the need to manage vegetation to approximate what are thought to be natural conditions. The Board notes that some fire control measures undertaken by Canada Parks Service, such as the burning of areas of forest to reduce risks to communities such as Banff, can assist in reaching this objective. Others, such as clearing understory vegetation around town and camp sites, are undesirable from a biological perspective but are necessary to protect the public. Clearing of firebreaks can also be beneficial to animals if they are not used to create new access to areas that are relatively undisturbed. Canada Parks Service pointed out that some developments such as golf courses can act as firebreaks for nearby settlements. On reviewing this evidence, the Board concludes that protection of area residents from fire must have the highest priority. Beyond this the Board believes that regional vegetation management, taking into account the fire cycle, is necessary and recommends that it be a subject for examination by the Regional Ecosystem Advisory Group proposed by the Board in Sections 10.4.3.1 and 10.5.2. Canada Parks Service and Alberta Forestry, Lands and Wildlife are the two agencies with broad management responsibilities in the region and the Board heard that they have already had some discussion on the matter in relation to wildlife management.

\subsubsection{Visual Resources}

Some interveners were concerned that the proposed development might have adverse effects on the scenic values of the Bow Corridor. This concern was acknowledged by Alberta Tourism, Parks and Recreation which had completed a Visual Impact Assessment Report for the Bow Corridor and by Three Sisters which had conducted some preliminary analysis and which undertook to carry out more detailed analysis at the subdivision stage of development if the project is approved. The Applicant stated that, of all its proposed development, only the multi-story hotel or hotels would be incompatible with Alberta Tourism, Parks and Recreation's priorities with respect to visual impacts. Three Sisters said that its architectural controls would 


\section{$10-28$}

ensure that trees remaining on the property after development would shield most of the buildings from view as seen from most locations in the Corridor.

The Board generally concurs with these conditions and accepts the Applicant's undertaking that the matter will be addressed in more detail by means of architectural controls and other measures applied at a more detailed design stage. The Board notes that the proposed multi-story hotel or hotels would be visible from many more locations than would smaller buildings. It also recognizes that commercial and residential development near the Trans-Canada Highway might be visible to motorists and that the result of habitat enhancement, fire protection programs and the construction of golf courses, all of which involve large scale manipulation of vegetation, may also be visible from afar. The Board believes that these disturbances should be considered in context. The Bow Corridor is not pristine. There have been extensive landscape alterations on the Three Sisters property by mining and subsequent reclamation; as discussed in the preceding Section, present vegetation cover is probably not representative of what would have been seen before European settlement. On the north side of the Bow Valley there is large scale quarrying activity and an industrial plant. There is also a human settlement of some 6,000 people. Furthermore, scenic values are subjective and are not universally held. On the other hand, the Three Sisters lands currently present a more natural appearance than many others in the Bow Corridor and it could be agreed that this appearance should be maintained for that reason. Taking into account the existing state of the corridor and its potential future aspect after construction and application of Three Sisters design measures and the subjective values involved, the Board does not believe that the potential visual impact of the proposed project is sufficient to justify denial of approval.

\subsubsection{Affected Ecosystem Components}

10.4.4.1 Soils and Surficial Materials

\section{Use of Soils and Surficial Materials}

Surficial materials on the Three Sisters property are predominantly glacial tills and alluvium. Topsoils are for the most part relatively thin and are underlain by sand and gravel. In some areas, bedrock outcrops at the surface. Typical soil types are brunisols and regisols with surface loams varying from gravelly and sandy to silty clay at some locally lower elevations. Drainage can range from poor to rapid. Fibric mesosol, an organic soil, is found down gradient of the Cairnes Creek recharge area.

The Applicant stated that there are four known peat deposits on its property. One occurs in the Wind Valley underneath the fen referred to in Section 10.4.3.3. Recovery of this deposit would require the utilization of drainage ditches and subsequent drying of the material making it costly. There is another deposit at the southwest side of a marsh in the Echo Springs area west of the Three Sisters alluvial fan. The estimated volume of the deposit is $5000 \mathrm{~m}^{3}$. A deposit in the Stewart Creek area adjacent to the main powerline right of way was identified 
as the most prospective area for peat materials. It has a dense cover of coniferous trees. The deposit contains in excess of $50,000 \mathrm{~m}^{3}$ of dry organic material.

Extensive gravel deposits exist throughout the Bow Corridor including the Three Sisters property. There are five locations on the property where granular deposits have been identified: the Bow River stratified sand deposit, Three Sisters Creek alluvial fan, Stewart Creek abandoned channel, Stewart Creek alluvial fan, and West Wind Creek flood plain. Deposits are readily accessible and require a minimum of overburden stripping. An unusual type of shale also occurs on the property. Three Sisters said it does not intend to promote commercial extraction of this shale because it would be incompatible with planned land uses.

The Applicant stated that whereas a typical golf course would involve the movement of 600,000 to $800,000 \mathrm{~m}^{3}$ of soil during its construction the Stewart Creek course as currently designed would involve the movement of less than $180,000 \mathrm{~m}^{3}$ of material. The Applicant's other proposed golf courses would be similar and would allow for the retention of the most "native looking environment to the Canadian Rockies that we can possibly put together". The Applicant also stated that the topsoil that is stripped from the golf course sites and is not suitable for greens and fairways could be accumulated and used in the development of other grassed areas. The Applicant did not expect to have to import "a lot" of soil and expected that most imported soil would be for greens and tees only.

The Applicant said that some of the peat deposits would be used for the purpose of soil building during golf course construction. Material would be obtained on site if it was of suitable composition but no commercial extraction was planned. Weed free peat will also be brought to the site for soil building purposes, minimizing on site extraction.

The Applicant has undertaken that granular deposits would not be commercially exploited because of the negative impact that this might have on the aesthetic quality of the property. However, it is the Applicant's intention to use gravel that does occur on site for road construction and as a substrate for soil in golf fairways. Substrate laying would be accomplished by gravel crushing within the confines of the fairways. Additional supplies of gravel needed for residential or commercial purposes are available in the local area from commercial suppliers. Although at the present conceptual design stage it is unclear which areas would be affected by soil, peat and granular material handling procedures, the Applicant stated that Alberta Environment reclamation and revegetation procedures would be followed. This undertaking was repeated when the Applicant stated that it might take gravel needed for subsidence correction from surficial deposits within its property and then reclaim the affected areas. This practice was followed in the 1960's and 70's in mining reclamation work.

The Board has reviewed the potential impact of Three Sisters' proposed treatment and use of soils and surficial materials and finds them acceptable. In general, using resources present on the property could be expected to have less impact than importing them would have. However, the Board believes that plans to use the resources would need further review at the detailed design stage by the Town and Alberta Environment. As these bodies would have to 
approve detailed development and reclamation plans at the subdivision level, the Board is confident that any potential impacts would be effectively managed.

\section{Chemical Contamination of Soils}

A number of interveners raised the possibility of contamination of soils by mercurial fungicides but Three Sisters said that it would not use such substances. The Board regards this statement as an undertaking. There was also discussion of past and possible future use of picloram to control knapweed and its persistence in cold, dry soils. The Applicant said that it would consider the use of non chemical measures if eradication measures are required in future. Eradication programs are conducted under the control of the appropriate municipality and the Board is satisfied that the Town would ensure that appropriate measures would be used.

A further potential for contamination of soils, and consequently of groundwater, was raised by the AWA Group. During the period when the mine was in operation, several industrial facilities were built and operated on the Applicant's property. There was a coking plant, a briquette manufacturing plant, several saw mills and some wood treatment plants. At all of these sites, soils could have been contaminated by industrial chemicals. Such contaminants could be moving from the sites in groundwater at present, but construction activity on the sites could result in mobilizing them in larger quantities. No evidence was available to the Board about whether or not these sites are actually contaminated, or, if they are, the nature and extent of the contamination. The Board would therefore recommend that before any construction begins, the Applicant conduct an initial evaluation of each site, including chemical analysis of soil and groundwater samples, and report the results to Alberta Environment.

\subsubsection{Vegetation}

In its Application, Three Sisters provided a description, classification and map of vegetation as wildlife habitat within its study area. Many interveners suggested that this provided an inadequate basis for detailed assessment of potential effects on vegetation and, in particular, on individual plant species. Because classification as wildlife habitat emphasizes physiognomy rather than composition by species, there is substance to this complaint. However, the Applicant said that more detailed information about plant communities and individual species would be obtained before detailed design of the proposed development is completed. The Board has accepted this as an undertaking by the Applicant and discusses the details of what may be required below. Three Sisters did provide a general description of the regional vegetation and its dynamics that was sufficient to allow the Board to address the matter of vegetation management.

Some participants in the public hearing began with the philosophical position that any interference with the natural processes that determine the composition and distribution of vegetation is undesirable; others generally supported this view, but advocated exceptions to 
preserve rare or unusual plant species or communities. Other participants wanted more active vegetation management to meet a variety of objectives including reduction of fire hazards to human settlements and improvements of the productive capacity of wildlife habitat.

The Board believes that a policy of noninterference is unrealistic because steps are already being taken, and will and should continue to be taken, to reduce fire hazards to settlements. The principle measure is fire fighting but others have been used as mentioned in Section 10.4.3.4. The last major fire in the Bow Valley was recorded in the early 1900's, since then there have been few wildfires. In nearby Kananaskis Country, a major fire occurred as recently as 1936, but did not extend to the Bow Corridor because of the southwest winds associated with it.

As the Applicant pointed out, the long term effect of fire fighting has been to increase the proportion of the area covered by forest and to decrease the proportion covered by grasses and herbaceous species. Wildlife habitat enhancement programs which consist of cutting or burning forested areas, and burning or mowing grassland to prevent forest regeneration, have been implemented to increase or maintain the proportion of grassland nearer to what are thought to be prehistoric levels. This is intended to increase the numbers of prized species such as elk which are dependent on grasslands. The Board agrees that it is desirable to maintain a mix of communities of different successional maturities in proportions similar to those thought to have been the norm before modern human interference.

Although the Board concludes that active vegetation management is desirable, it also believes that there may be particular stands of vegetation that should be protected and, to the extent practical, allowed to undergo only natural changes. Those suggested by participants in the review process included: old growth stands of both Douglas fir and subalpine fir, the fen in Wind Valley, patches of vegetation on groundwater discharge areas at the toes of alluvial fans, riparian vegetation and vegetation containing rare or endangered plant species should any be found. The Board accepts that stands of vegetation of these types are worthy of protection, although it believes that the term riparian vegetation was used very loosely by participants. To be more precise with respect to this particular vegetation type, the Board's view is that riparian vegetation along Pigeon Creek (except for the reach between the falls and the Trans-Canada Highway) and on the peninsula of land projecting into the Bow River west of the tipple site is worthy of protection.

The Board recognizes that areas of vegetation worthy of protection as defined above have not yet been fully delineated. It also recognizes that there are potential conflicts between fire management, wildlife habitat management and protection of vegetation. The Board recognizes Three Sisters' undertaking to prepare a vegetation inventory and management plan that would address local and regional needs. The Board would require that, before any geographically defined portion of the proposed development be allowed to proceed, the part of the vegetation management plan that applies to the area likely to be affected must be satisfactory to Alberta Forestry, Lands and Wildlife. 
In resolving conflicting objectives regarding protection of vegetation, the Board recommends that Alberta Forestry, Lands and Wildlife consider at how many sites a particular vegetation type or plant species is represented. Where destruction of a population of a rare species cannot be avoided by altering plans for the location of buildings, transplanting should be considered.

Concern was expressed at the hearing about effects on vegetation of increases in human activity that might arise from the development. Trampling of vegetation along trails and disturbance of vegetation near residences by children and gatherers of firewood were mentioned. A somewhat related concern was the import of weedy species as seed in topsoil or seed mixes. The Board recognizes that these are appropriate causes of concern. The Board would recommend to Alberta Forestry, Lands and Wildlife that they work with the Town and Three Sisters to harden pedestrian trails, construct permanent viewpoints, take steps to discourage other access, especially by off road vehicles, to unoccupied land adjacent to the proposed project and consider seasonal closure of some walking trails (see Section 10.4.4.3). It further recommends that Canada Class one seed mixes be used on the golf courses and in developed areas and that Three Sisters take whatever steps are possible to ensure that any imported topsoil is as free of seeds of weedy species as possible. Behavior of residents is not easily regulated or controlled. However, the Board recommends that the Town require Three Sisters to include in the material it provides to those purchasing property on the site an explanation of the need to protect, and the advantages to the purchaser of protecting, the natural vegetation adjacent to and surrounding the proposed development.

As emphasized earlier in this section, vegetation is always in a dynamic state. For this reason, a monitoring program is required not only to observe the effectiveness of the vegetation management plan and to identify the need for remedial measures where it is ineffective, but also to observe the changes that occur as a result of natural successional processes and to identify the need for further management action. The Board requires that Three Sisters prepare for approval by Alberta Forestry, Lands and Wildlife a vegetation monitoring plan to include periodic survey or inspection of protected sites. The Board recommends that periodic survey of areas of Crown land adjacent to the developed area for the purposes of resource and, in particular, wildlife management should be carried out by Alberta Forestry, Lands and Wildlife. Such surveys would indicate the need for management actions to maintain at desired levels the proportion of vegetation in various stages of succession.

Because of the lack of detailed information about the present vegetation cover of the area proposed for development, it is difficult to be precise about potential impacts on vegetation of any part of the project. However, there are differences between the Wind Valley and Bow Valley portions of the area. A significant part of the Bow Valley portion of the area has been disturbed by mining and reclaimed and revegetated. One might expect that rare plants would be less likely to be found in reclaimed areas than in relatively undisturbed ones. The Bow Valley does include the seepage areas at the toes of alluvial fans that were identified by the BV Naturalists as sites where rare plants might be found. Wind Valley, on the other hand, also includes areas of groundwater discharge, one of which is the site of the large fen. These areas 
are also likely places to find uncommon plant species. Because of the unusualness of the fen, and the fact that there has been little or no reclamation there, it could be argued that removal or disturbance of an area of vegetation in Wind Valley would be likely to have more adverse impact than removal or disturbance of an equal area in the Bow Valley. With respect to the extent of removal or disturbance in Wind Valley, a direct effect on the fen would be most undesirable; beyond that, and in the absence of more site specific data, potential effects on vegetation have to be assumed to be more or less proportional to the area disturbed.

\subsubsection{Wildlife}

The Board's analysis of the potential effects of the proposed project on wildlife focusses on the larger, more conspicuous wildlife species. There are a number of reasons for this. The most important is that the larger species have larger home ranges and tend to be present in smaller numbers than do the small ones; this makes them more vulnerable to the effects of any one development. Secondary reasons are that the larger species tend to have more economic value, for example for hunting, and are generally agreed to constitute more of an attraction to tourists. Naturalists, including those participating in the hearing, would prefer to distribute attention more evenly across the plant and animal kingdoms and the Board has some sympathy for their point of view. The Board's response to this, as explained in Section 10.4.2, is that conservation of smaller species is best approached through conservation of ecosystems of which they are components. Protection of larger areas needed to conserve the larger species would be sufficient to conserve most of the smaller species. The Board's analysis of potential impacts on ecosystems was conducted with that in mind.

$\underline{\text { Elk }}$

Elk are a very important species in the proposed project area. The Board heard evidence from the Applicant and interveners that the Three Sisters project could directly or indirectly affect several groups of elk known to inhabit this portion of the Bow Valley. Major sources of impact that were identified include the loss or alienation of important habitat, disruption of movement patterns, increased mortality, and the potential for habituation which, in turn, might adversely affect the survival or fitness of affected elk populations.

The Board heard much discussion concerning the status of elk in the project area and about the extent to which the various groups of elk that have been identified represent discrete populations or sub-populations. The Applicant recognized three groups of elk that might be affected. The group that would be most directly affected is a group that traditionally winters on Pigeon Mountain-Wind Ridge but that uses portions of the Three Sisters property both as winter and summer range and as a calving area. Winter aerial surveys conducted by Alberta Forestry, Lands and Wildlife and by the Applicant suggest that this group ranges in size from 136 to 186 animals. Part of the range of this group may overlap with that of another group of 70 to 80 elk that ranges throughout the Bow Corridor and is thought to spend a substantial 
portion of its time in the vicinity of Bow Valley Provincial Park. Data presented by Canada Parks Service, and used by the Applicant in its impact analysis, also suggests that the western end of the Three Sisters property approaches the eastern end of the range of a group of elk that is centered in the vicinity of the Banff townsite and Tunnel Mountain and is estimated to number more than 900 animals.

Although these various groups of elk appear to exist as geographically distinct groups, biologists apparently do not have a good understanding of the extent of range overlap and the extent to which movement of animals occurs between these groups. The Applicant suggested that, because the ranges of all three groups overlap, some interchange was likely. Canada Parks Service cited historical references to movements of elk from Banff National Park into the lower Bow Valley, between the east gate and Exshaw, particularly during severe winters. Based on a review of radiotelemetry studies conducted by Canada Parks Service and Alberta Forestry, Lands and Wildlife, it also concluded that "Home ranges of radio-collared elk form a continuous and often overlapping pattern of landscape usage from Lake Louise to Highway \#40". Dr. Woods, on behalf of Canada Parks Service, said that elk move in family units and that what appear to be herds are aggregations of family units that happen to be in the same area at the same time.

The Applicant said that use of habitat in the project area by elk changes seasonally. Elk are primarily grazers whose basic habitat requirements include grass or meadowland foraging areas situated in close proximity to dense forest cover to which animals can escape when disturbed. In winter, deep snow reduces forage availability and restricts movement, causing elk to seek grassland or meadows on south and southwestfacing slopes or in other warm microclimates where snow depths are shallow. For calving, elk prefer areas near water that provide secure cover.

A number of areas on, and in the vicinity of, the Three Sisters property are considered important as elk habitat. The Applicant identified critical winter habitat for elk as south and southeast facing slopes on Wind Ridge and Pigeon Mountain, although elk were also observed using the forested benchlands on the Three Sisters property between Wind Ridge and Canmore and in particular the area around the mineral lick near Stewart Creek. The south facing slopes along the north side of the Bow Corridor are also considered critical winter elk habitat, although use of these ranges is thought to have declined from historical levels because of development and current land use practices. Calving areas are thought to include the Bow Flats, benchlands in the vicinity of Stewart Creek and Golf Course C, the upper reaches of West Wind Creek and, possibly, the lower slopes of Wind Ridge.

Interveners were concerned that development in Wind Valley, and consequent activity in the area, would in the short term at least, result in elk not using the area for calving and that they may be discouraged from using the areas of critical winter habitat as well. In the longer term, the Applicant and some interveners thought it probable that elk using the critical areas for feeding would become habituated to human disturbances if development were to 
proceed in Wind Valley. In that case, the habitat would continue to be used, although perhaps not for calving, and at the cost of the unwelcome concomitants of habituation.

Whether or not alienation of adjacent habitat would result from the development, or whether habituation would offset these losses in time, there is agreement that a sizeable amount of year round elk habitat would be permanently lost due to clearing and facilities construction. As mitigation for these losses, the Applicant has proposed a number of habitat enhancement projects to increase the amount of grassland forage available to elk in the Bow Corridor. These would involve clearing areas of forest at elevations above the southern boundary of the proposed project. As discussed in Section 10.4.3.4, the proportion of the Bow Corridor covered by grassland may have declined since European settlement. Availability of grassland was suggested as a limiting factor for elk by the Applicant, although Canada Parks Service considered that there is insufficient information available to reach such a conclusion at the present time. Some interveners questioned the potential effectiveness of the proposed enhancement program, because the majority of the enhancement sites proposed by the Applicant are situated on north facing slopes and at somewhat higher elevations than the areas within the project area that are currently being used by elk. As well, the close proximity of the proposed enhancement areas to the edge of the proposed development means that the same arguments with respect to disturbance, habitat alienation and habituation that would apply to the critical habitat areas would apply to them. That is, either the close proximity of the proposed enhancement areas to sites of human activity may limit elk use through sensory disturbance, or alternatively, attraction of elk to these sites may encourage habituation because of their close contact with humans. The Applicant and Canada Parks Service suggested that protecting overwintering habitat on south slopes on the north side of the Bow Valley might be more effective in conserving regional elk habitat than would clearing for habitat enhancement on the south side of the Valley.

The Board heard a great deal of evidence about the movement of elk resident in the region including the Bow Corridor, Banff and Yoho National Parks, Kananaskis Country and some adjacent land. Canada Parks Service described a detailed analysis of radiotelemetry data obtained by two researchers, Woods, who collared a number of elk in the vicinity of the Banff townsite, and Jorgenson, whose collaring locations were centered farther east near Bow Valley Provincial Park. The results of both studies showed movement by elk into the region around Canmore. This analysis also revealed two distinct types of movement patterns. A portion of the population consisted of resident elk that remained in the Bow Valley year round, while the rest of the population underwent seasonal migrations between winter ranges in the Bow Valley and summer ranges located elsewhere in the region. Some of these movements were quite extensive. For example, Canada Parks Service described the movement of radiocollared elk from winter range in the Bow Valley that "move from the Bow Valley area, past the Banff townsite, up the Spray River, moving temporarily back outside of Banff Park in the area of the Spray Lakes reservoir, back into Banff National Park, up Bryant Creek, over Assiniboine Pass, and into Mount Assiniboine Provincial Park in British Columbia". As well, movements of radio-collared elk have been recorded from the Bow Valley through the Wind Valley, over 
Skogan Pass, and up the Kananaskis Valley as far as Evan Thomas Creek and Peter Lougheed Provincial Park.

In discussing the function of movement corridors Drs. Woods and Paquet noted that valley bottoms traditionally served as primary movement corridors for species such as elk and wolves, and that many of the corridors that presently exist in the area represent secondary corridors that have resulted from displacement. Their data show that elk and wolves use the same corridors and they indicated that it was likely that other large mammals use these same corridors as well. They pointed out that, in the case of species such as elk, the movement corridor may comprise a network of trails rather than a single trail or route. The Board also heard that the proportion of the landscape that is suitable for movement corridors in mountainous areas is actually quite limited, since topographic or climatic constraints generally limit use to elevations lower than $2000 \mathrm{~m}$ and because of the amount of development that has already taken place within valley bottoms.

A number of important movement corridors were identified in the vicinity of the proposed project. The Applicant recognized the presence of corridors extending from Wind Valley and Wind Ridge across the project area to the Bow River Flats, as well as a major movement corridor linking Wind Valley with Kananaskis Country over Skogan Pass. Information presented by Canada Parks Service suggested a regional network of movement corridors that, in addition to the above, includes corridors extending along both sides of the Bow Valley from Banff to Exshaw, with significant crossover points near Harvie Heights, east of the Town of Canmore, and at Dead Man's Flats. Canada Parks Service concluded that "the Benchlands between Harvie Heights and Cougar Creek are an important multi-species migration corridor out of BNP [Banff National Park] with links to the Wind Valley" and that "the Wind Valley area is an important travel corridor with linkages to the Kananaskis Valley". The Applicant and the interveners agreed ensuring continued elk movement along these corridors is essential to the health and survival of the population. Three Sisters proposed to establish movement corridors through its property, but some interveners were not satisfied that the Applicant's proposal with respect to corridors would be effective.

The potential for habituation of resident elk or for occupation of open areas of the proposed development by habituated elk from Banff townsite was a concern to the interveners. The Board heard evidence that elk at the Kananaskis country golf courses are not habituated whereas those at the Banff golf course are. The difference was attributed to the fact that development in Banff has been there longer and to the fact that hunting is not allowed within a large distance of Banff. Although hunting would not be allowed within the Town of Canmore, it would be allowed nearby, so the situation with respect to the proposed project would be somewhat different. Expert witnesses for the Applicant and interveners were in general agreement that habituation is undesirable and should be avoided. The Board has examined the evidence on habituation and agrees. Past experience indicates that habituation of elk increases the risk of aggressive encounters between elk and humans, which often results in human injury and destruction of wildlife. Continuation of hunting near the property, but at sufficient distance away to protect human residents, and use of aversive conditioning should be employed if the 
project proceeds. Hunting causes animals to fear humans and discourages habituation. When properly regulated it can also be a safe management tool to maintain wildlife populations at sustainable levels. Canada Parks Service said that efforts to conduct aversive conditioning of elk in Banff National Park have not been very successful to date, and that a continuous and rigorously applied program would have to be in place to have any hope of success. The Board accepts this opinion.

In a natural state, the predominant causes of death of elk would be predation, disease and starvation. Accidental death would be rare. There are three additional causes in today's environment: road and railway accidents, hunting, and removal of nuisance elk from human settlements. The Board heard evidence about the significance of road and railway kills and the extent to which the proposed project might add to them. It was reported that biologists with Alberta Forestry, Lands and Wildlife have expressed concern about levels of elk mortality in the Bow Corridor, suggesting that present mortality levels are at, or may have exceeded, the recruitment rate for the population. Dr. Woods said that he had reached a similar conclusion based on his population modelling efforts, and that he regarded the highway, and possibly the railway, as major mortality sinks for elk. He said that road kill statistics showed that about 20 elk are reported killed in this section of the Bow Corridor each year, but that actual mortality figures may be several times higher than this, since many injured animals do not die on the highway or the deaths go unreported.

The Board also heard suggestions from the Applicant and interveners about how these mortality levels may be reduced. The Applicant might install warning signs on the proposed parkway on its property and employ design measures to reduce speeds. The Town or Alberta Transportation and Utilities may impose speed limits. While supporting these measures, participants were generally more concerned about the losses occurring when animals cross the Trans-Canada Highway and railway lines between Canmore and Exshaw. They recommended construction of fencing and underpasses similar to the measures recently adopted in Banff National Park.

The Applicant and most of the interveners agreed that the severity of these effects might already be sufficient to threaten the population and that a regional management initiative that would include a response to existing impacts as well as management of potential impacts of the Three Sisters project and other new developments is necessary. The Board is in broad agreement with this view.

The Board has reviewed all of the evidence with respect to elk and concluded that if the project were to go ahead there would be significant adverse impacts on local populations. Development in Wind Valley would probably alienate critical habitat for elk in the short term. That being the case, critical habitat in Wind Valley could be lost to elk for at least a period of several years and perhaps longer. In the long term it might continue to be used if elk were to become habituated. However, the Board believes that the undesirability of habituation was well established by the biological witnesses before it, and would require that steps be taken to prevent it as set out below. Development in both Wind Valley and Bow Valley would disrupt 
movements by elk that are necessary to their survival as a population unless steps were taken to protect corridors along known migration routes. The Board believes that such steps could be taken.

With respect to habitat, the Board accepts the Applicant's evidence that grassland foraging areas are important to elk and that the area of grassland habitat available to the species in Banff National Park, Kananaskis Country and the Bow Corridor has probably declined as a result of fire suppression. The Board believes that completion of the proposed project would reduce this further and that, if the project were to proceed, some form of vegetation management to increase the availability of grassland would be desirable. However, the Board is not convinced that the Applicant's proposals for enhancement would be effective. The Board believes that vegetation management needs to be addressed on a regional scale to take into account public safety, conservation and resource management and that the Applicant's vegetation management plan should fit into a broader regional plan.

As noted earlier, the Board is of the view that the matter of road and railway kills of elk should be addressed along with hunting policy as part of the regional management of the species. However, the Board does believe that the design of the proposed project could incorporate measures to avoid road kills. The Board recognizes that some increase would be inevitable because of the construction of roads within the project area and roads to provide access to the project, and because regional traffic would increase.

The Board concludes that the Applicant and the various levels of government could implement a number of measures to protect or improve the regional population. Should the project proceed, the Board would require that the Applicant retain movement corridors for elk in as undeveloped a state as possible and that corridor locations be subject to approval by Forestry, Lands and Wildlife. They should also be subject to review and recommendation by the proposed Regional Ecosystem Advisory Group. One reason for regional design is that corridors on one property should connect with corridors on other properties and on Crown land. The Applicant proposed that wildlife corridors be legally designated and the Board would recommend such action to Alberta Forestry, Lands and Wildlife. The minimum width for primary corridors recommended by the Applicant was $350 \mathrm{~m}$. The Board would recommend that movement corridors should not be narrower than this except in very unusual circumstances. The Board would recommend to Alberta Forestry, Lands and Wildlife that widths and locations of corridors be reviewed with the full range of species that are expected to make use of each corridor in mind; that measures such as bundling road, utility line and pathway crossings be adopted to minimize fragmentation of corridors and that corridors correspond with known movement routes of the animals. Favouring areas unsuitable for development which may or may not be used by elk is not likely to result in successful mitigation.

The Board would recommend that the proposed Regional Ecosystem Advisory Group prepare a plan for the protection of critical habitat for elk in the Bow Corridor and submit it to Alberta Forestry, Lands and Wildlife. With respect to the project area, the Board concludes that continued use of the critical habitat in Wind Valley by unhabituated elk should 
be an objective. The Board considers that development in Wind Valley would make this objective difficult to achieve. On the other hand, if development were to be approved only in the Bow Valley portion of the project, the Board believes that it could be achieved provided certain actions are taken. To be specific, movement corridors should be protected as set out above. In addition, the Board would recommend to Alberta Forestry, Lands and Wildlife that hunting be allowed to continue beyond a safe distance from residences and that measures be taken to control access to Wind Valley. Such measures should include providing only hardened trails and viewing points, discouraging off trail pedestrian access, and prohibiting vehicular access. The Board would require that Three Sisters prepare a plan for the approval of Alberta Forestry, Lands and Wildlife to conduct aversive conditioning.

If any portion of the project is approved, the Board would require as set out in Section 10.4.4.2 that the Applicant's vegetation management plan be approved by Alberta Forestry, Lands and Wildlife. The Board would recommend to Alberta Forestry, Lands and Wildlife that the vegetation management plan include proposals to alter vegetation in order to enhance wildlife habitat and provide fire protection and that it be provided to the Regional Ecosystem Advisory Group for review.

\section{Bighorn Sheep}

Three Sisters introduced evidence from Alberta Forestry, Lands and Wildlife that more than 200 bighorn sheep use Wind Ridge, Pigeon Mountain and Mount Allan as critical overwintering range and spring range. Dr. Geist, on behalf of the CPAWS Group, suggested that it is one of the largest of the remaining bighorn sheep populations in North America and that its members are exceptional in their large size and healthy, vigorous condition. The population is large enough and vigorous enough to survive if left undisturbed.

The Applicant said that sheep from Wind Ridge and Pigeon Mountain move from one area to the other and back and forth onto Mount Allan. According to the Applicant, much of this movement takes place at high elevations around the edge of Wind Valley but sheep also move down and across Wind Valley between Wind Ridge and Pigeon Mountain. Sheep also move downslope from Wind Ridge via Stewart Creek to a mineral lick on Three Sisters' property. The lick is on spoil from an exploratory trench dug by a prior landowner near an abandoned coal pit that served as the Canmore town dump. The Applicant also indicated that some of the reclaimed areas within the Three Sisters project area are used as winter foraging areas by sheep.

The Board heard that little was known about movements of bighorn sheep in the region. Dr. Woods noted that the sheep range on Three Sisters Mountain and Wind Ridge is contiguous with known sheep range in the Goat River area in Banff National Park, and that movement of animals between these ranges was possible. It was also pointed out by Dr. Woods and Dr. Paquet that, although sheep populations in the Bow Valley are generally thought of as disjunct, it is certainly conceivable that some interchange occurs between populations located on 
the north and south sides of the Bow Corridor. The Applicant also cited a report that "the Carrot Creek-Cougar Creek-Ghost Creek-Exshaw herd and the Mt. Allan-Wind Ridge herd, have been known to intermix in the vicinity of Exshaw". Road kill statistics provided by the Applicant for bighorn sheep on the Trans-Canada and 1A Highways in the vicinity of Bow Valley Provincial Park provide further evidence that interchange between these populations may occur. Dr. Woods stressed the importance of dispersal and genetic exchange in maintaining isolated subpopulations, noting that the presence of the highways and the cement plant, and mortality sinks resulting from highway mortality and hunting, may be inhibiting this exchange.

A number of concerns were raised about potential impacts on sheep. It was suggested by several interveners that the proposed project could obstruct access by sheep to the mineral lick in the Stewart Creek drainage and movements between Wind Ridge and Pigeon Mountain across the floor of Wind Valley. Development in Wind Valley and increased backcountry use by a larger resident human population could disturb sheep using critical habitat on Wind Ridge and Pigeon Mountain and result in its alienation. In combination with increasing development in Kananaskis Country in general, and on Mount Allan in particular, the effective range of the sheep herd could be reduced to a level that would be insufficient to sustain it. Finally, development in Wind Valley in particular, and to a lesser extent development adjacent to the mineral lick trail, could lead to habituation of the sheep especially if hunting is prohibited. Dr. Geist said that even wild populations of bighorn sheep are attracted to human sources of food and tend to become habituated very easily. Habituation of sheep has been related to increased incidence of diseases and infestations of parasites in sheep and to general declines in health, vigour and what is assumed to be genetic fitness.

Three Sisters undertook to implement certain mitigation measures to ameliorate potential impacts. It said that it would conserve a large wedge of forest cover between Stewart Creek and the mineral lick, restrict heavy construction activity in the vicinity of the mineral lick to the season from September 1st to May 31st, and close a trail along the abandoned railbed in the same area from June 1st to September 1st. The Board accepts that those undertakings would be discharged and would recommend that Alberta Forestry, Lands and Wildlife review the detailed plans to provide cover along the mineral lick trail. Three Sisters also undertook to maintain a movement corridor for sheep across Wind Valley between Wind Ridge and Pigeon Mountain and identified the need to control access by people to sheep range on Wind Ridge and Pigeon Mountain in winter and spring. Although Three Sisters identified the need for such controls to reduce disturbance of sheep, it suggested that there was a significant probability that sheep might become habituated even if there were no development in Wind Valley and all mitigation measures were applied.

The Board accepts that the sheep population on Wind Ridge, Pigeon Mountain and Mount Allan is worthy of protection and that its range could be subject to encroachment and alienation from all sides. The Board notes that not allowing development in Wind Valley was considered by Alberta Government Departments as mitigation for potential impacts of the construction of alpine village facilities in Kananaskis Country. Destruction or alienation of the habitat on Wind Ridge and Pigeon Mountain would almost certainly result in loss of the herd. 
Large scale development in Wind Valley as proposed by Three Sisters could have this effect. Smaller scale activity in Wind Valley and increased public access could instead result in habituation of the herd to human activity, especially as hunting would not be allowed near residences or within range of human activities such as golf. On review of the evidence, the Board believes that both these outcomes might be avoided if no development were allowed in Wind Valley, if corridors were maintained with adequate vegetation cover across Wind Valley and from Wind Ridge to the mineral lick site, if access to Wind Valley were appropriately controlled, and if hunting of the sheep herd were allowed subject to Alberta Forestry, Lands and Wildlife regulation. It would also be desirable to provide a corridor for sheep to reach and cross the Bow Valley to facilitate exchange with the Exshaw herd, although the Board recognizes that the optimum location for such a corridor may not necessarily involve the Three Sisters property. The Board believes that the matter of movement corridors for bighorn sheep and the possible existence of mortality sinks are issues that should be addressed by the proposed Regional Ecosystem Advisory Group.

\section{Other Ungulates}

Moose occur infrequently in the Bow Corridor including the Three Sisters property, a fact attributed by Three Sisters to the generally poor quality of habitat for moose in the Bow Corridor and the high susceptibility of moose to road and railway collisions. Mule deer and white tailed deer are both found in the Bow Corridor and on the Applicant's property. White tailed deer are more common at lower elevations and are more numerous in road kill statistics; mule deer are more common at higher elevations and were seen more often on Three Sisters property. Mule deer utilize similar habitat to elk and are known to move in similar corridors. The Applicant concluded, on the basis of its own field surveys, that most of the Three Sisters property, including Wind Valley, contains moderate to high quality habitat for mule deer. Although there is evidence that mountain goats were present in the area historically, this species presently is not found on or in the vicinity of the Three Sisters property.

The Board has reviewed the evidence with respect to moose, deer and goats and concluded that the proposed project would be unlikely to have significant effect on regional populations. In reaching this conclusion, the Board noted that measures proposed to protect and enhance elk would also benefit deer.

\section{Grizzly Bears}

Grizzly bears are classified as vulnerable in Canada by COSEWIC. A recent assessment of the status of the grizzly bear quoted by Three Sisters concluded that the species is vulnerable in 8 of 12 biogeoclimatic zones of Canada and that the only southern area in which it is not yet vulnerable is comprised of southwest Alberta, southeast British Columbia and northern Montana. The CPAWS Group described to the Board a historical decline in numbers of grizzly bears and their retreat to ranges in the Rocky Mountains and northwestern Canada. 
The Applicant quoted an Alberta Forestry, Lands and Wildlife estimate that $\mathbf{7 3 3}$ grizzlies were resident in Alberta in 1990 but that the population was declining. Forty six grizzlies were thought to inhabit Bear Management Area No. 5 which lies immediately south of Wind Valley and includes areas within and south of Peter Lougheed Provincial Park. Three Sisters reported results of a 1989 study by the Alberta Fish and Wildlife Division which estimated a population of 50 grizzly bears in Kananaskis Country.

Participants said that Wind Valley includes the territories of at least one and possibly two breeding females and that the home range of at least one adult male overlaps the area. In Kananaskis Country breeding females occupy relatively small $\left(179 \mathrm{~km}^{2}\right)$, mutually exclusive home ranges, whereas adult males occupy much larger $\left(1183 \mathrm{~km}^{2}\right)$, overlapping home ranges. In addition, subadult bears and bears seeking territories may visit the area. The CPAWS Group gave evidence about the regional importance of the fen in Wind Valley and in particular the value of its large productive population of Equisetum as summer food for grizzlies and black bear. The existence of this unusual food source could encourage more individual bears to visit Wind Valley than would otherwise be expected. The CPAWS Group also pointed out that Wind Valley provides an opportunity for secure predation because of its relative isolation as well as its abundant supply of prey such as elk calves.

Dr. Herrero, on behalf of the CPAWS Group, described the existence of a regional network of probable grizzly bear movement corridors, noting the importance of such corridors in enabling bears to access resources or important habitat components in different parts of their ranges. Interruption of these corridors would result in habitat fragmentation and ultimately contribute to population declines. He suggested that certain other large carnivores, including wolves and wolverines, use the same corridors and went on to describe the Wind Valley as a "hub" within this regional network of corridors, noting that it "is a probable connector joining the Kananaskis, the Bow Valleys and the Spray Valleys and, in that sense, it is an important area".

Expert witnesses on behalf of the Applicant and the interveners agreed that should the proposed development in Wind Valley proceed, the minimum loss of grizzly bears would be one breeding female and one male. These would be permanently lost to the population because of the alienation of their territorial habitats. Opinions differed about the extent of losses that could be expected in addition to that. If two female bears are resident in Wind Valley, both would probably be lost. In addition, bears moving through the area, feeding at the fen or hunting elk calves would be displaced and suffer consequent losses in energy balance, or would be removed or destroyed if they come into direct contact with human residents or visitors. Dr. Herrero suggested that, because of the attractiveness of Wind Valley to grizzly bears, the proposed development could create a "mortality sink", in which bears are continually attracted to the fen and other resources in the valley bringing them into potential conflict with humans. He estimated that the number of grizzly bears using Wind Valley over a period of five years might total 19. Three Sisters said: "It is possible that the proposed Wind Valley development by Three Sisters, and the expansion of residential and recreational facilities to the north, west and south of the Town of Canmore (individually and cumulatively) could act as population sinks 
to grizzly populations in Kananaskis Country and Banff National Park, respectively, with ultimate effects on the maintenance of the regional population." This view was shared by other participants and the Board agrees. Three Sisters stated that tourism development in Wind Valley would be incompatible with its use by grizzly bears and that aversive conditioning would be used to discourage the animals and reduce mortality. All participants agreed that habituation of grizzlies is not desirable and the Board concurs.

Not only it is not possible to be certain of the number of grizzly bears likely to be affected by development in Wind Valley, it is even more difficult to be sure of the effect on the local and regional populations. Mr. Weaver, on behalf of the CPAWS Group, said that the welfare of grizzly bear populations hinged primarily on the adult female segment of the population. He reported that in most bear populations adult females comprise 10 to 12 percent of the population. On that basis he estimated that as few as three to five adult female grizzlies with cubs might exist within the $3,500 \mathrm{~km}^{2}$ carnivore conservation unit (Unit D) containing the Three Sisters project area. If that were the case, loss of even a single adult female grizzly in Wind Valley could represent 20 to 33 percent of the reproductive females in that management unit.

The Applicant based its estimate of the regional population size on an Alberta Forestry, Lands and Wildlife estimate of 50 to 77 grizzly bears in Kananaskis Country. Again assuming that 10 to 12 percent of those are breeding females, it would appear that there may be only five to nine adult females within this $5000 \mathrm{~km}^{2}$ area. Loss of two breeding females from Wind Valley could, on that basis, represent between 22 percent and 40 percent of the reproductive females in the regional population. An impact of that magnitude could pose a significant risk to the survival of that population. It can be argued that the numbers are somewhat speculative as explained above, but the Board believes it would be prudent to avoid such a risk at least until better information is available that would justify reaching a different conclusion.

Some participants in the Board's review suggested that development of the Bow Valley part of the Three Sisters property would alienate grizzly bears from Wind Valley because of increased incursion into the valley by tourists, hikers and off road vehicles that would originate from the enlarged human population. The Board recognizes the merit of this argument, but believes that the measures to control access outlined earlier in this section could prevent this, if they were effectively implemented.

The Board is therefore satisfied that development of the Bow Valley part of the Applicant's property could proceed without unacceptable risk to the local or regional population of grizzly bears if the Applicant were to implement the short term measures it has proposed with respect to them. The measures, which the Board regards as undertakings include:

- a combination of aversive conditioning and reduction in habitat suitability and food availability within the developed area (e.g., control of garbage disposal, minimum shrub and tree cover within development pods); and 


\section{$10-44$}

- protection of prime grizzly bear habitat adjacent to the Canmore Corridor and minimization of sensory and human disturbance within prime habitat areas (e.g., habitat protection and enhancement, control of trail design, location and use, restrictions on aircraft overflights, control of pets).

The Board recognizes that aversive conditioning could not be used without the approval of Alberta Forestry, Lands and Wildlife and would require that Three Sisters prepare a plan for the Approval of that Department that would deal with aversive conditioning of bears.

The Board recognizes that there may be conflict with other Three Sisters design objectives with respect to the retention of shrub and tree cover within development pods but expects that this would be resolved by the Town as part of subsequent detailed approvals should the project go ahead.

The Board believes that more work is needed to determine what measures are required to ensure the long term survival of the regional population of grizzly bears and it considers the proposed Regional Ecosystem Advisory Group the appropriate body to consider the matter. The Board also notes that Three Sisters provided in its response to the Board's request for supplementary information relatively detailed proposals setting out what is needed. The Board is in broad agreement with these proposals.

\section{Black Bears}

Three Sisters quoted an Alberta Forestry, Lands and Wildlife study of 1984 which concluded that there were 50,000 to 60,000 black bears in Alberta and that the numbers had increased in the previous 20 years. However, Mr. Hummel, on behalf of the CPAWS Group, said that most biologists agree that black bears are being killed at an unsustainable rate and that nationally the black bear population may now be declining. He said that Wind Valley is on the edge of the "extinction line", indicating that the species has disappeared from the prairie and parkland to the east. Three Sisters quoted a second Alberta Forestry, Lands and Wildlife study showing that densities of black bears in the Bow Corridor are low compared to areas such as the nearby Sheep River drainage. Black bears are known to frequent the Applicant's property and Canada Parks Service estimated that a minimum of six may be resident at least partly on the property and an indeterminate but larger number may pass through it when moving from one seasonal range to another.

Participants agreed that should the project proceed, at least six black bears would be displaced and effectively lost to the population. They also agreed that black bear movements through the area would be impeded and this could result in losses of production if bears could move between parts of their ranges, and indirect losses if bears were to encounter human residents and have to be destroyed or removed from the area. Several interveners noted that the Town is known to be a mortality sink for black bears. Habituation of black bears related to access to waste food and garbage is a well known problem leading to the death of bears. Three 
Sisters undertook to implement several measures described earlier in relation to grizzly bears to avoid this problem. Although there would still be a loss of capability for bear production on the property, adoption of these measures should minimize bear mortality arising from the project.

In contrast to the grizzly bear, both the Wind and Bow Valley portions of the Three Sisters property are known to be used by black bear, so that the development of either would affect the population. The Board heard however, that the Wind Valley may be particularly important, since it provides an unusually rich feeding area for black bears. Dr. Herrero noted that, like the grizzly bear, black bears depend heavily on the availability of horsetails during the early to mid summer period. The large Equisetum fen in Wind Valley is considered especially important since Equisteum communities have a very limited distribution in the region. In addition, bearberries, which are an important food source for black bears, are abundant in Wind Valley. Black bears also prey on the calves of elk and other ungulates, and consequently might be expected to take advantage of the abundance of ungulate prey in Wind Valley. This would suggest that if development were not allowed in Wind Valley, impact on black bears would be less than if the whole project were approved and that the decrease in impact would be greater than proportionate to the areas involved.

The Board concludes that there would be losses and adverse impacts to black bears should the project proceed and that these would be substantially reduced should the Bow Valley part of the project alone be approved. While the potential loss of six or more bears and the disruption of bear movements would affect the regional population adversely, it would be hard to argue that the provincial population of 50,000 to 60,000 animals would be threatened. The Board recognizes that there is substantial uncertainty about the significance of the possible effects, but the Board believes there is insufficient evidence to persuade it not to approve the project because of potential impacts on black bears, provided the Applicant's undertakings are carried out.

Wolves

Dr. Paquet said that wolves were historically common in the Bow Corridor, using the entire area and montane valley bottoms in particular. In addition to displacement by development, wolves have been subjected to several eradication programs. In the Bow Corridor, the last occurred about 40 years ago, and wolves have only recently re-established near enough to the Corridor to move through Wind Valley. Dr. Paquet's evidence was that wolves are continuing to increase in numbers and to reoccupy more of their former ranges. Extensive development in the Bow Valley portion of the proposed project area would exclude wolves from that area, and development in Wind Valley would block movement of wolves between the Bow and Wind Valleys and Kananaskis Country. It was suggested by several interveners and by the Applicant that if Wind Valley were developed wolves would either abandon the area or their use of it would be greatly reduced. There is no mitigation for this potential impact. The Board agrees with this conclusion and would regard it as an undesirable consequence of the proposed project. 


\section{Wolverines}

Wolverine is rated as a vulnerable species by COSEWIC, but partly because of the animal's reclusive habits there is too little information about it to be confident about its status. The Applicant and interveners agreed that wolverines are present in at least the Wind Valley part of the project area and that they would abandon any part of the area where development takes place. The number of resident wolverine is probably small, but is unknown, and the consequence of any potential losses to the regional population cannot be determined.

The Board believes that development in Wind Valley would have an effect of uncertain magnitude on the local and regional wolverine population. The Board also concludes that development on the Bow Valley part of Three Sisters' lands would probably not have a significant effect on wolverine if there were effective controls on access to Wind Valley.

\section{Other Carnivores}

Although the cougar is not presently listed as threatened or endangered by COSEWIC, it is on Alberta Forestry, Lands and Wildlife's blue list. Species are placed on the blue list when their popluations are either known or suspected to be vulnerable to decline. Cougars exist at very low densities throughout the Eastern Slopes and front ranges of the Rocky Mountains. While its status in the project area is not well known, the Applicant and a number of other witnesses testified that the cougar does regularly inhabit the Three Sisters property. An adult cougar was recently seen near Three Sisters Creek and an adult female with a kitten was recently reported in the vicinity of Wind Valley and Stewart Creek. Dr. Paquet said he had observed cougar tracks and evidence of cougar kittens in Wind Valley and in the adjacent part of the Bow Valley. Valley bottoms, particularly in the montane ecosystem, are considered important winter habitat for cougar. Canada Parks Service suggested that one cougar may be displaced from its home range if the development proceeds. Cougars are also likely to be killed as a result of interactions with human residents if the project is built. Three Sisters predicted that in the long term, the cougar population in the Bow Corridor will decline because of the impact of development. The Board agrees with this assessment.

Lynx are not considered vulnerable by COSEWIC but are on Alberta Forestry, Lands and Wildlife's blue list. They have been reported on the Three Sisters property, but the property affords only low quality habitat for the species. Three Sisters concluded that, although lynx would probably be displaced by development in the area, the number of animals affected would probably be small and the impact on the regional population would probably not be significant. The Board agrees.

Coyotes are thought to be relatively common in the project area, and Canada Parks Service indicated that they appeared to use the same corridors as elk and wolves. Smaller carnivores generally have smaller home ranges and occur in larger regional populations. Dr. Paquet, on behalf of Canada Parks Service, said that there is hard data to support the opinion 
that small carnivores are not threatened. The Board agrees with this conclusion. As mentioned in Section 10.4.3, management and conservation of smaller species may be best addressed at the ecosystem level.

\section{Amphibians and Reptiles}

Three Sisters reported the wandering and red-sided garter snakes, the northern long-toed and tiger salamanders, the western toad, the boreal chorus frog, the wood frog, the spotted frog, and the northern leopard frog as present or possibly present in the Bow Corridor. Of these species, the northern long-toed salamander and the northern leopard frog are rated by Alberta Forestry, Lands and Wildlife as at risk in Alberta. The northern leopard frog has not actually been seen in the vicinity of the proposed project but the northern long-toed salamander has been found near Quarry Lake close to the western boundary of the Three Sisters project. The proposed project area offers relatively little high quality habitat for amphibians or reptiles. Three Sisters said that it does not intend to develop wetland areas where these species may be found and noted that its proposed monitoring program would include monitoring water levels in wetlands should the project be approved. The monitoring program would include the two small wetlands near Quarry Lake where the northern long-toed salamander may occur.

The Board has reviewed the evidence about potential impacts on amphibians and reptiles and the Applicant's proposals for monitoring wetlands. The Board accepts that adverse effects on the long-toed salamander are possible even at some distance from potential breeding areas because this species spends much of its adult life away from open water. The poor quantitative record of occurrence of the species makes assessment difficult. Given the fact that the Town would be reviewing and approving detailed designs of subdivisions near wetlands, including those near Quarry Lake, and that more information would probably be available at that time, the Board is satisfied that the Applicant's proposals with respect to reptiles and amphibians are adequate.

\section{Birds}

The Board heard extensive argument about the potential impacts of the proposed project on birds, but little information was provided about the species and numbers of birds resident on the Three Sisters property. Canada Parks Service explained that the montane and aspen parkland ecosystems are unusually rich in bird species and especially in species of migratory songbirds. Populations of songbirds that winter in Central and South America have declined in recent years at a pace greater than impacts on their winter range can account for. Canada Parks Service suggested that the decline is attributable to cumulative effects on songbird summer ranges in Canada and the United States and that the Three Sisters development would contribute to it by destroying some habitat and alienating other. Canada Parks Service also observed that habitat fragmentation associated with forest clearing and residential development benefits species such as magpies, crows, starlings, house sparrows and possibly jays and ravens. 


\section{$10-48$}

Some of these species prey on songbirds and others, especially the non-native ones, compete aggressively with songbirds for nest sites and food. Finally, development introduces domestic pets which often prey heavily on small birds.

The Board has reviewed the evidence with respect to songbirds and is of the view that impacts would be locally significant. Impacts would be reduced by implementation of the undertakings for mitigation that the Applicant has put forward. One of these undertakings, that of prohibiting free ranging cats and dogs within the project area by by-law, would require action by the Town. The Board would recommend that the Town accept the Applicant's proposal. The Board believes that the undertakings with respect to mitigation would represent an appropriate contribution by the Applicant to the protection of birds. However, the Board believes that the conservation of songbirds should be addressed at the ecosystem level. The Board notes that the Applicant indicated that it would cooperate with a Regional Ecosystem Advisory Group and songbirds could be one of the subjects of such cooperation.

Three Sisters assessed the potential effects of its proposed project on waterfowl, raptors, corvids, and upland game birds. In making its assessment, it took into account its proposed mitigative measures. It concluded that residual impacts would be, at worst, of local significance and suggested that this would be acceptable. Interveners did not take issue with this conclusion. The Board concurs and considers the Applicant's undertakings sufficient to limit impacts on these species to an acceptable level.

Some interveners expressed concern about rare and endangered species of birds. The Applicant reported that a Cooper's hawk had been seen on the property in 1991 and that the great grey owl might occur in the area. The Peregrine falcon inhabited the area in the past and might be reestablished there in the future. Given the rarity of these species, the Board considers that there is little Three Sisters could do to protect them other than to implement its undertakings that apply to all raptors. Canada Parks Service notes that it is difficult to deal with rare and endangered songbirds because it is not clear which species fall into this category. This being the case, the Board accepts that Three Sisters' undertakings with respect to birds would be adequate.

\subsubsection{Conclusion with Respect to Terrestrial Ecosystems}

The Board has assumed in its analysis of residual impacts on terrestrial ecosystems that, if the project were approved, Three Sisters' undertakings and the Board's conditions with respect to matters dealt with under air and aquatic ecosystems would be implemented or observed. Two items reviewed by the Board involve the potential effects of chemicals on both aquatic and terrestrial ecosystems. Chemical contaminants associated with abandoned industrial sites and with the use of pesticides and fertilizers on the Three Sisters property might affect soil and water. The Board would recommend, as described in Section 10.4.4.1, that Three Sisters conduct initial site evaluations of abandoned industrial sites and report the results to Alberta Environment. In Section 10.3, the Board dealt with the use of pesticides and fertilizers. The 
Board took into account the Applicant's undertakings with respect to its IPM program and concluded that the probable impacts of what Three Sisters proposed would be acceptable. The Board would require that Three Sisters periodically review its IPM program with Alberta Environment and that it would monitor the quality and quantity of surface and groundwaters to detect problems that might arise. The Board is of the opinion that anticipated water quality would not pose a threat to components of terrestrial ecosystems. It has also reviewed the possibility that application of pesticides and fertilizer could directly affect non-target plants and animals. The Board concluded that such direct effects would probably be minor and insufficient to put local populations of these plants and animals at risk provided the measures referred to above are implemented.

The Board believes that there are three fundamental questions about impacts on terrestrial ecosystems that must be answered:

- Is the area that the Three Sisters project would alienate sufficient to result in unacceptable damage to the ecosystem?

- Would the Three Sisters project unacceptably damage an ecosystem by obstructing or impeding movement of organisms between areas occupied by the ecosystem?

- Would the Three Sisters project unacceptably damage an ecosystem by generating or facilitating sufficient increased access by people to areas occupied by the ecosystem?

In determining what is acceptable and in defining conditions and recommendations with respect to regional ecosystems and their biological components, the Board had in mind the objective of conserving unusual natural resources that are not only valuable for their own sake but also form a substantial part of what attracts people to the Bow Corridor as residents or visitors. Assuming that its conditions and the Applicant's undertakings would be observed, the Board believes that the Three Sisters project would not have sufficient effect on the regional alpine ecosystem to threaten its survival or to bring about irreversible changes of significant magnitude in its composition. With respect to the montane ecosystem and at least one component of the subalpine ecosystem, the situation is less clear. The Board believes that its conclusion with respect to effects on the alpine ecosystem would also apply to the subalpine and montane ecosystems if development were only to occur in the Bow Valley portion of Three Sisters' lands and if the Board's conditions were observed. However, the Board believes on the evidence before it that if the entire project in the Bow and Wind Valleys were to proceed, there would be a very substantial risk of major adverse impacts on the montane ecosystem and the important species that live within it, and on bighorn sheep which are a component of the subalpine ecosystem.

This conclusion was not reached simply because a larger area would be disturbed but because Wind Valley includes components of the montane and subalpine ecosystems that are 


\section{$10-50$}

unusually valuable. It is an exceptionally fertile and diverse area with a relatively mild climate and is rich in species of animals and plants and affords them unusually productive habitat. Wind Valley is of particular importance for large carnivorous species such as grizzly bear, wolverine and black bear and is unusual in the number of carnivorous species occurring there." It also includes critical habitat for bighorn sheep and elk. The Wind Valley is an important route for movement of all these species between Banff, the Bow Valley and the north, and Kananaskis Country and the south. The Board believes that at present insufficient information is available to determine with certainty the magnitude of the potential impacts of the proposed project on the montane ecosystem and the important species that live within it and on bighorn sheep. The Board concludes that on the basis of the evidence before it, development in Wind Valley would be accompanied by a very substantial risk of major adverse impacts on those resources even after implementation of Three Sisters' mitigation measures and the various requirements and recommendations of the Board.

During the public hearing, there was some discussion of the possible effects of different levels of development in Wind Valley. Indeed the applicant spoke of gradually "phasing in" development there with the implication that development could be stopped if the consequences were becoming unacceptable. The Board finds this suggestion somewhat unrealistic because a large hotel is proposed as the first step in this phased development and this would have a substantial impact. However, the Board has examined the possible impacts of different scenarios of development in Wind Valley.

On the basis of the evidence before the Board, the difference in impact of different types and intensities of development in Wind Valley would vary with the impacted ecosystem component. However, there are some consequences that any level of development would share. Witnesses agreed that most of the large mammalian carnivorous species including grizzly and black bears and wolverine would be lost from the area and use of the area by others such as cougar, lynx and wolf would be reduced. Any development would increase access to and disturbance within Wind Valley and this would make it difficult to prevent habituation of ungulates, especially sheep and elk. Elk may be inhibited from using Wind Valley for calving if any development occurs there or if public access increases. Increased access could result in abandonment of the sheep range.

Any development in the area of Wind Valley proposed by Three Sisters could affect wildlife movements through it. Although the Applicant proposed to reserve corridors for wildlife movements in which buildings would not be constructed, the Board is not convinced that these would be adequate as proposed. However, some development could occur without blocking wildlife movements provided large enough movement corridors were protected. Loss and alienation of habitat for ungulates, smaller species of animals and plants would be related to the area taken up by development and the intensity of use of the area.

At the ecosystem level, any development in Wind Valley would result in losses of some important components of the montane ecosystem and damage to others. These would 
result in some degradation of the ecosystem, impair its natural function and reduce its attractiveness to tourists and residents.

In addition to the matter of Wind Valley, the Board concludes that a number of other measures would be necessary if development in the Bow Valley portion of the area were to proceed. Many of these measures were included in Three Sisters' undertakings but some were not. Others fell under the broad sweep of an undertaking but had not been specifically addressed by Three Sisters. For example, Three Sisters undertook to prepare a vegetation management plan but the Board is recommending in Section 10.4.4.2 that that plan include surveys for rare plants and important plant communities that would be taken into account in the detailed design of the proposed project as well as Three Sisters' proposals for regional vegetation management related to fire protection and wildlife habitat enhancement.

Should the Bow Valley portion of the project go ahead, the Board believes that unacceptable adverse impacts on Wind Valley and on the biological resources it sustains would not be avoided unless appropriate controls were imposed on access to it. The Board agrees that proposals by Three Sisters and by the CPAWS Group for construction of hardened trails and viewing points would both conserve the attractions and make it possible for people who find the existing trails too difficult to use to enjoy them. The Board would recommend the proposals to Alberta Forestry, Lands and Wildlife, the Town and the Applicant. Construction of a road from the Bow Valley through Skogan Pass to Kananaskis would clearly be inconsistent with these recommendations.

The Board is concerned about the potential for habituation of wildlife and would condition any approval to require Three Sisters to prepare a plan satisfactory to Alberta Forestry, Lands and Wildlife for aversive conditioning of wildlife on project lands. The Board would also recommend to Alberta Forestry, Lands and Wildlife that aversive conditioning be used on surrounding Crown lands, including hunting within a safe distance of human settlements and in accordance with wildlife management objectives.

A further potential for major impact on large animal species in particular would be blockage of their movement through the proposed project area. To combat this, the Board would require that the Applicant retain corridors in as undeveloped a state as possible in order to allow animal movements to continue and would recommend to Alberta Forestry, Lands and Wildlife the legal designation of such corridors. The Board would also make recommendations to Alberta Forestry, Lands and Wildlife to ensure the continuity of corridors through adjacent lands. The Board notes that Canada Parks Service supports this approach. The Board heard evidence that mammalian carnivores would probably use the same corridors as elk and deer, but that sheep would use different ones. The Board's recommendations would include both types. The Board also heard evidence about the incidence of road kills on the Trans-Canada Highway and the desirability of measures like those employed in Banff National Park to reduce them. This might involve construction of passes under the highway in the vicinity of wildlife corridors. The Board concludes that this is also an appropriate matter for review by the proposed Regional Ecosystem Advisory Group. A supplementary measure to reduce killing and disturbance of 
wildlife that the Board would recommend to the Town would be control of free ranging dogs and cats by by-law.

The Board believes that performance of the Applicant's undertakings and observance of the Board's conditions would reduce impacts on biological resources of the proposed Bow Valley portion of the development to acceptable levels.

\subsection{Ecosystem Management}

\subsubsection{Regional Outlook}

The Board believes there is a need at this time for a regional ecosystem perspective in assessing and maintaining natural resource value. As noted in the Canada Parks Service submission, the health of the wildlife resources intended for conservation in Banff National Park is inextricably linked to the health of the same resources in adjacent areas. It is also important to note that not all wilderness areas are of equal value. Of major importance are those areas of significant value as habitat, food and shelter sources and the linking areas or corridors which allow animals to move among them.

Both the Applicant and the CPAWS Group testified about the importance of Wind Valley as a key habitat area to which animals need access in both summer (particularly for bears) and winter (particularly for ungulates) in order to maintain viable populations. Mr. Kerr and Canada Parks Service spoke of the importance of the concept of linkages of key habitat areas when discussing the value of the Pigeon Mountain - Wind Valley - Ribbon Creek complex of habitat systems. Canada Parks Service also gave evidence that ranges for individual bear, elk and wolves could extend as far as Montana and southeastern British Columbia.

The Board considers that decisions as to where to place new developments in previously undeveloped areas are critical, given the unchallenged evidence of the Applicant that the first intrusion of development into undisturbed areas is the most disruptive to an ecosystem. The Board believes that regional management should take into account cumulative effects of existing and foreseeable developments, the key areas and the corridors linking them which should be preserved for ecosystem health, the types and extent of programs to control human access to such key areas and corridors and the types and frequency of monitoring programs to assist in ongoing management decisions. The Board considers that the appropriate region to be considered would include Banff National Park, the Bow Corridor, the Spray Valley and the Kananaskis Valley. Many participants urged the Board to recommend or consider the establishment of a regional advisory group. The Board considers the matter in Section 12. Its views on the environmental objectives of such a group are set out in Section 10.5.2 below. 


\subsubsection{Tasks and Goals for Regional Ecosystem Advisory Group}

The Board believes that the overall objective of regional ecosystem management should be the conservation of ecosystems and their key components. A corollary of this objective is to ensure that development within or affecting the region is sustainable. Some participants in the hearing took the position that continuing development would eventually lead to the degradation of regional ecosystems including, for example, the disappearance of some of the large animal species from the area and that this progressive cumulative effect is inevitable. The Board does not accept this view and believes that the conditions it would attach to development on Three Sisters' lands with respect to regional ecosystem management could avoid ecosystem degradation of significant magnitude and extent.

At a number of places in this Decison Report, the Board has made recommendations about matters that should be referred to the proposed Regional Ecosystem Advisory Group for review. These include:

- an assessment of regional ecosystems and their components and the capacity of both to sustain development, with particular emphasis on identifying what core areas need to be protected to ensure the survival of ecosystems and their key components that would include a review of critical habitat for ungulates in the region and preparation of a plan recommending what should be protected;

- review of regional vegetation management needs;

- the locations and widths of corridors to be set aside for wildlife movements; and

- review of cumulative effects on alluvial fans; and

The Board has also recommended that the Group review some specific detailed plans that Three Sisters would prepare if the project proceeds. Examples are:

- review of the detailed vegetation management plan; and

- review of measures proposed to prevent wildlife road kills. 
As indicated in Section 10 of the Decision Report, the area included in the Three Sisters Application is large and somewhat diverse. For this reason, and consistent with the approach used in Section 10, the Board will consider the economic and social effects not only for the total proposed project but also as they relate specifically to Wind Valley.

\subsection{Economic Effects of the Proposed Project}

\subsubsection{Introduction}

Prior to addressing the economic effects of the Three Sisters proposal, the Board believes it would be useful to briefly summarize the approach it will use. There are many different ways of defining and assessing economic effects of a proposed project. The Board will, in terms of economic impacts, focus its attention on the funds which would be expended as a result of the project, for materials and for labour, during construction and during operations. The Board will include in its consideration direct expenditures on-site, indirect expenditures off-site but related specifically to the project and induced expenditures which would occur off-site because of the economic activities related to the project.

A significant portion of the funds expended would be for labour, most of which would occur in the area of the proposed project during the operation of the project. The number and types of jobs that would be created would influence the public interest and the Board will, as part of its assessment, give specific consideration to estimates of the jobs that would result if the project goes ahead. Another portion of the total expenditures which might play a particular role in the assessment of the public interest are the amounts that would accrue as taxes to the various levels of government. The Board will also give specific consideration to this part of the total economic effects.

The Board is directed by the $N R C B$ Act to assess the Alberta public interest and therefore its primary analysis will be of the project related expenditures that occur within the Province of Alberta, as opposed to those that would leak or flow out of the province as expenditures elsewhere. An important aspect of measuring the economic effects on Alberta is to focus attention on those expenditures within the province which would be truly incremental as a result of the Three Sisters project and which would not occur if the project did not proceed.

The Board fully recognizes the importance of the economic and related social effects to the Town of Canmore and its citizens. As a result, the Board will also make an assessment of the portion of the economic effects that are likely to impact on the Canmore region, which for this purpose, the Board considers to be the Town of Canmore and the Bow Corridor. 


\subsubsection{Potential Markets For the Proposed Facilities and Services}

As the initial step in its analysis of the economic effects of the proposed project, the Board believes it should make a general assessment of the potential markets for the facilities and services which would be provided by the proposed Three Sisters project. This is not intended to be an evaluation of the financial viability of the project. In the Board's view, since this would be a privately funded project on privately owned lands, an evaluation of financial viability is properly the prerogative of the owners and investors.

The economic effects of the project on the province and on the region for which it is proposed would be dependent on the marketability of its various components. The Board therefore considers it appropriate to review the information submitted regarding markets and to draw conclusions as to whether there is sufficient potential demand to justify the timing of the various parts of the project as proposed by Three Sisters and its estimates of the revenues that would result. The Board believes it should also reach conclusions as to whether or not the demand is likely to be such that it would create incremental economic effects on the province. To illustrate the importance of this question, we might look first at the economic effect on Alberta of an international visitor who would not otherwise be here except for the Three Sisters project playing a round of golf on one of its courses. There would be a significant difference between that effect and one which would result from a Calgary resident playing a round on a Three Sisters course, who otherwise could have been accommodated and would have played on another course in the same general region if the Three Sisters project did not exist.

The facilities and services to be provided by the Three Sisters project can be generally categorized as follows:

- tourism

- resort destination and other hotels

- convention facilities

- shopping facilities

- golf courses and other recreational facilities

- other commercial space

- residential

- single family detached and multi-family: all price ranges

- staff dormitory type housing

- weekend and holiday homes.

The information received by the Board regarding potential markets was somewhat general in nature. In addition to the information from the Applicant, the Board did receive and hear evidence on reports prepared for government departments respecting housing and demand 
for golf and tourism facilities. There were also comments by many participants reflecting their views on the demand for the various facilities and services.

11.1.2.1 Hotels and Related Convention, Commercial and Recreational Facilities

The project proposed by Three Sisters would include 2,425 hotel rooms, 2,275 of which would be in Wind Valley. There would also be a total of some 600,000 square feet of convention and commercial space, approximately one-half of which would be in Wind Valley, and a total of three golf courses in addition to the Site C course which is currently under construction.

As indicated in Section 8 of the Decision Report, there are a significant number of hotel and motel rooms, in excess of 700 , planned and previously approved for the area. There is also discussion of not yet approved hotel projects or expansions, other than the Three Sisters proposal, that would involve more than that many rooms again. Also, information provided at the hearing indicates that three golf courses, including the Three Sisters Course C, have recently been approved for the area.

The Board agrees with the position put forward by Three Sisters, Tourism, Parks and Recreation and certain other participants that tourism is a growing industry and that the Bow Corridor is potentially a very important growth area. The Board is therefore satisfied that there will be increased demand for quality tourism accommodation in the Canmore area. The more difficult question is whether the demand will be sufficient to result in incremental use of the proposed Three Sisters facilities, as opposed to simply a shift from one set of tourism facilities to another by individuals who would be in the area regardless of whether or not the project went ahead.

Three Sisters took the position that much of its proposed hotel accommodation and related facilities would be aimed at international and other visitors who would spend a significant block of time at the destination resort in Wind Valley, where essentially all amenities would be provided. It contended that the destination resort type facility with the synergism of a variety of hotels and related facilities in close proximity, combined with the beauty of Wind Valley, would attract many new visitors. Three Sisters stated that these additional visitors and their longer stays would mean much of the associated economic effects would be incremental to the province but it did not submit specific estimates.

A number of the other participants in the hearing questioned whether demand for such an international resort exists, and even the Applicant acknowledged that it would have to rely on the reputation of vacation spots like Banff and Lake Louise for an initial period while it established an international reputation. Mr. Perras, for the AWA Group, made specific reference to the low occupancy rates that exist for area hotels during winter and presented statistics suggesting that the number of skiers using the area had not grown over the past ten 
years. Others raised concern that the demand for golf could be satisfied at recently constructed or approved courses in the area.

The Board, on the basis of the information received at the hearing, has some concern regarding potential markets for a destination resort as proposed by Three Sisters for Wind Valley. This is particularly the case in the short term, having regard for the current uncertainty in the Canadian economy and in the economies of other countries that would be expected to provide visitors to the area. This short term concern regarding the economy is heightened by Three Sisters' plans to proceed with the Wind Valley resort first in the overall scheduling of the project. Also, Tourism, Parks and Recreation concluded that the Canmore area needs to become a stand-alone resort area with 1,000 plus rooms and emphasis on the midprice range, while the Three Sisters proposal and already approved projects total in excess of 3,000 rooms. Notwithstanding these concerns, the Board is prepared to accept, for purposes of its economic assessment, that there would be sufficient long term demand to justify the proposed hotels and related facility portions of the Three Sisters project. The Board would however, reflect a modest delay and a more gradual build-up in the pattern of usage of these facilities than was projected by Three Sisters in its Application.

With respect to the question of whether the proposed Three Sisters hotel and related facilities would represent incremental impacts on the province or the region, there was considerable discussion at the hearing but no analyses specific to the Three Sisters proposal were submitted. Dr. Power, on behalf of BowCORD, indicated that there may be some difficulties in estimating incremental impacts and described how it might be done, but did not present specific estimates. Three Sisters stated that the incremental impact would be large and gave as its primary supporting rationale the fact that it would offer a destination-type resort located in a very attractive area. Some participants generally supported this position, but it was challenged by others.

A Peat Marwick study presented at the hearing on behalf of Tourism, Parks and Recreation indicated that there is growth in international visitors to the area, but that they represent less than one-third of the total visitors. Tourists from elsewhere in Canada are substantial in number and are growing. The Board believes the growth in visitors from outside the province will continue whether or not the Three Sisters project proceeds, but accepts that the attractive setting of Wind Valley and the particular resort facilities planned by Three Sisters would likely increase the rate of growth. At the same time, the Board agrees with a number of interveners that a considerable portion of the use of the Wind Valley facilities would be by Albertans, or by visitors from outside Alberta, who would have been visiting the region in any case. The Three Sisters facilities, if they went ahead, might have some potential for lengthening the average duration of a stay in Alberta for the latter group. Additionally, the Board would expect the portion of usage of the Three Sisters project which has an incremental impact on the province to grow with time as the number of out-of-province visitors to the area grows.

Referring specifically to golf, the Peak Marwick study dated 1989 suggested a current demand for four new courses and a projected demand for an additional four courses in 


\section{$11-5$}

the Canmore/Bow Corridor by the year 1999. The Three Sisters Application includes three golf courses. Three other courses have recently been approved for the area and several others have been proposed. The Banff Springs golf course has recently been expanded and the NRCB recently approved an additional 18 holes for the Kananaskis golf course. Additionally, golf facilities have recently opened or are planned on the western edge of the City of Calgary.

All of these developments raise doubt as to the ongoing excess of demand over supply for new golf courses. In the Three Sisters case, the demand would be partially driven by other elements of the proposed project, such as weekend and other homes surrounding golf courses and the Wind Valley destination resort. The Board is prepared to accept that there is reasonable long term justification for the golf course components of the project but believes that a considerable amount of their usage would be by Alberta golfers or other visitors who have simply shifted a round of golf from one course in the area to another.

Regarding commercial space, whether at the proposed Wind Valley resort or elsewhere, the Board believes the demand would be driven by the growth in the Town, the development of tourism facilities and the number of visitors. Generally, the Board would expect the economic effects related to this space to represent incremental effects on the province more or less in proportion to that which would occur with respect to hotels and related facilities.

Overall, the Board believes that much of the use of the proposed hotels, convention, commercial and recreational facilities would be by Albertans or by others who would likely be in the region whether or not the Three Sisters project proceeds. As an example, the Board accepts Three Sisters' contention that its proposed Wind Valley facilities would be attractive and capable of accommodating many conventions and business meetings, but believes that a large percentage of these would be otherwise held at facilities in Banff, Lake Louise, Jasper or other Alberta centers. They therefore would not represent incremental economic effects on the province.

In the absence of special studies dealing with the incremental issue, the Board will use in its economic impact assessment, judgmental estimates based on the views expressed at the hearing. The Board has assessed all of the evidence before it and estimates that only about onethird of the expenditures at the proposed hotel and related facilities would be incremental to the province in the initial years of development, but believes that this could grow to about two-thirds over a period of some 20 years.

\subsubsection{Residential}

This Section of the Decision Report deals only with the potential demand for the residential components of the Three Sisters proposal. Other issues related to housing are dealt with in Section 11.2.4. 


\section{1-6}

Three Sisters is proposing a total of some 6,085 housing units, of which some 1,500 would be in the Wind Valley portion of the project. The situation regarding potential markets for this housing must be considered in the light of other developments already approved in the Canmore area. There is no guarantee that they would all go forward, but the information provided to the Board indicates that almost 2,000 housing units are currently approved but not yet built.

If the Three Sisters project proceeds, in whole or in part, there would be a related creation of jobs and other economic activities and a growth in the population of the Town. This would result in increased demand for housing for full time residents of the area. Three Sisters suggested that the housing it would provide would be sufficient to meet the needs of the direct and indirect employment created by the development.

Recognizing the current shortage of housing in Canmore, the size of the proposed project, the number of jobs that might be created, and the planned staging of housing developments over a 20 -year period in reasonable size increments, the Board is satisfied that there are sufficient potential markets for housing to justify the approximate number of those residences that would be intended for full-time use. Three Sisters implied that this would be about 70 percent of the total houses planned as part of the project. Since the demand for housing would depend, in part, on the population growth associated with the Three Sisters hotel and other commercial developments, and since the Board has concluded that market considerations would likely cause a modest delay and more gradual buildup in use of these developments, for purposes of its economic assessment it will reflect a similar delay in residential developments.

With respect to housing for permanent residents of the community, most of the demand would result from population growth related to the project. Accordingly, after leakages from the province are taken into consideration, much of the economic effects related to the construction and ongoing maintenance of the residences would likely be incremental to the Canmore area. The Board is also prepared to assume, for purposes of its analysis, that a large portion of the economic effects related to full-time resident houses would be incremental to the province.

Three Sisters suggested that approximately 30 percent of the housing component of its project would be intended as weekend or holiday homes for the so-called shadow population who do not reside in Canmore on a full time basis. The Board accepts this estimate and also that there is sufficient demand for such housing to justify that particular component of the proposed project. However, current economic conditions may affect the demand for second homes and their construction may be somewhat delayed and more gradual than indicated by Three Sisters in its Application.

Whether or not the expenditures related to second homes are incremental would depend on who would purchase them and what they otherwise would do if the Three Sisters project did not proceed. Those part-time residents of the Three Sisters project who would not 
otherwise own a second residence or would own one outside of Alberta, would represent an incremental economic effect on Alberta. Three Sisters contended that Alberta is exporting a great deal of second home related economic impacts to British Columbia, Montana and further afield. Tourism, Parks and Recreation referred to a possible estimated demand in Calgary for 4,000 second homes. A number of other interveners, particularly the AWA Group and BowCORD, contended that there would be little incremental effect associated with part-time residences, but little hard evidence was presented. Recognizing the proximity of Canmore to Calgary and the relative lack of second home recreational areas within easy driving distance of Calgary, the Board believes it reasonable to estimate that some 80 to 90 percent of the part-time residences would represent incremental economic impacts on the province.

\subsubsection{Economic Effects of The Proposed Project and Alternative Scenarios}

As indicated in the Introduction to this Section, the Board will consider the economic effects for the total proposed project and also as they relate specifically to Wind Valley. With respect to Wind Valley, a number of different possibilities were discussed at the hearing. They included the total proposed project with a major resort development in Wind Valley as put forward by the Applicant, and at the other extreme, no development in Wind Valley or on any of the Three Sisters lands, as advocated by certain of the interveners. There was also discussion of scenarios involving a variety of developments in Wind Valley smaller than that proposed by Three Sisters plus the developments as proposed for the remainder of the Three Sisters lands in the Bow Valley. The possibility of a scenario with no development in Wind Valley but with the proposed development in the remainder of the Corridor including an expanded hotel component was also explored at the hearing.

The Board recognizes that it has only one application before it, that for the entire project as proposed by Three Sisters. Nevertheless, Three Sisters did indicate that in the event the Board found one part of its proposal not acceptable, it would wish to have a decision with respect to the remainder of the proposal. Three Sisters made it clear in this regard, that if such an event did occur, it would have to re-evaluate many components of its project.

The Board did not receive an economic impact assessment for a project other than that proposed by Three Sisters. However, the data which forms the basis for Three Sisters' economic assessment, the questions raised and comments of other participants respecting that basic data, and the discussion of other possible development scenarios at the hearing, have provided the Board with sufficient information to make a qualitative assessment of the economic effects that would likely result from development scenarios other than as proposed by the Applicant. The Board believes that assessments of potential alternatives are necessary in order for it to properly determine whether, in its opinion, the proposed project or parts thereof may be in the public interest.

In terms of the development scenarios which the Board will consider, it will focus its attention on the Application before it, that is the project as proposed by Three Sisters. It will 
then make a qualitative assessment of the proposed project but with no development in Wind Valley. It will similarly make a qualitative assessment of the project as proposed in the Bow Valley but with a substantially reduced development in Wind Valley.

With respect to the no development in Wind Valley scenario, the Board recognizes that such a development could be primarily a residential expansion of the Town, which would not be expected to be subject to review by the NRCB. The Board believes there is considerable likelihood that if Three Sisters were to proceed with a project with no development in Wind Valley, such a project would likely involve a significant hotel complex elsewhere in the Bow Valley. In fact, the Applicant indicated that an earlier version of its plans involved such a complex, to be located at the Three Sisters site in the west central portion near pods 16, 17 and 18 of the Three Sisters lands, as shown on Figure 1-3. The Board believes it should, in assessing the economic effects of the proposed project, make a qualitative assessment of such a scenario, with no development in Wind Valley but with a significant hotel component in the Bow Valley.

\subsubsection{The Proposed Project}

The evidence presented by Three Sisters indicates that, over a 20 -year period, the total economic impacts in Alberta due to construction and operations would be about $\$ 3.7$ billion. Some 15,000 person-years of employment would be provided by the construction phase, and the project at full build out, would directly employ over 5,200 persons. Three Sisters suggested that indirect and induced economic activities would provide about 1,800 additional jobs by the time of build out.

Three Sisters did not make specific estimates as to where the expenditures and jobs would occur but indicated that most would be within Alberta, with little leakage to outside the province. Mr. R. Melchin said that he expected a local to provincial split of 50:50 for construction and 70:30 for tourism operations.

According to figures derived from Three Sisters' data, the project would, over the period to build out, generate a total of some $\$ 400$ million in corporate and personal income tax, of which one-third would accrue to the province. It would increase the municipal assessment base by some $\$ 580$ million by the end of the project and beyond. Combining Three Sisters' assessment values with the 1991 mill rate would result in total taxes of some $\$ 100$ million to the municipal government over the 20 -year period.

Dr. Kubursi, in a report for Tourism, Parks and Recreation, used a model to evaluate the economic effects of the proposed project and projected somewhat different impacts than those presented by Three Sisters. Due to insufficient information respecting the details of his model, the Board is unable to evaluate the applicability of the model or reconcile the differences with Three Sisters' projections. 
Several of the other interveners, most notably the AWA Group and BowCORD, challenged particular aspects of the economic impact assessment submitted by Three Sisters, but no other detailed analysis was presented.

The Board has reviewed the Three Sisters assessment and all other information in considerable detail and believes that certain modifications should be made to the assumptions and calculation procedures used by Three Sisters. The first modification relates to the timing and usage of the proposed facilities. As pointed out in Section 11.1.2, the Board has concerns that the existing facilities in the area, those recently approved, and the Three Sisters proposal might be more than can be absorbed by the market place. Although the Board has accepted that there may be sufficient demand to justify all of the proposed facilities, it believes that such demand would likely materialize over a longer period than projected by Three Sisters. In its economic assessment, the Board has therefore extended each five-year phase of the Three Sisters proposal to a six year period. The result would be a 24 year project to total build out. In this regard, it should be noted that Three Sisters indicated that a build out period of up to 30 years was a possibility. For each phase of hotel or commercial development, the Board has also staged the growth in demand and thus the revenue and expenditures over a six year growth period.

Aside from these modest delays in timing, the Board has generally accepted Three Sisters' projections of expenditures related to the construction of its proposed facilities and residences.

Three Sisters projected its total revenue from the hotel and ancillary services, such as food, beverage and conventions, at some $\$ 58,000$ per room per year. Key assumptions were an average occupancy rate of some 60 percent, an average room rate of about $\$ 140$ per night, and ancillary revenue approximately equal to the room revenue. Having regard for the information placed before it, the Board believes this estimate may be too high, particularly with respect to the ancillary revenue. For this reason, the Board in making its assessment, has reduced the hotel and related revenue and expenditures by some 20 percent.

With respect to the proposed residential development, the Board has essentially accepted Three Sisters' estimates except that it has included as an economic impact the municipal taxes that would be paid and presumably expended to provide the necessary municipal services. With this recognition of municipal taxes in its assessment, the Board has excluded Three Sisters' estimate of revenue from the proposed commercial space which would be used for municipal purposes. It has otherwise generally accepted the Applicant's estimates regarding commercial space.

The Board's estimate of expenditures resulting from construction and operation of the proposed facilities is very large, particularly when expressed as a total over the 24 year period being analyzed. To provide a better perspective, the Board has considered the economic impacts on the basis of an average annual impact. In doing so, it recognizes that each unit of construction is basically a one-time activity, and as a result, the actual impacts would vary from 
year to year. Also, the Board is looking at the average effect over a 24 year period, but recognizes that the economic effects due to operations would continue beyond that period.

With the previously mentioned adjustments to Three Sisters' data, the Board estimates that total construction and operating costs related to the Three Sisters project would average some $\$ 125$ million per year. Three Sisters suggested that most of the expenditures would be within the Province of Alberta. Notwithstanding that this was questioned by some participants, the Board generally agrees, and expenditure leakages to outside the province are estimated not to exceed 10 to 15 percent. The Board also agrees with Three Sisters that there would be substantial induced expenditures as a result of the direct and indirect economic activity. The end result would likely be total annual expenditures in Alberta of over $\$ 150$ million as a result of the proposed project. The portion of expenditures which would occur in the Canmore area would likely range from relatively low for construction, to as much as two-thirds for operations. On average, about one-half of the total expenditures would likely be in the Canmore region, amounting to over $\$ 75$ million per year.

With respect to the question of incremental impacts on Alberta, the Board believes that some 90 percent of the construction impacts would be incremental in that they would not occur in Alberta without the proposed Three Sisters project. Section 11.1.2 summarizes the Board's conclusions regarding the origin of the likely demand for the proposed residential and tourism components of the project. Combining and averaging these conclusions over the 24 year period would suggest that on average, about two-thirds of the total expenditures would be incremental to Alberta. This would mean an incremental impact on the province averaging some $\$ 100$ million per year for the 24 year period.

In terms of the labour component of the total expenditures, the Board's analysis suggests that over the 24 year period, the project would create an average of 4,000 full-time equivalent jobs per year, for some 96,000 person years of employment. The Board estimates that about two-thirds of these jobs would be incremental to the province as a result of the Three Sisters project and would not likely otherwise exist. Most of the jobs would be in the Canmore region.

With respect to taxes, the Board's analysis suggests that the local municipality would, on average, collect almost $\$ 4$ million per year over the period studied. Additionally, some $\$ 20$ million in project related income taxes would likely accrue annually to governments, with about one-third to the provincial government.

\subsubsection{Alternative Scenarios}

As indicated earlier, the Board also analyzed the economic effects that would likely accompany certain alternative development scenarios. For the project as proposed but with no development in Wind Valley, the development would be primarily a residential development. Construction impacts would be significantly reduced and most of the commercial 
operations effects would be eliminated. As a result, the beneficial economic effects on the province and the region would be less than one-quarter of that which might be expected if the full project was completed.

Another alternative scenario would involve a reduced development in Wind Valley which would exclude the relatively land intensive golf course and residential developments and downsize the hotel and commercial space to about one-half of that proposed by Three Sisters. The Board has made no assessment of the economic viability of such a scaled down project, nor indeed of the proposed project, but if it was viable and did proceed, the total and incremental economic effects that would result, the jobs that would be created, and the taxes that would accrue to governments, would be somewhat more than one-half of those that would result from the full project as proposed.

The Board also analyzed a scenario with no development in Wind Valley but with an expanded hotel and commercial space on the Three Sisters site in the Bow Valley. The hotel development assumed in this scenario was about one-half of that proposed for Wind Valley, which appears appropriate given the area that might be available at that site. Again no economic viability test was made, but the Board's assessment suggests that the total and incremental economic impacts, job creation and taxes, would be about one-half of what would occur with the proposed project. In looking at this particular scenario of no development in Wind Valley, the Board recognizes that the Applicant and certain others contended that a resort development in Wind Valley would be critical to the tourism potential of the proposed project. The Board has some reservations in fully accepting this position, having in mind that a major hotel chain is developing a large hotel in the Bow Valley, and that another expressed some interest in a development on the Three Sisters site and the Applicant was at one time planning such a development. The Board does however recognize that the Wind Valley location would be important to the tourism aspects of the proposal. Therefore, in assessing this scenario, it has assumed somewhat lower room rates and numbers of international visitors because the site would not be as attractive as Wind Valley.

\subsubsection{Maximization of Economic Benefits to the Province}

This Section of the Decision Report is involved primarily with the assessment of the economic effects of the project on the Canmore region and on the Province of Alberta. The Board has assumed, in making the assessment, that Three Sisters would endeavor in developing its project to maximize the local and provincial content to the extent practical. This would involve the obtaining of goods and labor within the Canmore area when available and practical to do so, and when this is not the case, would give practical priority to workers and suppliers of goods in the remainder of Alberta. Three Sisters indicated at the hearing that it would be prepared to proceed on this basis. (Further comments respecting this matter, at it relates specifically to the Stoney Tribe, are included in Section 11.2.6.) 


\subsubsection{Conclusions Regarding Economic Effects}

The proposed Three Sisters project has the potential to result in a very large beneficial economic effect on the Canmore region and the province. Incremental impacts on Alberta would likely average in excess of $\$ 100$ million a year, including some 2,500 new jobs, over a 24 year period. Over one-half of these effects would likely take place in the Canmore region.

Total taxes would likely average about $\$ 24$ million per year, of which some $\$ 4$ million would likely accrue to the local municipality and some $\$ 7$ million to the provincial government.

As compared to the project proposed by Three Sisters, eliminating the Wind Valley portion of the development would reduce economic impacts by at least three-quarters. A scaled-down development in Wind Valley and the development as proposed in the remainder of the Bow Corridor would likely reduce economic effects by almost one-half. A project with no development in Wind Valley but with an expanded hotel complex in the Bow Valley, would likely reduce economic effects by about one-half.

The Board emphasizes that all of its economic impact estimates are based on an assessment of the information received at the hearing and the assumption that there would be long term markets for the proposed tourism facilities. The likelihood of this was questioned by a number of participants, and as pointed out in Section 11.1.2.1, the Board does have some reservations regarding the attracting of sufficient new tourists to the proposed project, particularly in the short term. It is therefore necessary to have in mind, when reviewing the economic impact estimates, the risk that tourism markets will not develop as rapidly as assumed in the analysis.

\subsection{Social Effects of the Proposed Project}

\subsubsection{Introduction}

There was much discussion of the potential social effects of the proposed Three Sisters project on the Town of Canmore and its citizens. Most of the participants dealt with one or more of the social aspects of the proposal and numerous specific issues were raised, some of which are major and thus critical to an assessment of the public interest and some of which the Board views as less important in terms of the overall public interest even though of importance to those raising them.

In dealing with the social effects of the proposal, the Board will first assess the anticipated growth of the Town and the likely effect of the proposed project on the lifestyle of its residents. It will then address the potential effects on services to the people of Canmore, dealing first with the physical facilities which provide utility services, including water, sewers, 


\section{$11-13$}

disposal of solid wastes, transportation and other utilities. The Board will then deal with the other community services including education, health care, social services, library, recreation, fire and police protection and response to emergencies. The availability of housing, particularly of an affordable nature, is of great interest to many participants and the Board will deal with that matter separately. It will then comment on the current recreational use of the area included in the proposal and on potential impacts on historical resources. Finally, because of the special history of the Stoney peoples in the region, the Board will deal specifically with certain social effects that are unique to the Stoney Tribe, recognizing that many of the issues identified earlier will also have the potential to impact on the Tribe.

\subsubsection{Growth of the Town and the Effects on the Lifestyle of Its Citizens}

The population of Canmore has been increasing at almost 10 percent per year for the last few years. Three Sisters included in its Application projections of population and sensitivity analyses. Although many participants questioned or commented on specific aspects of the projections, no one disputed that the Town would continue to grow rapidly if Three Sisters' project were to proceed. The Applicant's submission suggested that the population of the Town would grow from the current level of about 6,000 to as much as 15,000 in 20 years, even if the Three Sisters development did not go ahead. It further suggested that with the proposed development, the population could be as much as 30,000 in 20 years, representing a growth of about 15,000 as a direct result of the Three Sisters project.

The Board considers that these estimates of population may be somewhat on the high side, but believes the growth in population which would accompany those developments described in Section 8 as already approved coupled with the growth associated with the Three Sisters project, would likely average some six to seven percent per year over the next 20 years. This is a rapid growth rate if sustained over a lengthy period and it would have the potential to significantly change the Town of Canmore. This concern over possible change was a focal point of many questions and comments by local groups or individual residents at the hearing.

Although a number of local participants raised concerns about potential impacts on their lifestyle, most of the supporting reasons and examples of possible change dealt with specific issues such as housing and community services, which will be addressed later in this Section. Those most concerned about effects on lifestyle generally referred to a desire to retain a small town atmosphere. BowCORD raised the question of whether second home owners felt a sense of community. Others referred to the likelihood that, if the project proceeds, Canmore would become totally a tourism town, and suggested that this would bring with it an artificial "good-times" atmosphere which was not consistent with small-town family values. Indeed, the desire on the part of the Town to separate the existing residential development from new tourism development was stated by Three Sisters as one of the reasons it had changed its planned location for a major hotel development from the Three Sisters site to the Wind Valley. 
A theme of several interventions, which was emphasized by BowCORD, is that the residents of Canmore should have an opportunity to consider a number of alternatives for the future rather than simply having to face the large growth accompanying a mega-type project like that proposed by Three Sisters.

The Board recognizes that the choice of lifestyle is a personal one and that some individuals prefer a small-town atmosphere. It does not believe that such personal preferences should be incorporated in a significant way into its assessment of whether a particular proposal is consistent with the broad public interest. This is not to suggest that they have no importance, but in the Board's view such preferences should primarily be recognized in decisions at the local level. In that regard, it should be recognized that reviewable projects such as Three Sisters' proposal require approvals from both the NRCB, which emphasizes the broad public interest, and the municipality, which emphasizes local issues.

In terms of the Application before it, the Board believes that the effects of the Three Sisters project and related rapid growth on the lifestyle of Canmore residents could be greatly affected by the approach taken with respect to many of the social issues to be dealt with later in this section. Careful planning to ensure these issues are recognized and provided for, coupled with ongoing monitoring and appropriate changes where problems are occurring, would do much to reduce the impacts on lifestyle. The Board notes that Three Sisters expressed sensitivity to these concerns, and, for example, suggested it would be prepared to establish what it called a "foundation" to provide funds to assist cultural, recreational or similar endeavors.

Some participants raised concerns regarding the effects on the Town of the large number of transient workers during periods of heavy construction. If the project goes ahead the building industry in Canmore would expand but the Board agrees with the Applicant that considerable construction labor in peak periods would likely be brought into the region from elsewhere. Some might commute daily, but many would stay in the area during the week and return home on the weekends. Three Sisters indicated that a camp would be provided for such workers, if and when needed.

The Board is generally satisfied with the Applicant's plans in this regard. However, the Board expects that any construction camp would require approval from the Town and would rely heavily on the Town's controls to ensure that any camp is appropriately located and operated. If the project proceeds, the Board would recommend that Three Sisters involve the Town and local people in planning the details of matters such as the hours of work and other worker and camp related rules.

Regarding the issue of growth in the Town and effects on lifestyle, the alternative scenarios with a smaller development in Wind Valley or no development in Wind Valley would probably create slightly lesser effects as compared to the Applicants' proposal. Eliminating or reducing the scale of the resort development would presumably slow the rate of growth and provide greater time for planning and response to problems. 


\section{$11-15$}

If a hotel development were located at the Three Sisters site in the Bow Valley, it would be closer to existing residential developments, which apparently is not desired by the Town. The Board notes that the Three Sisters site would be separated from residential developments by planned golf courses, and believes this would at least partially offset perceived negative effects related to its proximity to the developed Town. Nevertheless, locating major hotel facilities at the Three Sisters site could require even more careful planning and ongoing monitoring to minimize negative effects on the lifestyle of residents of the Town.

\subsubsection{Effects on Services to Canmore Residents}

\subsubsection{Utility Services}

With respect to utility services and related infrastructure needs, Three Sisters outlined its plans in some detail. Three Sisters indicated that the existing sewage system is operating near capacity, is somewhat inefficient and requires upgrading even without the Three Sisters project. The Town confirmed that some expansion, rehabilitation and replacement of the facilities is required.

The Applicant said that a new sewage facility would be built at Dead Man's Flats to serve the eastern 60 percent of its proposed project and the existing Canmore facilities would be upgraded. It proposed that the new and upgraded facilities would be designed to meet stricter effluent standards than those currently in use and would improve the quality of the effluent entering the river.

According to Three Sisters, in 20 years domestic water demand for the Town of Canmore would be about 30 times greater than the current demand if the proposed project proceeds. The project would at that time utilize about one-half of the total demand. The water for most of the development in the Bow Valley would come from the Town's existing supply sources, while the Wind Valley area would be supplied from newly developed local sources.

Three Sisters stated that solid wastes from the Town are currently disposed of in a Calgary landfill. It also said that the existing recycling program is relatively ineffective. The construction phase of the project would add greatly to the waste, as would operations at full build out. Three Sisters estimated that waste generated in the region in 20 years would exceed 20 tonnes per day without the proposed project and would total some 65 tonnes per day with the project.

The Applicant would institute and operate, in coordination with the Town and other jurisdictions in the area, a program to Reduce, Reuse and Recycle solid wastes. It suggested that such a program might reduce by about 50 percent the waste generated by its project. It acknowledged that even with an effective "three R's" program, the amount of solid waste to be disposed of would require investigation of alternative landfill sites or other disposal methods such as incineration. These would require approval from Alberta Environment. 
With respect to transportation, Three Sisters indicated that traffic volumes would increase substantially, particularly at the local level, as a result of its project and other expected growth in the area. It is proposing a highway and roadway system designed to minimize traffic problems and impacts on the Town. The main component of its proposal includes a low-speed parkway through the development with interchanges at the east and west ends and at an intermediate point.

Three Sisters stated that natural gas, electricity, telephones and television cable would be provided in its project area by the commercial organizations currently serving the region.

A number of participants, including local residents, expressed some concern regarding Three Sisters' plans to provide utility services, but most of them related to potential costs and financial effects on the Town and its citizens. These matters are addressed in Section 11.3.

The Property Owners/Residents Association expressed support for the transportation plan because it would solve current existing access problems. At the same time, the CRPC expressed concerns regarding the impact of the proposed parkway on the TransCanada Highway and the Town suggested a fixed transportation corridor at this time would be premature. The MD of Bighorn indicated that some of the proposed facilities had the potential to improve utility services in its jurisdiction.

The Board recognizes that the demand for utility services and related infrastructure will increase greatly in the Canmore area, even if the Three Sisters project does not proceed. With the project, the potential increase is much larger. As a result, detailed long term planning and coordination with local jurisdictions are essential if significant negative effects on local residents are to be avoided.

The Board has reviewed the Applicant's plans for these services, and subject to its views respecting environmental effects in Section 10 and financial impacts on the Town in Section 11.3 , is generally satisfied. Any approval issued by the Board would provide flexibility to ensure that steps taken now and in future to provide these services would be reflective of the then existing circumstances, subject to approval by the Town. Regarding the proposed transportation system, the Board agrees with the concept of a parkway and appropriate interchanges to the main highway. It also agrees with the general location, but believes flexibility is required with respect to the details of location and construction.

With respect to the alternative Wind Valley scenarios considered by the Board, if any of them were to proceed, significant changes would be required in terms of planning for utility services. In particular, the Board notes that a large hotel at the Three Sisters site rather than in Wind Valley, would cause changes in planning for sewage and other services. The Board is satisfied that such changes could be handled without negative impact on the public interest and has considered estimates of changes in costs in its economic assessment. 


\subsubsection{Other Community Services}

There was discussion at the hearing regarding the full range of community services, but much of it focussed on education needs and social services. This Section deals with the adequacy of Three Sisters' plans in that regard.

Three Sisters suggested that its project would result in the need for school facilities and teachers for some 480 additional students by 1997 . It identified several potential school sites at different locations and suggested that the 10 percent of land required for municipal reserve would be more than adequate for all schools and similar requirements.

With respect to other community services, Three Sisters estimated a need for 15 additional police officers by the time of biuld out and a new fire emergency response station near Dead Man's Flats with eight additional full-time persons and 40 volunteers. In addition to normal municipal recreational facilities, Three Sisters said its project would include racquet courts, hiking and biking trails, theatres and other recreational facilities.

Three Sisters stated that it expects that other social support services would grow with the population and emphasized the need for extensive monitoring and close communication to ensure problems do not occur. To assist in dealing with potential problems, particularly for working mothers, it undertook to provide for daycare at the proposed hotel in Wind Valley and for a workers' shuttle bus from the Town centre.

Town and School Division representatives generally expressed agreement that Three Sisters' plans for community services were adequate. They emphasized that careful ongoing planning and monitoring was essential to avoid unforeseen problems, for example related to growth rates significantly different than those projected. The Town emphasized the importance of its control over the monitoring and suggested monitoring should be based on extensive work now occurring, for example in the social services area.

The CRPC emphasized the importance of adequate planning and detailed negotiations between the developer and local authorities regarding community service needs.

Some local participants expressed concern that social needs would grow much more rapidly than projected by Three Sisters due to the transient type of people sometimes employed in seasonal tourism jobs. The Women's Resource Centre pointed to one example in Wyoming where it was reported that social needs grew nine-fold with a doubling of population. The Centre also expressed great concern regarding childcare for single working mothers, and strongly urged a daycare and shuttle bus service for hotel operations.

The Local Chamber of Commerce cautioned that the negative effects on services in Canmore could be greater without the Three Sisters project than with it. 
The Board has reviewed Three Sisters' plans respecting community services and its undertakings, particularly regarding provision of daycare and shuttle bus service for hotels, and is generally satisfied. Its greatest concern would be for the unexpected. For this reason, if the project proceeds, the Board would recommend that the Town ensure that an ongoing monitoring and planning group is in place so that social needs are anticipated as much as possible and accounted for in ongoing developments. The Board is recommending in Section 12 the formation of a regional planning group but agrees with the Town's position that the matter of social planning should be primarily left as the responsibility of the Town of Canmore.

\subsubsection{Housing}

Section 11.1.2.2 deals with the potential demand for the various housing components of the Three Sisters project. This Section deals with other housing related issues.

Much of the concern, raised primarily by local hearing participants, related to the availability of affordable housing in Canmore and the effects the proposed Three Sisters project might have in that regard. Other major housing issues, somewhat related to the matter of affordable housing, were the provision of staff housing for those who would be employed by Three Sisters, the relatively large number of Canmore residences that are second homes, and the concentration of ownership of developable lands in the Canmore area.

Essentially all participants who commented on the matter agreed that there is a housing shortage in Canmore which applies to all pricing levels and to rental properties, but is particularly acute in the lower price ranges. This shortage has led to recent escalation in house prices.

Three Sisters stated that its proposed project includes sufficient housing to accommodate the growth in population that would result from the project. It also said that the zoning and density of housing would be mixed, with about 50 percent being relatively low-cost apartments, condominiums, multi-family units and single-family units on lots less than 50 feet in width. Three Sisters estimated that perhaps 30 percent of the total residences in its project might become second or recreational homes to part-time residents of the area.

Regarding staff housing, the Applicant indicated that it would provide dormitorystyle housing for 1,400 employees. Three Sisters said this should more than satisfy the Town's requirements for housing for 50 percent of new hotel employees and added that it would give some preference to staff in the marketing of residential units.

Three Sisters fully acknowledged the need for affordable housing and noted that a lengthy complex planning process adds to the price of homes. It stated a willingness to sell some land at less than market value for affordable housing purposes, and to provide for some low-cost housing in a development agreement. It also commented on the importance of closely 
monitoring the housing situation on an ongoing basis, with significant involvement of the Town and local interests.

The report filed on behalf of Municipal Affairs acknowledged the affordable housing problem and offered a number of possible solutions. The preferred ones were a municipal employee housing charge on employers, and the municipality acquiring land at less than market value from Three Sisters and utilizing it for affordable housing. Other options referred to included requirements in a development agreement, regulatory constraints, ground leases, and formation of a non-profit housing cooperative. It was also recommended that the municipality be in charge of staff housing, rather than Three Sisters.

The CRPC also noted the affordable housing problem, the important role for the Town in planning and monitoring, and the need to pay attention to experience elsewhere in similar situations.

The Town indicated that it had a housing strategy, had investigated similar situations elsewhere and had looked at various options. Its draft GMP provides for affordable housing, it requires new hotel developments to provide housing for at least 50 percent of their employees, and it attempts to obtain at least 20 percent multi-family units in new sub-divisions. The Town said that it recognized these efforts were not totally successful and that more vacant land was needed to provide sufficient affordable housing. The Town asked for assistance in empowering it to establish an employee housing charge against area employers, to negotiate towards a private housing corporation, and to assess charges related to affordable housing against a developer.

Many local individuals and groups expressed great concern regarding affordable housing. The Women's Resource Centre stated that there was a serious housing crisis and that some people were spending 40 to 50 percent of their incomes and higher on shelter. It suggested 32 percent should be a defined maximum.

There was considerable concern that the desire by outsiders for second homes in the area was driving up prices and that control in population growth was needed if the housing problems were to be successfully dealt with. The Women's Resource Centre presented information suggesting that some 74 percent of the employees of Three Sisters would not be able to afford housing toward the lower end of the range included by Three Sisters in its project because wages in the tourism industry are low.

The Board believes that the question of affordable housing is a critical element in any assessment of socio-economic issues. If housing problems exist, efforts to address and mitigate other social problems may be somewhat pointless. Similarly, if there are not housing problems, other social shortcomings may not be as serious as they would otherwise be.

At the same time, the Board recognizes that the issue of affordable housing is a problem throughout society and does not believe that any one proponent for one project can be 
expected to solve such problems. A fair test is whether a proponent has adequately provided for the matter in its proposal, and whether the proponent is prepared to work with others on an ongoing basis in an attempt to ensure that, as a minimum, the problem would not be made more serious.

With respect to housing for staff, the Board understands that the provision by Three Sisters of staff dormitory accommodation for 1,400 would meet the 50 percent requirement imposed by the Town. Of equal importance, any additional staff accommodation must be affordable to the employees who would use it. Some participants argued that this would not be possible because a large percentage of employees would be paid wages too low.

The Board recognizes that a significant number of tourism jobs are at the lower end of the wage scale, but does not accept that such is necessarily contrary to the public interest. Unless the lower paid employees in a particular tourism project would have other jobs available to them at higher wages, they would be no better off, in terms of affordable housing, not working in the tourism project. If there are higher paying jobs available elsewhere, presumably they would take them if qualified, leaving the lower paying jobs to others. If no other employees are available, the laws of supply and demand should dictate higher wages in the tourism project, or if the project could not afford them, a smaller project. On this basis, the Board would not turn down a project with regard to the public interest, simply because many of its employees would be at the lower end of the wage scale. However, the Board recognizes that there may well be increased social needs to be met when there is a concentration of lower paying jobs in a community, particularly a community in which the real estate market is supply constrained. The Board has had regard for this in reaching conclusions respecting the need for monitoring of social matters and for measures to deal with the affordable housing issue.

Other participants commented on the concentration of land ownership in the area as a problem in terms of affordable housing. Three Sisters owns most of the privately held land, and Mortgage Properties Inc. on behalf of the Alberta Crown is the only other owner of-large amounts of patented land in Canmore. The Board agrees that this concentration of ownership has the potential to work against affordable housing and believes this situation justifies some intervention in the housing market. Recognizing that the project would not be approved unless it was in the overall provincial public interest and that affordable housing is a broader societal issue, the Board believes that Crown lands should play a role in dealing with this matter.

The Board agrees with the contention that the ownership of second homes by a shadow population could push prices upward and work against affordable housing for the lower paid employees of Three Sisters. However, if appropriate measures are put in place to provide affordable housing, and if such housing is not used for other purposes, the Board does not believe that this second home factor would be significant.

A number of alternative ways of addressing the affordable housing question were raised at the hearing. In the Board's judgement the most effective approach would be through a municipal housing agency with a specific affordable housing mandate, but the Board does not 


\section{$11-21$}

believe that it has the jurisdiction to require that such an agency be formed. It also recognizes that the formation of such an agency would be complex and that there are other ways in which the affordable housing issue could be addressed. In the Board's view, and because Canmore is increasingly becoming a tourism centre, some definite action regarding low-cost housing for tourism workers is needed if the problems of several other fast-growth tourism towns are to be avoided. The Board therefore recommends that the Government form a task force to review possible ways of addressing this issue and to make recommendations towards implementing a plan of action.

Whether the plan of action is the formation of an agency such as mentioned previously or some other mechanism, the Board believes the following principles should be reflected:

- the Town and its citizens should play a lead role;

- lands should be available from the Crown, Three Sisters, and possibly other developers, at below market prices. Three Sisters stated a willingness to take such steps and the Board strongly recommends that the Crown do likewise;

- there should be provision for an employee housing service charge to be collected from certain employers in the area; and

- the mandate should be to provide the lowest cost housing practical on a fair and equitable basis to employees of Three Sisters or others at the lower end of the wage scale.

The Board would, if it approves the project, recommend that the Town require of Three Sisters, a commitment to appropriately participate in the development of an affordable housing plan or take individual measures to deal with affordable housing.

If a development proceeded similar to the alternative scenarios being looked at by the Board, with a reduced hotel complex either in Wind Valley or in the Bow Valley, there would be fewer employees. This would likely affect the financial viability and reduce economic benefits that would result from the project, but would also likely make the affordable housing problem more manageable.

The Three Sisters Application provided relatively detailed information respecting various residential pods, their location, intended use and planned density. Subject to the environmental concerns dealt with in Section 10, the Board is generally satisfied with these aspects of Three Sisters proposal. Recognizing that the developments would occur over a period of some 20 years, the Board believes it should, if it approves the project, provide flexibility to make changes to the overall design of residential pods, subject to approval by the Town. 


\subsubsection{Effects on Historical Resources and On Current Recreational Use of the Area}

Three Sisters indicated that a historical resource impact assessment was carried out on its behalf. It began with a file search and a literature overview. Following that; a ground reconnaissance was conducted which focused on areas that had potential as pre-historic or historic sites. One historic and ten pre-historic sites were identified. A report was provided to Alberta Culture and Multiculturalism including plans for preservation of the sites. Three Sisters filed a letter from Alberta Culture and Multiculturalism setting out certain comments on the report and requiring a more detailed assessment before the development proceeds. Three Sisters gave an undertaking to meet the further requirements.

The Board is satisfied that the issue of historical resources has been and will be adequately handled by Alberta Culture and Multiculturalism.

A number of participants suggested that approval of the project would limit the current recreational use of some areas by the public, particularly in Wind Valley. There were also references to utilizing the area for ecotourism and establishing limited paths and viewing points for wildlife and vegetation. Three Sisters stated a belief that its project would provide access to its lands, particularly in Wind Valley, for many more potential users than currently use the site.

The Board notes that the lands in question are privately owned and presumes that access to them has been somewhat limited. It agrees with Three Sisters that its proposed project would provide increased access to the lands for recreational purposes. (The matter of recreational use of the area is dealt with more extensively in Section 10.)

\subsubsection{The Stoney Tribe}

Many of the environmental, social and economic effects of the proposed project would have the potential to impact on the Stoney Tribe, as well as other members of the broad public. However, because of the historic role the Stoney Tribe has played in the region and because of particular requests made in its submission, the Board is addressing itself specifically to certain of the Tribe's interests as one component of the overall public interest.

The members and elders of the Stoney Tribe described the traditional importance of their use of the general area and the proximity of their Reserve to the proposed project. They outlined recent economic and business developments on the Reserve and commented on the employment and other resources available. The Stoney Tribe contended that it would suffer permanent loss as a result of the project and expressed an entitlement to mitigation from Three Sisters and to share in employment and business opportunities associated with the project.

The Stoney Tribe specifically requested conditions to any approval that would require Three Sisters to give priority to the Stoney people regarding employment, use of 


\section{$11-23$}

materials from the Reserve and business opportunities. It also requested conditions requiring that Stoney place names and culture be given a prominent role in the development and that Three Sisters be required to compensate for loss of hunting, trapping and other use of the area. The Stoney Tribe also requested that any conditions of the Three Sisters approval be binding on the successors and assigns of Three Sisters.

Three Sisters stated that it was willing to employ Stoney Tribe members and to do what it could to ensure that independent contractors and the hotel operators would do likewise. It specifically committed to make recommendations to the hotel operators to include the Stoney people in ongoing training programs. Three Sisters pointed out that it would be better served by working with the local population or those close at hand. It also stated that it was prepared to work with the Stoney Tribe to establish business opportunities for its members in conjunction with the development.

The Board does not believe the conditions requested by the Stoney Tribe, to apply to one particular group within the overall Alberta public, should be included in any approval it might issue. Many of the requested conditions would involve affirmative action measures to ensure the involvement of Stoney people in the project. The Board notes that Three Sisters stated a willingness to work with the administration of the Stoney Tribe to maximize potential benefits to the Stoney people. The Board is satisfied with this undertaking and would recommend that Three Sisters make a determined effort in this regard. The Board also believes that the Stoney Tribe should be included in any ongoing planning or monitoring group that may be established as a result of its hearing of the Three Sisters proposal.

With respect to the request for compensation, the Board does not consider that the Stoney Tribe provided evidence that demonstrated that specific losses would occur, nor did it link any quantifiable loss directly to the incremental effect of the project on the use by the Stoney people of the general area. The Tribe did identify certain potential effects that could impact on the Stoney people and the Board is having appropriate regard for them in its assessment of the public interest.

\subsection{Financial Effects on the Town of Canmore}

The Three Sisters proposal, if it proceeds, would require certain infrastructure within the Town of Canmore. Some of the infrastructure would be facilities to provide services such as water, sewers, utilities and transportation to the hotels and residential developments. Other parts of the infrastructure would relate more specifically to social needs, such as for education and community support. This Section of the Decision Report deals with the financial effects that the provision of such infrastructure might have on the Town and its citizens.

Three Sisters plans to begin development of its project in Wind Valley and work from east to west toward the existing town. It stated that this would result in a logical extension to infrastructure because some 60 percent of its project would have to be serviced from an 
expanded water and sewage facility at Dead Man's Flats. This would be the site of a major sewage expansion that would be required early in the project. Three Sisters pointed out that such an expansion and upgrading would be required in any case.

Three Sisters also referred to the other utility-type infrastructure that might involve capital expenditures early in the life of the project. It stated that it would provide the portion of such infrastructure costs that were related to its project and were not covered by a grant from the Provincial Government. Three Sisters said that it was not unusual for the province to participate in the funding of infrastructure with municipalities. Mr. R. Melchin indicated that an effort was being made to achieve a 75:25 sharing of funding, with the Provincial Government providing 75 percent. The estimate that was most frequently referred to at the hearing was a requested government grant of some $\$ 77$ million of a total cost exceeding $\$ 100$ million for the major projects currently proposed in Canmore.

Three Sisters also referred to other possible capital expenditures for education and other community services, but did not include estimates as to what such costs might be. It did refer to ongoing need for additional teachers, police officers and firemen.

Three Sisters said that it had a four point plan that would safeguard the Town of Canmore and its citizens against any risk related to the funding of infrastructure. It committed to provide any necessary front end capital costs not provided by the Province, and in response to questions from the Town, said it would even consider operating certain necessary infrastructure in the early years.

Three Sisters took the position that whatever the infrastructure funding arrangements, the revenue and taxes from the hotel and commercial facilities would quickly balance those front end costs.

The Town expressed concern at the financial risk it would face if the pace of developments slowed before a certain threshold was reached that would cover front end capital and operating costs. It stated a preference that the hotel and commercial facilities proceed first, in order to reach this threshold as early as possible.

The Town confirmed the position put forward by Three Sisters that it was normal for the Provincial Government to help fund utility and certain other infrastructure. It said this is particularly important for a location such as Canmore where infrastructure costs are high due to the dispersed geographic setting of the Town and the need for a high level of sewage treatment upstream of the City of Calgary.

The Town stated that it would negotiate a development agreement with Three Sisters in which the developer took the risk. It specifically requested that the developer be required to provide any front end costs and to operate and pay any utility costs until a certain threshold was reached, no residential development be allowed in Wind Valley until the resort 
was constructed, and a detailed information exchange and monitoring take place involving the Town.

The MD of Bighorn is supportive of the Three Sisters proposal and indicated that it might utilize some of the expanded and improved servicing infrastructure.

A number of other participants, including several local groups and individual citizens, expressed concern that the taxes would not be sufficient to cover the costs related to the project. They generally referred to the risk to the taxpayers of the Town and some said that their taxes would increase as a result of the project.

Mr. Greenberg stated that he was not assured by the knowledge that $\$ 77$ million would come from the Provincial Government to support the project, since it would be coming from the taxpayers and the developer's profits would not be returned to the public. Dr. Power also referred to the funding by the Province and questioned why, if the proposed resort could pay its own way, it was necessary to go to the government.

The Board recognizes that the Town of Canmore faces costs for operating and expanding service infrastructure even without the proposed Three Sisters project, but is focussing its attention only on those costs that would relate to the proposal. The Board takes no position as to how the infrastructure costs should be shared among the developer, the Town and the Provincial Government. The important aspects from a public interest viewpoint are whether the project is likely to proceed and generate sufficient economic benefits to make worthwhile the investment in infrastructure and whether the taxpayers of the Town and Province would face a large burden of risk associated with the front end and ongoing costs. Three Sisters referred to the possibility of phasing developments in Wind Valley and stopping development if problems became apparent. The Board believes this would be impractical having regard for the need for major front end infrastructure costs related to the first phase of such developments.

The Board's assessment of economic effects referred to in Section 11.1.3 of this Decision Report indicates that the proposed project would likely have an average economic impact on the province exceeding $\$ 100$ million per year over the next 24 years. Additionally, taxes to all levels of government from the project as proposed, if it proceeds more or less in the manner described by the Applicant, would be some $\$ 24$ million per year and almost one-half would accrue to the provincial and municipal governments. This would exceed any front end infrastructure costs as well as related ongoing costs.

With respect to the alternative scenarios considered by the Board, even though they would involve less tourism and commercial development, the Board would not expect that the infrastructure costs would be proportionately reduced. For these scenarios, the tax revenue to government would be substantially reduced as compared to the Three Sisters proposal, but would nevertheless be larger than the infrastructure costs and costs to governments, particularly at the local level for social and other services. 
Accordingly, the Board concludes that the required front end and ongoing infrastructure and service costs would be covered by the projected economic benefits if the project as proposed or as reflected in any of the alternative scenarios proceeded through to conclusion and demand for the facilities materialized more or less as projected. The ultimate real potential risk is that taxpayer funds may be used for infrastructure that is not fully needed or utilized in future. The Board considers that such a risk is an ordinary and manageable one faced whenever infrastructure is added because it is usually added in anticipation of demand. Further, the Board believes that such risk is not unreasonably large because the project is a long term one to be built over a considerable period depending on demand and other factors and because the Board believes that significant growth can be expected in any case. This would allow some staging of the infrastructure and would provide revenue from other than Three Sisters to help pay for it. Also, and most importantly, an agreement would be necessary between the Town and the developer if the project is to proceed. The Board is satisfied, on the basis of statements made at the hearing by the Town and commitments given by Three Sisters, that such an agreement would not be put in place without adequate safeguards against risk to the Town and its citizens. The Board recommends that this be the case and also that any funding provided by the Provincial Government also be done in a manner that places on the Applicant the appropriate degree of the risk of the project not proceeding in a manner that covers front end capital and early operating costs. 


\section{THE NEED FOR ONGOING PLANNING AND CONTROLS}

\subsection{Introduction}

There was discussion at the hearing of a large number of potential projects in the Canmore/Bow Corridor, some of which have received some of the required approvals and others of which have not. In total, they would require numerous additional approvals before they could proceed. The Three Sisters project, if approved by the NRCB, would require a number of additional licences, permits, approvals and other authorizations before it could proceed. These requirements for approval of the Three Sisters and other projects are administered by a variety of departments or agencies in several different jurisdictions. Most of them have controls with respect to approved projects that include ongoing inspection and monitoring functions. However, it was widely suggested that the regional impacts of development were not capable of effective management by any one department or agency.

As a result of these circumstances, a number of participants in the hearing suggested the need for ongoing planning and controls from a regional perspective, with respect to projects already approved or to be proposed in future. Three Sisters suggested that the Bow Valley has tremendous potential to accommodate tourism and indicated that it would support the formation of a commission or committee to address the cumulative effects of planned and proposed developments in the area. Three Sisters referred specifically to the need for a coordinated effort as related to policy regarding public access to trails in the region and potential impacts on certain wildlife species. With respect to the latter, it suggested as a mitigation measure, an initiative to identify and retain protected natural areas.

The Town of Canmore supports a broad planning approach and pointed out that the traditional municipal approach to approvals could lead to development on an incremental basis without ever addressing the broad public interest aspects. The MD of Bighorn expressed support for a regional monitoring committee, and the CRPC responded positively to the suggestion of an ongoing regional advisory body. It suggested that the existing planning mechanisms should be used effectively and referred to several possible models. The CRPC said that local interest groups should be included and asked the Board to consider some direction respecting regional management as part of its decision.

Canada Parks Service took a strong position that there was a need to co-ordinate ecosystem wide development and mitigation efforts through a multi-jurisdictional, multidisciplinary commission. It suggested that the temptation to overdevelop the natural resources of the Bow Valley would be very real and said it would be prepared to participate in a regional body by providing staff, expertise and funding commensurate with the degree of involvement and commitment by others.

The environmental special interest groups were very supportive of the need for regional planning and controls. The AWA Group suggested an inter-agency task force that would include a public component and would look at all of the proposed developments and recommend an overall plan. The CPAWS and Trout Unlimited Groups also expressed support for a regional management and monitoring group and stressed the need for involvement of many 
different stakeholders including local representatives. The BV Naturalists emphasized the need to assess proposals on a cumulative effects basis, and the Alberta Naturalists noted the possibility of a jurisdictional mechanism with a long term regulatory function. The Alberta Naturalists suggested that involved groups might include the Town, several Alberta Government Departments, Canada Parks Service, the CRPC and representatives of environmental organizations.

Other local groups and individuals did not deal extensively with the concept of an ongoing planning committee but several referred to the need for improved community planning. The Stoney Tribe suggested that the Stoney Tribal Council should be a participant in any regional management or decision making body for the Bow Corridor.

\subsection{Views of the Board}

The Board, as indicated in Section 11, recognizes the great potential of the Canmore area for tourism developments. It expects that the pressure for expansion of tourism in Alberta will be greatest in areas of substantial natural resource value, such as the Bow Corridor. It is therefore important that the developments complement and not detract from the continued value of the natural resources which are the base for the tourism attraction. In the Board's judgment, these natural resources cannot be maintained without ongoing involvement by capable persons in a wide variety of disciplines having involvement in the ongoing planning and monitoring processes. The Board recognizes that planning and monitoring is taking place now through a number of government departments and agencies and through existing plans and planning mechanisms, such as the Calgary Regional Plan and the Integrated Resource Planning process. Each of these can be effective when applied generally throughout the province, but there is question as to whether they are sufficiently coordinated for environmentally sensitive areas such as the Bow Corridor, where there are also tremendous pressures for tourism and other developments.

In Sections 5 and 8 of this Decision Report, the Board endorses the concept of having regard for cumulative effects of all projects when assessing an individual project. It is not reasonable to expect an applicant for an individual project to be responsible for an extensive regional cumulative effects assessment, particularly if its proposal is for a relatively small project, but the Board does expect an applicant to assess its project in the context of existing and expected developments in the surrounding area.

In Section 9, the Board evaluates the Three Sisters proposal from the viewpoint of potential hazards related to the earlier coal mining operations in the Canmore area. In that Section, the Board has noted the need for a group of technical experts to be involved in assessing the possible hazards and to provide advice to the Town of Canmore and other decision making agencies. Also, Section 10 of this Decision Report regarding environmental effects refers to the importance of ecosystem management if attractive areas of the province, such as Wind Valley, are to be maintained in a healthy state. It also refers to the need for monitoring to deal with 
many of the uncertainties that exist with respect to possible impacts on the environment. Such ecosystem management and ongoing monitoring would benefit greatly from involvement of experts with different backgrounds and broad experiences.

These requirements coupled with the broad agreement from participants respecting the need for improved planning and controls, cause the Board to recommend to the Alberta Government the formation of a committee to better ensure the coordination of current efforts and the channelling of future efforts in a more effective and efficient manner. The Board has given this recommendation careful consideration because it does not wish to introduce another layer of bureaucracy into the planning process. For this reason it is recommending a committee, as opposed to a new organization, made up primarily of representatives of groups already involved and expending considerable effort in the region. The emphasis would be on coordinating that effort and providing advice to decision makers and the public. For convenience in this Decision Report, the Board will identify the recommended committee as the Bow Valley Planning and Advisory Committee (BPAC). The Committee would deal with the Bow Corridor and surrounding region, and its existence should be reviewed on a regular basis to ensure it is making a positive contribution with respect to the area.

\subsection{Guidelines and General Principles}

The evidence presented at the hearing indicates that there are different ways that BPAC could be structured and operated. The Board has reviewed the evidence and recommends that the Government give consideration to the following general guidelines and principles in establishing the Committee.

(a) BPAC should consist of senior level decision makers who have the capability of participating in timely and decisive recommendations. There would be topical subcommittees or task forces to focus on particular issues and carry out detailed work. Membership in subcommittees should be selected on the basis of expertise in the task, and might include agencies such as the ERCB. There should be representation from the general public. Pursuant to the Board's review, recommendations for subcommittees have been made, including an Undermining Review Group and a Regional Ecosystem Advisory Group. BPAC should have the flexibility to appoint additional subcommittees to deal with new or changing issues.

(b) The geographical area of greatest concern to BPAC would be the Bow Valley between Banff National Park and the Stoney Indian Reserve. However, in order to reflect an ecosystem approach, the Committee would also have to address the surrounding areas that are generally part of the same ecosystems and have much potential to effect the Bow Corridor. These would include at least parts of Banff National Park, the Wind Valley, the Spray Valley and the Kananaskis Valley. The specific area of detailed interest may vary depending on the task being 
addressed and should be decided by BPAC. Much of the development activity and population growth would be in the municipal jurisdictions of the Town of Canmore and the MD of Bighorn and they should have significant input to BPAC.

(c) BPAC's function would be primarily advisory in nature. It would provide advice to government departments that would ensure better coordination of planning and data gathering efforts in the area. It would also provide advice regarding ongoing controls and monitoring. Where new projects are being considered, BPAC would provide advice to decision makers regarding the consistency of the new projects with overall plans for the region and the need for monitoring and other controls should they proceed. If the Three Sisters project goes ahead, the Board sees some urgency in the formation of BPAC and several subcommittees such as the Undermining Review Group. Therefore, the Board offers the following additional suggestions respecting possible tasks that BPAC might be involved in:

- through its subcommittees, report on the status quo from time to time in respect of the environment of the region and the social and economic systems in place. These reports would serve to assist bodies with jurisdiction in defining with confidence the "base case" in the region against which proposed developments could be assessed;

- identify information gaps in existing studies by various public and private agencies, and recommend such further studies as may be considered important to determine the proper use of natural resources in the Bow Corridor and any mitigative measures which may be necessary given the impact of development;

- review the monitoring that occurs through various agencies, identify informational and operational gaps in existing monitoring studies and methods and recommend such further studies and methods as may be considered important to monitor effectively;

- actively promote an approach to planning, monitoring and determining mitigation in respect of the appropriate use of natural resources in the Bow Corridor which is more open to the public, coordinated and cooperative than the approaches now being utilized;

- support planning and conflict resolution programs in order to effectively assist and expedite the decision making process in respect of development proposals;

- be available to consult with applicants prior to the filing of applications for approval of developments to identify important issues and to advise of problems, concerns and other matters which might be dealt with in an application; 
- at the request of various bodies with jurisdiction, and having regard to all existing and proposed projects, review applications for approval of developments or projects to identify the need for further information and provide advice to the body with jurisdiction (the Board would see this initiative as integrated with, not overlapping, existing interjurisdictional screening or review processes undertaken by government agencies);

- recognize that, in the Bow Valley and adjacent areas, there are several different jurisdictions and agencies that have many statutory responsibilities which include ongoing planning and monitoring functions;

- at the request of various bodies with jurisdiction, and having regard to all existing and proposed projects, review proposed developments to determine if they are consistent with long term plans for management of natural resources in the area and provide advice to decision makers;

- provide for appropriate public participation processes in the planning, reviews of monitoring studies, mitigation proposals and controls of projects in the area; and

- all reports of BPAC and its subcommittees should be made available to the public in a timely manner.

(d) Membership of BPAC should be limited to senior representatives of key participants, but there would be more extensive membership in subcommittees or task forces. BPAC should determine the participation in each of the sub-groups. Having regard for the evidence at the hearing, the Board recommends that the following participants be considered for BPAC:

- Town of Canmore;

- MD of Bighorn No. 8;

- Deputy Minister of Alberta Environment;

- Deputy Minister of Alberta Forestry, Lands and Wildlife;

- Deputy Minister of Alberta Municipal Affairs;

- Banff National Park ;

- Kananaskis Country;

- Stoney Tribal Council; and

- One representative of the general public in the Bow Valley.

(e) BPAC and its subcommittees would require funding support, although much of the work it would be involved in is presently being done by various jurisdictions. Hopefully, improved coordination would make for greater efficiency and some additional tasks would be possible without the need for more funding. The Board suggests that the Deputy Minister of Alberta Environment chair BPAC. Each 
participating organization would be responsible for the support of its representative, except for the public representative who would be supported by the Province. Funding for project related studies or reports that are site specific and required for review of an application should normally be provided by the applicant for the project. Funding for regional studies would be by responsible jurisdictions as arranged by BPAC.

These guidelines and general principles are the result of an analysis of the information received at the hearing and it may be that not all of them can be incorporated into the organization of BPAC. The final mandate of BPAC should be determined by the Government and participating jurisdictions. 

INTEREST OF THE PROPOSED PROJECT

\subsection{Overall Conclusions}

Sections 10 and 11 of the Decision Report deal with the environmental and socioeconomic effects of the proposed project in detail, and Section 9 describes certain potential geotechnical hazards that relate primarily to earlier undermining in the area. The conclusions from those and other relevant Sections of the Decision Report are brought together in this Section where the Board presents its overall conclusions as to whether the proposed project is in the public interest.

The Board has confirmed in Section 5 that its assessment of the public interest is based on a balancing of the various social, economic and environmental effects that would result from the project. The Board has also indicated that the assessment is on a cumulative basis and reflects the effects that would result from the Three Sisters project and a reasonable consideration of the effects of other existing developments in the area and of those that can be expected in the near future with some degree of certainty. Section 8 describes the base situation from which the Board has assessed the cumulative effects of the proposed project and Section 6 confirms that the Board believes it has sufficient information to do so.

The Board heard considerable discussion respecting the need to coordinate the NRCB process with the existing municipal planning process and the need for ongoing planning and controls respecting future developments in the Canmore/Bow Corridor. The Board has dealt with these matters in Sections 7 and 12 and has recommended the formation of a senior level Bow Valley Planning and Advisory Committee which, with the assistance of appropriate technical working level subcommittees, would provide ongoing advice to decision makers.

As a consequence of the large area of the Application and its diversity and because the proposal is for a large project to be phased over some 20 years, the Board, in addition to considering the effects of the project as proposed, also considered potential effects of the project with some modifications. In particular, the Board considered several variations of the resort development proposed for Wind Valley on the southeastern edge of Three Sisters' lands.

With respect to geotechnical hazards, undermining and the potential for subsidence leads the Board to conclude that certain parts of Three Sisters' proposed project should not proceed without further detailed work. The Applicant proposed a four stage procedure for assessing whether undermined areas are safe for development. The Board generally agrees with the approach suggested. It would condition any approval issued with a requirement that Three Sisters carry out its assessment to the satisfaction of the Town of Canmore, prior to proceeding with any development on undermined areas. The Board believes that an Undermining Review Group, possibly working as a technical subcommittee under the guidance of the previously mentioned Bow Valley Planning and Advisory Committee, could provide assistance and advice to the Town in this regard. 
In the areas underlain by coal seams, the Board sees some risk of methane migration and accumulation in residences or other buildings that would be part of the project, but not sufficient to cause the Board to refuse the Application. To reduce the likelihood of methane related incidents, the Board would prohibit the pumping of water from mine workings for irrigation or similar uses because such pumping could release additional methane from the coal seams. Additionally, the Board would recommend that the Town require the utilization of appropriate safeguards to minimize the risk of accumulations of methane in buildings.

With respect to mining related hazards,-the Board would also recommend that the Town take steps to ensure that prospective purchasers of homes in the area be informed that there are some risks related to undermining and the possible accumulation of methane from coal seams.

In terms of environmental effects, the Board concludes that atmospheric emissions from the proposed project and others in the region could have the potential to occasionally exceed Alberta standards for certain pollutants. These exceedances could be minimized or eliminated by control of emissions from wood burning stoves. If the Board approves the project, it would recommend that the Town of Canmore impose architectural controls to ensure that direct air intake fireplaces would be the only wood burning equipment in residences and that it consider introducing a by-law that would allow it to curtail wood burning during periods when air in the region is likely to be stagnant.

The Board considers the Bow River, its tributaries and surface and groundwater that flow into them to be a single eco: stem. With respect to that ecosystem, the Board is satisfied that the maximum water withdriwals proposed by Three Sisters would have little effect on downstream users. It is also satisfied that water supplies from municipal sources would be adequate for the project. In this regard, it notes that the ultimate withdrawals of water for the project would be subject to approval by Alberta Environment.

The Board would accept the use of water from either Stewart or Three Sisters Creeks, but would prohibit the use of water from Pigeon Creek because of possible effects on fish. As indicated, the Board would not allow the pumping of water from the mine workings for use in the project, but would have no objection to the use for irrigation of water which is naturally draining from the mines at the tipple site. Similarly, the Board would have no objection to the use of greywater from the sewage treatment facilities for golf course irrigation provided it has been sterilized by treatment with ozone.

With respect to water quality, the Board does not believe there is likely to be acid mine drainage. Given the undertakings of the Applicant regarding design and drainage systems, the Board would not expect significant drainage of chemicals from golf courses and residential developments or of oil products and salt from paved areas, to the Bow River or other streams in the area. The irrigation and use of chemicals on golf courses should be limited by their operators to the minimum quantities consistent with acceptable operations, and the design respecting surface drainage and holding ponds should be such that it minimizes runoff of 
contaminated water. Care would also be required by homeowners to avoid problems due to the use of chemicals on lawns and the release of contaminants to the storm sewage system. Three Sisters undertook not to use mercurial fungicides on its proposed golf courses.

With appropriate controls, the Board does not anticipate that there would be significant negative effects on fish or other aquatic biota. This assumes that sewage wastewater facilities would be upgraded to include tertiary treatment, which the Board is recommending to the Town. Construction in or near creeks could affect both riparian vegetation and streambed habitat that are important to - fish. As a result, the Board would require the utilization of construction practices that would minimize potential impacts on the environment and that the design of buffer strips along watercourses be approved by Alberta Forestry, Lands and Wildlife.

There would be uncertainties regarding possible impacts on the aquatic ecosytem, but these could best be handled by a monitoring program which the Board would require. It has made detailed recommendations regarding the program.

Overall, the Board does not believe that effects of the proposed project on the aquatic ecosystem would be such to conclude that the proposal, with appropriate mitigative controls, would not be acceptable. Development of the Wind Valley portion of the project would mean that a longer stretch of Pigeon Creek and its tributaries could be affected by the project. Also, the larger development would contribute to the number of people residing on project lands and to activity levels. It therefore would have the potential to increase negative effects on the aquatic ecosystem. As a result, the project without the Wind Valley would have some advantage in terms of the aquatic ecosystem.

In terms of terrestrial ecosystems, the project would have significant impact on vegetation. With preparation of an acceptable vegetation inventory and management plan and preparation and implementation of an acceptable vegetation monitoring plan, most unacceptable effects could be avoided. The Board is concerned that the project would cause the removal of trees and shrubs along a number of creeks and affect a number of wetlands. The Board believes these effects could be avoided or mitigated for most areas, the major exception being the fen in Wind Valley.

Wind Valley is an exceptionally fertile and diverse area and is rich in species of animals and plants. It is of particular importance for large carnivorous species such as grizzly bear, wolverine and black bear and also includes critical habitat for bighom sheep and elk. The Wind Valley is an important route for movement of all these species between Banff, the Bow Valley and the north, and Kananaskis Country and the south. Recognizing that the Bow Valley as opposed to Wind Valley, is already extensively developed and therefore disturbed, the environmental concerns are much greater with respect to Wind Valley than the remainder of the project lands. Additionally, Wind Valley is somewhat physiographically separate from the Bow Valley. 
Having regard to its detailed assessment of possible effects of the proposal on terrestrial ecosystems, the Board believes that the proposed development could proceed in the Bow Valley portion of the Three Sisters lands, and with careful planning and appropriate mitigative measures and monitoring, the risk of substantial lasting negative impacts on vegetation or wildlife would not be unacceptable. These measures would include incorporating into the design of the project, provision for wildlife movement corridors and development of a wildlife habitat mitigation and enhancement program. A Regional Ecosystem Advisory Group, working as a technical subcommittee of the recommended Bow Valley Planning and Advisory Committee, could play an important role in ensuring that such is the case.

Respecting Wind Valley, the Board is concerned that potential negative effects on terrestrial ecosystems would not be manageable. On the basis of the information currently available, the Board believes there to be a serious risk of substantial lasting effects on certain vegetation types and species of wildlife, including large camivores and ungulates. Indeed, the Board considers that Wind Valley plays such an important role in the broad terrestrial ecosystems of the region that long term effects might be experienced well beyond the Valley. Such effects would have the potential to negatively affect certain features of the terrestrial ecosystem which contribute greatly to the attractiveness of the area to visitors.

The Board has concluded that certain measures would be necessary to protect wildlife should the project proceed. The Board would require that Three Sisters retain corridors in as undeveloped a state as possible to allow wildlife movements to continue, and that the location and width of these corridors and a wildlife aversive conditioning plan be approved by Alberta Forestry, Lands and Wildlife. The Board has also made a number of specific recommendations to Alberta Forestry, Lands and Wildlife with respect to wildlife movement corridors, the protection of elk habitat, aversive conditioning of animals and habitat enhancement. In addition the Board has recommended to the Town that it accept Three Sisters recommendation for control of free ranging dogs and cats. Should development not proceed in Wind Valley the Board believes that hardened trails and viewpoints should be constructed and that off-trail pedestrian access should be discouraged.

With respect to economic effects of the proposed project, the Board accepts that there are likely sufficient long term potential markets for the proposed facilities and services to justify proceeding with the project. It does however expect that a significant portion of the demand, particularly for tourism facilities in the short term, would be from Albertans or other visitors who would otherwise be using some other resort or recreational facility in the province. That portion of the economic effects would therefore not be incremental to the province.

Assuming that sufficient demand does develop to justify build out of the entire project as proposed, the Board estimates that the economic effects on the province would be considerable, likely averaging in excess of $\$ 100$ million annually over a future period of some 24 years. Over 2,500 new jobs would be created, and additional tax revenues averaging some $\$ 24$ million per year would be generated, almost one-half of which would accrue to the local 
municipality and provincial govemment. To the extent that demand for the tourism facilities does not materialize from outside Alberta, the estimates would be on the high side.

The Board made a qualitative assessment of the economic effects that would likely result from projects with different development scenarios for Wind Valley. If the project proceeded as proposed, but with no development in Wind Valley, beneficial economic effects would likely be reduced by about three-quarters. A project as proposed but with a significantly scaled down resort development in Wind Valley could have beneficial economic effects that are somewhat greater than one-half of those estimated for the total project. A similar project with no development in Wind Valley but with a larger hotel development elsewhere in the Bow Valley would likely have economic impacts of about one-half of those associated with the proposal.

The large project proposed by Three Sisters has the potential to add greatly to the population of Canmore and to change the character of the Town. The Board believes that careful planning for social services and ongoing monitoring would be capable of holding such effects to an acceptable level and recommends a lead role for the Town and its citizens in that regard. An example of appropriate involvement for the Town would be in the planning details for any construction camp that might be required. Any action that reduced the size of the Three Sisters project, for example with respect to the development in Wind Valley, would have the potential to make the social problems related to rapid growth of population more readily manageable.

The Board is satisfied with respect to the Applicant's plans regarding utility and other services. The potential economic benefits to the province and the Canmore area, in the judgement of the Board, would be sufficient to offset related infrastructure costs and ongoing operating costs. Strictly from this financial viewpoint, none of the scaled down versions of the project would be as attractive as that proposed, assuming sufficient demand materializes, but they would all likely result in the recovery of capital and operating costs related to municipal services.

The greatest risk with respect to the cost of infrastructure and services would be that the project proceeds, considerable front end costs are encountered, and then lack of markets or other problems cause major delays in ongoing developments. Due to this risk the Board would recommend that, if the project proceeds, both the Town of Canmore and the Provincial Government proceed in a manner that would place on the developer the appropriate degree of the risk regarding possible future changes that would cause the financial benefits flowing from the project to be less than required to pay capital and operating costs for infrastructure and services.

The issue of affordable housing, if not properly addressed, has considerable potential to impact negatively on the community. The Board generally accepts the plans of Three Sisters to provide for staff accommodation and some relatively low cost housing. It recognizes that the issue of low cost housing in Canmore cannot be handled by one developer. 
If the project proceeds, the Board recommends that the Government establish a task force to investigate the possibility of a local housing agency or some other mechanism for providing low cost housing to tourist industry workers that are at the low end of the pay scale. The Board believes the mechanism should involve purchasing lands from the Crown and developers such as Three Sisters at less than market prices and an employee housing charge against certain employers in the area. The Town should be significantly involved in the formulation and implementation of any such plan. The Board recommends that the Town require of the Applicant a commitment to appropriately participate in the development of an affordable housing plan.

The Board does not believe the proposed project would have significant negative effects on historical resources in the area, nor with respect to current recreational users of the region.

The Board has carefully considered the many approval conditions requested by the Stoney Tribe that would require affirmative action on the part of Three Sisters with respect to employment, business and other opportunities. The Board does not believe such conditions should be included but notes Three Sisters' stated willingness to work with the Stoney people to increase the potential for them to benefit from the project. The Board also believes the Stoney Tribe should be involved in the Bow Valley Planning and Advisory Committee it has recommended for the region.

The above conclusions, which are more extensively described in earlier Sections of the Decision Report, impose on the Board the difficult task of balancing certain adverse effects against certain benefits that would result from the project. The benefits would be the substantial employment and expenditures that would be generated if the project goes ahead. The most significant adverse effect and the only one which in the Board's opinion could be classified as unacceptable, would be related to the serious risk that developments in Wind Valley would likely cause major irreversible effects on the environment, particularly wildlife. The balancing which the Board must do is made more difficult because Wind Valley, where the most serious adverse effects would occur, is also most attractive for tourism and would play a major role in terms of the economic benefits which might flow from the project.

In weighing these competing values, the Board considers that it should determine what natural resources are truly of value and worthy of special measures to ensure their sustainability in the long run. The natural resources which are highly valued in society are often valued by many people for different reasons, thereby practically assuring controversy, and at times confrontation, over their use. This is certainly the situation with respect to Wind Valley, but the Board considers that in the long run the different reasons for seeing Wind Valley as important actually tend to merge. In order for the proposed development to be economically healthy over time, such development must accord with the goal of preserving or maintaining those resources which make it attractive. Because the value of wilderness appears to be increasing worldwide the importance of maintaining the wilderness areas which we have is all the more pressing. 
Having this in mind, using the information received and on the basis of its best judgement, the Board concludes that the risk to the environment from significant development of Wind Valley would be too great to be offset by the additional economic benefits that would result. This, coupled with the possibility that markets for the Three Sisters facilities may not develop as rapidly as projected and the reduced social effects that would likely result from a smaller project, causes the Board to conclude that the Wind Valley portion of the proposed development should not be approved.

If there is no development in Wind.Valley, the Board is satisfied that the adverse effects associated with the remainder of the proposal, mostly environmental and social in nature, would not be unacceptable and could be substantially mitigated with careful planning, monitoring and controlled activities. Such a scenario would have associated economic benefits, although they would be considerably less than would result from the total project. The adverse social effects would be less because the project would be smaller and the environmental effects would be greatly reduced by avoiding Wind Valley. As a result, the proposed project as it relates only to the Bow Valley, in the Board's opinion, would be in the public interest. The Board is therefore prepared to approve the project, subject to certain terms and conditions, one of which would prohibit the proposed development in Wind Valley.

The Board has described in Section 1 of this Decision Report, the portion of the Three Sisters lands which it generally considers to be within Wind Valley. The Board approval would prohibit the proposed development south of a line $200 \mathrm{~m}$ north of and parallel to the boundary between Sections 1 and 12, township 24, range 10, and between sections 6 and 7, township 24, range 9, all west of the 5th meridian, as shown on Figure 1-3. This boundary has been based on the Board's assessment of the information presented by participants in the hearing and the topography of the area. It is just south of the existing and proposed development at Alpine Resort Haven. The line would pass through at least one proposed design pod and a golf course and would obviously require a redesign of the project in that area. The Board would provide flexibility in the approval to allow such redesign, subject to it being acceptable to the Town, and also to Alberta Forestry, Lands and Wildlife with respect to the provision for wildlife corridors.

The Board does not have an application before it for a reduced development in Wind Valley and therefore could not approve one. However such possible scenarios were discussed at the hearing, for example one with no residences or golf course and a smaller resort facility. Such a reduced development would likely have associated with it more than one-half of the economic benefits of the total proposed project, but, in the Board's judgement, would continue to represent a serious risk of major adverse affects on the environment. Indeed, the Board has on the basis of currently available information, concluded that developments in Wind Valley should probably involve no more than hiking trails, viewpoints and similar facilities designed with controlled access as the goal. These might have some benefits in terms of ecotourism opportunities. 


\section{$13-8$}

This position regarding a reduced development in Wind Valley is taken without prejudice to any future application that might be made. If the Board were to receive an application for a reviewable project which involved development in Wind Valley, it would assess that application on the basis of the best information then available and placed before it. The Board would expect such information to incorporate interdisciplinary viewpoints from a regional perspective.

As indicated previously, the Board is recommending the formation of a Planning and Advisory Committee for the region. It believes such a group should play-a lead role in the monitoring and gathering of additional data that would advance the understanding of the regional ecosystem. If this Committee were to conclude at some future date, on the basis of further detailed data and studies, that some development in Wind Valley could proceed without significant environmental risk, the Board would give significant consideration to that conclusion in any decision it might be required to make. Indeed in such a situation where the proposed Bow Valley Planning and Advisory Committee were to conclude that some development in Wind Valley is appropriate, there may be little to be gained by causing the development to be reviewed by the NRCB.

The Board also considered in a qualitative manner the effects that might result from Three Sisters' proposal with no development in Wind Valley, but with an expanded hotel development in the Bow Valley. The logical location would be the Three Sisters site where the major resort component was apparently to be located in an earlier version of the Three Sisters project. Such a scenario would have considerable economic benefits, even though they would likely only be about one-half as large as for the total project as proposed. The adverse environmental and social effects that might result from the expansion of the Bow Valley portion of the development to include a more significant hotel development would be somewhat greater than for the Bow Valley portion of the development as proposed, but in the Board's view, the adverse effects would be manageable with proper planning and monitoring.

Again the Board must make it clear that it does not have an application before it for a project with an expanded hotel component in the Bow Valley and therefore could not approve it. However its assessment of such a possibility, based on the information which was provided at the hearing and which the Board believes is the best now available, leads the Board to conclude that such a development would be in the public interest. In the Board's view, if an expanded hotel development in the Bow Valley were proposed, and if the Town of Canmore were to conclude that the development was appropriate, making such a proposal reviewable under the NRCB legislation might not be necessary. The cost associated with a further NRCB review of such an expanded proposal could be more beneficial to the public interest if used on studies and other work of the Bow Valley Planning and Advisory Committee.

The Bow Valley portion of the proposed project, which the Board is prepared to approve, includes general plans for the phasing of the proposed developments and for use of the Three Sisters lands in categories such as residential, tourism and commercial, community services, golf courses and other public open space, transportation routes and public utilities. The 
plans for residential developments include the type of intended housing and population densities. The Board, with respect to the Bow Valley portion of the proposed development, is prepared to approve the general plans of the Applicant, subject to certain controls for purposes of mitigating environmental and other effects. The Board wishes to provide a degree of certainty to the Applicant regarding its approval of the general plans, but recognizes a need for flexibility. Accordingly, it would condition the approval to allow changes to the details of timing and land uses, including an increase in population densities, and with respect to the locations of transportation and other services, if such changes were acceptable to the Town. This would be in part, a recognition that the developments would take place over a 20 year period and would provide flexibility to accommodate changing circumstances.

The proposed project, including the Wind Valley portion which the Board is not prepared to approve, would be located on private lands. This raises a question as to whether some form of compensation should be provided to landowners where development of their land is prohibited for public interest reasons. A number of participants in the hearing who argued that the Application should be denied, added that the Government should purchase the lands in question, but others disagreed with this position.

The Board believes there should be some form of remedial action available to the owner of the lands in Wind Valley for which the proposed development is being refused. A number of possibilities come to mind including the purchase of the Wind Valley lands by the Crown and ongoing administration of them as public lands, and the swapping of the private lands in Wind Valley for land now held by the Crown in the Bow Valley, which lands could then be used by Three Sisters to replace parts of the project not allowed in Wind Valley.

The Board takes no position as to whether either of these, or some other arrangement, would be most desirable. It does recommend that the Government of Alberta be prepared to negotiate with Three Sisters towards some resolution. Recognizing that the Board is refusing the Wind Valley portion of the application on the basis of its assessment of the best information available today, and that there may be a possibility that further regional studies would result in allowing some development in Wind Valley in future, the owners of the lands may wish to retain them. 
In addition to the conditions contained in the draft approval, the Board would expect Three Sisters to discharge all of the relevant commitments and undertakings included in its Application or given at the hearing. Additionally, the Board has made several recommendations to the Applicant, the Town of Canmore, the Government of Alberta and a number of government departments. - These recommendations and their supporting rationale are contained throughout the Decision Report and for the convenience of the reader the recommendations are summarized in Appendix D.

DATED at Calgary, Alberta on 25 November 1992.

\section{NATURAL RESOURCES CONSERVATION BOARD}
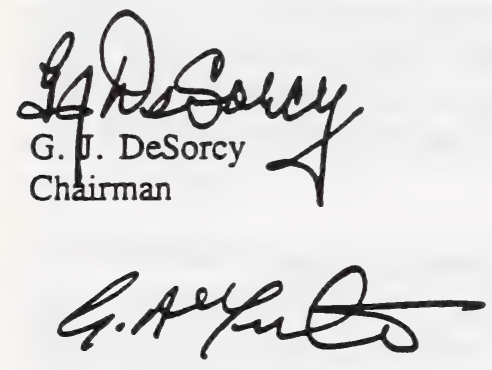

G. A. Yarranton

Vice Chairman

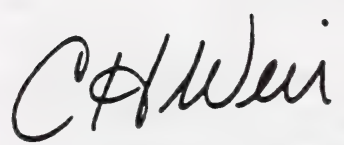

C. H. Weir

Board Member

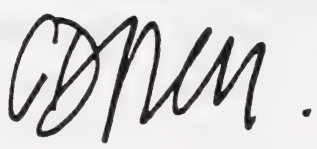

C. Dahl Rees

Acting Board Member 


\title{
APPENDIX A
}

\section{THREE SISTERS GOLF RESORTS HEARING}

\author{
LIST OF PARTICIPANTS
}


THREE SISTERS GOLF RESORTS HEARING

\section{LIST OF PARTICIPANTS IN ORDER OF APPEARANCE}

Three Sisters Golf Resorts Inc.

(The Applicant/Three Sisters)

Mr. W. Tilleman

Mr. A. Lucas

Mr. R. Melchin

Mr. T. Atkinson
Mr. R. Melchin

Mr. B. Melchin

(Riddell Group Architects \& Engineers Ltd.)

Dr. R. Crowther, P.Biol.

Mr. J. Leszkowicz, P.Eng.

Mr. W. Koning, P.Biol.

Mr. J. Olyslager

Mr. L. Visser

Mr. J. Holden

Mr. D. Kelly, P.Eng.

Ms. P. Maloney

Mr. B. McTavish

(all of UMA Engineering Ltd.)

Mr. M. Davies

(Concord Environmental Corporation)

Mr. J. Green, P. Biol.

Ms. H. Ferguson, P.Biol.

Mr. K. Strom

Mr. T. van Egmond, P.Biol.

(all of The Delta Environmental Management Group Ltd.)

Dr. G. Fedirchuk (Fedirchuk McCullough \& Associates)

Mr. D. Parker, P.Eng. (MPE Engineering Ltd.)

Mr. B. Scott, Q.C. (Milner Fenerty)

Mr. G. Stephenson, P.Eng.

Mr. G. Jordan, P.Geol. (both of Norwest Resource Consultants Ltd.)

Mr. E. Romanowski (Pannell, Kerr, Forster) 
Three Sisters Golf Resorts Inc. (The Applicant/Three Sisters)
Ms. C. Colborne (Re/MAX Alpine Realty Ltd.)

Mr. J. Raines (Science Applications International Corporation)

Mr. J. Telford (TELCAN Management Consultants Inc.)

Dr. J. Morrall, P.Eng.

(University of Calgary)
Canadian Parks and Wilderness Society

The Alpine Club of Canada

The Sierra Club of Western Canada

(CPAWS Group)

Mr. H. Locke

Ms. E. Soper
Mr. T. Bryce

Ms. W. Francis

Dr. A. Gareau

Dr. J. Remmers

Ms. P. Remmers

(all of Canadian Parks and Wilderness Society)

Ms. Leah De Marsh

Ms. Leslie De Marsh

Mr. B. Fairley

Mr. B. Spear

Mr. G. Thompson

(all of Alpine Club of Canada)

Mr. B. Geisler

Mr. J. Haveron

Mr. D. Wilding

(all of Sierra Club of Western Canada)

Dr. S. Herrero

(BIOS Environmental Research and Planning Associates Ltd.)

Mr. J. Weaver

(Ph.D. Candidate, University of Montana)

Dr. V. Geist

(University of Calgary) 
Principals and Representatives

Witnesses

(Abbreviations Used in Report)

Canadian Parks and Wilderness Society

The Alpine Club of Canada

The Sierra Club of Western Canada

(CPAWS Group)

Mr. M. Hummel

(World Wildlife Fund Canada)

Mr. G. Kerr

(Director, Corporate Affairs, Department of Environment, Government of Canada)

Government of Canada - Environment Canada -

Canadian Parks Service

(Canada Parks Service)

Mr. G. Irwin

Mr. K. Lambrecht

Mr. C. Zinkan

Mr. S. Faulknor

Dr. G. Holroyd

Mr. G. Irwin

Dr. P. Paquet (John-Paul Associates Ltd.)

Ms. H. Purves

Dr. J. Woods

Mr. F. Zaal

Bow Valley Naturalists

(BV Naturalists)

Mr. P. Duck

Mr. M. McIvor

Mr. P. Duck

Mr. M. McIvor

Dr. D. Walker, P.Biol. (David Walker and Associates Ltd.) 
Bow Valley Naturalists

(BV Naturalists)

Dr. P. Achuff

(Subcontractor to Willowroot Environmental Limited)

Mr. J. Kansas, P.Biol.

(Sentar Consultants Ltd.)

Dr. L. Nkemdirim

(University of Calgary)

Alberta Wilderness Association

Speak Up For Wildlife

Adventure Group Ltd.

(AWA Group)

Mr. S. Ross

Ms. V. Pharis

Ms. H. Prus

(Alberta Wilderness Association)

Dr. B. Horejsi

(Speak Up for Wildlife)

Mr. J. Perras

(Economic Consultant)

Dr. S. Swanson

(Sentar Consultants Ltd.)

Dr. U. Weyer

(WDA Consultants Inc.)

Town of Canmore/Mount Rundle

School Division

(Town/School Division)

Mayor P. Andrews

Mr. T. Bosse

Mr. P. Bates

Dr. G. Lewis

(Town of Canmore)

Mr. J. Vanderlee

(Mount Rundle School Division) 
continue....

A-6

Principals and Representatives

Witnesses

(Abbreviations Used in Report)

Town of Canmore/Mount Rundle

School Division

(Town/School Division)

Mr. H. Ham

(Ogilvie and Company)

Mr. D. Steele

(Dames \& Moore)

Mr. B. Butler

Mr. G. Fardoe

Mr. P. Nichols

(all of Nichols Applied Management)

Mr. D. Taylor, P.Eng. ( $\mathrm{CH}_{2} \mathrm{M}$ Hill Engineering)

Mr. B. Baxter (self)

Mr. B. Baxter

Mr. R. Haimila (self)

Mr. R. Haimila

Calgary Regional Planning Commission (CRPC)

Mr. I. Robinson

Ms. L. Pesowski

Mr. K. Nemeth

Mr. J. Rusling

Ms. L. Pesowski

Mr. I. Robinson

Mr. J. Rusling

Federation of Alberta Naturalists

(Alberta Naturalists)

Ms. M. Posey

Ms. I. Ektvedt

Ms. M. Posey

Ms. I. Ektvedt

Mr. D. Styles 
Northern Light Society

(Northern Light)

Mr. C. Saunders

Mr. C. Saunders

Ms. B. Belyea (self)

Ms. B. Belyea

National Trail Association

(Trail Association)

Mr. D. Campbell

Mr. D. Campbell

Trout Unlimited (Canada)

The Upper Bow Valley Chapter of Trout Unlimited (Canada)

The Upper Bow Valley Fish and Game Association

Banff Fishing Unlimited

(Trout Unlimited Group)

Mr. D. Pike

Mr. G. Szabo
Mr. D. Pike

Mr. G. Szabo

Mr. K. Brewin

(Trutta Environments and Management)

Mr. J. Stelfox

(Alberta Forestry, Lands \& Wildlife)

Government of Alberta - Alberta Tourism, Parks and Recreation

(Tourism, Parks and Recreation)

Dr. A. Kubursi

(Econometric Research Ltd. and McMaster University) 
Government of Alberta - Alberta Tourism, Parks and Recreation (Tourism, Parks and Recreation)

Ms. R. Aronitz

(Peat Marwick Stevenson \& Kellogg Management Consultants)

Government of Alberta - Alberta Muncipal Affairs

(Municipal Affairs)

$$
\begin{aligned}
& \text { Ms. V. Doroshenko } \\
& \text { Mr. N. MacLean } \\
& \text { (both of IBI Group) }
\end{aligned}
$$

Bow Valley Women's Resource Centre

(Women's Resource Centre)

Ms. V. Danielson

Ms. L. Taylor

\author{
Ms. A. Wilson \\ Ms. S. Ketterer \\ Ms. B. Watkins \\ (Research and Education Services) \\ Mr. J. Ambrosi \\ Ms. N. Marshall \\ (both of Aurora Consulting)
}

Three Sisters Property Owners \& Residents Association

(Property Owners/Residents Association)

Ms. E. Freels

Ms. E. Freels

Bow Corridor Organization For Responsible Development (BowCORD)

Mr. E. McAvity

Ms. F. Klatzel

Mr. T. Bryce

Mr. T. Auger 
Bow Corridor Organization For Responsible Development (BowCORD)

\author{
Mr. S. de Keijzer \\ Mr. B. Sanford \\ Dr. T. Power \\ (Consulting Economist, University of \\ Montana) \\ Mr. J. Wollenberg \\ (Coriolis Consulting Corp.)
}

Municipal District of Bighom No. 8

(MD of Bighom)

Mr. S. Hall

Mr. S. Hall

Mr. G. Birch

Ms. L. Fraser

Pacific Westem Tours

(Pacific Westem)

Mr. B. Gordon

Mr. B. Gordon

Mr. B. Iverach

Mr. B. Iverach

Ms. S. Webb (self)

Ms. S. Webb

Bow Corridor Adult Literacy Project

(Adult Literacy Project)

Ms. H. Olorenshaw

Ms. H. Olorenshaw 
University Women's Club of Calgary

(University Women's Club)

Dr. S. Miller

Dr. S. Miller

Stoney Tribe

(Stoney Tribe)

Ms. J. MacLachlan

\author{
Ms. G. Chiniki \\ Mr. S. Powderface \\ Mr. L. Wesley \\ Mrs. L. Wesley \\ Mr. P. Wesley \\ Mr. I. Getty \\ Mr. K. Tulley
}

Ms. L. Klatzel-Mudry (self)

Ms. L. Klatzel-Mudry

Mr. S. Lamont (self)

Mr. S. Lamont

Ms. A. Wilson (self)

Ms. A. Wilson

Alberta Construction Association

(Construction Association)

Mr. G. Graham

Mr. V. Ellis

Mr. G. Graham

Canmore, Bow Valley \& Kananaskis Chamber of Commerce (Local Chamber of Commerce)

Mr. M. Jennings-Bates

Mr. Y. Asselbergs

Ms. C. Colborne

Mr. M. Jennings-Bates 
Tourism Industry Association of Alberta (TIAALTA)

Mr. J. Couture

Mr. J. Couture

Ms. H. Bracco (self)

Ms. H. Bracco

Green Central Station

Mr. P. Carson

Mr. P. Carson

Canadian Ski Association - Alberta Division

(Ski Association)

Mr. A. Fischer

Mr. A. Fischer

Mr. J. Streda (self)

Mr. J. Streda

Ms. C. Campbell (self)

Ms. C. Campbell

Mr. L. Upton (self)

Mr. L. Upton

Ms. M. Nicks (self)

Ms. M. Nicks

\section{Earth First!}

Mr. R. Fisher

Ms. N. Hardy

Mr. R. Fisher

Mr. K. Beitel (self)

Mr. K. Beitel

Mr. S. Greenberg (self)

Mr. S. Greenberg 

Mr. B. Davis (self)
Mr. B. Davis
Mr. J. Kievit (self)
Mr. J. Kievit

Government of Canada - Department of Fisheries and Oceans (DFO)

Mr. G. Hopky

Mr. F. Hyntka

Government of Alberta - Alberta Environment

(Alberta Environment)

Ms. B. Magill

Mr. B. Stone

Government of Alberta - Alberta Forestry, Lands and Wildlife (Forestry, Lands and Wildlife)

Ms. B. Danielson

Government of Alberta - Alberta Municipal Affairs

(Municipal Affairs)

Mr. B. Gillespie

Natural Resources Conservation Board (NRCB)

Mr. P. Cleary

Ms. J. Ingram

Mr. W. Kennedy

Mr. J. McKee 
Natural Resources Conservation Board (NRCB)

Dr. R. Powell

Dr. A. van Roodselaar, P.Eng. (all NRCB Staff)

Ms. K. Hale

Mr. D. Henderson

Dr. G. Power

Mr. D. Westworth

(Consultants to the NRCB) 


\section{APPENDIX B}

\section{THREE SISTERS' SUMMARY OF IMPACTS AND MITIGATION}

(Reprinted from Application) 
CLASS I Important impacts that cannot be mitignted or avoided. These impocts require decision makers to make findings of overriding consideration for project approval).

\begin{tabular}{|c|c|c|c|}
\hline & Descriptioa of Impact & Mitigation & Residual Impocts \\
\hline \multirow[t]{3}{*}{ Large Camivores } & $\begin{array}{l}\text { Long-term loss of } 408 \mathrm{HU} \text { (11 percent) of } \\
\text { black bear habitat. Loss of habitat for grigaly } \\
\text { bear and cougar in Wind Valley and the eantern } \\
\text { portion of the Project Area. Grizly bear may } \\
\text { abandon a portion of their home range. }\end{array}$ & $\begin{array}{l}\text { Maintain habilat in areas adjacent to the Project } \\
\text { Area. Discourage large carnivores from } \\
\text { maintaining residency within Project Area by } \\
\text { negative operant management practices. Off-site } \\
\text { habitat enhancement for ungulates may provide } \\
\text { prey (elk, deer) for cougar as well as some } \\
\text { berry production for bears. }\end{array}$ & Imporant \\
\hline & $\begin{array}{l}\text { Habitat fragmentation. human presence and as- } \\
\text { sociated disturbances. construction clearing of } \\
\text { vegetation, and access roads combine to directy } \\
\text { obstruct movements of large carnivores. }\end{array}$ & $\begin{array}{l}\text { Auempt to reatrict human access in the Npine } \\
\text { and Subaipine areas during October to early } \\
\text { November. when bears are searching for den } \\
\text { sites as well as trying to develop winter fat } \\
\text { tores. }\end{array}$ &. \\
\hline & $\begin{array}{l}\text { Development in the Wind Valley area will } \\
\text { obruct movements of large camivores from } \\
\text { southerly portions of home ranges to the lower } \\
\text { areas around Wind Valley and Wind Ridge and } \\
\text { the Canmore Corridor. }\end{array}$ & & Important \\
\hline Wolverine' & $\begin{array}{l}\text { The wolverine is recognized as being a vulner- } \\
\text { able species. Due to consruction and } \\
\text { operntional disturbance it is predicted that } \\
\text { wolverine will permanently abandon the Three } \\
\text { Sisters Project Ares. May result in the loss of } \\
\text { small numbers of animals (ie., <10) from the } \\
\text { regional population. }\end{array}$ & No mitigation possible. & $\begin{array}{l}\text { Regionally } \\
\text { Imporant }\end{array}$ \\
\hline Grizzly Bear & $\begin{array}{l}\text { Grizaly bear were just recently designated as } \\
\text { vulnerable (1991). At least two grizaly bears } \\
\text { utilize the Wind Creek area. Construction will } \\
\text { result in the loss of a pontion of their home } \\
\text { nange. Grizaly is incompatible to the } \\
\text { development. }\end{array}$ & $\begin{array}{l}\text { Because of probable human/ bear interactions, } \\
\text { no mitigation measures have been proposed } \\
\text { within the Project Area for grizdy bears. Off- } \\
\text { site habilat enhancement for ungulates may } \\
\text { provide some berry production for bears. }\end{array}$ & $\begin{array}{l}\text { Regionally } \\
\text { Importans }\end{array}$ \\
\hline NOTE: & $\begin{array}{l}\text { ied Class I impacts are only partly anributed to } \\
\text { n nature. }\end{array}$ & e Three Sisters Development and can in fact & \\
\hline
\end{tabular}


CLASS II Important impects that can be mitiented or avoided. (Decision makers are required to make findings that inpects have been mitigated to the maximum ertent feasible by implementabion of mitipation).

Description of Impect

Vegetation

Removal of Dougles fir during clearing.

Longterm loses of $624.3 \mathrm{ha}$ of nutural forea and mesdow cover. This represents 6.5 percent of biophysical sudy area.

Songbinds

Small Mammals

Loss of forested and grasaland babiuts as direct reault of clearing, recontouring and construction of facilities. Los of high quality habiut is greatert for meadow vole, and redbacked vole.

Small

Furbearers

Lange

Carnivores

Ungulates

A reduction in use or abandonment of critical overwinering habilat on Wind Ridge as a reault of incressed sensory disturbance and uaintentional harasment by back coumry users (pariculariy during the overwintering and apring periods). accidental mad kills, excessive aress from landowner conflicts, bear-dog harasment, and management actions.

Human-bear and buman-cougar encounters can be expected to occur as a direct result of the proposed development. Bears will likely be anracted to the area by food odours.

Sensory disturbance for black and grizaly bean will cause the direct lose of solitude and eecurity within a zone of influesce that may extend everal $\mathrm{km}$ from the location of consunction. May also cause abandonment of habilat.

Mritiention

Residual Impects

Prevent any cuning of this species.

Negligible

Minor

Regionally

Negligible

Design of residential and direct control pods to communities. Use of native species in landscaping and reclamation.

Minimal or no maintenance of nawnal vegetution areas. Initial site clearing will occur during fall period.

Minimize clearing of vegetution. Maximize residual blocks of matural vegetation in and berween development pods. Use nutive species in landecaping and reclamation effors.

Design development pods to minimize clearing. Maximize size of residual blocks of natura habitats within and between pods. Enhancement for large wildlife and movement corridors will also provide additional habitat for small furbearers.

Restricted rosd speeds within the Three Sisters Project Area will help minimize road morality.
Avoid large amounts of concealing vegetation and timbered corridors within the development pods, while maintaining maximum habiut quality away from humans.

Residential garbage must not be allowed to sit outside for pickup, it must be transported 10 , and dieposed of in bear-proof contuiners. Use of negative operant conditioning to help discourage bears from habituating to the buman presence.

Close trils in Wea Wind Creek and Wind Ridge from I December to 15 June 10 help provect Alpine and Subalpine habitat along the fringes of the Project Area. This is especially imporant for grizaly at the end of hibernation (April to May) when they are particularly censitive.

Restrictions on public access to Wind Ridge and the Stewan Creek tril, contruction cloaures in the vicinity of Stewan Creek and Wind Ridge and phased implementation of development pods.
Locally imporant for maren only

Regionally

Minor

Locally Important, Regionally minor

Minor

Regionally Minor 
CLASS II Important impacts that can be mitigated or avoided. (Decision makers are required to make findings that impacts have been mitigated to the maximum extent feasible by implementation of mitization).

Descriptioa of Impoct
Mitipentice
Residual Impects

If proximity to consuruction compromises bighom theep use of habitat, supplemenul food cources will be provided as described by Jorgenson (1988), wo auract bighorn theep away from the immediate vicinity of the construction. Interpretive signage will be used in combination with area and/or trail closures, and at the mineral lick site $\omega$ inform public users of the reasons behind the clowres, and the importance of not dimurbing bighom sheep.

Groups of bighom sheep that move between wintering ranges on Pigeon Mounuin and Wind Ridge vis a route along Pigeon Creek and the lower area of Wind Valley will be diswrbed by consruction activities, human use, and vehicular traffic in Wind Valley.

Loss of 11.5 percent (538 HUs) of available elk habilat in the surrounding area as a direct result of clearing and alterations. (7.6 percent high and 3.7 percent moderate habitat quality.)

Sensory disturbance will result in avoidance of remaining habilat areas by elk. As much as 16 percent of the existing habitat capability could be affected through the combination of direct habilat losses and increased activity.

A reduction in the use of the mineral lick near Stewan Creek by bighom sheep.

Use of the proposed Rail Bed Pathway during the epring to summer period, direct apprasches by golfers, and low-level helicopter flights could reault in panic reaponses by bighom sheep.

Widlife

The chemical usage could impact wildlife in general through various pathways; direct consumption, uptake through prey etc.
Three Sisters Resors Inc. will undertake measures to encourage bighom sheep movememts from Pigeon Mouninin to Wind Ridge slong the eecondary movement corridor. Selective hand curning will be used $t 0$ create network of narrow trils from the exiating abeep trail to the power line right-of-way and the secondary movement corridor. If approval is received, exixting trails along the Pigeon Creek bluffs will be obliterated to encourage use of the new trails.

A number of habitat mitigation projects will be implemented to provide and protect altemative habitat for elk through enhancement of forage and cover habint. These enhancement siles will provide 361 HUs. Habitat loss will be reduced to 3.9 percent of the available habitat.

Timing, procedural practices, maintenance of off-site mitigation areas and large thermal and movement blocks will reduce impsets. A number of habitat enhancement projects will provide altemate habiut.

Major clearing activities within the timing closure area for the Stewan Creek Mineral Lick will continue to be rearicted to the period of 1 June to Augus 31 in onder to minimize interference with the peak period of use of the lick by bighom sheep. Heavy equipment use will avoid the peak period of lick use by bighom sheep (mid-June to mid-August).

Pathway in the vicinity of Site C Golf Course will be prohibited during the 1 June to the 1 September period to minimize human interference with bighom sheep access to the lick.

Gates and signage will be used to diven pathway users from the Rail Bed Pathway. Public access only be permitued if monitoring indicates sheep are using altemate routes to the lick, and public use of the trail is not impeding aheep use of the trail.

Follow guidelines outlined in Integrated Peat Management Program ie., rextrict use of chemicais and only use chemicals screened for non-loxicity, with low bio-accumulation chancteriatics of parent compound and
Regionally Minor

Regionally Minor

Regionally Minor

Minor

Minor

Negligible

Negligible 
CLASS II Important impects that can be mitiented or avoided. (Decision makers are required to make findings that impacts have been mitizated to the maximum ertent fessible by implemeatation of mitization).

Descriptioe of Impect
Mitization
Residal Impacts
Honsing

Construction

Disnuption of existing circulation panerns due to the movemen of vehicies through Canmore and along the Trans Canada Highway and Highway and $11 \mathrm{~A}$. Disruption will include inpact from noise, dust and traffic congextion resulting from introduction of consunstion vehicies.

Increase trafic in and around Dead Man's Flats.

Fire Protection

There is potential for fire damage to the foreat lands adjacent to the development propenty as a result of anuetural fires. Convernely, there is potential for fire damage to developed aructures as a reault of forest fires.

There is potential for chemicals associated with golf course development and mainienance to burn and be released.

There is potential for spill of golf course mainlenance chemicals in rorage ares.

During conanction building materials and aupplies could be auseptible to fire.

With the increased development there will be a demand for a fire depanment with trained full time employees. Consideration ahould be given to s new facility within the proposed development.
A variety of bousing types have been planned 10 accommodate various levels of houschold iscome. This will include anf housing, manufacured bomes, cooperative bousing and various multiplex housing units. Increased supply may lead $t o$ decrease in housing costs.

Development will be planned and undertaken in accordance with general municipal plans and A.S.P.'s prepared with the Canmore Pianning departments.

Regulation related to wubdivision standards and planning bylaws will be adhered $t 0$.

Movement of conaruction vehicles will be controlled. Proper access 10 and from the site will be deliseated in such a way as to minimize traffic congeation and to respect the concems of the Town of Canmore and Aberu Transportation and Utilities. Information about travel times, rearicted routes, modified trafic tlows will be disseminated to the community at large. Sigoage will be posted at appropriate places to further distribute this information. Dua abatement controls will be used where appropriate. Traffic will have limited access to Canmore and will be directed to use the temporary conanuction access off the Trans Canada Highway.

Upgrade Highway Interchange at Dead Man's Flats. Construction vehicles will be controlled as above.

Design and development of the Three Sixters Ares will incorporate, where possible building and landscape features that retard natural and man made fire hazards. Hydranis will be insalled throughout the development. The Applicant will consull with the Albern Foreatry lo develop fire safety features.

Development of storage structures will be done in accordance with all federal, provincial and local regulations and will conein appropriate fire and anfety equipment.

Storage facilities will be developed in accordance with appropriate local and provincial guidelines peruining to management of dangerous goods. Suff will be trained in appropriate fire and handling procedures according to Provincial requiremenes.

Malerials will be atored in a afe and secure manner in sccordance with local juriadictional bylaws. Emergency resources plans will be prepared in consuluation with local and provincial fire marahals.

The town will be required to hire full-time anff. Size and location of new facilities will be determined as part of the detailed aubdivision design.
Negligible

Negligible

Negligible

Negligible

Negligible

Negligible

Negligible

Negligible

Negligible 
CLASS II Important impacts that can be mitigated or avoided. (Decision makers are required to make findings that impacts bave been mitigated to the maximum extent feasible by implewentation of mitiqution).

Water Quality Sedimention my occur during and after con-
aruction.

Residential/Reson runoff may contaminate aquatic syrtems.

Golf course runoff and seepage may contnminate aquatic systems with fertilizers and pesticides.

Air Quality

Aquatic

Resources

During operation. Benzo (a) Pyrene (BaP) concentrations may exceed air quality objectives in selected areas of the Canmore/Bow Valley Corridor under poor dispersion conditions. Visibility restrictions may also occur under poor dispersion conditions.

\section{Construction Activities}

Surface Runoff

Stormwater Runoff

Irrigation Water Withdrawal

Application of Perticides

Application of Fertilizers

Aquatic Resources
Buffer arips will be constructed where possible. Intream work will be restricted. Creek crossing aruetures and locations will be ppecially choeen to minimize impact. Vegetation will be retained when possible. and disturbed areas will be quictly revegeuted. Physical control structures will be used such as retention ponds, berms and aubsurface collection drains.

Streamaide vegetation strips will be provided where poasible. Vegetaled filter strips, seepage/infittration basins, retention ponds. catch basins, scupper drains, and plaxtic or ceramic drainge aructures will be used. Chemicals to be applied only as required and under permit to Alberia Environment.

Buffer arips will be constructed where possible.

Drainage patterns as outlined above will be used. Applications of chemicals will adhere to guidelines set out in the Integrated Pest Management Program. Ground and surface water monitoring programs will be operated 10 detect any leakage.

Implement architectural controls to reduce residential wood combustion emissions by ensuring only fresh air fire places are instalied. This will reduce ambient BaP and particulate concentrations.

Provide environmental monitoring and inspection of all conatuction activities. Provide $25 \mathrm{~m}$ construction buffers from stream courses. No direct discharge of wumps and equipment rinse water to creeks.

Construction of dykes, berms and swales next to area creeks.

Use of aedimentation ponds, and drainage vaults as well as monitoring of stormwater quality to protect areams before final discharge of stormwater.

Monitor and regulate water withdrawal to mainuin instream flows for fisheries (Pigeon Creek) as determined by monitoring.

Ensure Integrated Pest Management program is implemented and enforced.

Use slow releake nitrogen formulae. Construct berms and surface swales to avoid surface runoff to creeks. Follow guidelines outlined in Integrated Pest Management Program. Monitor wriace water quality.

Allow for channelization only in portions of Three Sisters and Stewan Creeks. No channelization in the Pigeon Creek drainage allowed.
Negligible

Negligible

Minor to

Negligible

Negligible

Minor to

Negligible

Negligible

Negligible

Negligible

Negligible.

Negligible

Negligible. 
CLASS II Important impects that can be mitigated or avaided. (Decision makers are required to make findings that inpects have been mitigated to the maximum ertent feseible by implementation of mitization).

Description of Impect

Mitiention
Residual Impects

Negligible.

Conformance with erosion prolection requiremens within the cleared channel. Locate depoaitional areas in appropriate areas to catch major debris movemens. migration.

Flooding could destroy bomes and endanger lives.

Flooding could destroy golf course greens, lee boxes and fairways.

Construction of bouses will not be allowed within 100 year flood piain.

Setbacke or elevation of greens and lee boxes.

Negligible

Negligible

Avoidance by relocation of facilities; or mitigative excavations: discouragement of recreational

Negligible
Historical

Resources
Construction of roads and disturbance from laying of utilities will impact on archacological aites. interpretive progm condinate resource studies through an archaeologist. 
CLASS III Impocts that are not significant. (These impocts do not require that findings be made.)

Use of Don-aative plants on the fairways, greens, and residential pods may result in competition with native species.

Increased recreational use in the area will cause an impact to vegetation in the surrounding area due to trampling and aubsequent erosion.

Increased silution in creeks.

Changes in drainse pauems will affect natural vegetation down slope.
Amphibians and Reptiles
Long-term loss of 8 percent of the low and moderate quality habitat for the wandering garter snake and associaled species.

Clearing of vegetation and consruction may prevent access to hibernacleum.

Amphibians and reptiles may be directly killed by project activities.

Direct morulity will occur as a result of collisions with overhead wires. moving vehicles on roadways and domertic pets (mostly cats).

Construction during the snow-free period may result in the accidenul destruction of nests. eggs and/or unfledged young.

Consanction activities could result in the loss of at leas one year's production of songbirds.

Long-term loss of 11 pereent of available habiut. Most is low quality.

Sensory disturbance may disrupt drumming siles and neating, but few suiluble sites are present.

Habitat fragmentation due to development will obaruct movement patuerns, increase predation of birds in unfamiliar open areas, separate birds into smaller, less viable sub-populations and decrease efficient use of habitat.
Use native plant seed and rock for all golf course hazand areas, development pods and reclamation effors.

Regionally Negligible

Piace restrictions on recreational access and use in the back-country which limits people, anjmals, and vehicles to non-sensitive triits and rexting places.

Regionally

Negligible

See water quality.

Negligible

Monitor down slope vegetation. If changes occur, implemens measures to modify site drainage or to improve water retention.

Minimize all clearing around water bodies during construction.

Reclaim all disturbed sites that are not required for the golf courses, with native plant epecies.

Maintain as many of the wetland and shrub bog sites as possible within the project area.

Regionally negligible

Habitat retention and movement corridors for large wildlife movement corridors may provide some use for amphibians and reptiles.

Regionally Degligible

Design buffer zones along all water courses in order to reuin matural riparian vegetation and decrease the potential for silution.

Design of residential and direct control pods to minimize clearing of natural vegetation communities.

Regionally negligible

Use underground servicing where possible. Pet control bylaws.

Regionally negligible

Where possible, schedule site clearing during fall to minimize destruction of nests, eggs, and unfledged young during the peak nesting period. Phased development will reduce sensory disturbance. Maximize the size of residual blocks of natural vegetation within and between pods. Use native species in landscaping and reciamation effors. Exercise minimal or no maintenance of natural vegetation areas.

Design development pods to minimize clearing.

Regionslly negligible

Scheduling of site clearing to avoid peak breeding and nexting activity. Habitut retention and enhancement.

Regionally negligible

Habiut retention and movement corridors for large wildlife will provide some unable habilat for upland gamebirds.
Locally important, Regionally negligible 
CLASS III - Impects that are sot significant. These impects do not require that findines be made.)

Raptors and Corvids

Great Grey Ow and Cooper's Hawk

Somall Mammals Avoidance of habiut due to sensory disturbance.

Direct mortality during construction and opention of development and from domestic pets.

Fragmentation of habilat due to obstructions 10 movements caused by clearing, roadways and trails.

Senall

Furbearers

Large

Carmivores

Habiut loss for lynx. Project area conuins low quality habizat.

Ungulates hindered by clearing of vegetation cover, roadways and trails which will obstruct movements.
Description of Impoct

Direet mornlity, particularly of young of the year as a result of accidental death from collisions with consaruction vehicles, trafic and pels.

Mowing of golf course hazard areas could result in the bas of neas and young.

Mitipation

Residuel Impacts landecaping and reclamation effors. Minimal
Schedule clearing and maintenance outside peak nexing times. Prohibit free-ranging pets.

Restrict rosd speeds.

Schedule maintenance, i.e. mowing of fairway verges, trail edges and roadsides, outside the peak nesting period.

Minimize clearing of natural vegetation. Retain buffer zones around riparian areas. Use native epecies in landscaping and reclamation effors. Construction nexing platforms in adjacent undisturbed areas if required.

If nesting is found on site, schedule sctivities around that site to minimize harasument. $500 \mathrm{~m}$ buffer area in April to June period may be required.

Avoid identified raptor nexing siles. Where possible, schedule initial clearing during the fall. Use underground services where possible. Prohibit free-ranging pets.

National significance may exist if nex sites for Cooper's hawk or great grey owl are present. Project biologist will inspect development pods for neat aites prior $w$ clearing. If neat is present, fall clearing will be used. Nhernate nest sites will be conancted.

Minimize maintenance in nawal vegetation areas.

Regionally negligible

Where possible, initial site clearing in fall. Maintain golf course verges only during July and August. Prohibit free-ranging pets.

Regionnlly negligible

Mainuin buffer zones around riparian areas. Use mative plant species in landscaping and reclamation efforts. Habitat retention areas and large wildlife movement corridors will also provide additional habitat.

Retain buffer zones around satural riparian areas. Where possible, initial sile clearing in the fall.

Regionally negligible

Minimize clearing. Use native vegetation in maintenance of natarl vegetation sreas. Enhancement areas and movement corridors for large wildlife will also provide additional habiut and movement areas.

Regionally negligible

Regionally negligible

Regionally

Regionally Degligible

Regionally Minot

Regionally negligible

Regionally negligible

Regionally

Minor

Regionally Minor

All on-site conatuction aff will be briefed on proper procedures and activities to minimize wildlife harasument and prevent accidens.
Regionally

Minor the combination of sensory diswrbances, the atieration of habitat, the physical presence of residential and reson developments and the conaruction of linear right-of-ways. 
CLASS III Impects that are not sipnificant. (These impacts do not require that findings be made.)

Description of Impect

Increase in direct morality of ungulates.

Aanction of some ungulates to artificial salt supplies or sew forage areas may reauh in damage to facilities and human injury, with the resulting need to control ungulate distributions through management controls.

Habituation of elk to human activities within the Three Sisters Project Area could increase their susceptibility to hunting during use of seasonal ranges in Kananakis Country. Animals that remain on-site will not be affected. whereas animais that move into Kananaskis Country will be affected. Change in the seasonal diaribution of elk may occur.

Mule and white-uiled deer will be initially disurbed by construction and human activities in the project area, but are expected to habituate.

Over-wintering bighom sheep on Wind Ridge may be disturbed by construction noise and aseociated human activity during construction and use of the resort complex and residential developments in Wind Valley.

Recreation

Public access to the propenies affected by conaruction will be temporarily rearicted.

Hunting activities currently allowed on properties will be dieallowed by Town of Canmore by-law.

Recreational passive facilities and services will experience greater activity as a result of increased population.

Increased activity at exixting facilities may rewh in over crowding.
Mitientioa

Residual Impects

All anff will be asked to avoid the wildlife mitigation areas during constuction.

Fencing will only be allowed in areas where afety is a concern. Fences will nol exceed $1.2 \mathrm{~m}$ and will not be wrought iron or wire.

Free-ranging doge will be arictly prohibited and leased dogs will not be permined in any wildlife mitigation areas.

Crossings of primary and secondary movemen corridors for wildlife by rosdways, pathways, service right-of-ways and golf coure fairways will be minimized. Widths of these facility clearings within the movement corridor will be as emall as posaible.

Landecaping along the central parkway and in the vicinity of the developmens pods will utilize tree and shrub epecies which are less palatuble to elk in order to avoid auracting animals to areas where elk-human encouniers may occur.

No on-site mitigation possible. Habitat enhancement in off-site areas will provide alternate habitat for elk.

Regionally
Minor

Regionally Degligible

Where possible, initial site clearing will be limited to fall.

Regionally negligible

Initial clearing, rad construction and heavy equipment use will be scheduled outside the 1 December to 15 June period to avoid sensory disturbance to bighom sheep during the overwintering and lambing periods.

Phased implementation of some development pods. Off site habitat enhancement and possible supplememary feeding program.

Inform local residents of the timing and location of construction activities to limit inconveniences.

Not required.

Not Applicable

Design a walkway, and bicycle cross country path syotem which is compatible with exiaing trails in order to increase opportunities for par sive recreation. Direct pethway syatem away from critical wildlife zones. Enforce clomures when necessary to protect wildife.

Develop policies which idemify priorities and privileges for use of private and municipal facilities by residents, employees and tourias.
Negligible

Regionally Minor

Negligible

Negligible 
Summary of Impects and Mitigation (Reprimted froen Applicatioa)

CLASS III Impects that are not sipaificant. (These impacts do not require that findings be made.)

Descripbion of lompect

Mitizatioa

Residual Impects

Surface Water
Hydrology
Impect from
Diversions
/water with-
drawal

Water retention ponds

\section{Historical} Resources

Pedestrian and nonmotorized vehicular trafic
Lower Creek flows may affect quantity and quality in Bow River downtream.

Creation of water bodies along golf courses to act as catchment basins for golf course runoff.

Ground disturbances to sites EgPt 19 and EgPt 20.

Hirtoric sites, Canmore Mine No. 2, contains 121 discrete features which lie within the proposed golf course area and will be impacted by conaruction of fairways, access raeds, and associated facilities.

Increased conflict and potential safety hazards due to the increased volume of traffic and number of people in the area during construction and operation phases.
Diven only water as required for productive grass growh. Monitor weather conditions and irrigate when necesary. Develop monitoring program to determine water consumptive use. implement and enforce active water conservation program by: metering of water and change syatem. Use of low demand appliances such hower heads, wilets etc.

Installation of impermeable liner and continment of epill within basin.

None. Required isolated fines.

In situ preservation of 8 features; lamphouse, pumphouse, open mine shaft, open fan shaft, tipple foundation, railroed grade, "shop'. Additional preservation of railway cars, hoist, and aled by removal and incorporation into ditplay items; incorporation of coal mining theme into coscept plan; full historical documentation of remaining features prior to construction activities; coordination of all hirtorical sudies through archaeologist. Open mine ahaft and open fan shaft may have to be closed for public wfety.

Dexign and conaruction of pathways 20 accommodate pedearian and non-vehicular inffic within Three Siaters Propenies to compliment proposed and existing pathways within the Canmore boundaries.
Negligible

Negligible

Negligible

Negligible

Negligible 
CLASS IV Positive impects.

Description of Impoct

Small Mammals

Linear right-of-ways meh as radside verges or cullines can assis movements by smull mammals that se adapted to grassiand or shrub meadow habiuts.

Ungulates

Reclamation of minimal lick and maintenance of movement corridor from Stewan Creek.

Cloaure of Stewan Creek Trail. Wind Ridge and Wind Valley 10 recreational access.

Establishment of off-site grazing ares will reduce human/wildlife conflict.

Job Creation

Increased

Government

Revenue

Through Taxes

Increased Property Tax Base

Manufacturing

\section{Construction}

Communication \& Utilities

Wholesale and Retail Trade

Economic Sectors
An addition of 5,650 permanent positions in the Bow Valley by the end of Year 20.

An additional 2.680 permanent positions as a result of indirect expenditures.

Conanction activity would generate toul corporate ux of approximately $\$ 7$ million.

Personal income ux generaled during construction would be approximately $\$ 98$ million.

Upon final build-out corporate uxes should generate approximately $\$ 3$ million/year from operations.

Operations and indirect impacts would generate S41 million/year by the end of the 20 year build-out (in current doliars)

Expanded Town of Canmore would increase the ux assessment base by $\$ 1.4$ billion by final build out. This would allow for increased revenue without increasing the mill rate.

Building and construction activities will expand the need for local and regional manufacturing concerns.

Considerable construction will occur throughout the entire development phase.

Expanded service base will be crealed for communication and utilities.

Expanded population base created by permanent and par time residents and touriats will increase and reinforce the demand for a diversified range of retsiled goods.

Increase of offaite natural resource extraction related to road development and building conanction.
Positive

Positive

Positive

Positive

Encourage local bire policy to ensure maximum benefits to the local residents.

Not Applicable

Not Applicable

None required.

Not Applicable

None required.

Not Applicable

None required.

Not Applicable

None required.

No Applicable

Local suppliers will be given every opportunity to provide needed materials at competitive nates.

Positive

Local hire policy will be implemented to ensure maximum benefits are afforded to local residents

Positive

The planning for and provision of services will be done in concen with the preparation and implementation of Area Structure Plans and detailed Subdivizions Plans. The necesary agency requirements will be met.

Aress within the development will be provided to accommodate additional retail space. Preparation of local economic development plans will help ascerain appropriate type and timing of business opportunities.

Appropriate local and regional sources will be identified in accordance with their capability to provide the materials.
Limited to construction phase (20 years) 
Sunmary of Impects and Mirigation (Reprinted freen Application)

\begin{tabular}{ll}
\hline CLASS IV & Pesitive inpects. \\
\hline Deseription of Impect \\
\hline $\begin{array}{l}\text { Commercial } \\
\text { Sector }\end{array}$ & $\begin{array}{l}\text { lecreased demand on existing commercial } \\
\text { facilities and for service expansion in Canmore, } \\
\text { Dead Man's Flats, and Harvie Heights in order } \\
\text { to eervice increases in local populations and } \\
\text { touriat trafic. }\end{array}$
\end{tabular}

Mitipation

Controlled commercial development in accordance with approved Area Structure Plans and planning of additional commercial facilities wo be in concen with Canmore's longterm objectives.

Encourage educational programs to maximize beocfits associated with increased courism setivity.

\section{Accommodation} and other services
A sypergetic relationship will result among existing and funure accommodations as in increasingly varied cliemtele is auracted to the ares.
The basis upon which this expansion takes place can be directed by local economic development plans and tourism action plans.

\section{Residal Impects}

Negligible 


\section{CLASS V Cumulative Impacts. A result of successive additional derelopmeats in the Bow Corridor. Successive} developments include those curreatly planoed or approved ie.. Hyaut Cadco and Mountain Meadows phus Canmore's natural growth.

Air Quality

An increase in ambient $\mathrm{NO}_{2}$ and particulates, as irffic increases, may exceed the eir quality objectives in selected areas of the Bow Corridor under poor dispersion conditions.

Transportation

Increased unfic flow $t 0$ and from Highway 11, SH 742 (when completely constructed) and through the Town of Canmore.

Vegetation

Loss of vegetation and subsequent wildlife habilat from the Bow Corridor.

Amphibians and Reptiles

As a result of direct loss of habitat, obstructions to movements, changes in drainage patterns, and direct moriality, it is possible that an unknown but lange proportion of the local population of amphibians and reptiles may be permanently eliminated.

Songbinds

All impacts to songbinds are expected to result in an overall reduction in the diversity of songbirds. as well as the abundance of most native songbirds.

Upland

Gamebirds

Loss of habitat due to overall residential and recreational developments.

Habiut fragmentation due to development will obstruct movement panems, increase predation of birds in unfamiliar open areas, separate into smaller. less viable sub-populations, and decrease efficient use of habitat.

Raptors and Over time, population densities for forestCorvids

S m a 11 Mammals and Furbearers

Lange Carnivores
Encourage the use of public transportation (buses) 20 reduce ambiens NO, and pariculate concentrations from traffic sources. Cycle/pedeatrian walkways would encourage the use of alternative non-polluting transportation.

Circulation patterns to. from. and through the Three Sirters sile will be developed according to the Abern Transportation and Town of Canmore anodards. Partway may channel a portion of the traffic away from Town.

See Three Sisters Mitigation Plans. Similar participation required by other developers in Corridor.

Locally Imporian

Majority of potential habitat is adjacent to Bow River and in Bow River Flats. These areas musa be protected.

Regionally Minor

A regional initiative is required to identify and retain protected matural areas that will provide - diversity of habitat areas that are of an adequate size to wastain the present diversity of songbirds, and viable breeding populations.

A regional initiative is required 20 identify and retain protected natural areas that will provide - diversity of habitat areas that are of an adequate size to muain the present diversity of upland gamebinds and viable breeding populations of these species.

Regionally Minor

Regionally Minor associated raptors will diminish with loss of potential nesting and feeding habiut. Corvid numbers may increase.

Species adapted to mature coniferous forests (ie., red-bscked vole, red equirrels) will decline in numbers in the area when foreated areas are cleared.

A regional initiative is required to identify and retain protected matural areas that will provide - diversity of habitat areas that are of an adequate size to manin the present diversity of raptors and viable breeding populations of these species.

Minimize clearing. Without mitigation, the combined effects of habitat loss and increased direct mortality will rezult in local declines in the number of ermine, manten, and coyote in the Bow Corridor.

Large carnivores habitat thould not be encouraged in close proximity to human seulement. Habiut should be maintained in adjacent undistubed areas (ie., Kanansakis Country and north of Bow Corridor).

Regionally Minor

Regionally Minor the obstruction of travel corridors for large carnivores. The concentration of human presence and activities in the area will lead to diaplacement of black and grizly bear. 
CLASS V Comulative Impacts. A result of successive additional developments in the Bow Corridor. Successive developments inchude those curreatly planoed or approved ie., Hyatt Cadco and Mountain Meadows plus Canmore's natural growth.

Description of Impect

Ungulates

Education

Health

Social Services

Social Support Service

Police

Protection
Increased demand on social services Aberans and Camadians migrate in search of employmens.

It can be asumed that continued developments in the Corridor will reduce the capability of the Corridor to appon a viable elk population. Without mitigation, it is predicted that long-term reduction in elk numbers.

10,550 population increase over 20 year period if developments as described in the Area Structure Plans, are buitt out between 1991 and 2011.

The proposed development will ux existing sewage treatment facilities beyond current capaciny.

Substantial pressure on existing educational facilities and resources in order to accommodate the influx of new residents.

Increased demand for health professionals to address the health needs of area residents and censonal visitors.

increased demand on Social Services auch as child care, unemployment and welfare during operation and construction of the development

One additional R.C.M.P. officer for the Town of Canmore should be hired during the first years of development and approximately 20 additional officers by the final years of build out. Additional officers will be required from the Banff delachment due to increased highway traffic.

Construction vehicle movements will increase demand on the Canmore and Banff deuchments.

The potential for crime related activities will increase as a rewult of the transiens elemen during conaruction and operation.
Mirigatioa

Residuel Impects

A number of habitat mitigation projects will be implemested by Three Sirters to enhance forage and cover habitat for elk to leasen regional impacts. Similar types of projects may be required on a regional basis to maisenin population levels.

Regionally Minot

Comrolled pianning and development process

Important through regulating bodies.

Negligible

A new Tertiary Treatment Plant will be conaructed and the existing plant upgraded for Canmore.

A municipal reserve will be dedicated on the property for the future development of educational facilities. Given the length of time required to develop additional facilities. the affected school boands should be consulted from the onset of the planning process. Crowding may occur until new facilities can be built.

Assirance will be provided in attracting health professionais to the area.

Three Sisters will promole a local hiring policy 10 minimize the number of migrant workers.

Wort with the social service agencies to identify possible areas of concem and arategies 10 minimize the effects.

The provision of facilities for municipal and Provincial agencies will be encouraged to underuke proactive measures and address concerns.

Government funding relative to police manpower will need to be increased in accordance with the police services formuls. Deuniled aubdivision plans prepared by the developer in conjunction with local planning agencies should include input from the Canmore detachment. This input will contribute to the design of "crime resistant" areas as well as assist in determining its local manpower requirements (phasing and number) to meet local needs.

The Canmore and Banff delachments will be kept apprised by the local municipalities and the developer about the traffic movement pauern and timing relative to conaruction vehicles.

Conculution with the Banff and Canmore deuchmems regarding the planning and deaign of the detailed aubdivision will help in preparation of a "crime resistant" development.
Negligible

Negligible

Negligible

Negligible

Negligible

Negligible

Regionally Minor 
Summary of Impects and Mitization (Repriated froen Application)

CLASS V Cumulative Impects. A resalt of successive additional developenents in the Bow Corridor. Successive derelopments include those curreatly planned or approved ie.s Hyatr Cadco and Mountrin Meedows phus Canmore's natural growth.

Description of Impect

An increase in municipal services to serve the increased population base locally and regionally.

Goverumed Services

Air Qunlity

During operations, increased $\mathrm{CO}, \mathrm{NO}_{2}$. particulate and BaP concentrations can occur over a larger area in the Canmore/Bow Valley Corridor.

Fisheries

Increased development and increased access to the Bow River will place greater pressure on existing fish stocks.
Mitigation

Effors will be made through proper design and conseruction in accordance with local and provincial requirements to minimize the eervice infrasucture.

The reps identified under Class II impacts would reduce these impacts.

The Provincial Govemment should consider reduced catch limits, restrict bait usage, reduce angling season and if necessary, institute selective catch-and-release policy. Increased ataf requirements for Fish and Wildlife to enfore reatrictions both on wildlife and fish
Residual Lmpacts

Larger local administative

orgenization.

Imporan

Important and Long-term 


\section{APPENDIX C}

\section{FORM OF APPROVAL}




\author{
THE PROVINCE OF ALBERTA \\ NATURAL RESOURCES CONSERVATION BOARD ACT \\ NATURAL RESOURCES CONSERVATION BOARD
}
IN THE MATTER of a project of Three Sisters Golf Resorts Inc. for the construction of a recreational and tourism project in the Town of Canmore

\title{
APPROVAL NO. 3
}

WHEREAS the recreational and tourism project proposed for the Town of Canmore by Three Sisters Golf Resorts Inc. is a reviewable project under s. 4(b) of the Natural Resources Conservation Board Act; and

WHEREAS the Natural Resources Conservation Board is prepared to grant the application by Three Sisters Golf Resorts Inc. for a recreational and tourism project in the Town of Canmore, subject to the conditions herein contained, and the Lieutenant Governor in Council has given his authorization, hereto attached.

THEREFORE, the Natural Resources Conservation Board, pursuant to the Natural Resources Conservation Board Act, being chapter N-5.5 of the Revised Statutes of Alberta, 1980, hereby orders as follows:

1. The project of Three Sisters Golf Resorts Inc. (hereinafter called "Three Sisters") for a recreational and tourism project in the Town of Canmore, as such project is described in Application No. 9103 from Three Sisters to the Board dated October 9, 1991, and descriptive material supporting the application marked as exhibits at the Canmore, Alberta hearing by the Board from June 15, 1992 to July 23, 1992, including undertakings of the Applicant, is approved, subject to the terms and conditions herein contained.

2. Three Sisters shall not develop the portion of the project proposed for the area known as Wind Valley, located south of a line $200 \mathrm{~m}$ north of, and parallel to, the boundary between sections 1 and 12, township 24, range 10, and between sections 6 and 7, township 24, range 9 , all west of the 5 th meridian.

3. The design of the project in the area immediately north of the boundary referred to in clause 2, may be changed with the approval of the Town of Canmore, provided that the changes are satisfactory to Alberta Forestry, Lands and Wildlife with respect to the provision of wildlife corridors. 


\section{C-3}

4. The phasing of the project, the land uses and related population densities, as proposed by Three Sisters for the Bow Valley portion of the project, are approved, but the detailed timing and the specific land uses and population densities may be changed with the approval of the Town of Canmore.

5. The locations of community services, transportation routes and public utilities, as proposed by Three Sisters for the Bow Valley portion of the project, are approved, but the locations and design details may be changed with the approval of the Town of Canmore.

6. Prior to the construction of any facilities over an undermined area, Three Sisters shall, to the satisfaction of the Town of Canmore, complete the four stage assessment of the safety of the area for development and take any remedial action required by the Town of Canmore.

7. Three Sisters shall not withdraw water for use in the project from wells accessing minewater, except for monitoring purposes or emergencies such as fires.

8. Three Sisters shall not take water for use in the project from Pigeon Creek or its tributaries.

9. Three Sisters shall, every three years, review its Integrated Pest Management program and the chemicals it uses on golf courses to determine if there are more environmentally acceptable altematives and report the results to Alberta Environment.

10. Three Sisters shall utilize construction techniques that will reduce disturbance of the environment to the lowest practical level and these techniques shall include but not be limited to:

- elevating the tops of any tees and greens constructed in the Pigeon Creek, Three Sisters Creek and Stewart Creek flood plains to above the one in 100-year flood level, installation of impermeable barriers under such structures and armouring them adequately to avoid washouts;

- sodding areas of graded soil within five metres of Pigeon, Three Sisters and Stewart Creeks within five days of construction;

- carrying out in-stream construction work in accordance with the Water Resources Act and in a manner that would reduce the amount of sediments entering streams, and only during time periods approved by Alberta Forestry, Lands and Wildlife; and

- providing an orientation program for construction workers to ensure they understand the potential seriousness of sedimentation problems.

11. Three Sisters shall design and implement a water monitoring program satisfactory to Alberta Environment and Alberta Forestry, Lands and Wildlife. 


\section{C-4}

12. The design of buffer strips along all water courses shall be approved by Alberta Forestry, Lands and Wildlife prior to related construction.

13. Prior to the commencement of any particular portion of the project, Three Sisters shall, for the particular portion, prepare a vegetation inventory and management plan and a vegetation monitoring plan which includes periodic inspection of protected sites, satisfactory to Alberta Forestry, Lands and Wildlife.

14. Three Sisters shall incorporate into its detailed design, provision for wildlife movement corridors in as undeveloped a state as possible, and prepare a wildlife aversive conditioning plan, both satisfactory to Alberta Forestry, Lands and Wildlife.

15. Three Sisters shall comply with the Planning Act, with the permits and licenses of the Water Resources Act, the Clean Water Act and the Agricultural Chemicals Act or any subsequent amendments thereof issued by Alberta Environment, and with all other applicable regulations and standards of the Province of Alberta.

1992.

MADE at the City of Calgary, in the Province of Alberta, this day of 


\section{APPENDIX D}

\section{SUMMARY OF BOARD RECOMMENDATIONS}




\section{D-2}

Throughout this Decision Report, the Board has included a number of recommendations regarding the proposed project of Three Sisters for the Town of Canmore. Most of the recommendations are intended for Three Sisters as the proponent for the project, the Town of Canmore, the Government of Alberta, Alberta Environment and Alberta Forestry, Lands and Wildlife. The following is a summary of those recommendations.

\section{Recommendations to Three Sisters}

- It is recommended that-Three Sisters take into account the desirability of reducing $\mathrm{NO}_{\mathrm{x}}$ emissions when designing roads in the project.

- It is recommended that Three Sisters take the following steps to assist it in designing a program to monitor water quantity and quality:

- gather information about shallow groundwater movement throughout the property;

- identify contaminants most likely to be entering and moving through ground and surface water and locations where these are most likely to be released; and

- identify seasonal periods when contaminant releases are likely to occur and when stream or groundwater flows are of particular importance.

- It is recommended that Three Sisters, prior to construction, conduct an initial evaluation of sites previously used for industrial purposes and report the results to Alberta Environment.

- It is recommended that Three Sisters use Canada Class one seed mixes for golf courses and developed areas and that it take whatever steps are possible to ensure that any imported topsoil is free of weed seeds.

- It is recommended that Three Sisters involve the Town and local people in planning the details of matters such as the hours of work and other worker and camp related rules.

- It is recommended that Three Sisters make a determined effort to work with the administration of the Stoney Tribe to maximize potential benefits of the project to the Stoney people.

\section{Recommendations to the Town of Canmore}

- It is recommended that the Town take the initiative in the formation of an Undermining Review Group, including experts retained by the Town and by Three Sisters and from the ERCB. 


\section{D-3}

- With respect to the mapping of constraints over undermined areas and where the existing mine maps are incomplete, it is recommended that the Town require Three Sisters to carry out extra ground truthing by way of drill testing, radar evaluation and other surface reconnissance work.

With respect to any development over coal seams, it is recommended that the Town require the utilization of appropriate safeguards to minimize accumulations of methane in buildings.

It is recommended that the Town take steps to ensure that prospective purchasers of undermined lands or buildings on undermined lands are informed that there is some risk regarding possible accumulations of methane and with respect to potential risks from undermining.

It is recommended that the Town require appropriate measures to minimize the possibility of underground fires in coal seams.

It is recommended that the Town require appropriate groundwater testing to establish whether foundations can be safely laid in areas where the water table is high.

It is recommended that the Town impose an architectural control or by-law to ensure that direct air intake fireplaces are the only wood burning equipment allowed in residences built within the project area, and consider introducing a by-law that would allow it to curtail wood burning during periods when air in the Bow Valley is likely to be stagnant.

It is recommended that the Town ensure that tertiary wastewater treatment becomes the standard treatment with respect to facilities installed or upgraded in connection with the Three Sisters project.

It is recommended that the Town require Three Sisters to include in the material it provides to those purchasing property within the project, advice to residents and business operators on the desirability and methods of avoiding the release of contaminants into storm drainage, and a written explanation of the need for and advantages to the purchaser of protecting the natural vegetation of the area.

It is recommended that the Town accept Three Sisters' proposal for a by-law prohibiting free ranging cats and dogs within the project area.

It is recommended that the Town establish a planning and monitoring program with respect to social effects on citizens of the Town and the need for actions to reduce these effects. 
- It is recommended that the Town require of Three Sisters a commitment to appropriately participate in the development of an affordable housing plan.

- With respect to infrastructure funding, it is recommended that the Town proceed in a manner that would place on Three Sisters, the appropriate degree of risk that the project would not adequately cover front end capital and early operating costs.

\section{Recommendations to the Government of the Province of Alberta}

- It is recommended that the Government take the initiative in the formation of a senior level Planning and Advisory Committee, with appropriate subcommittees, to provide advice to decision makers respecting ongoing development in the Canmore/Bow Corridor. The subcommittees would include an Undermining Review Group and a Regional Ecosystem Advisory Group.

- It is recommended that any funding provided by the Govemment for up-front infrastructure costs with respect to the Three Sisters project be done in a manner that places on Three Sisters, the appropriate degree of the risk that the project would not adequately cover front end capital and early operating costs.

- It is recommended that the Government establish a task force to investigate ways of addressing the affordable housing issue. It is also recommended that the Government be prepared to provide some Crown land at less than market prices to assist in the provision of affordable housing.

- It is recommended that the Government be prepared to negotiate with Three Sisters towards some form of remedial action which would provide alternatives to Three Sisters respecting the lands in Wind Valley owned by Three Sisters and for which the proposed development is being refused.

\section{Recommendations to Alberta Environment}

- It is recommended that Alberta Environment, through the Sustainable Development Coordinating Council, take the lead role in a study to ensure that the planning process is environmentally sound and responsive to public concerns, while at the same time reasonably efficient.

- It is recommended that Alberta Environment have regard for the advice of the recommended Undermining Review Group in assessing the safety for development and public safety of undermined provincial lands adjacent to the Town of Canmore. 


\section{Recommendations to Alberta Forestry, Lands and Wildlife}

- It is recommended that Alberta Forestry, Lands and Wildlife, in reviewing vegetation inventory and management plans, have regard for the rarity of particular vegetation types or plant species and consider requiring transplanting where necessary to maintain rare species.

It is recommended that Alberta Forestry, Lands and Wildlife require that the Applicant's vegetation management plan include proposals to alter vegetation to enhance wildlife habitat or provide fire protection.

It is recommended that, in order to minimize the disturbance of vegetation and impacts on wildlife, Alberta Forestry, Lands and Wildlife work with the Town and Three Sisters to harden pedestrian trails, construct permanent viewpoints, take steps to control access to Wind Valley and to discourage other access to unoccupied land adjacent to the project and consider seasonal closure of some walking trails.

It is recommended that Alberta Forestry, Lands and Wildlife conduct periodic surveys of vegetation on Crown lands adjacent to the project to provide information necessary for management of resources including wildlife.

It is recommended to Alberta Forestry, Lands and Wildlife that locations for wildlife movement corridors be legally designated and that in determing their locations and widths, primary corridors should not be narrower than $350 \mathrm{~m}$ except in unusual circumstances, that widths and locations be reviewed with the full range of species that may make use of them in mind, that corridors be located to allow movement across adjacent properties, that measures such as bundling road, utility line and pathway crossings be adopted, and that corridors correspond with known movement routes of the animals.

It is recommended that Alberta Forestry, Lands and Wildlife, in order to minimize habituation of ungulates, require the use of appropriate aversive conditioning methods on Crown lands near the project and allow hunting beyond safe distances of human settlement in accordance with wildlife management objectives.

It is recommended that Alberta Forestry, Lands and Wildlife review the plans of Three Sisters to provide cover for bighom sheep along the mineral lick trail. 


\section{Recommendations to Alberta Environment and to Alberta Forestry, Lands \& Wildlife}

- It is recommended to Alberta Environment and to Alberta Forestry, Lands and Wildlife that the water monitoring program required of Three Sisters include the following features:

Regarding water quantity:

- monitoring of areas of groundwater discharge including the toes of alluvial fans to determine whether or not they remain moist or retain open water conditions throughout the same season as at present;

- monitoring of downward flows on golf courses as proposed by Three Sisters to avoid unnecessary irrigation and reduce chemical leaching;

- and in each case, sampling throughout the season of active flow.

Regarding water quality:

- selecting for analysis contaminants of primary concern, such as pesticides and nutrients, rather than expending resources on analysis of a large suite of general parameters of water quality;

- if greywater irrigation is used, analyzing for microbial organisms;

- sampling surface water, groundwater and sediment as appropriate throughout the season of active flow;

- sampling on specific occasions after irrigation or after the release of contaminants; and

- locating sample stations in surface and groundwater sites where there is a reasonable expectation that contaminants may be intercepted and which bear relation to resources that may be threatened. 

